\title{
Integrated Energy System Investigation for the Eastman Chemical Company Kingsport, Tennessee, Facility
}

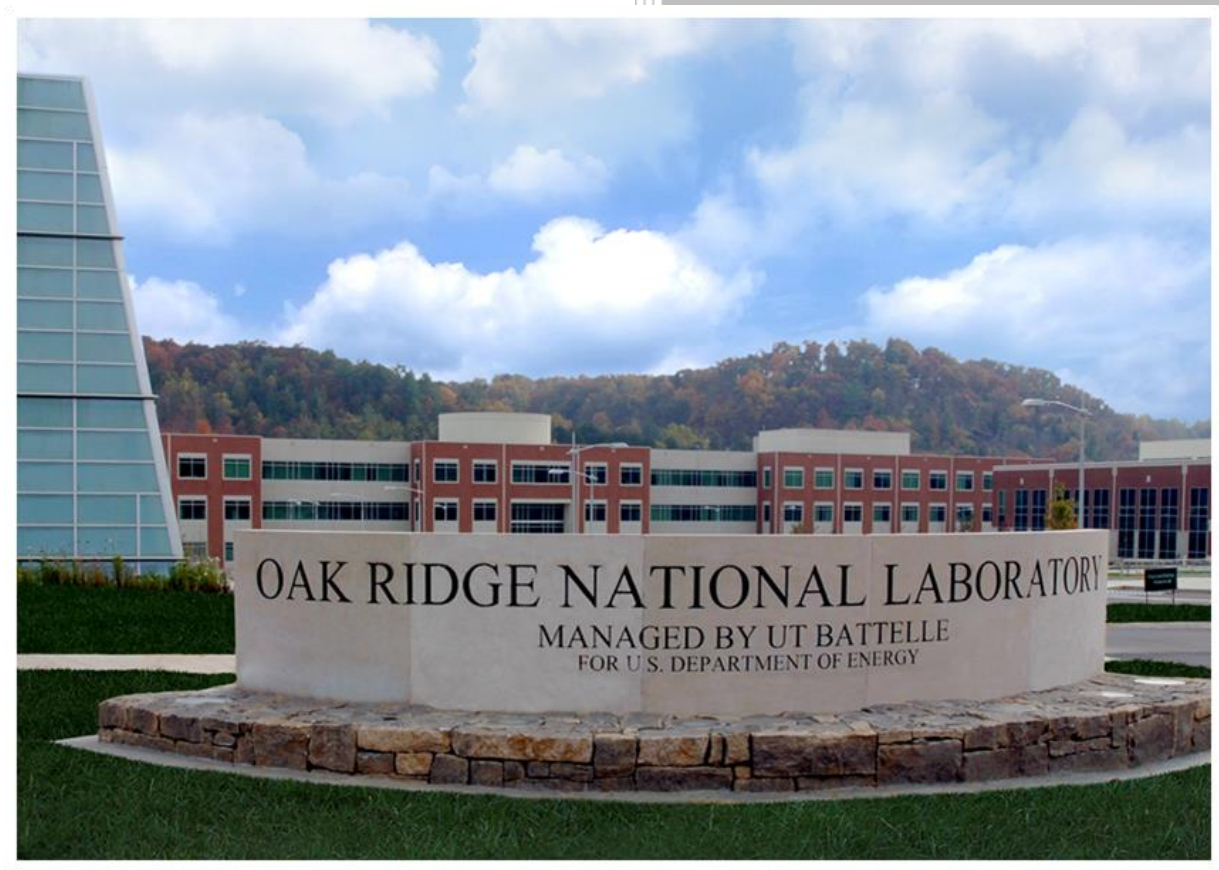

Unlimited Release

CRADA final report for CRADA number NFE-19-07651
M. Scott Greenwood Askin Guler Yigitoglu Jordan D. Rader Whitney Tharp Mike Poore Randy Belles Bob Zhang Riley Cumberland Mike Muhlheim

May 2020 


\section{DOCUMENT AVAILABILITY}

Reports produced after January 1, 1996, are generally available free via US Department of Energy (DOE) SciTech Connect.

Website www.osti.gov

Reports produced before January 1,1996, may be purchased by members of the public from the following source:

National Technical Information Service

5285 Port Royal Road

Springfield, VA 22161

Telephone 703-605-6000 (1-800-553-6847)

TDD 703-487-4639

Fax 703-605-6900

E-mailinfo@ntis.gov

Website http://classic.ntis.gov/

Reports are available to DOE employees, DOE contractors, Energy Technology Data Exchange representatives, and International Nuclear Information System representatives from the following source:

Office of Scientific and Technical Information

PO Box 62

Oak Ridge, TN 37831

Telephone 865-576-8401

Fax 865-576-5728

E-mail reports@osti.gov

Website http://www.osti.gov/contact.html

This report was prepared as an account of work sponsored by an agency of the United States Government. Neither the United States Government nor any agency thereof, nor any of their employees, makes any warranty, express or implied, or assumes any legal liability or responsibility for the accuracy, completeness, or usefulness of any information, apparatus, product, or process disclosed, or represents that its use would not infringe privately owned rights. Reference herein to any specific commercial product, process, or service by trade name, trademark, manufacturer, or otherwise, does not necessarily constitute or imply its endorsement, recommendation, or favoring by the United States Government or any agency thereof. The views and opinions of authors expressed herein do not necessarily state or reflect those of the United States Government or any agency thereof. 
ORNL/TM-2020/1522

CRADA/NFE-19-07651

Reactor \& Nuclear Systems Division

\title{
INTEGRATED ENERGY SYSTEM INVESTIGATION FOR THE EASTMAN CHEMICAL COMPANY, KINGSPORT, TENNESSEE, FACILITY
}

\author{
M. Scott Greenwood \\ Askin Guler Yigitoglu \\ Jordan D. Rader \\ Whitney Tharp \\ Mike Poore \\ Randy Belles \\ Bob Zhang \\ Riley Cumberland \\ Mike Muhlheim
}

May 2020

\author{
Prepared by \\ OAK RIDGE NATIONAL LABORATORY \\ Oak Ridge, TN 37831-6283 \\ managed by \\ UT-BATTELLE, LLC \\ for the \\ US DEPARTMENT OF ENERGY \\ under contract DE-AC05-00OR22725
}




\section{CONTENTS}

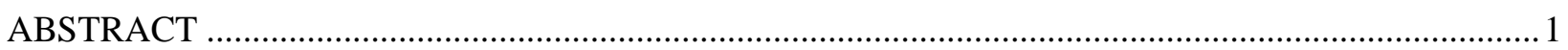

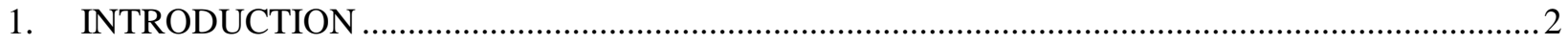

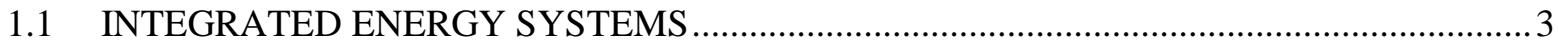

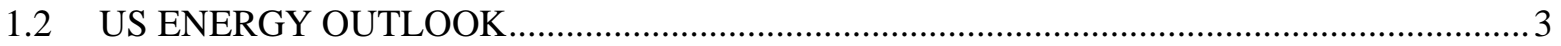

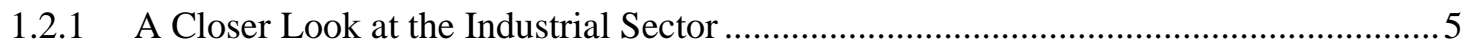

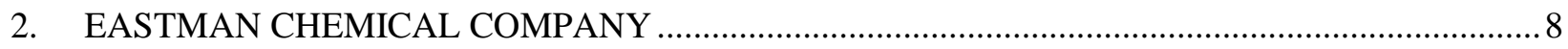

2.1 EASTMAN KINGSPORT, Tennessee | LOCATION AND SITE CHARACTERISTICS ........8

2.2 ENERGY PRODUCTION REQUIREMENTS ...............................................................

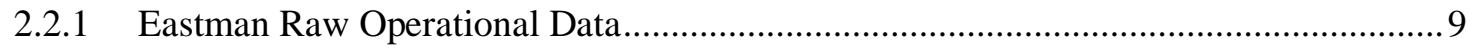

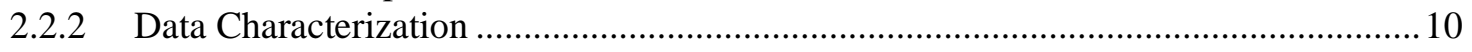

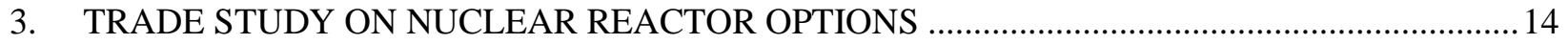

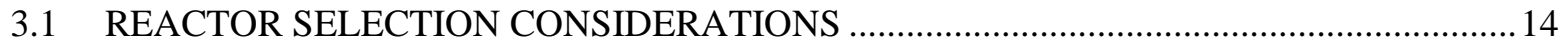

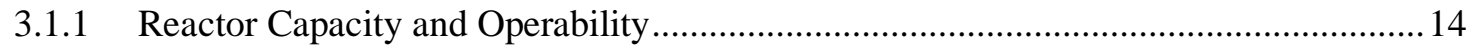

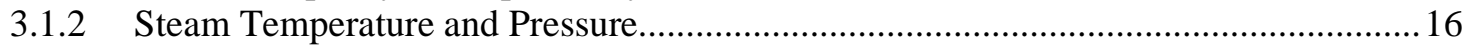

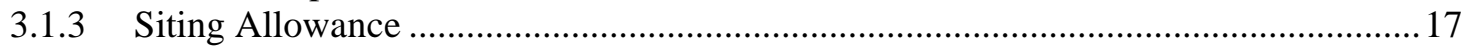

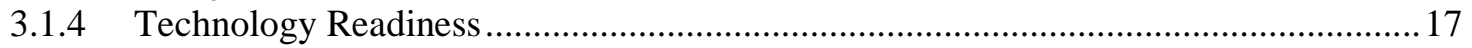

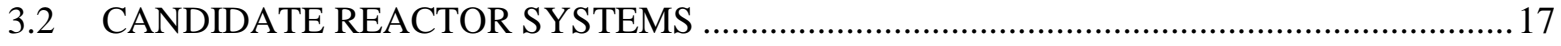

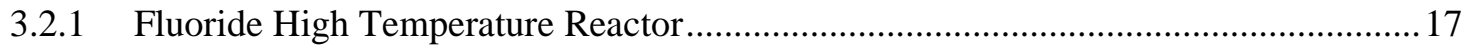

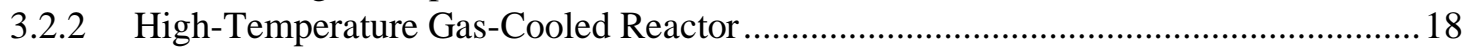

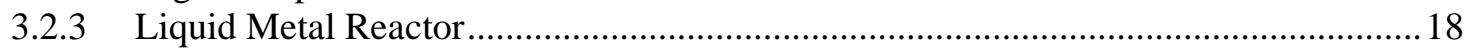

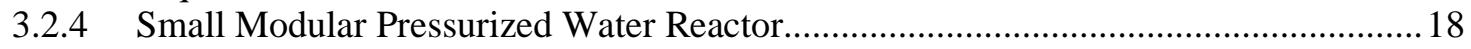

3.3 REACTOR TECHNOLOGY SUMMARY .................................................................... 19

4. DYNAMIC SYSTEM MODELS FOR AN EASTMAN INTEGRATED ENERGY SYSTEM........20

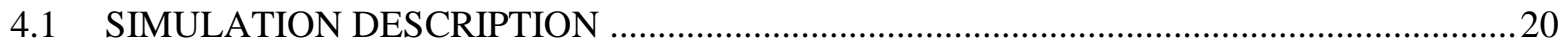

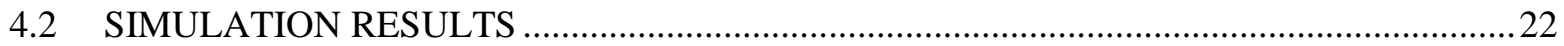

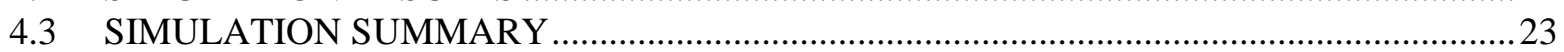

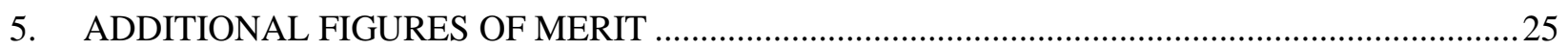

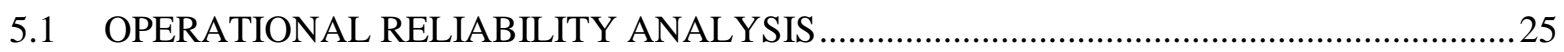

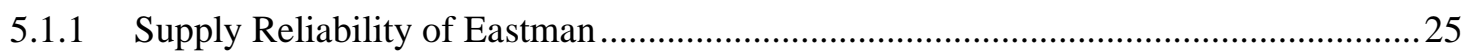

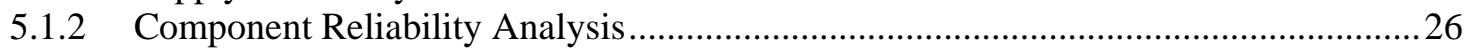

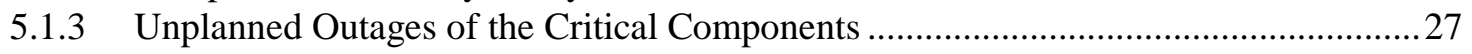

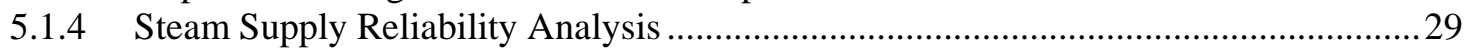

5.1.5 NuScale Operational Reliability Demonstration Case .............................................. 30

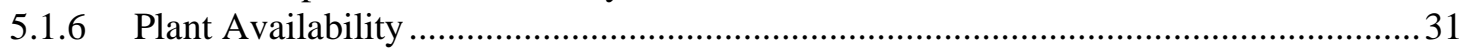

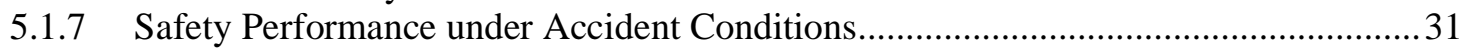

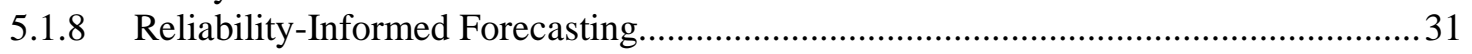

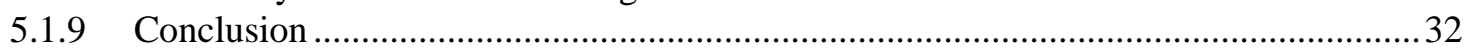

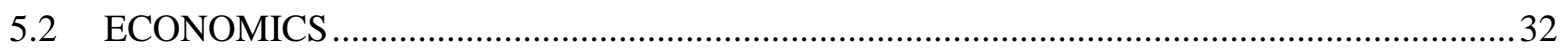

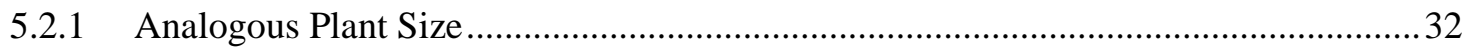

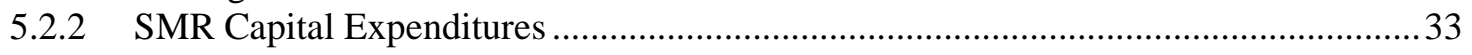

5.2.3 Capital Expenditures for Combustion Turbine and Combined Cycle .......................... 34

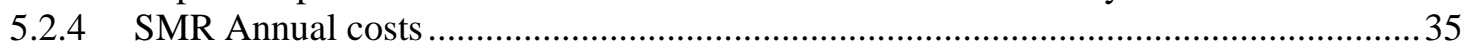

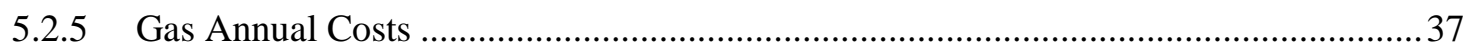

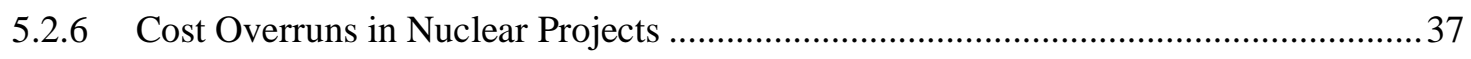

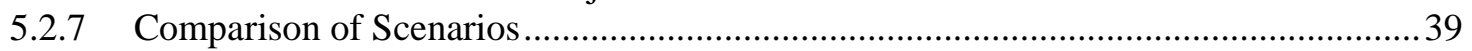

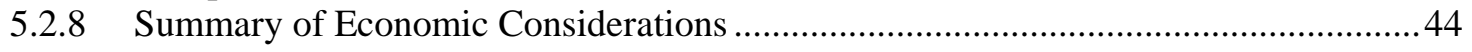

6. REGULATORY, LICENSING, AND SITING CONSIDERATIONS .........................................45

6.1 NUCLEAR PLANT REGULATORY AND LICENSING CONSIDERATIONS ..................45 


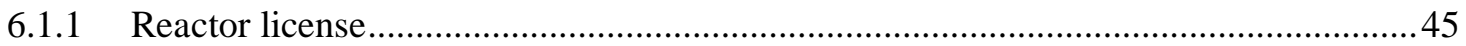

6.1.2 Construction Permit and Operating License (10 CFR 50)........................................46

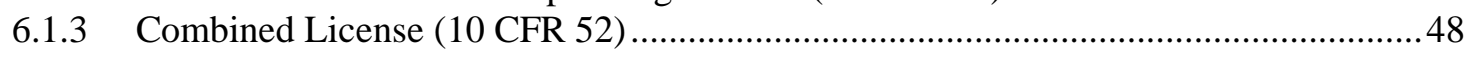

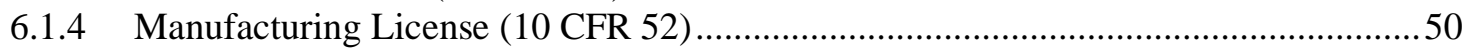

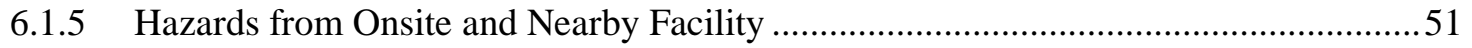

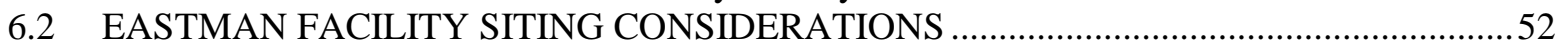

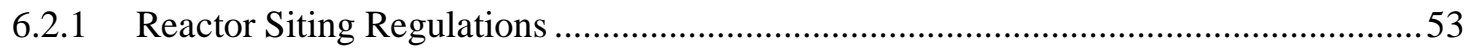

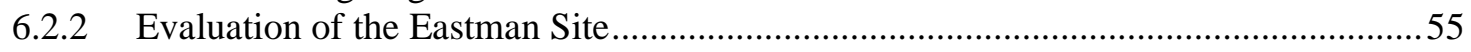

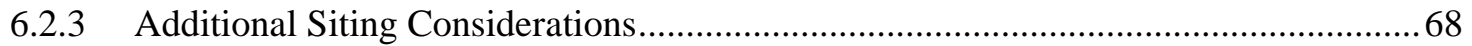

7. SUMMARY OF NUCLEAR REACTOR OPTIONS FOR THE EASTMAN KINGSPORT,

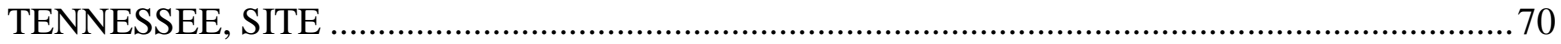

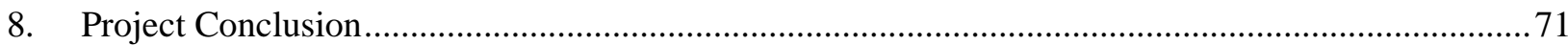

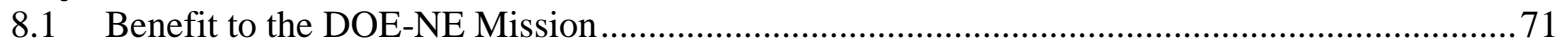

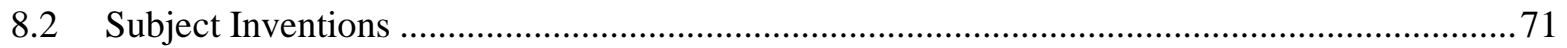

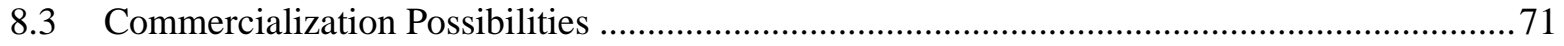

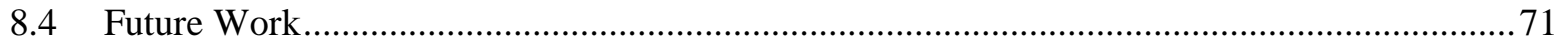

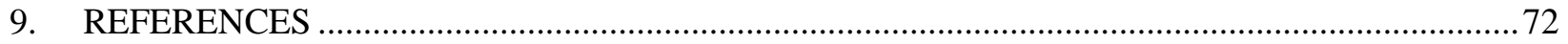

APPENDIX A. EASTMAN OPERATIONAL DATA CHARACTERIZATION …............................. A-1

APPENDIX B. ELECTRICITY AND STEAM FORECASTING …................................................ B-1 


\section{LIST OF TABLES}

Table 1. Four identified task areas for the Eastman-GAIN IES investigation

Table 2. Summary statistics of the generation rate of the Eastman Kingsport facility over the 6year period of 2014-2020 using a daily moving average to smooth signal noise ......................... 12

Table 3. Representative list of SMR concepts under some level of development...................................16

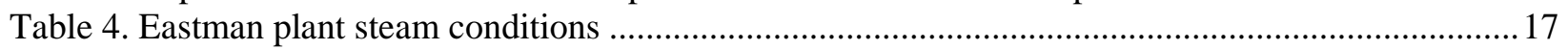

Table 5. Summary of reactor technology compared to Eastman conditions ............................................19

Table 6. Summary of candidate nuclear technology simulations as compared to current Eastman

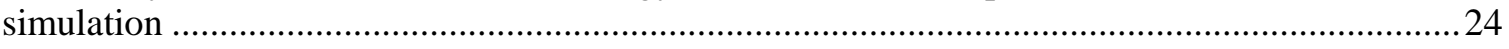

Table 7. Cumulative unplanned outage days of boilers at Eastman .......................................................2

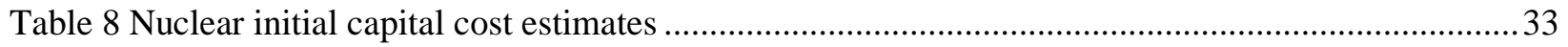

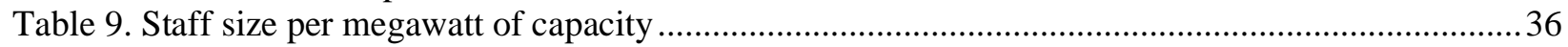

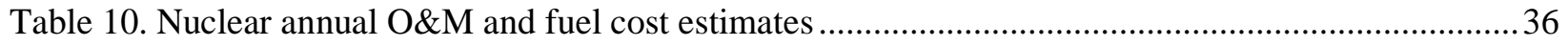

Table 11. Summary of annual O\&M and fuel costs for natural gas plants...........................................37

Table 12. Cost overrun tabulated by year of construction start (Data from DOE EIA-0485).....................38

Table 13. Schedule overrun tabulated by year of construction start (Data from DOE EIA-0485) .............39

Table 14. Summaries of natural gas and SMR scenarios evaluated .......................................................40

Table 15. Summary statistics of the first derivative with respect to time for the signals shown in Figure 44. Units are the measurement unit of the original signal per time unit of the column

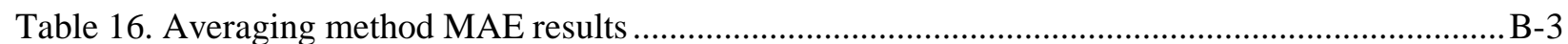

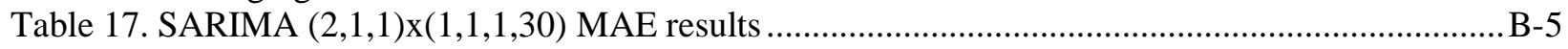

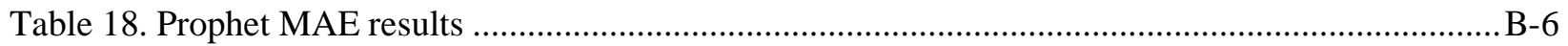

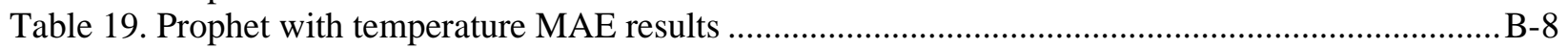

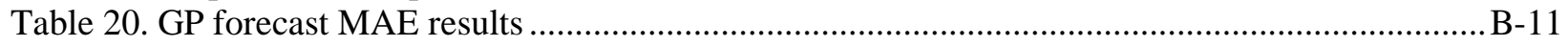




\section{LIST OF FIGURES}

Figure 1. EIA reference case for annual electricity generating capacity additions and retirements [2].

Figure 2. EIA reference case for industrial energy consumption by energy source and subsector [2].

Figure 3. EIA projections for $\mathrm{CO}_{2}$ emissions under various economic growth scenarios [2] ................... 5

Figure 4. EIA report on the US industrial sector energy use by source form, 1950-2018........................ 6

Figure 5. EIA report on industrial sector energy consumption by type of industry in 2018 .................... 6

Figure 6. EIA report from 2002 summarizing the use of fuel within the chemicals industry. A significant portion of fuel used in the chemicals industry is directly tied to heat and electricity production...............................................................................................

Figure 7. EIA report on the energy expenditures in the chemicals industry in 2002 . Total
expenditures were $\$ 32$ billion in $2002,92 \%$ of which came from liquified petroleum gas,

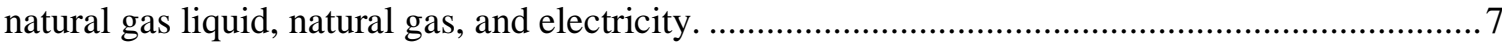

Figure 8. Eastman Chemical Company plant site, Kingsport, Tennessee.............................................. 9

Figure 9. Eastman Kingsport electricity generation and steam lines for the period of 2014-2020 at

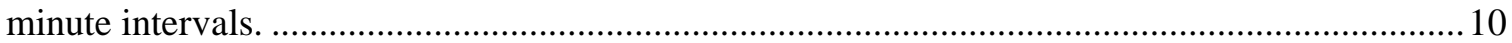

Figure 10. Electricity generation data displayed using various simple moving averages........................11

Figure 11. First derivative of time for electricity generation (see Figure 10 for baseline data). The

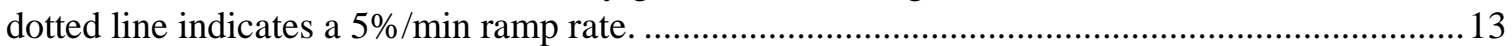

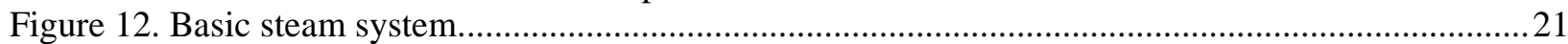

Figure 13. Steam system used for nuclear technology simulations ......................................................22

Figure 14. Example electrical supply and demand results for Eastman-like simulation..........................22

Figure 15. Electric demand and supply curves for selected nuclear technologies. ..................................2

Figure 16. Simplified fault tree of the steam supply failure.............................................................28

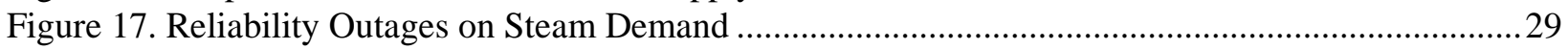

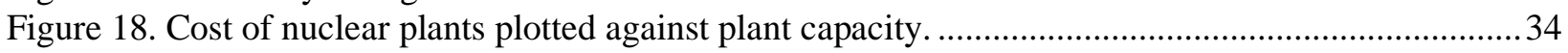

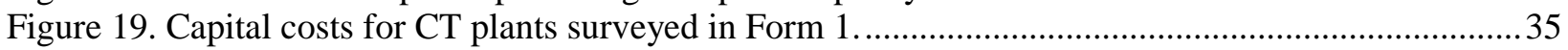

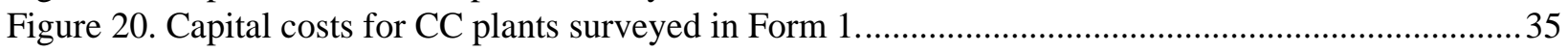

Figure 21. Cost performance with constant dollars............................................................................. 41

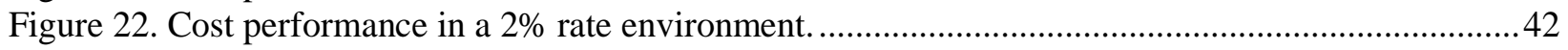

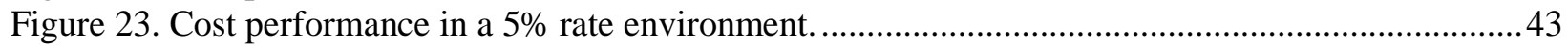

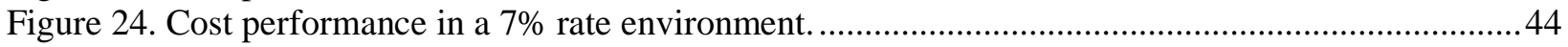

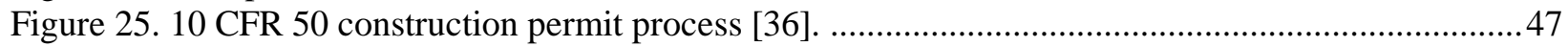

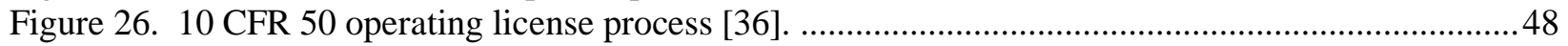

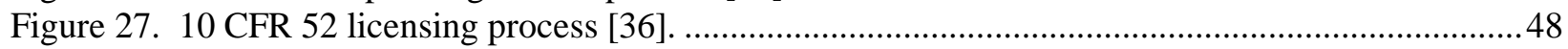

Figure 28. Eastman site SMR fault line proximity and safe shutdown earthquake SSEC layers...............57

Figure 29, Eastman site SMR landslide hazards SSEC layer.................................................................58

Figure 30. Eastman site SMR high slope SSEC layer............................................................................5

Figure 31. Eastman site SMR protected lands SSEC layer. ..................................................................5

Figure 32. Eastman site proximity to hazards SSEC layer.....................................................................60

Figure 33. Eastman site SMR minimum low stream flow SSEC layer. Stream flow is conservatively calculated using USGS low stream flow data and existing lakes and reservoirs with average

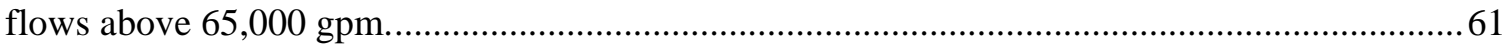

Figure 34. Eastman site SMR wetlands and open water SSEC layer...................................................61

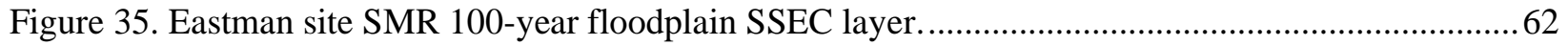

Figure 36. Limitations on populations near nuclear power plants......................................................... 64

Figure 37. Proposed NRC advanced reactor siting guidance - Case 1. DBE - design basis event,

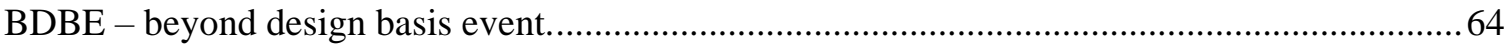

Figure 38. Proposed NRC advanced reactor siting guidance - Case 2 .................................................65 
Figure 39. Proposed NRC advanced reactor siting guidance - Case 3 ..............................................65

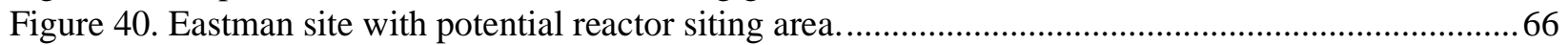

Figure 41. Daytime population for the Eastman site (LandScan ${ }^{\mathrm{TM}}$ USA) ........................................67

Figure 42. Electricity generation and steam line data displayed using various simple moving

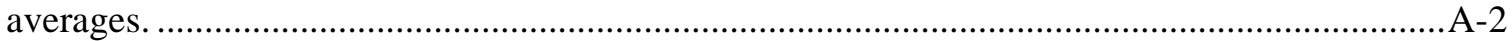

Figure 43. Electricity generation and steam line raw vs. daily moving average data. ...........................A-2

Figure 44. First derivative with respect to time for electricity generation and steam line data for raw and moving averages. The dotted line indicates a $5 \% / \mathrm{min}$ ramp rate.

Figure 45. Electricity generation raw (blue) and moving averaged data (red indicates the hourly average, and orange indicates the 12-hour average) for 3-day periods in January, April, July, and October for 2016-2018.

Figure 46. 600 psig line raw (blue) and moving averaged data (red indicates hourly average; orange indicates 12-hour average) for 3-day periods in January, April, July, and October for 20162018 .

Figure 47. 100 psig line raw (blue) and moving averaged data (red indicates hourly average; orange indicates 12-hour average) for 3-day periods in January, April, July, and October for 20162018

Figure 48. 15 psig line raw (blue) and moving averaged data (red indicates hourly average; orange indicates 12-hour average) for 3-day periods in January, April, July, and October for 20162018.

Figure 49. Electricity generation and steam line histograms for 2016-2018 over total timeframe (left) and per year (right).

Figure 50. Electricity generation and steam line boxplots of the smoothed data using months for the entire timeframe 2016-2018

Figure 51. Electricity generation and steam line boxplots of the smoothed data using days of the week for the entire timeframe 2016-2018.

Figure 52. Electricity generation and steam line boxplots of the smoothed data using hours of the day for the entire timeframe 2016-2018.

Figure 53. Electricity generation and steamline periodogram plots using data resampled at various rates for the entire timeframe 2016-2018 (Resampling definitions: $\mathrm{T}=$ Minute, $\mathrm{H}=$ Hour, $\mathrm{D}=$ Day, $\mathrm{W}=$ Week).

Figure 54. Electrical generation frequency data grouped by periods of time, analyzed, and averaged to produce the show frequency plots. The longest time in each plot represents the period grouped.

Figure 55. Averaging forecasts for electricity generation (a) and steam mass flows at various pressures $(b-d)$

Figure 56. SARIMA forecasts for electricity generation (a) and steam mass flows at various pressures (b-d).

Figure 57. Forecasts with Prophet for electricity generation (a) and steam mass flows at various

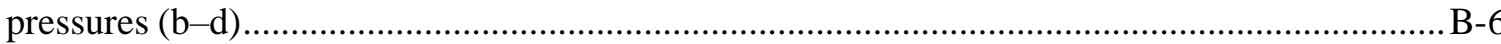

Figure 58. Location of the weather station in Kingsport, Tennessee, indicated by the red pin................. B-7

Figure 59. Temperature range from the weather station near Eastman's site. ....................................... B-8

Figure 60. Prophet forecasts for electricity generation demonstrating overfitting to 2018-2019............. B-9

Figure 61. GP forecast for 100 psig steam mass flow rates................................................................ B-10 


\section{ABBREVIATIONS}

A

AEA

AEP

AR

ARIMA

BOP

$\mathrm{CC}$

CDM

CFR

CHP

$\mathrm{CM}$

COL

$\mathrm{CP}$

CT

DBE

BDBE

DBN

DOE

DOE-NE

EA

EAB

EIA

EIS

EMD

EP

EPRI

ESP

ETA

FAA

FEIS

FERC

FHR

FMEA

FMECA

FOAK

FTA

GAIN

GE

GIS

GP

GPU

GRU

HTGR

IES

ITAAC

$\mathrm{K}$

$\mathrm{L}$

LMR

LOLP

LOSE availability

Atomic Energy Act

American Electric Power

advanced reactor

autoregressive integrated moving average

balance of plant

combined cycle

condition-directed maintenance

US Code of Federal Regulations

combined heat and power

corrective maintenance

combined license

construction permit

combustion turbine

design basis event

beyond design basis event

deep belief network

US Department of Energy

DOE Office of Nuclear Energy

exclusion area

exclusion area boundary

Energy Information Administration

environmental impact statement

empirical mode decomposition

emergency planning

Electric Power Research Institute

early site permit

event-tree analysis

Federal Aviation Administration

final EIS

Federal Energy Regulatory Commission

fluoride salt-cooled high-temperature reactor

failure-mode effect analysis

failure-mode effect \& criticality analysis

first of a kind

fault-tree analysis

Gateway for Accelerated Innovation in Nuclear

General Electric

geographic information systems

Gaussian process

graphics processing unit

gated recurrent unit

high-temperature gas reactor

integrated energy system

inspections, tests, analyses, and acceptance criteria

failure rate (i.e. number of failures per unit time)

maintenance rate

liquid metal reactor

loss of load probability

loss of steam load expected 


\begin{tabular}{|c|c|}
\hline LPZ & low population zone \\
\hline LSTM & long short-term memory \\
\hline LWA & limited work authorization \\
\hline LWR & light-water reactor \\
\hline M & maintainability \\
\hline MAE & mean absolute error \\
\hline MAMT & mean active maintenance time \\
\hline MDT & mean down-time \\
\hline MHTGR & modular high-temperature gas reactor \\
\hline MTBF & mean time between failures \\
\hline MTBM & mean time between maintenance (operations) \\
\hline MTTR & mean time to repair \\
\hline MWe & mega-watt electric \\
\hline MWt & mega-watt thermal \\
\hline NEPA & National Environmental Policy Act \\
\hline NG & natural gas \\
\hline NOAA & National Oceanic and Atmospheric Administration \\
\hline NPRDSR & nuclear plant reliability data systems report \\
\hline NRC & US Nuclear Regulatory Commission \\
\hline NSSS & nuclear steam supply system \\
\hline O\&M & operation and maintenance \\
\hline $\mathrm{OL}$ & operating license \\
\hline ORNL & Oak Ridge National Laboratory \\
\hline OR-SAGE & Oak Ridge Siting Analysis for Power Generation Expansion \\
\hline PM & preventive maintenance \\
\hline QA & quality assurance \\
\hline $\mathrm{R}$ & reliability \\
\hline RAMS & reliability, availability, maintainability \& supportability \\
\hline RCA & root cause analysis \\
\hline RCM & reliability-centered maintenance \\
\hline RG & regulatory guide \\
\hline $\mathrm{s}$ & seconds \\
\hline SAR & safety analysis report \\
\hline SARIMA & seasonal autoregressive integrated moving average \\
\hline SER & safety evaluation report \\
\hline SMR & small modular reactor \\
\hline SSEC & site selection and evaluation criteria \\
\hline SSC & structures, systems, and components \\
\hline SVRM & support vector regression machine \\
\hline $\mathrm{t}$ & time \\
\hline TEDE & total effective dose equivalent \\
\hline TG & turbogenerator \\
\hline TRANSFORM & Transient Simulation Framework of Reconfigurable Models \\
\hline TVA & Tennessee Valley Authority \\
\hline UAMPS & Utah Associated Municipal Power System \\
\hline USGS & US Geological Survey \\
\hline VTR & Versatile Test Reactor \\
\hline
\end{tabular}




\begin{abstract}
The industrial manufacturing industry is looking to implement new methods of energy production to ensure a consistent energy supply while reducing economic costs and environmental impacts. Much of the manufacturing industry relies on fossil fuels - primarily coal and natural gas - of which there are finite resources subject to price volatility due to an inelastic demand. These resources also come with significant negative environmental impacts related to emissions. While complete independence from fossil fuels is not immediately realistic, options are available to significantly reduce dependency on fossil fuel supplies, including integrated energy systems (IESs) which tightly couple nuclear energy source generators with energy consumers (i.e., industrial factories) to fulfill power and energy requirements. Once realized, optimized IESs may yield significant economic and environmental benefits over traditionally isolated generator and consumer facilities.

This report presents a feasibility study for siting an IES to meet the steam and electricity needs of Eastman Chemical Company's facility in Kingsport, Tennessee. This study explored reactor technology options, evaluation, and optimization, with a focus on meeting the facility's operational and reliability requirements. This work is part of an ongoing effort by Eastman to be good environmental stewards and meet the demands of their customers by shifting to more environmentally sustainable solutions for their energy needs. Outcomes of this report are also of general interest and value to any design or development team seeking to deploy an IES, as many topics described herein are generally applicable to any nuclear power facility.
\end{abstract}




\section{INTRODUCTION}

This work summarizes assistance provided to Eastman in the conceptual design and analysis of an integrated energy system (IES) to replace the existing energy production infrastructure at the Eastman site in Kingsport, Tennessee. The efforts are focused on resource productivity, reducing energy intensity, reducing greenhouse gas emissions, and increasing water conservation and reuse. Because Eastman needs both steam and electricity to make its products, they use combined heat and power (CHP), or cogeneration, at the largest manufacturing sites. Through CHP, Eastman's Kingsport site produces on the order of 1,000 MWt of energy including an onsite electricity generation capacity of approximately $200 \mathrm{MWe}$, with an average load greater than $150 \mathrm{MWe}$. The power is produced with 17 coal or natural gas boilers and 19 turbogenerators. Currently, natural gas provides about $50 \%$ of the site's energy, and the remainder comes from other fossil fuels, including coal. ${ }^{1}$

However, the existing power plants were installed in stages dating back to the 1930s and require updating or conversion. Recently, Eastman converted some coal boilers to natural gas boilers, but they recognize that low-cost natural gas market conditions may shift. Additionally, natural gas reduces, but does not eliminate, environmental emissions relative to coal.

Therefore, Eastman is exploring the option of converting their power production system to a nuclear IES for combined thermal and electrical production as a potential path to simultaneously update and upgrade the internal process systems while decreasing Eastman's exposure to natural gas market volatility and environmental emission requirements. This is the first time that an assessment of this type has been completed for a specific chemical company with known end-user requirements such as economics, reliability, and demand.

Following this introductory section, this report includes the analysis for four identified tasks (Table 1). An appendix includes information on supplemental studies related to the primary objective. The objective of this report is to provide Eastman an appropriate level of analysis to assist in understanding nuclear energy for Eastman's exploratory stage of sustainability efforts. This includes an understanding of nuclear deployment scenarios for Eastman's Kingsport site, as well as more general but critical aspects of any future nuclear deployment scenario. This study was conducted in collaboration with the Gateway for Accelerated Innovation in Nuclear (GAIN), which was established by the US Department of Energy Office of Nuclear Energy (DOE-NE) to provide the nuclear community with access to the technical, regulatory, and financial support necessary to move innovative nuclear energy technologies toward commercialization while ensuring the continued safe, reliable, and economic operation of the existing nuclear fleet.

Table 1. Four identified task areas for the Eastman-GAIN IES investigation

\begin{tabular}{ll}
\hline Task & \multicolumn{1}{c}{ Description } \\
\hline 1 & Benchmark of existing facility \\
2 & Trade study on nuclear reactor options \\
3 & Optimization and figures of merit \\
4 & Summary of Eastman nuclear power options \\
\hline
\end{tabular}

\footnotetext{
${ }^{1}$ The ratio of natural gas to other sources of energy fluctuates depending on plant demand.
} 


\subsection{INTEGRATED ENERGY SYSTEMS}

Integrated energy systems (IES) are "cooperatively-controlled systems that dynamically apportion thermal and/or electrical energy to provide responsive generation to the power grid" using nuclear as a heat generation source [1]. These systems focus on creating financial and technically synergistic partnerships among various energy producers and consumers. Naturally, a given IES is tailored to the specific application of interest and the market in which it resides. To achieve acceptable technical and economic performance, various subsystem designs, integration options, and deployment scenarios must be evaluated. However, three general categories are considered for IES architectures as identified in the DOE-NE IES Program 2020 Roadmap [1]:

1. Tightly coupled IES $\mid$ Thermally and electrically coupled and co-controlled systems.

2. Thermally coupled IES $\mid$ Subsystems are only coupled via thermal energy networks and cocontrolled to manage thermal demands. Electrical needs are indirectly met by connections to the grid.

3. Loosely coupled, electricity-only IES $\mid$ Subsystems are only coupled via electrical energy networks and co-controlled to manage electricity demands.

An additional item of note is the ownership of an IES. The establishment of an IES will require new business and legal strategies to allow for proper management and ownership of the tightly linked systems. Single ownership is a clear possibility, but multiple owner and/or operator strategies are also possible. Just as with physical IESs, business arrangements for the systems will be varied and tailored for individual applications. An industrial company may prefer to form a tightly coupled IES but also may have no desire to own or operate a nuclear facility. Proper business and legal agreements will be critical for enabling these systems. Although this topic is critical to the realization of IESs, this report focuses on the technical aspect of an Eastman IES, leaving an in-depth investigation of business and legal strategies as an area of future work. At this stage, a tightly coupled or thermally coupled IES is likely most appropriate for Eastman.

\subsection{US ENERGY OUTLOOK}

There is a continuing global shift away from the types of energy that have traditionally powered the world economy toward a new resource mix. This topic is briefly addressed here from the US perspective to provide background information on the market signals Eastman may be receiving from customers and policy makers. Note that the information discussed here is only for purposes of information and does not indicate any knowledge of Eastman's official position, motivation, or business strategy.

Under the umbrella of DOE, the mission of the Energy Information Administration (EIA) is to "collect, analyze, and disseminate independent and impartial energy information to promote sound policymaking, efficient markets, and public understanding of energy and its interaction with the economy and the environment." ${ }^{2}$ Each year, the EIA evaluates the data and trends regarding US energy and provides projections of what may occur over the next few decades based on certain assumptions. The latest annual report from EIA, the Annual Energy Outlook [2], includes a few key predictions ${ }^{3}$ that help elucidate market expectations:

\footnotetext{
${ }^{2}$ https://www.eia.gov/about/strategic_plan.php\#: :text=Mission,the\%20economy\%20and\%20the\%20environment.

${ }_{3}^{3}$ Predictions are presented only as a possibility of what may occur. Projections or commentary on them are in no ways an endorsement of any policies, recommendations, or conclusions. These projections are simply used for illustrative purposes.
} 
1. A continued shift away from coal generation is expected via retirements and no additional capacity installed (Figure 1). The underlying cause of this trend is due to low natural gas prices, continued growth of the renewable energy market, and market pressures and public policies which encourage the shuttering of coal generation facilities.

2. Nuclear energy is expected to have very few additions and instead is predominantly anticipating retirements (Figure 1), most of which are currently announced and scheduled. EIA's most recent report does not address the optimism around advanced nuclear, improvements to nuclear-related policy and regulation, and increasing recognition of the importance of nuclear energy as a major component of a sustainable clean energy market. As it is difficult to incorporate those types of metrics into a data-based analysis, the EIA report assumes that nuclear energy will remain essentially constant based on current production levels, notwithstanding announced retirements.

3. In the industrial sector, natural gas is projected to remain the dominant energy supply, and the chemical and non-manufacturing industries are the major areas of growth. As plotted in Figure 2, nuclear energy contributes only to the purchased electricity category. IES could dramatically alter this.

4. Despite the substantial growth in renewable energy and decrease in coal generation, greenhouse gas emissions do not substantially decrease through 2050. As demonstrated in Figure 3, emissions do not significantly decrease in the evaluated scenarios, and they may even increase above 2019 emission levels. The principal reasons for this behavior are due to the increased use of natural gas, exacerbated by (1) the heavy reliance of renewable energies on natural gas to make up for its intermittency and to supply other necessary grid needs besides capacity alone, and (2) the diminishing contribution of nuclear energy to the market.

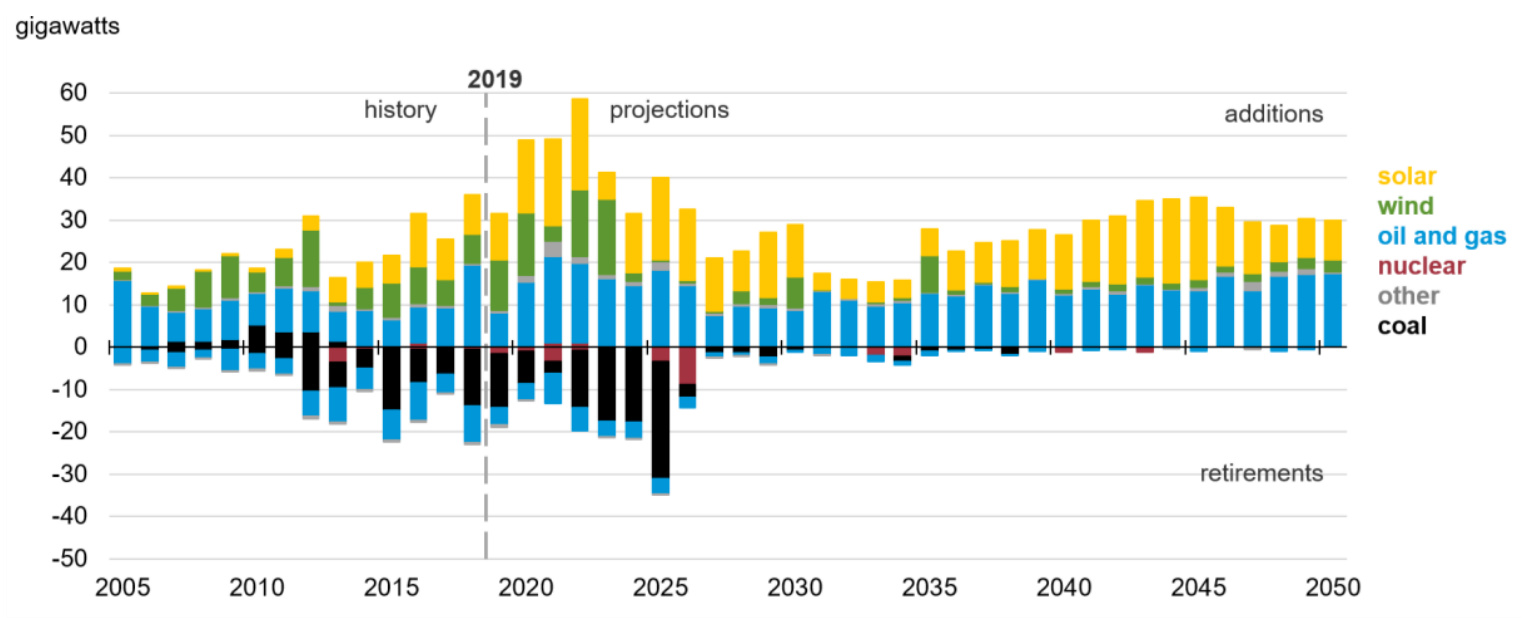

Figure 1. EIA reference case for annual electricity generating capacity additions and retirements [2]. 

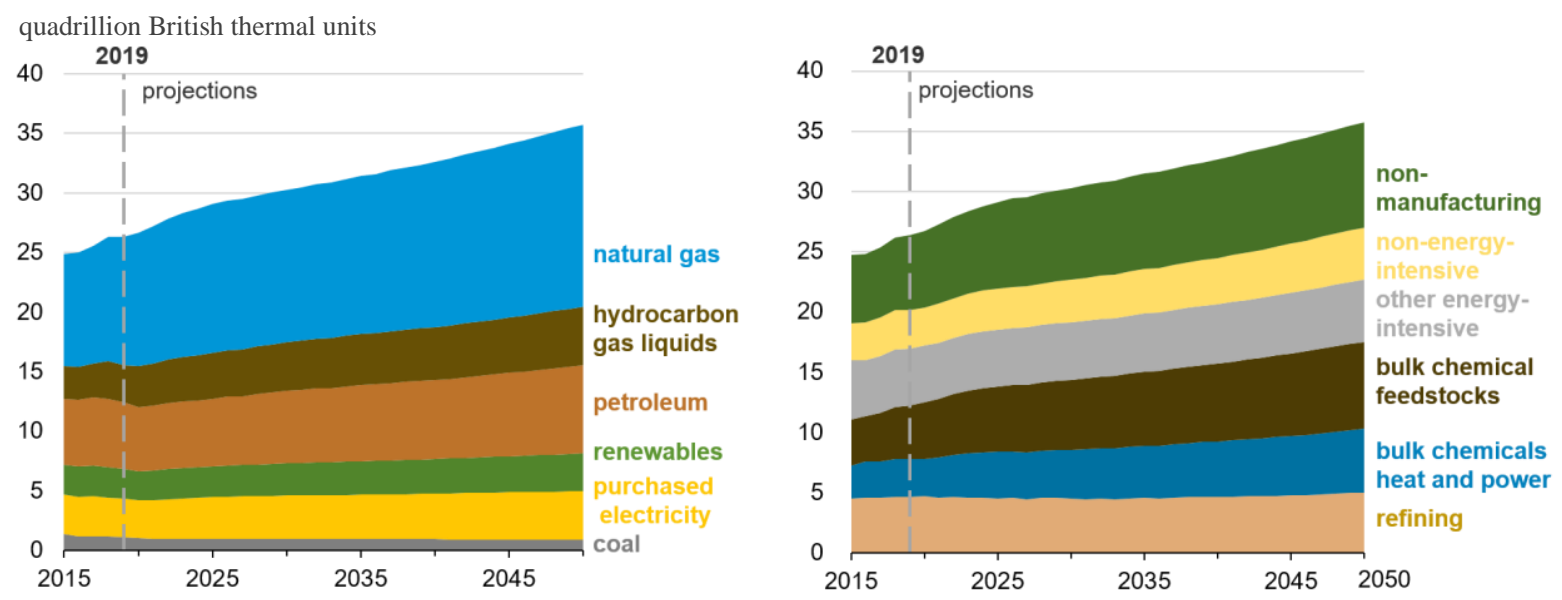

Figure 2. EIA reference case for industrial energy consumption by energy source and subsector [2].

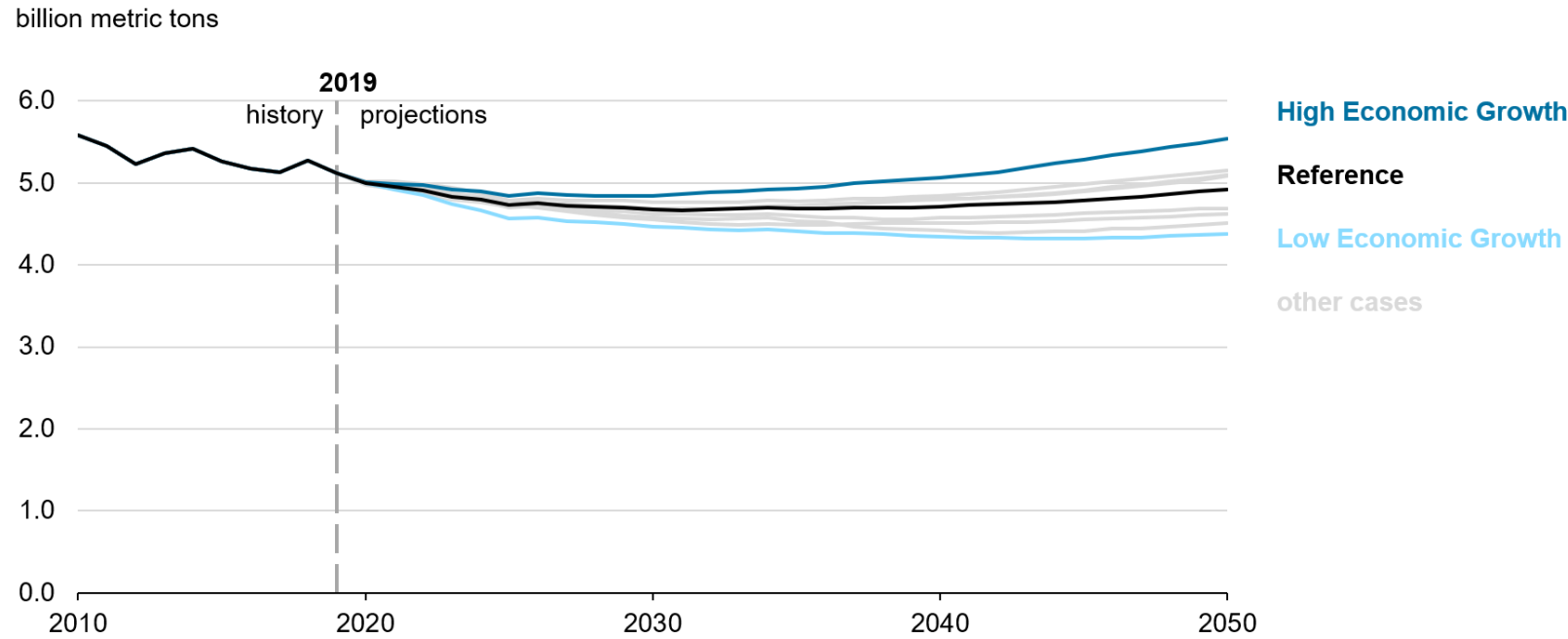

Figure 3. EIA projections for $\mathrm{CO}_{2}$ emissions under various economic growth scenarios [2].

\subsubsection{A Closer Look at the Industrial Sector}

According to the EIA, approximately $32 \%$ of total US energy consumption has been attributable to the industrial sector. ${ }^{4}$ The historic distribution of industrial sector energy sources is shown in Figure 4, and a breakdown of energy usage by industry type is shown in Figure 5. The salient aspects of these plots are three-fold: (1) the ever decreasing role of coal, (2) the significant roles of natural gas and petroleum, and (3) the energy-intensive needs of the chemical industry. These points support the idea that there is potential for significant alterations to the market via the introduction of IES, especially in the chemical industry, which requires large amounts of energy and which may offer substantial opportunities to shift away from natural gas and petroleum toward nuclear and electrification.

\footnotetext{
${ }^{4}$ https://www.eia.gov/energyexplained/use-of-energy/industry.php
} 
To further highlight the potential market for IES in the chemical industry, Figure 6 and Figure 7 show that as of 2002 , at least $1 / 3$ of fuel consumption in the chemical industry was for boiler fuel. This is likely to have increased given the significance decrease in natural gas prices since 2002 and the significant expenditures incurred for fuel-related purchases. Clearly, not all processes are amenable to an IES, but there are ample opportunities for exploration and identification of those processes which are suitable. As IES opportunities are identified by interested parties and implemented, significant shifts in these plots will result, and a more sustainable, forward-looking industry sector will be realized.

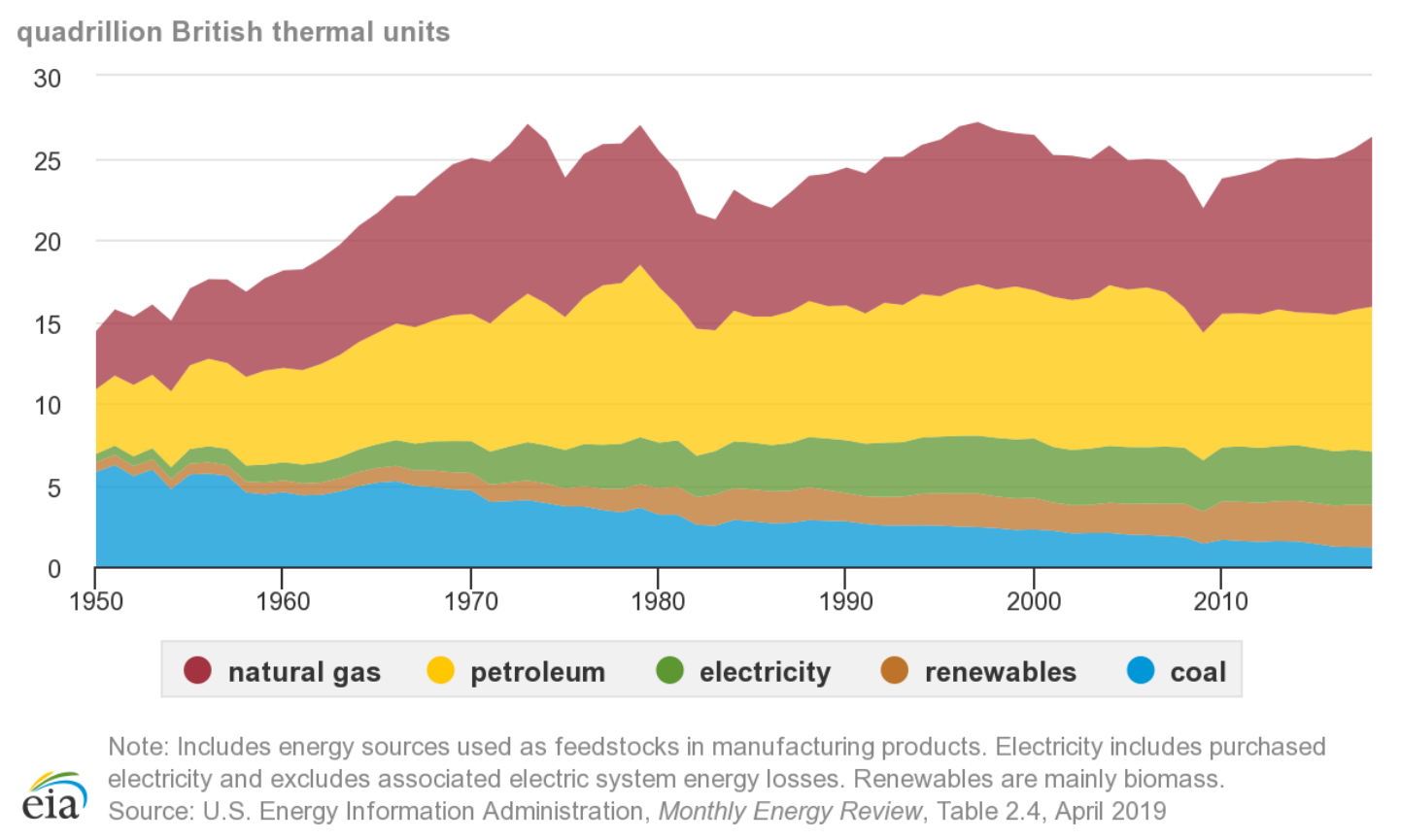

Figure 4. EIA report on the US industrial sector energy use by source form, 1950-2018.

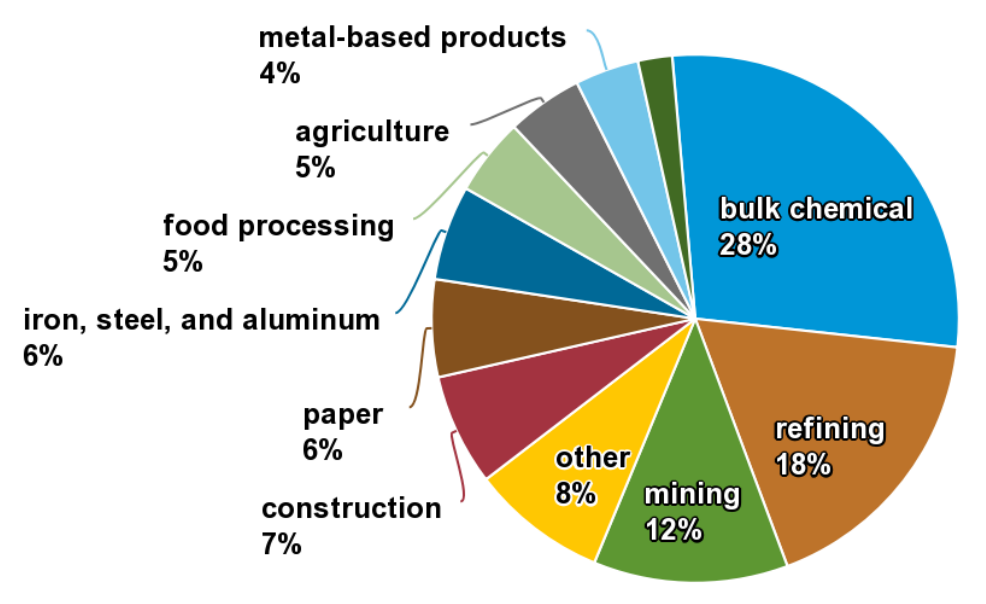

Note: Includes electricity purchases and energy sources used as feedstocks for making products. Other includes wood products $(2 \%)$, plastics products $(1 \%)$, and all others $(6 \%)$.

Source: U.S. Energy Information Administration, Annual Energy Outlook 2019, Tables 25-35, January 2019

Figure 5. EIA report on industrial sector energy consumption by type of industry in 2018. 


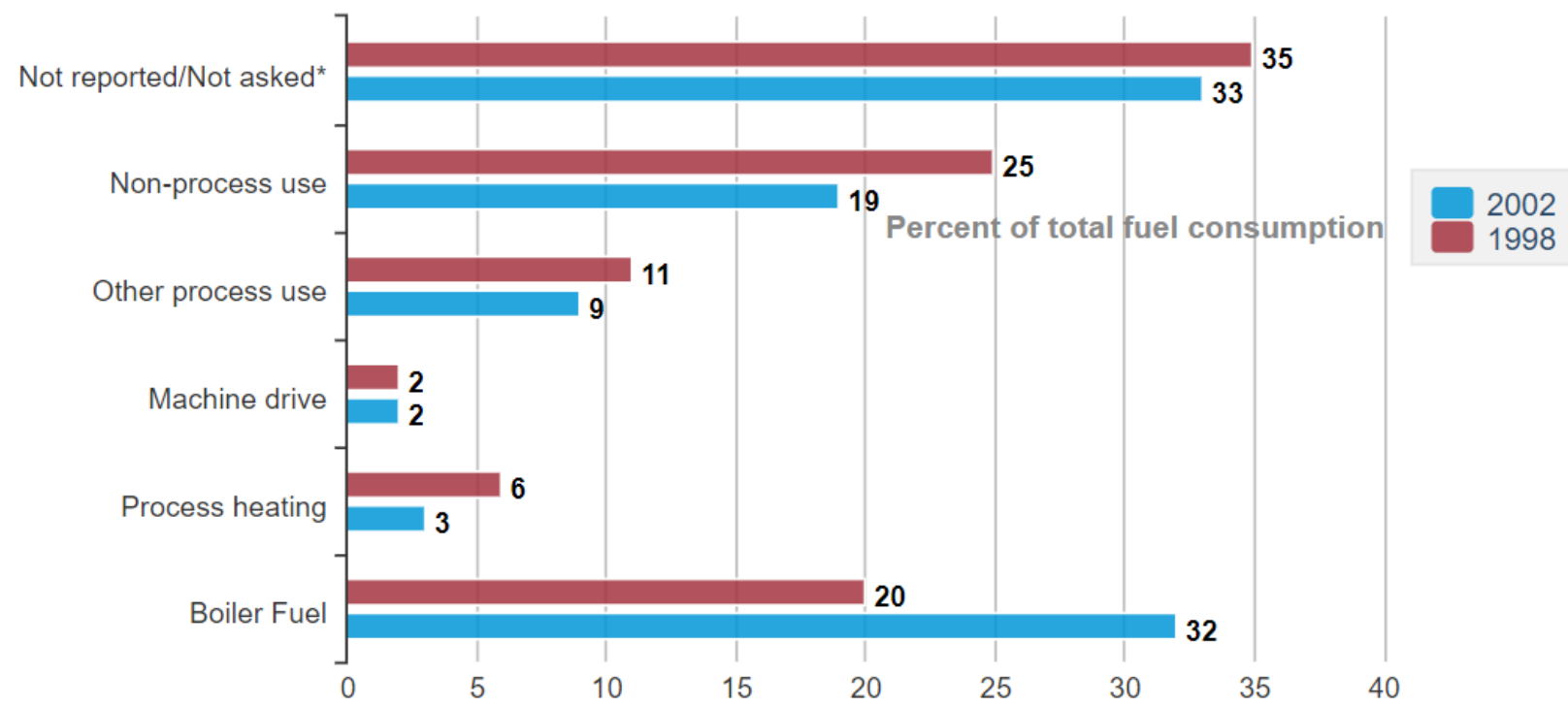

Sources: U.S. Energy Information Administration, Manufacturing Energy Consumption Survey - Table 5.2: End

Figure 6. EIA report from 2002 summarizing the use of fuel within the chemicals industry. A significant portion of fuel used in the chemicals industry is directly tied to heat and electricity production.

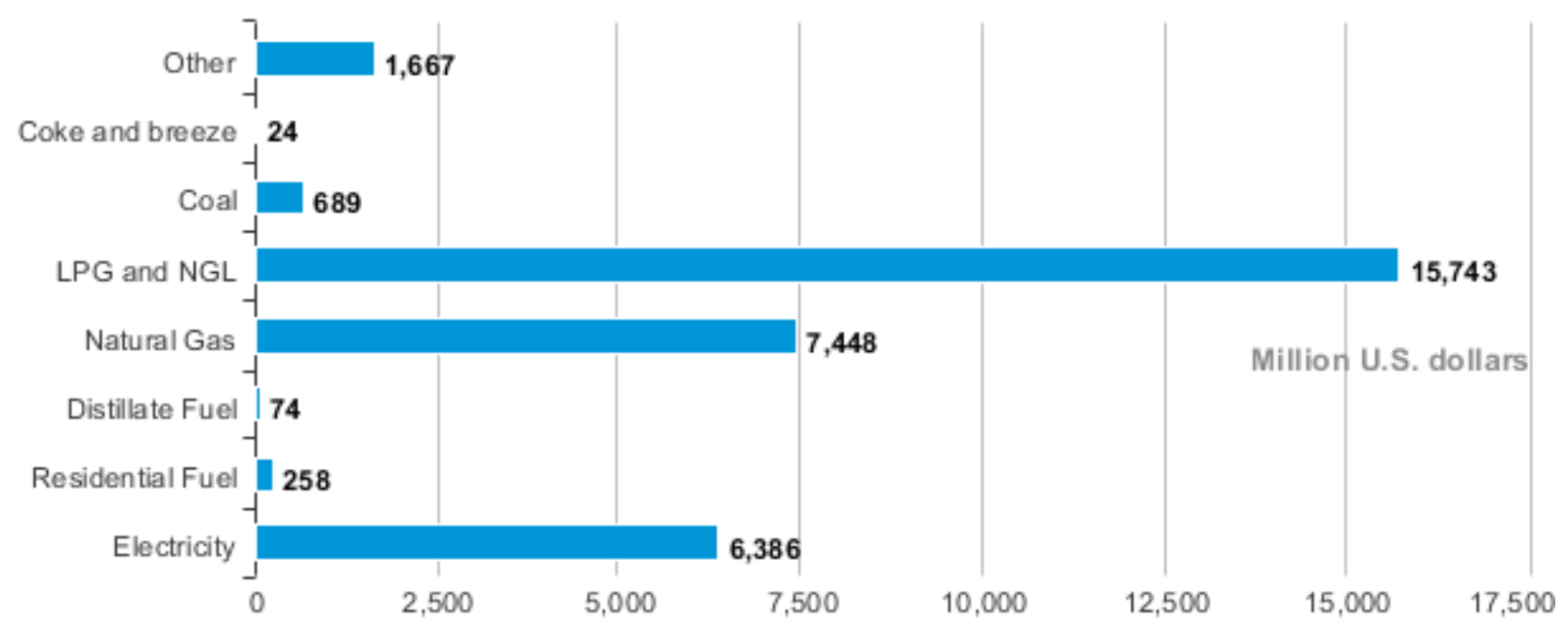

Total energy expenditures (million U.S. dollars)

Figure 7. EIA report on the energy expenditures in the chemicals industry in 2002. Total expenditures were $\$ 32$ billion in $2002,92 \%$ of which came from liquified petroleum gas, natural gas liquid, natural gas, and electricity. 


\section{EASTMAN CHEMICAL COMPANY}

Eastman Chemical Company (Eastman) is a global specialty materials company. ${ }^{5}$ Established in 1920 in Kingsport, Tennessee, by George Eastman, the company has since expanded from its original site and production platforms of organic chemicals and acetyls to produce a wide variety of products at several manufacturing facilities around the world. Today, Eastman is one of the largest chemical companies in the United States, manufacturing chemicals, fibers, and plastics. Regarding sustainable development and environmental stewardship, Eastman has a long history of interest in improving emissions and ecological footprint (e.g., combined heat and power systems ${ }^{6}$ ), receiving multiple awards for their efforts. ${ }^{7}$

This work focuses on IES deployment options for the steam and electricity needs of Eastman's Kingsport, Tennessee, site which currently uses a mix of coal and natural gas energy sources. The following sections will describe some pertinent details related to the Kingsport facility for this IES study.

\subsection{EASTMAN KINGSPORT, TENNESSEE | LOCATION AND SITE CHARACTERISTICS}

As the original manufacturing site of Eastman, the facility in Kingsport (Figure 8) is celebrating 100 years of operations as of 2020. The main Eastman plant site is located approximately 2 miles southeast of Kingsport city's downtown area. This site produces a broad range of chemicals, fibers, and plastics found in products such as paint, adhesives, textiles, sports bottles, pharmaceuticals, and medical devices. The site comprises approximately 4,000 acres, of which the main plant site covers approximately 900 acres, with more than 550 buildings supporting engineering, processing, and administration functions. A major geographical aspect of the site is the Holston River, which bisects the plant and is viewed as a valuable water resource not only to the company but to the community; therefore, it is actively monitored and protected. ${ }^{8}$

The Kingsport site includes large steam and electricity production units which primarily operate on coal or natural gas. These units provide most of the necessary steam and electric energy for the large variety of onsite chemical production. Some additional onsite facilities include a wastewater treatment facility and hydrogen production facilities. Dedicated medical and fire departments that solely support Eastman are located on site, as well. Transportation capabilities throughout the Kingsport site include railway, roads, and potential waterway access.

\footnotetext{
${ }^{5}$ https://www.eastman.com/Company/About_Eastman/Pages/Introduction.aspx

${ }^{6}$ https://www.eastman.com/Company/Sustainability/features/Environment/Pages/Cogeneration.aspx

${ }^{7}$ https://www.eastman.com/Literature_Center/Misc/Kingsport_Facts_Figures.pdf

${ }^{8}$ https://www.eastman.com/Company/Sustainability/features/Environment/Pages/River_Studies.aspx
} 


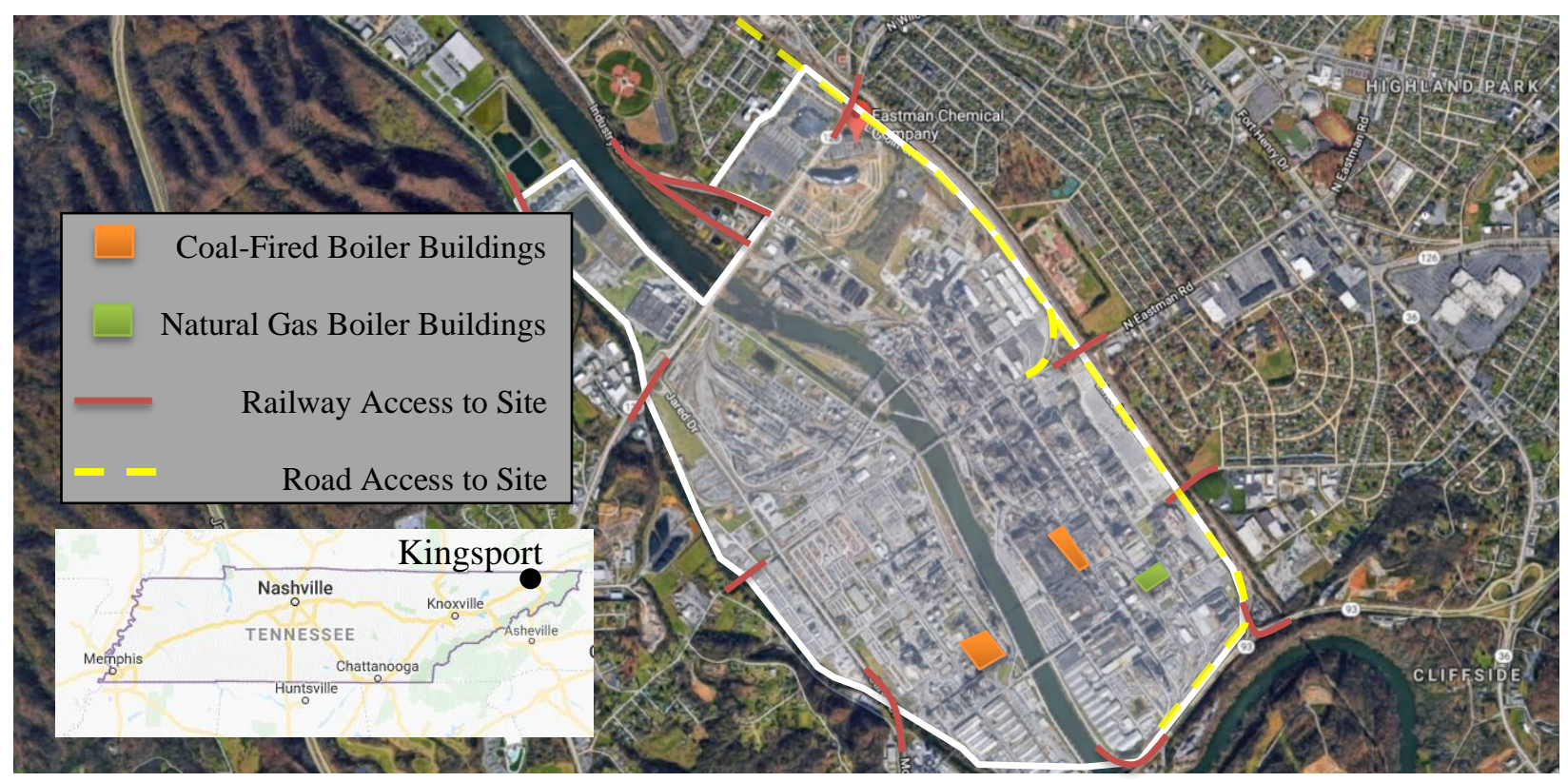

Figure 8. Eastman Chemical Company plant site, Kingsport, Tennessee.

\subsection{ENERGY PRODUCTION REQUIREMENTS}

The Eastman Kingsport facility requires a significant amount of energy to fulfill its production targets. Electricity and steam are produced onsite at the Kingsport location as needed using a tightly coupled generator-steam network which produces electricity and delivers steam to the various plant processes at 600,100 , and $15 \mathrm{psig}$. Only a relatively small amount of electricity ( $9 \mathrm{MWe}$ on average) is bought from the grid operator. Average total energy needs at any given moment for the Eastman Kingsport site is about 1,000 MWt and $150 \mathrm{MWe}$. To provide the necessary steam and electricity at an appropriate level of reliability, Eastman operates approximate 17 boilers - 9 coal and 8 natural gas-and 19 turbogenerators. The following subsections provide additional information regarding operational characteristics of the facility drawn from operational data provided by Eastman.

\subsubsection{Eastman Raw Operational Data}

To assist in the investigation of potential IES options, Eastman provided 6 years of operational data (20142020) for their Kingsport site. Figure 9 provides an unfiltered look at the raw data as received from Eastman. The data represent approximate system demands for the high-level metrics of overall electricity production, steam line flow rate, and purchased electricity from the grid. These data are approximate, as the site's energy sources are not co-located with each other and monitored in such a way to provide a result that simplifies precisely to the level of detail investigated in this report. However, the data are believed to capture the major needs of the facility and are therefore representative and adequate for the purposes of this study. 

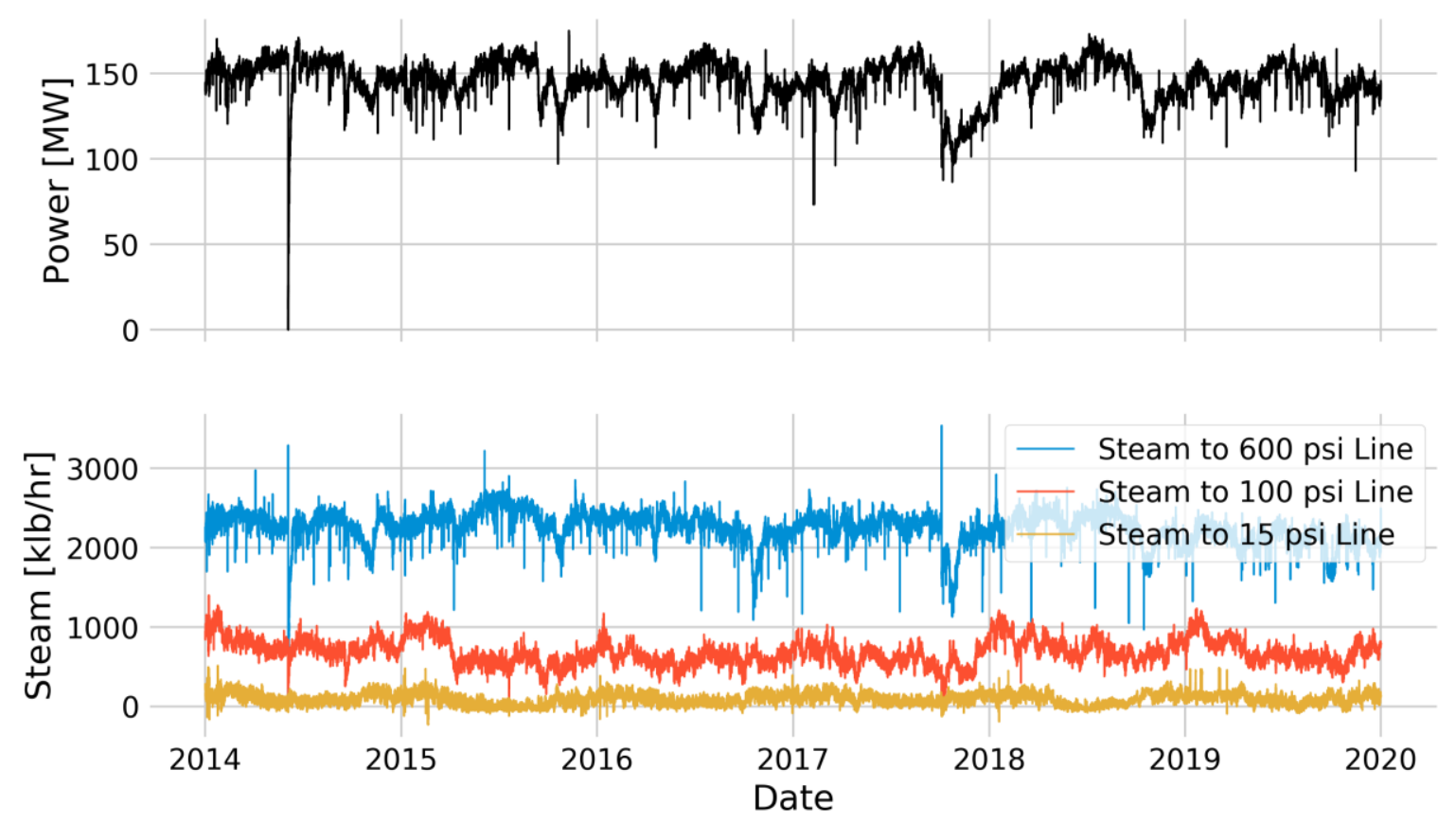

Figure 9. Eastman Kingsport electricity generation and steam lines for the period of 2014-2020 at minute intervals.

\subsubsection{Data Characterization}

To better understand the data and hence the operation of the Eastman facility, the raw data were manipulated in a variety of ways. Aspects of interest included filtering spurious signals, understanding the general demands of the system including averages, ramp rates, seasonal behavior identification, and predictability. For brevity, only the results considered directly pertinent to the primary four tasks of this analysis are included. To focus on the necessary information, results are presented for the electricity production only. Notable aspects of other raw data signals are addressed in the text. Additional supporting analysis for all data signals are included in the appendix. The electricity data alone is presented in the main body of the report as the electricity and 600 psig steam line are directly related and represent the primary aspect of interest by Eastman.

\subsubsection{Spurious Signals}

Spurious signals, marked by sharp vertical lines in Figure 9, deviate significantly from the baseline, and they appear frequently in all raw data signals. It is necessary to determine whether these are real signals or artifacts of the various measurements systems from which the data were compiled. A simple moving average based on a 24-hour period (Figure 10) sufficiently suppressed the noisiness of the data while retaining the major transients that are more likely associated with unplanned maintenance activities (see Section 5.1). Two exceptions are the large downward spikes in 2014 and 2017. The 2014 spike was a result of an unplanned total plant shutdown caused by a problem that originated in the plant power system. The 2017 spike is thought to be a computer system failure and not an actual plant behavior based on the abruptness of signal deterioration and the prompt manner in which the data returned back to reflecting typical plant behavior without the slower ramp-up behavior expected in plant malfunctions. Although sufficient denoising was implemented for this work, future work should include more detailed signal analysis to inform other targeted applications. 

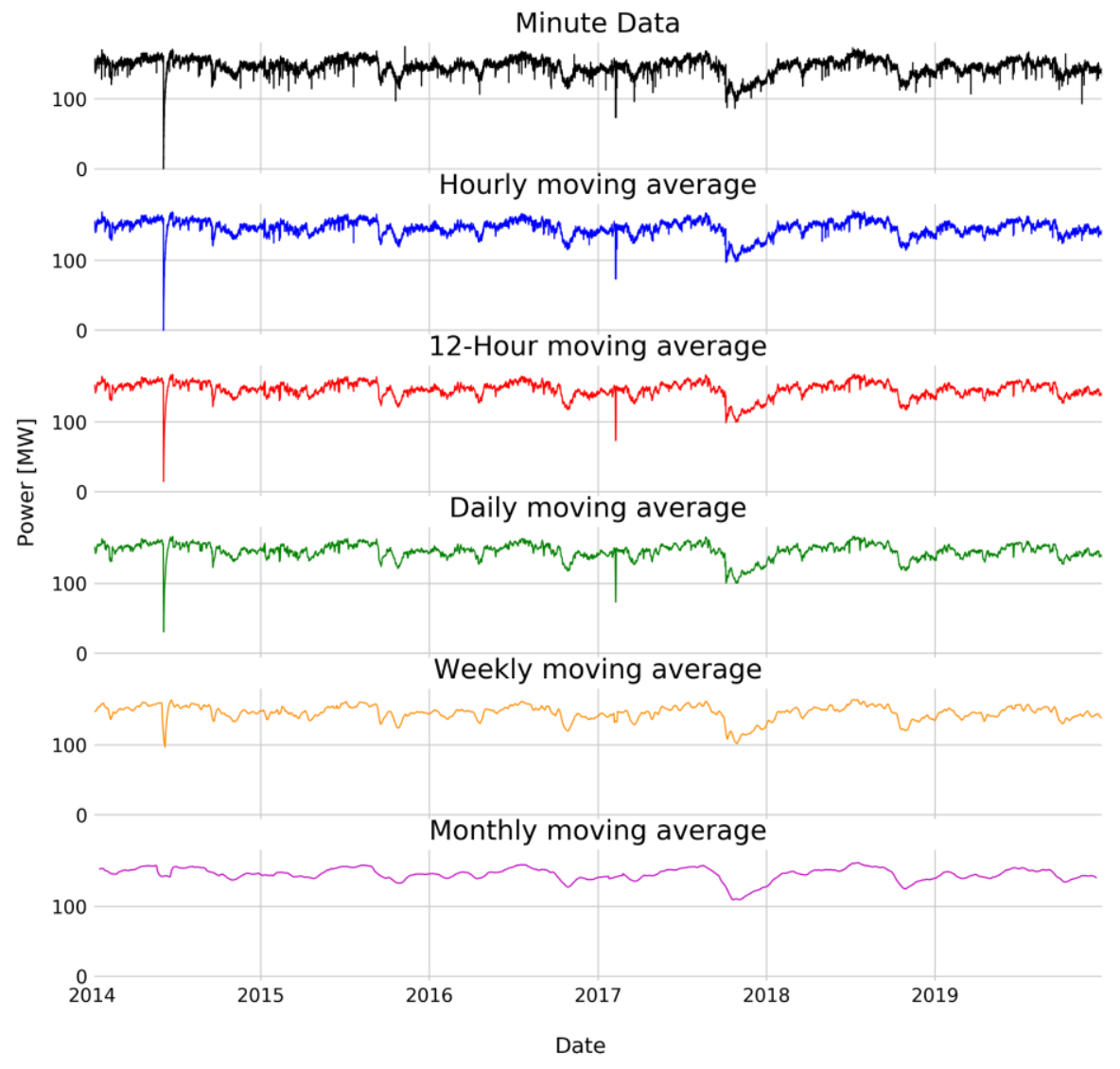

Figure 10. Electricity generation data displayed using various simple moving averages.

\subsubsection{Basic Statistics}

A simple daily (24-hour) moving average was used to smooth signal noise, resulting in the high-level generation rate summary statistics presented in Table 2 . The daily moving average was selected for data presentation and in subsequent analysis throughout this report unless otherwise noted because it provides sufficient smoothing to remove spurious, short-term signals which are likely errors in the measurement system while maintaining any short timeframe (> 1 day) facility dynamics. Table 2 presents the mean, minimum, and maximum of each type of data, along with the standard deviation $(\sigma)$ and the percentiles in which $50 \%$ represents the median value of the data. The minimum value of electricity generation and the 600 psig are impacted by the spurious signal mentioned above, so they represent a minimum that is likely lower than reality. Also, the 15 psig line at times returns negative values associated with steam being inducted and/or used in the powerhouse. This occurs when there is an excess of steam being produced by waste heat in the plant or from steam being let down through plant turbines. 
Table 2. Summary statistics of the generation rate of the Eastman Kingsport facility over the 6-year period of 2014-2020 using a daily moving average to smooth signal noise

\begin{tabular}{ccrrr}
\hline & $\begin{array}{c}\text { Electricity } \\
\text { generation } \\
(\mathbf{M W e})\end{array}$ & $\begin{array}{c}\mathbf{6 0 0} \mathbf{~ p s i g} \\
(\mathbf{k l b} / \mathbf{h r})\end{array}$ & $\begin{array}{c}\mathbf{1 0 0} \mathbf{~ p s i g} \\
(\mathbf{k l b} / \mathbf{h r})\end{array}$ & $\begin{array}{c}\mathbf{1 5} \mathbf{~ p s i g} \\
(\mathbf{k l b} / \mathbf{h r})\end{array}$ \\
\hline mean & 146.0 & $2,248.8$ & 678.9 & 92.8 \\
$\boldsymbol{\sigma}$ & 11.2 & 184.2 & 157.7 & 71.9 \\
$\mathbf{m i n}$ & 30.7 & 573.9 & 157.4 & -151.9 \\
$\mathbf{2 5 \%}$ & 140.7 & $2,166.0$ & 570.8 & 37.3 \\
$\mathbf{5 0 \%}$ & 147.5 & $2,270.3$ & 661.0 & 92.8 \\
$\mathbf{7 5 \%}$ & 153.8 & $2,369.4$ & 775.6 & 145.6 \\
$\mathbf{m a x}$ & 167.3 & $2,675.7$ & 1223.9 & 451.4 \\
\hline
\end{tabular}

\subsubsection{Facility Ramp Rates}

Current regulations on nuclear facilities limit the rate at which the facility may output power ( $5 \%$ change in power/minute). This limit is specified not only by boundaries which will keep the reactor core in a safe condition, but also by all piping and electricity production equipment. As such, in an IES, functional requirements will govern the rate at which a facility can ramp up or down its output. Figure 11 presents the rate of change experienced by the facility. The data shows infrequent ramp rate occurrences for electricity and $600 \mathrm{psig}$ steam lines exceeding the $5 \% / \mathrm{min}$. However, given the infrequent nature of those events, this very fast rate of change is not a common occurrence for the facility. Therefore, if needed, various operational and technological options (e.g., energy storage) could be leveraged to handle the infrequent ramp rates of the facility. The 100 and 15 psig steam lines ramp rates are more aggressive but that is the nature of the facility. They do not impact the gross ramping requirement of the generating facility given that those fast ramp rates do not propagate back into the electricity and/or 600 psig signals. Based on the behavior shown, no major hurdles are expected regarding the rate of change required for an IES. However, this factor would require a more detailed analysis in future work, but it is not an area of concern at this point in the exploratory process. 


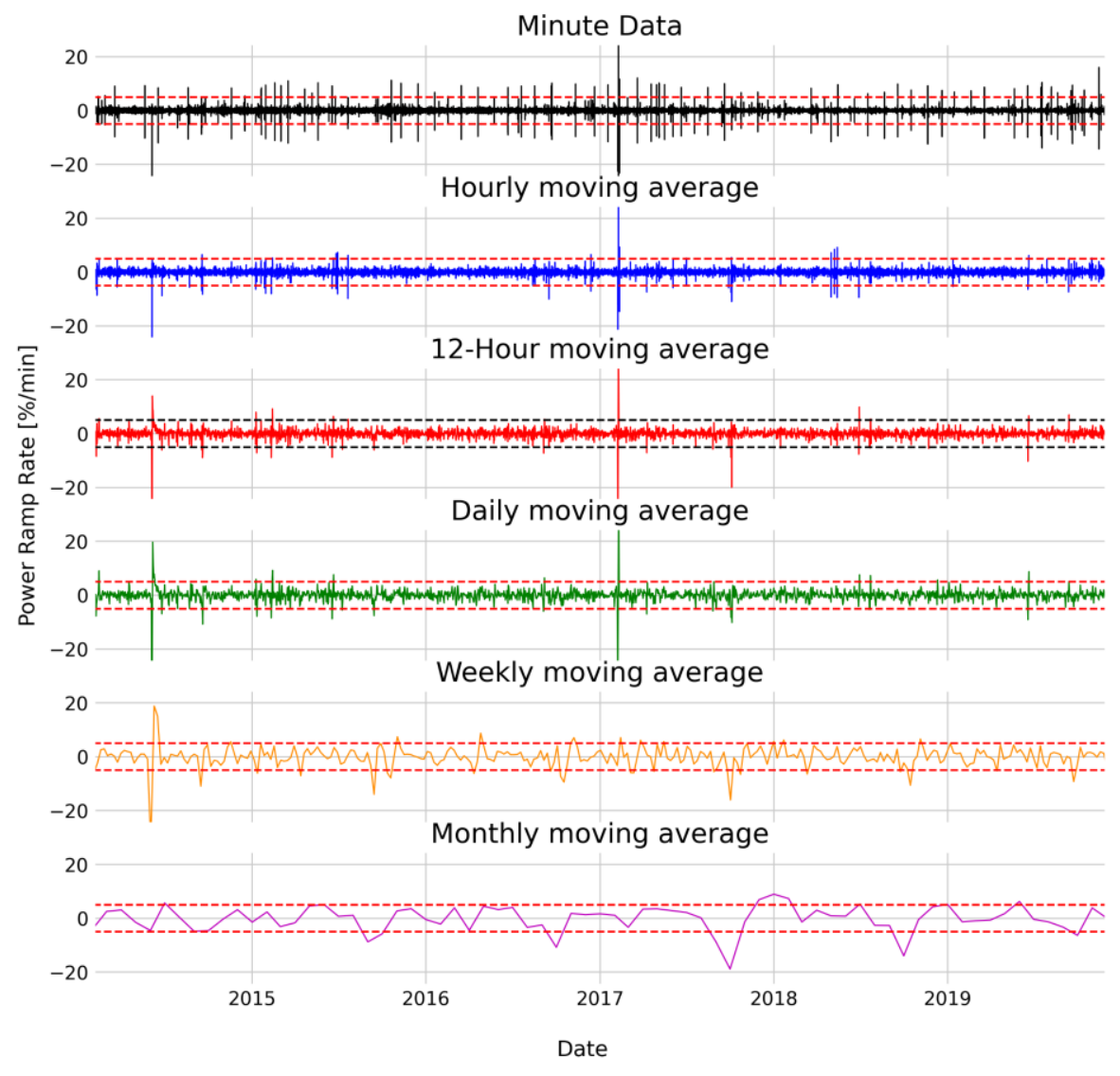

Figure 11. First derivative of time for electricity generation (see Figure 10 for baseline data). The dotted line indicates a $5 \% / \mathrm{min}$ ramp rate.

\subsubsection{Seasonality}

In this report, the term seasonality refers to events which repeat at some rate over time. This may include behaviors such as diurnal cycles and annual seasons. At the Eastman Kingsport site, strong seasonal behavior occurs near the fall of each year, and a smaller seasonal behavior appears in the spring in both electrical production and $600 \mathrm{psig}$ steam flow rate. Eastman has confirmed that this behavior was due to scheduled maintenance periods. The 15 psig also has seasonal behavior associated with winter/fall cycles. This is likely due to the use of the steam for plant heating and cooling. The data were also investigated for shorter time scale seasonality such as weekends, holidays, day/night behavior, and changing shift impacts. The level of analysis performed in this report did not produce any clear evidence for additional seasonal behavior, indicating that the plant operates at a very consistent rate in which only planned and unplanned maintenance and long-term annual seasonal variations seem to impact facility output. 


\section{TRADE STUDY ON NUCLEAR REACTOR OPTIONS}

For the Eastman site in Kingsport, Tennessee, the nuclear reactor is the primary aspect of the IES under consideration since the plant is already established, along with its network of steam and electricity. In this analysis, the nuclear reactor would connect to the $600 \mathrm{psig}$ steam line, leveraging the rest of the steam network as it currently exists, along with as much of the current electricity network as possible. Therefore, the primary modeling activity associated with this work is for the evaluation of nuclear reactor technologies to incorporate into the IES.

\subsection{REACTOR SELECTION CONSIDERATIONS}

Several criteria were used for the down-selection of nuclear reactor options for the Eastman facility in Kingsport, Tennessee. Selection criteria considerations include the following:

- Reactor capacity and operability

- Steam temperature and pressure

- Technology readiness

- Siting allowance

These criteria permit a simple approach for selecting a candidate reactor, but they do not encapsulate all the complex aspects of operating and maintaining a nuclear reactor. Quantitative requirements help ensure, to a first approximation, that the nuclear reactor options evaluated would be good candidates to meet the steam, electrical, and reliability needs of the Eastman Kingsport site. Qualitative design criteria help with further down-selection by incorporating technology maturity for timeline/availability estimation, along with considerations for regulations, licensing, and siting. This section discusses the criteria that were identified and used to down-select the nuclear reactor options for subsequent evaluation.

\subsubsection{Reactor Capacity and Operability}

Reactor capacity and operability are key considerations in any IES. Traditional power plants are large, single-unit producers which would not be amenable to a tightly coupled IES such as that being investigated for the Eastman Kingsport site due to such items as reliability, cost, and scale. However, "advanced nuclear power plants" and non-traditional nuclear technologies are much more suited to this site and to IESs in general. For example, the designs for many advanced nuclear power plants consist of multiple reactor modules, an arrangement which would offer significant benefits in terms of scaling capacity, flexible operation, and reliability, similar to the existing fossil-powered units with which Eastman has extensive experience. Some additional beneficial features of advanced nuclear power include the following: ${ }^{9}$

- Simpler designs as compared to traditional power plants

- Inherent safety by design

- Small land requirements

- Factory construction with substantial reduction in fieldwork

- Economies of scale in design, manufacturing, construction, and operation

- Better cost competitiveness with other forms of energy generation, such as natural gas

- Capability to produce electricity and process heat

- Capability to respond to fluctuations in load

\footnotetext{
${ }^{9}$ Nuclear Energy Institute, Advanced Reactors, https://www.nei.org/advocacy/build-new-reactors/advanced-nuclear, Reviewed February 19, 2020.
} 
- Resilience to short- and medium-term fuel supply disruptions and price volatility

Advanced reactors (ARs) use a variety of coolants and can offer capacities ranging from a few MWe to over 1,000 MWe. Small modular reactors (SMRs) are a subset of reactors that produce energy ranging from $>50 \mathrm{MWe}$ to $300 \mathrm{MWe}$ or less. SMRs typically incorporate the desirable features of ARs. Microreactors, with capacities ranging from a few MWe up to about $50 \mathrm{MWe}$, are considered too small to be suitable for the Eastman Kingsport facility ( $150 \mathrm{MWe}$ and 1,000 MWt). ARs which have capacities much greater than $300 \mathrm{MWe}$ are considered too large. It is not considered appropriate to have two or more large reactors in which the total capacity is well beyond Eastman's needs in order to be able to supply loads when one of the large units would be unavailable. Therefore, a multi-module SMR power plant is considered large enough to supply the plant's peak loads and also to supply needs if one module is out of service - provided a sufficient number of modules. Furthermore, having multiple modules will be more reliable, as it would lend itself to different operational frameworks such as modules dedicated only to electricity or thermal energy.

There are six general types of $\mathrm{ARs}^{10}$ (though these are often expanded into various subtypes) as well as advanced LWR based SMRs which are applicable to this study. Collectively these will be termed ARs in this report for convenience. Several possible reactor types and variations have the potential to meet the steam and electrical needs of the Kingsport facility. However, because commercial concepts for ARs are at different developmental stages - most relatively early - this study focused on the ability to supply the appropriate steam conditions to Eastman from the nuclear plant's power cycle. Table 3 provides a representative overview of the SMR landscape. This list is not inclusive of all companies; see "Small Nuclear Power Reactors"11 for more reactor designs. Also, besides NuScale, the table does not provide estimates of when license applications will be submitted or when license approvals are expected from the US Nuclear Regulatory Commission (NRC).

\footnotetext{
${ }^{10}$ https://www.gen-4.org/gif/jcms/c_59461/generation-iv-systems

11 https://www.world-nuclear.org/information-library/nuclear-fuel-cycle/nuclear-power-reactors/small-nuclearpower-reactors.aspx
} 
Table 3. Representative list of SMR concepts under some level of development

\begin{tabular}{|c|c|c|c|c|}
\hline SMR developer & Reactor model & Reactor technology & $\begin{array}{l}\text { Reactor size } \\
\text { per module }\end{array}$ & Interaction with NRC \\
\hline Framatome & SC-HTGR & HTGR & $625 \mathrm{MWt}$ & \\
\hline General Atomics & EM2 & HTGR & $265 \mathrm{MWe}$ & \\
\hline X-energy & $\mathrm{Xe}-100$ & HTGR & $75 \mathrm{MWe}$ & $\begin{array}{l}\text { Pre-application interactions } \\
\text { began Sept. } 2018\end{array}$ \\
\hline Columbia Basin & LBFR & $\begin{array}{l}\text { LBFR } \\
\end{array}$ & $240 \& 100 \mathrm{MWe}$ & \\
\hline Hydromine & AS-200 & $\begin{array}{l}\text { LFR } \\
\end{array}$ & $200 \mathrm{MWe}$ & \\
\hline Westinghouse & LFR & LFR & $450 \mathrm{MWe}$ & \\
\hline$\overline{\mathrm{GE}}$ & BWRX-300 & Light-water reactor & $300 \mathrm{MWe}$ & $\begin{array}{l}\text { Licence application submitted } \\
\text { to NRC in January } 2020\end{array}$ \\
\hline Holtec & SMR-160 & Light-water reactor & $160 \mathrm{MWe}$ & \\
\hline NuScale & $\begin{array}{l}\text { NuScale Power } \\
\text { Module }\end{array}$ & Light-water reactor & $60 \mathrm{MWe}$ & $\begin{array}{l}\text { NRC completion of application } \\
\text { review expected Sept. } 2020\end{array}$ \\
\hline Kairos & KP-FHR & Molten-salt-cooled reactor & $140 \mathrm{MWe}$ & $\begin{array}{l}\text { Pre-application interactions } \\
\text { began Nov. } 2018\end{array}$ \\
\hline Flibe Energy & LFTR & Molten-salt-fueled reactor & $250 \mathrm{MWe}$ & \\
\hline Muons, Inc. & GEM*STAR & Molten-salt-fueled reactor & $220 \mathrm{MWe}$ & \\
\hline Terrestrial Energy & $\mathrm{IMSR}^{\circledR}$ & Molten-salt-fueled reactor & $195 \mathrm{MWe}$ & $\begin{array}{l}\text { Pre-application interactions } \\
\text { began Oct. } 2019\end{array}$ \\
\hline ARC & ARC-100 & SFR & $100 \mathrm{MWe}$ & \\
\hline GE Hitachi & PRISM & SFR & $311 \mathrm{MWe}$ & \\
\hline \multicolumn{2}{|c|}{$\begin{array}{l}\text { HTGR: high-temperature gas-cooled reactor } \\
\text { SFR: sodium-cooled fast reactor }\end{array}$} & $\begin{array}{l}\text { 1-bismuth-cooled fast reactor } \\
\text { id-fluoride thorium reactor }\end{array}$ & \multicolumn{2}{|c|}{$\begin{array}{ll}\text { LFR: lead-cooled fast reactor } & \text { FHR: fluoride-salt-cooled } \\
\text { IMSR: Integral Molten Salt Reactor } & { }^{\circledR} \\
\text { high-temperature reactor }\end{array}$} \\
\hline
\end{tabular}

\subsubsection{Steam Temperature and Pressure}

As discussed above, three process steam lines are currently installed at the Eastman Kingsport site (600, 100 , and $15 \mathrm{psig}$ ). While some steam is produced at $600 \mathrm{psig}$, most is produced at 1,500 psig and stepped down to 600 psig through a step-down turbine, making electricity as a byproduct. The 1,500 psig steam does not travel outside the building where it is produced; it is only produced for electricity generation, so it is not considered a process line. The $100 \mathrm{psig}$ line is fed by the $600 \mathrm{psig}$ line by passing steam through mechanical drive turbines and turbogenerators. Similarly, the 15 psig line is fed by the 100 psig line. Electricity is thus generated as a byproduct when passing steam between the four steam levels.

The nominal steam pressures and temperatures at the four steamline statepoints are given in Table 4. Note the superheat present at high pressure. The superheat in the high-pressure systems allows for electricity production when stepping down through turbines while maintaining superheated steam conditions at lower pressures. It is important to compare this feature with the traditional Rankine cycle steam systems typically attached to nuclear systems, which do not typically have high superheat. However, as will be discussed later, ARs that can operate at high temperatures may be able to include this feature. 
Table 4. Eastman plant steam conditions

\begin{tabular}{cccccc}
\hline \multicolumn{2}{c}{$\begin{array}{c}\text { Steam pressure } \\
(\mathbf{M P a} / \mathbf{~} s i a)\end{array}$} & \multicolumn{2}{c}{$\begin{array}{c}\text { Steam temperature } \\
\left(\mathbf{K} /{ }^{\circ} \mathbf{F}\right)\end{array}$} & $\begin{array}{c}\text { Degrees superheat } \\
\left(\mathbf{K} / \mathbf{\Delta}^{\circ} \mathbf{~} \mathbf{)}\right)\end{array}$ \\
\hline 10.4 & 1,515 & 783 & 950 & 196 & 352 \\
4.24 & 615 & 672 & 750 & 145 & 261 \\
0.79 & 115 & 463 & 375 & 20.5 & 36.9 \\
0.21 & 30 & 400 & 260 & 5.4 & 9.7 \\
\hline
\end{tabular}

\subsubsection{Siting Allowance}

The siting allowance or footprint of the nuclear facility includes the reactor building, primary and secondary support buildings, administrative and security buildings, and boundaries required for the type of reactor in use. For most reactor types, buildings for support, administration, and security will all assume similar footprints, the greatest difference being in the reactor building size and the boundary required for the associated system. The reactor building size may vary for several reasons, including the number of units or modules required and the number of support or cooling systems necessary. An additional consideration in siting is the availability of cooling water necessary for the reactor facility. A detailed discussion of siting considerations specific to the Kingsport, Tennessee location are presented in Section 6.2.

\subsubsection{Technology Readiness}

Technology readiness for the nuclear technologies is based on the implementation timeline. Certification of nuclear reactor designs is an exhaustive process that requires many years of NRC review. The Eastman Kingsport site may have multiple near-term ( 10 years) and long-term (10-30 years) opportunities to implement an IES based on conversations regarding replacement timelines of different coal and natural gas boilers, so technologies under consideration can range from those that could be deployed in the next few years (i.e., NuScale) to other non-water technologies at lower levels of technology readiness.

\subsection{CANDIDATE REACTOR SYSTEMS}

Based on the criteria discussed above, representative reactor technologies and SMR designs within the selected technologies were chosen for use in the analysis of an Eastman IES. The following subsections provide brief overviews of these selected designs and technologies. In general, each of the specific SMR designs selected was chosen only as representative of the broader technology operating conditions and is not an endorsement of the design.

\subsubsection{Fluoride High Temperature Reactor}

The fluoride salt-cooled high-temperature reactor (FHR) is a class within the molten salt reactor concept which uses solid fuel and molten fluoride salt coolant. While commercial concepts for an FHR exist, Oak Ridge National Laboratory (ORNL) performed a detailed study [3] of an FHR concept, which is used for this report. The FHR is notable for its very high operating temperature.

The fuel and core of an FHR is similar to those in an HTGR: carbon/graphite-based moderator and fuel. The principal difference is that the molten salt coolant will provide some neutron moderation compared to the near-zero neutron interaction cross section for helium. Therefore, less graphite is required to provide a thermal neutron spectrum. Issues with leaking high-temperature gas are avoided in the FHR, and the FHR operates at a relatively low system pressure created by an inert cover gas. 
The technology behind molten salt reactor technology is generally considered to be less advanced compared to most other advanced fission concepts. Only two molten salt reactors have ever operated, both at ORNL. No FHR-style reactor has ever been operated.

\subsubsection{High-Temperature Gas-Cooled Reactor}

Several varieties of high-temperature gas-cooled reactor (HTGR) have been proposed by DOE and industry. DOE studied the modular HTGR (MHTGR) for several years. While some variants proposed a gas Brayton cycle for electrical power generation, one concept proposed the use of a steam cycle [4]. The HTGR is distinguished by solid fuel, which is typically carbon based, and gas coolant, which is typically helium. The fuel can be in the form of plates, rods, or pebbles, or it can be in a prismatic form. High temperatures in the primary system can be achieved using gas coolant and carbon-based fuel, resulting in efficient thermal cycles $(>40 \%)$.

Though not always helium-cooled, there have been operational gas-cooled reactors in the United States and abroad. Notably, the United Kingdom has operated carbon dioxide-cooled reactors for electrical generation for many decades.

\subsubsection{Liquid Metal Reactor}

The most developed domestic liquid metal reactor (LMR) technology is PRISM, which was developed by General Electric (GE). While several variants of PRISM have been proposed, the version [5] selected for this study is one of the smaller varieties that better fits the Eastman project.

PRISM is a liquid sodium-cooled fast reactor. The fuel takes the form of an array of hexagonal rod bundles. Several LMRs have operated domestically and internationally for research and electric power purposes. It is notable that the PRISM technology is similar to that being co-developed by DOE and GE for the Versatile Test Reactor (VTR) program. ${ }^{12}$ Current estimates project that the VTR will come online in the late 2020s.

\subsubsection{Small Modular Pressurized Water Reactor}

Several domestic companies are developing advanced pressurized light-water reactor (LWR) technology. Given its advanced state, the NuScale design for a small modular LWR was chosen to represent LWRs. Data for the NuScale plant were obtained for this analysis from publicly available licensing documents posted on the NRC website (Table 5.4-1 [6]).

The NuScale plant has a core similar to a large pressurized water reactor: bundles of fuel rods with water coolant. However, the NuScale plant does not rely on forced convection for primary heat removal or designbasis accident scenarios. Instead, it uses natural convection for primary and decay heat removal. The NuScale plant is intended to be built with six or twelve reactors at a single site.

As mentioned previously, large LWRs are simply too large to be suitable candidates for pairing with Eastman. Therefore, the emphasis for LWR technology was placed on NuScale, which is the most fully developed small LWR technology available domestically.

\footnotetext{
12 https://inl.gov/trending-topic/versatile-test-reactor/
} 


\subsection{REACTOR TECHNOLOGY SUMMARY}

To model the effectiveness and capability for the reactor technologies described above to meet the steam and electrical demands of the Eastman system, representative temperatures and pressures for process steam were selected from reference design documents, with the exception of NuScale, as described in the following paragraph. Table 5 shows the steam cycle parameters for each candidate reactor technology and the current conditions of the two Eastman steam systems with the highest pressures.

The steam conditions for the NuScale plant are not indicative of large LWRs. To fit the modeling paradigm described below, the steam pressure for the NuScale design was increased. This increase is justified, as an additional tertiary steam loop would likely be required to compartmentalize the nuclear steam system from the Eastman steam system. Additionally, the NuScale steam generator has undergone significant testing at the lower steam pressure, so it would likely be cost prohibitive to design a new helical coil steam generator for this specific application. Furthermore, the higher pressure in the tertiary loop provides assurance that any leak in the tubes of the secondary-to-tertiary heat exchanger would go from the tertiary loop into the secondary loop and not the other way around, thus helping to contain any potential radionuclide release.

More generally, it is likely that a tertiary cooling loop would be required for each reactor type to prevent radionuclide release and to reduce undesirable feedback on the primary loop. For example, the FHR would include three loops: the primary coolant salt loop that contacts the fuel, a secondary coolant salt loop or "clean" salt loop, and then a power conversion or process steam loop. Similar arrangements are likely for each candidate to avoid having the chemical plant steam interact directly with the nuclear coolant.

Table 5. Summary of reactor technology compared to Eastman conditions

\begin{tabular}{lcccccc}
\hline Technology & $\begin{array}{c}\text { Steam pressure } \\
(\mathbf{M P a} / \mathbf{~ p s i a})\end{array}$ & \multicolumn{2}{c}{$\begin{array}{c}\text { Steam temperature } \\
\left(\mathbf{K} /{ }^{\circ} \mathbf{F}\right)\end{array}$} & \multicolumn{2}{c}{$\begin{array}{c}\text { Degrees superheat } \\
\left(\mathbf{K} / \Delta^{\circ} \mathbf{F}\right)\end{array}$} \\
\hline FHR & 24 & 3,483 & 923 & 1,202 & $276^{*}$ & $497^{*}$ \\
HTGR & 16.5 & 2,394 & 858 & 1,085 & 235 & 423 \\
LMR & 14.7 & 2,135 & 725 & 846 & 112 & 201 \\
LWR ** & 7.0 & 1,015 & 580 & 584 & 20.9 & 37.5 \\
Eastman 1500 & 10.4 & 1,515 & 783 & 950 & 196 & 352 \\
Eastman 600 & 4.2 & 615 & 672 & 750 & 145 & 261 \\
* Steam pressure for FHR above critical pressure of water: 22.064 MPa or 3200.1 psia. Difference in steam temperature and \\
critical temperature $\left(647.1 \mathrm{~K}\right.$ or 705.1 $\left.{ }^{\circ} \mathrm{F}\right)$ shown \\
** Steam pressure increased above design spec.
\end{tabular}




\section{DYNAMIC SYSTEM MODELS FOR AN EASTMAN INTEGRATED ENERGY SYSTEM}

As described above, Eastman has provided six years of actual steam and electrical demand data. These data were processed to show daily averages. According to generally accepted best practices and regulatory guidance for power ramping of nuclear systems, the data indicate that daily ramp rates are within the bounds of nuclear power systems. It is accepted that some type of fossil heating will be required to make rapid changes that occur on timescales of minutes and seconds. The nuclear systems are capable of accommodating changes on timescales of hours and days.

To demonstrate the capability of nuclear systems to meet the steam and electrical demand, a model of the Eastman system was created using the ORNL-developed TRANSFORM dynamic modeling tool [7]. The model is first used to approximate how the plant currently operates and is then modified to use nuclear steam supply.

The six years of operational data were used to drive the model and confirm that it is capable of delivering the steam and electrical demand as required using the baseline 1,500 psig steam conditions. The model was then modified to use the values given in Table 5 for the candidate nuclear technologies. The simulation results show the relative capability of each candidate technology to meet the steam and electrical demands of the Eastman plant. Figures of merit include net electrical cogeneration and required fossil heating.

The modeling paradigm assumed for this analysis is as follows: steam is produced at some high pressure (greater than $600 \mathrm{psig}$ ) and temperature and is stepped down through a turbine to the $600 \mathrm{psig}$ conditions. Controllers are used to maintain the nominal conditions of the 600 psig system. The turbine step-down process results in a temperature decrease and electricity cogeneration. Some fossil heating is required to maintain the temperature in the $600 \mathrm{psig}$ system. An additional turbine is placed between the $600 \mathrm{psig}$ volume and the $100 \mathrm{psig}$ boundary condition. The lower pressure (100 and $15 \mathrm{psig}$ ) steam systems were not explicitly modeled as a means to simplify the model. Since all low-pressure steam originates from a highpressure source, it is sufficient to show that the total 600 psig steam demand can be met for the purposes of this work. The low-pressure steam systems would essentially continue to function as they currently do.

There are alternate means ${ }^{13}$ to simultaneously meet the steam and electrical demand, but the above method was chosen because it more closely represents what is currently done at the Eastman facility.

\subsection{SIMULATION DESCRIPTION}

A steam system model representative of the 1,500 and 600 psig Eastman steam conditions was created using TRANSFORM as shown in Figure 12. The steam 1500 component supplies steam at the conditions from Table 5 corresponding to Eastman 1500. The PID_steam600p controller maintains the pressure in the steam600 volume to the pressure value in the table for Eastman 600 by adjusting the admittance into the turbineHP component. The controller settings can be adjusted to simulate different ramp rate limits. The

\footnotetext{
${ }^{13}$ Segmenting the load into electricity only and steam only portions may be advantageous, as nuclear power systems are designed primarily to produce electricity and not to process steam. Best practices exist for handling loss of load for nuclear electricity generation. When generating process steam, there is uncertainty about how to accommodate some transients. Furthermore, reliability of the process steam option would need to be verified in licensing, which would add review time and would require design modifications, thus reducing the economy of standardization inherent in SMR designs. Supplying steam also risks placing steam system modifications under additional regulatory scrutiny to ensure system dynamics are compatible with the reactor supplying the heat. Drawbacks of the load-segmentation option include the need to maintain more diverse systems and the need to rework the steam supply system.
} 
volume of steam600 was determined by approximating the volume of the 600 psig piping using the drawings provided by Eastman. The PID_steam600flow controller ensures that the steam flow demand from the demands block is met by adjusting the admittance into the turbineIP component. The demands block outputs the daily averaged steam and electric demands, as described above.

The mechanical energy extracted from the two turbines is summed and compared to the electrical demand coming from the demands block using the netElectric block. The power coming from the turbines can be adjusted to account for efficiency and for non-electrical use of steam by tuning the gains on the netElectric block. For this study, $100 \%$ of the 1,500 psig steam and $40 \%$ of the 600 psig steam is used for electrical production (shown as gains on the inputs to the netElectric block). The values assumed for the turbine isentropic and mechanical efficiency can also be adjusted to more closely match plant behavior if needed.

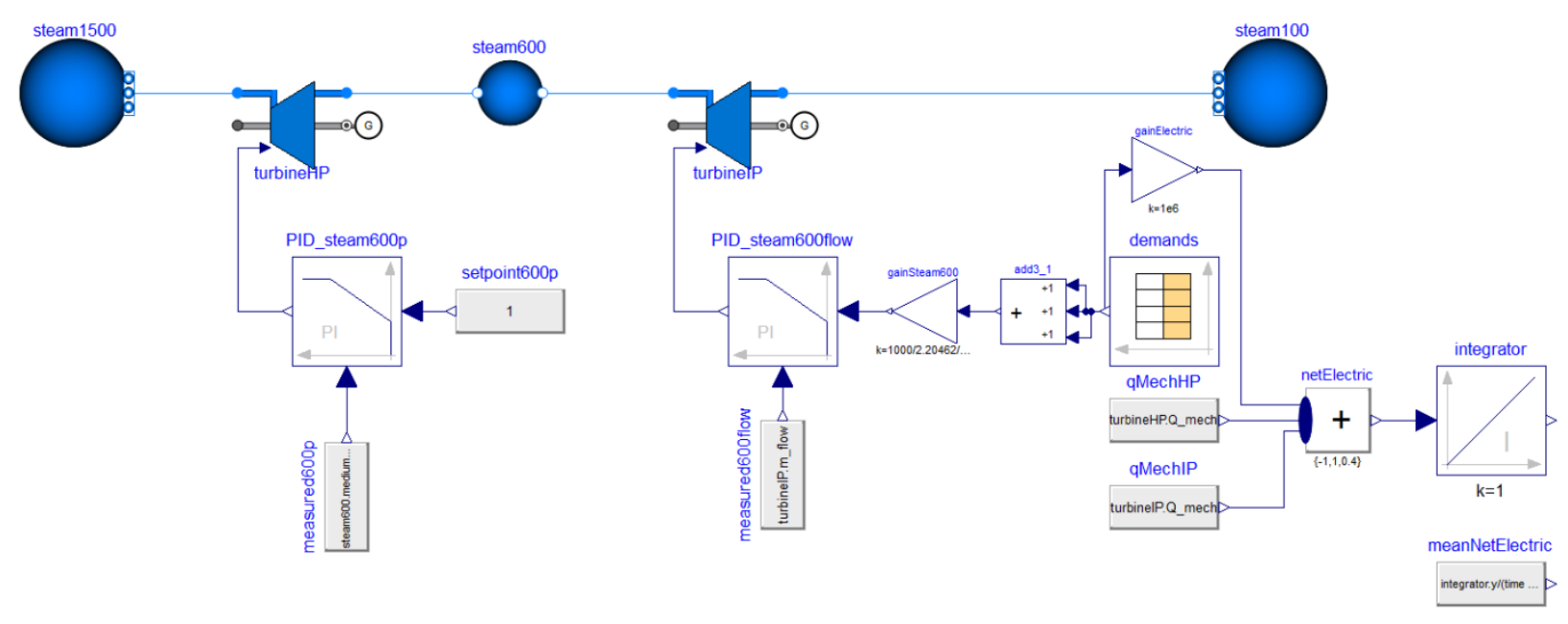

Figure 12. Basic steam system.

The model shown in Figure 12 was used as a basis for the nuclear steam models created for each reactor technology described in the previous sections, as shown in Figure 13. To simulate the nuclear reactors, the steam conditions provided in Table 5 were used as boundary conditions for the steamSource component, and a natural gas heater, NGheater, was added to supply additional thermal energy as necessary to meet the thermal demand. The remainder of the model works as before. 


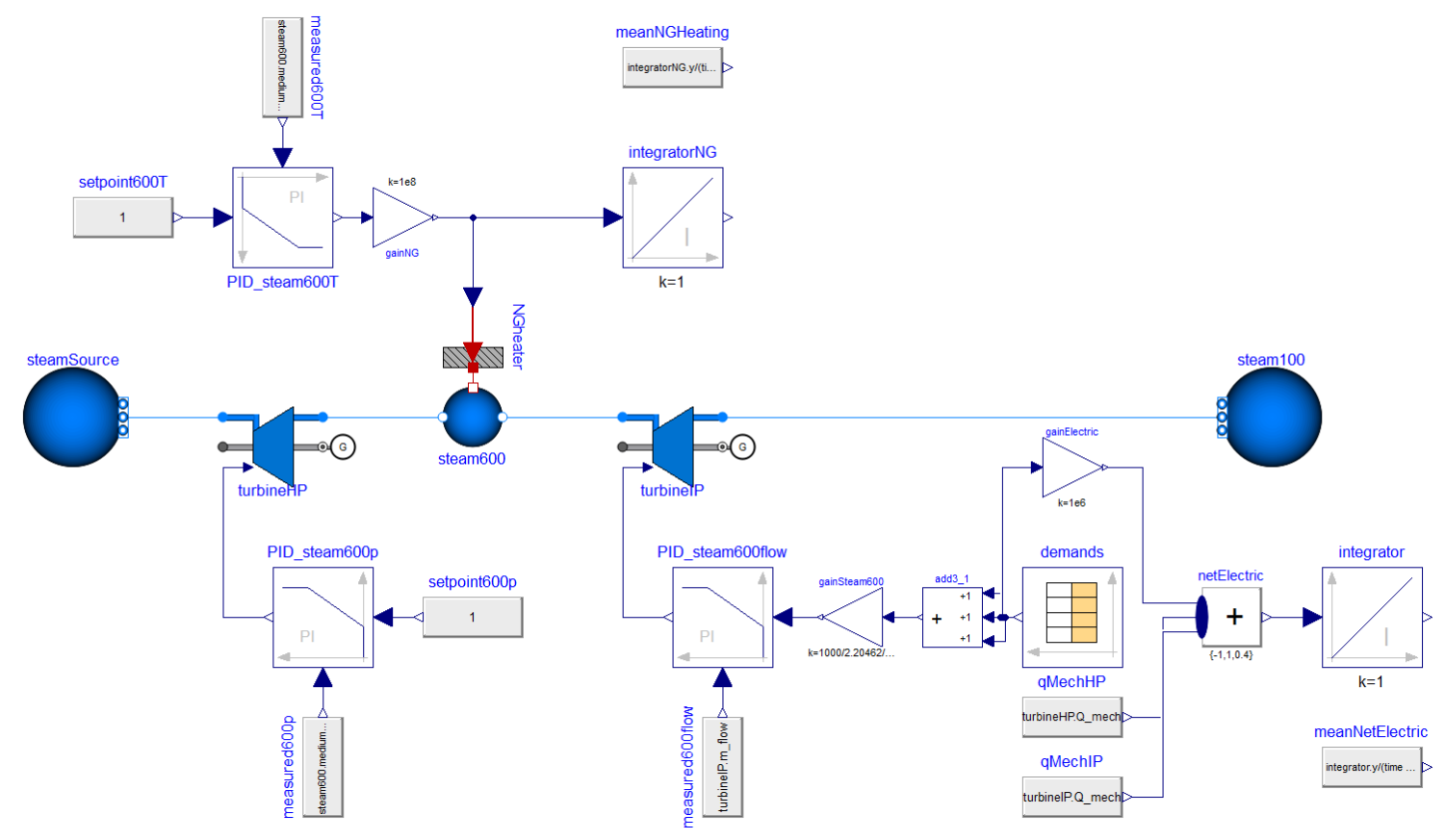

Figure 13. Steam system used for nuclear technology simulations

\subsection{SIMULATION RESULTS}

Data for steam and electrical demand was provided by Eastman for six years: 2014-2019. Daily averaged values were used for this study. An example of the electric demand and supply for an Eastman-like case is shown in Figure 14. The blue line represents electrical demand, the green and red lines represent the mechanical powers produced by the turbineIP and turbineHP components, respectively, as scaled by the gains applied at netElectric, and the pink line represents the difference between the two supply curves and the demand curve. Similar steam demand curves are not produced because the controllers ensure a nearly exact match of the supply and demand. Each six-year simulation takes about fifteen seconds to run on a basic desktop computer.

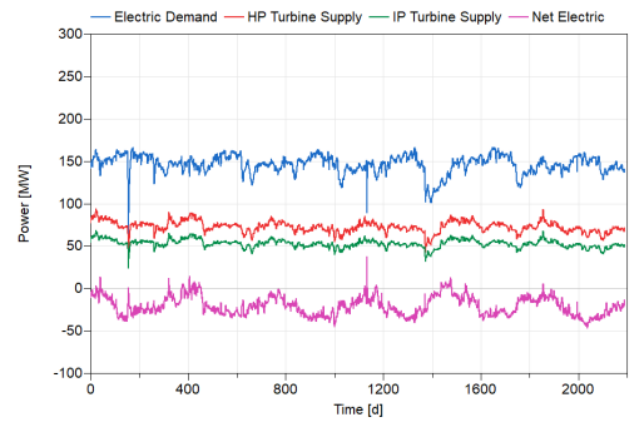

Figure 14. Example electrical supply and demand results for Eastman-like simulation.

Curves such as those shown in Figure 14 were produced for each of the four nuclear technologies investigated and are shown in Figure 15. The black line was added to show the amount of additional heat required to maintain the temperature of the 600 psig system. 


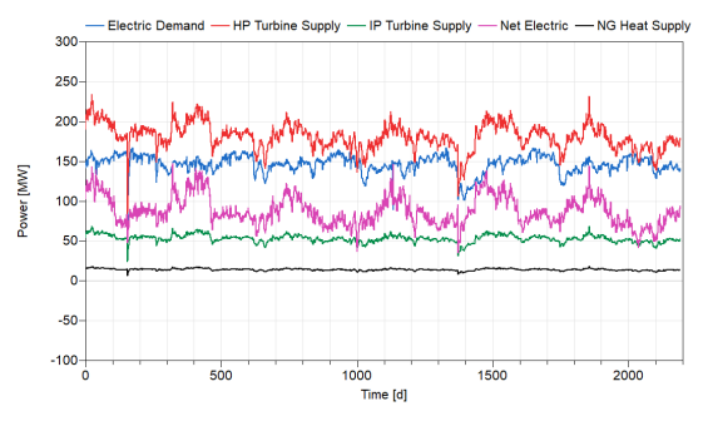

(a) FHR

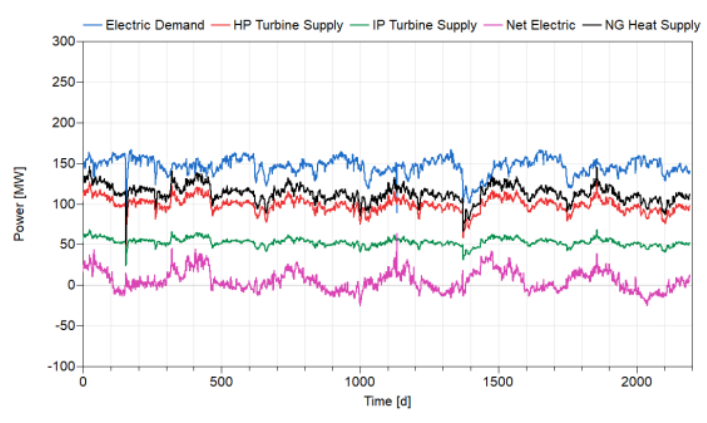

(c) LMR

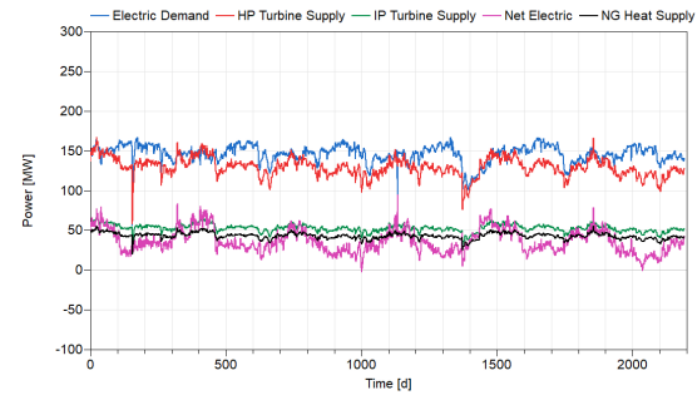

(b) HTGR

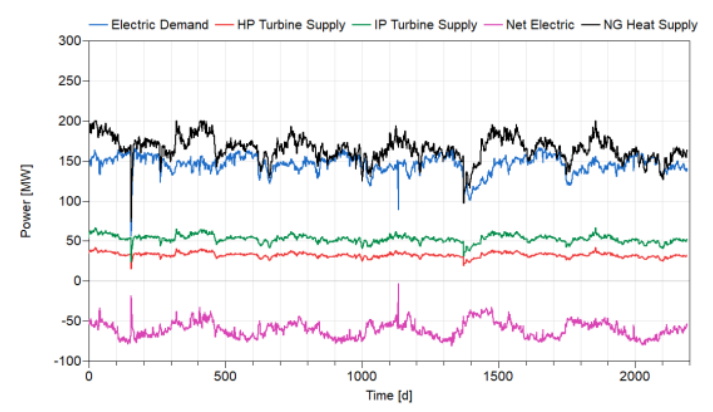

(d) LWR

Figure 15. Electric demand and supply curves for selected nuclear technologies.

The results shown in Figure 15 are straightforward. The nuclear technologies with high steam pressures and temperatures produce a significant amount of electricity from cogeneration, just by stepping down to the $600 \mathrm{psig}$ level. Some conditioning from a fossil source is needed for all cases, though it can be a small fraction of the total power for the high-temperature reactors. The LWR technology with low temperature requires the most fossil heating to meet demand ( 165 MW).

\subsection{SIMULATION SUMMARY}

A TRANSFORM model was developed to simulate steam and electrical demand for the Eastman system. The model was extended to evaluate several candidate nuclear technologies. The results from simulating six years of Eastman steam demand show that the electrical demand can be met or exceeded using hightemperature reactor technologies. Some fossil fuel heating is required to maintain steam conditions; the amount required varies inversely with the temperature of the nuclear steam. Consequently, a significant amount of fossil heat is required for the LWR application. Table 6 includes a summary of the results. 
Table 6. Summary of candidate nuclear technology simulations as compared to current Eastman simulation

\begin{tabular}{cccc}
\hline $\begin{array}{c}\text { Average natural gas } \\
\text { makeup heating } \\
\text { [MW] }\end{array}$ & $\begin{array}{c}\text { Maximum absolute steam } \\
\text { supply ramp rate } \\
\text { [W/s] }\end{array}$ & $\begin{array}{c}\text { Average net electricity } \\
\text { generation } \\
{[\text { [MW] }}\end{array}$ \\
\hline Eastman & N/A & 518 & -20.9 \\
FHR & 13.9 & 1287 & 87.3 \\
HTGR & 42.9 & 921 & 36.0 \\
LMR & 113 & 702 & 5.40 \\
LWR & 165 & 290 & -60.7 \\
\hline
\end{tabular}

The results presented in Table 6 are meant to be a comparison of similar scenarios and do not necessarily reflect the actual operating parameters of the current Eastman system or a proposed nuclear steam system. For example, the net electric generation for the baseline Eastman configuration in Table 6 is known to be more negative than the typical value for the facility. However, one can compare this value to those generated using the nuclear steam systems with similar operating assumptions and arrive at some basic conclusions regarding the effectiveness of certain nuclear technologies' capabilities to meet the demands of the Eastman facility.

A negative electricity generation value indicates that electricity would need to be acquired in some other way. This could be from purchasing from the grid or by onsite generation from additional nuclear or fossil units dedicated to electrical production.

The requirement for makeup fossil heating should be understood in the overall context of the facility. As the facility currently uses over $1000 \mathrm{MW}$ of fossil heat retaining even $200 \mathrm{MW}$ to meet the needs of the LWR-based system may be reasonable. Some fossil heating is required to support high rate-of-change requirements, so some type of fossil infrastructure will remain regardless of the nuclear technology selected. As described elsewhere, other considerations, such as economic and regulatory aspects, that are specific to the different commercial designs will also play a significant role in determining what is the best nuclear system for Eastman. 


\section{ADDITIONAL FIGURES OF MERIT}

\subsection{OPERATIONAL RELIABILITY ANALYSIS}

In the current application, reliability is defined as the probability of system performance in a period of time and a specific operation condition. This section focuses on the reliability analysis of the current portfolio, which was modeled as described in Section 4, and the proposed portfolio, including assessment of ARs for combined heat and power (CHP).

Conversion of the Eastman power production portfolio to nuclear power for CHP production could lead to the simultaneous update and upgrade of the internal process systems while decreasing exposure to natural gas market volatility and environmental emission requirements. This section presents results of the evaluation of reliability metrics and compares the proposed portfolios to demonstrate whether ARs are a promising option to upgrade the plant's overall reliability.

Using outages and steam production data provided by Eastman, reliability of the existing power production portfolio was analyzed based on the performance of components critical to plant operation. In power plants, reliability is defined as the system's ability to deliver expected service throughout planned and unplanned events and changes in operating periods (i.e. between scheduled outages), budget periods, and peakproduction periods [8].

It should be noted that there is no scheduled total outage for Eastman's Kingsport facility. This was taken into account in the overall plant availability comparison presented in Subsection 5.1.6 regarding the capacity factor. Budget periods do not appear to affect the reliability of nuclear power operation. Therefore, peak production periods and unplanned outages were considered for both portfolios, and failure rates were calculated based on these operating states for the reliability assessment.

The reliability analysis was focused on unplanned outages, including peak production periods of operationcritical components - boilers and turbogenerators of the current portfolio. This was then extended to the portfolio to include ARs for CHP to develop the demonstration case presented in Subsection 5.1.5.

\subsubsection{Supply Reliability of Eastman}

This section presents a method developed to investigate the reliability analysis of Eastman's electrical, chemical and thermal supplies. Consequently, investigations concerning new and future power systems should incorporate these three supplies as dependent or combined systems. A major synergy concerns the reliability of supply.

In this analysis, steam (thermal) and electric supply reliability were taken into account as part of the operational reliability metrics reported by Eastman to assure steam and electric supplies are always available to the plant. The defined metrics are as follows:

- Steam supply reliability: $N+1$ steam generation capacity with $120 \%$ of the rated capacity of the largest boiler online for 600 psig steam reserve where, $N$ is number boiler units

- Electric supply reliability: $N+1$ for bus and AEP Southwestern Electric Power tie line connections

These two metrics indicate Eastman's power system is operated with redundancy. Steam supply reliability metric ensures that in the event of the loss of the largest boiler, there is enough capacity to not only cover the lost capacity of the largest boiler, but also enough capacity to quickly restore the steam header pressure 
to 600 psig. Same level of redundancy, $N+1$, applied to electric power at the bus pair level along with synchronizing bus and AEP tie line connections.

The general approach and analysis procedures are the same for all three outputs; electrical, steam and chemical. For the remainder of this section, only the steam output is considered, but the methods can simply be transferred to the electrical or chemical output. Subsection 5.1.2 and 5.1.3 can be applied to electric or chemical output and supply specific fault trees will be built.

Eastman's steam supply reliability mainly depends on the availability of boilers and turbogenerators. Unplanned outage dates and durations of these components, as provided by Eastman, were used to calculate the unplanned outages of the steam production and to estimate failure rates of these critical components to capture operational trends.

The main goal of this analysis was to capture the unmet steam demand due to unplanned critical component failures and point to these dates in the steam production data (see Figure 9). These will represent unmet steam demand due to reliability-induced supply failures, and then the AR's influence on the reliability and availability of the steam supply will be evaluated and compared.

\subsubsection{Component Reliability Analysis}

This subsection quantifies reliability at the output as a function of the plant components' reliability characteristics to determine the steam supply capacities of different boilers and combinations of connections to the steam header pressure to $600 \mathrm{psig}$, since the AR will be connected to the $600 \mathrm{psig}$ steam line (see Section 3).

Figures of merit for reliability analysis are as follows:

- Expected steam demand not supplied: not able to maintain the steam demand plus $120 \%$ capacity of the largest online boiler

- Expected annual outage time: loss of load per year

The loss of steam load expected (LOSE) is expressed as the total times that 600 psig steam is not supplied as expected, as shown in the equation below:

$$
\text { LOSE }=\sum_{t=1}^{24} t_{S}^{N S}(t)
$$

where 24 hours $(t)$ and $t_{s}^{N S}$ is steam not supplied during hourly steam demand.

Loss of load probability (LOLP) evaluates the ratio of total steam not supplied to total demand at a given year, as shown in the equation below, used to represent the top event failure probability in the fault tree analysis:

$$
L O L P=\frac{\sum_{t=1}^{365} P_{s}^{N S}(t)}{\sum_{t=1}^{365} P_{S}(t)}
$$

where 365 days (t) and $P_{S}^{N S}$ is probability that steam is not supplied during yearly demand. 


\subsubsection{Unplanned Outages of the Critical Components}

Critical steam supply components in the Eastman plant are boilers and turbogenerators. Unplanned outage dates for these components were provided by Eastman for 2008 through September of 2018. Table 7 presents a summary of boiler types, unplanned outage days per year, planned maintenance activities and outage durations, dedicated turbogenerators for each boiler, and building locations. Outage date covers data between 2013 and 2018 due to overlap of outage and steam data availabilities.

Boilers: 17 boilers of three types exist on site: coal-fired stoker boilers (7), pulverized coal boilers (2), and natural gas-fired boilers (8).

Each boiler type has specific maintenance activities for pressure part inspection based on State of Tennessee boiler/vessel regulations and annual maintenance outages to minimize downtime. To prevent overlap between the 1,500 psig coal boilers, the annual planned outages for Boilers 23 and 24 were scheduled during the ozone season (May 1 - Sep 30), and Boilers 30 and 31 were scheduled at other times.

Table 7. Cumulative unplanned outage days of boilers at Eastman

\begin{tabular}{|c|c|c|c|c|c|c|c|c|c|c|c|c|c|c|c|c|c|c|}
\hline & \multirow[b]{3}{*}{ Year } & \multicolumn{7}{|c|}{ Coal Fired Stoker Boilers } & \multicolumn{2}{|c|}{ Pulverized Coal Boilers } & \multicolumn{8}{|c|}{ Natural Gas Fired Boilers } \\
\hline & & 600 psig & 600 psig & 600 psig & 600 psig & 600 psig & 1500 psig & 1500 psig & 1500 psig & 1500 psig & 1500 psig & 1500 psig & 1500 psig & 1500 psig & 1500 psig & 600 psig & 600 psig & 600 psig \\
\hline & & BL18 & BL19 & BL20 & BL21 & BL22 & BL23 & BL24 & BL30 & BL31 & BL25 & BL26 & BL27 & BL28 & BL29 & A & B & c \\
\hline \multirow{6}{*}{$\begin{array}{l}\text { Unplanned Outage } \\
\text { (days) }\end{array}$} & 2013 & 11 & 18 & 0 & 0 & 3 & 22 & 14 & 0 & 1 & 4 & 0 & 0 & 0 & 0 & 0 & 0 & 0 \\
\hline & 2014 & 10 & 9 & 21 & 0 & 3 & 9 & 13 & 9 & 11 & 6 & 6 & 10 & 11 & 3 & 0 & 0 & 0 \\
\hline & 2015 & 11 & 0 & 75 & 6 & 2 & 5 & 16 & 8 & 0 & 0 & 17 & 12 & 6 & 0 & 14 & 4 & 3 \\
\hline & 2016 & 16 & 17 & 23 & 0 & 2 & 0 & 20 & 5 & 0 & 6 & 0 & 0 & 0 & 9 & 0 & 0 & 0 \\
\hline & 2017 & 14 & 0 & 33 & 0 & 7 & 33 & 39 & 10 & 0 & 6 & 0 & 0 & 3 & 1 & 0 & 0 & 0 \\
\hline & 2018-Sept & 0 & 16 & 4 & 19 & 0 & 14 & 6 & 0 & 2 & 0 & 0 & 0 & 0 & 0 & 0 & 0 & 0 \\
\hline \multirow{3}{*}{ Planned Outage } & Annual & \multicolumn{5}{|c|}{3 weeks } & \multicolumn{2}{|c|}{4 weeks (May 1-Sept 30) } & 3-4 weeks (Feb-April) & ) $3-4$ weeks (Oct-Nov) & \multicolumn{5}{|c|}{ 10-day } & \multicolumn{3}{|c|}{ 3-5 days annual maintenance } \\
\hline & Notes & \multicolumn{5}{|c|}{ N/A } & Nox SIP & & \multicolumn{2}{|c|}{ Out of SIP Call } & \multicolumn{5}{|c|}{ 1st year pressure part inspection } & \multicolumn{3}{|c|}{1 down each time } \\
\hline & $\begin{array}{c}\text { Following } \\
\text { Year }\end{array}$ & \multicolumn{5}{|c|}{ N/A } & \multicolumn{2}{|c|}{ N/A } & \multicolumn{2}{|c|}{$\mathrm{N} / \mathrm{A}$} & \multicolumn{5}{|c|}{ Following year 14-day full maintenance (staggered 2-3) } & \multicolumn{3}{|c|}{$\begin{array}{l}\text { Every } 2 \text { nd year } 7 \text { to } 9 \text { days all } \\
\text { together }\end{array}$} \\
\hline \multicolumn{2}{|c|}{ Dedicated TGs } & \multicolumn{5}{|c|}{ N/A } & TG13 & TG15 & TG22 & TG26 & TG16 & TG17 & TG18 & TG19 & TG20 & \multicolumn{3}{|c|}{ N/A } \\
\hline \multicolumn{2}{|l|}{ Building } & \multicolumn{7}{|c|}{ B-83 } & \multicolumn{2}{|c|}{ B-325 } & \multicolumn{5}{|c|}{ B-25 } & \multicolumn{3}{|c|}{ B-423 } \\
\hline
\end{tabular}

The planned outage schedule for Boilers 25-29 shown in the table indicates a staggered outage model that was used when these boilers were fired with coal to allow the pulverizers to be rebuilt when they were replaced with gas boilers. Each of these boilers has a planned annual outage lasting 17-18 days every year, and these outages are not staggered. Boilers 23-31 generate 1,500 psig steam @ $950{ }^{\circ} \mathrm{F}$, as indicated by darker shades in Table 7. Boilers 23, 24, 30, and 31 are topping boilers requiring 3-4 weeks of planned maintenance which is not overlapping, as can be seen in Table 7 .

Boilers dependency and steam supply system are represented on the simplified fault tree shown in Figure 16 to capture the overall steam supply outage for the $600 \mathrm{psig}$ line, which is based on unplanned component outages in Building 83, coal fired stoker boilers 18-22. To capture dependency and maintenance overlaps between 1500 psig line connections, all boilers are included in fault tree. 


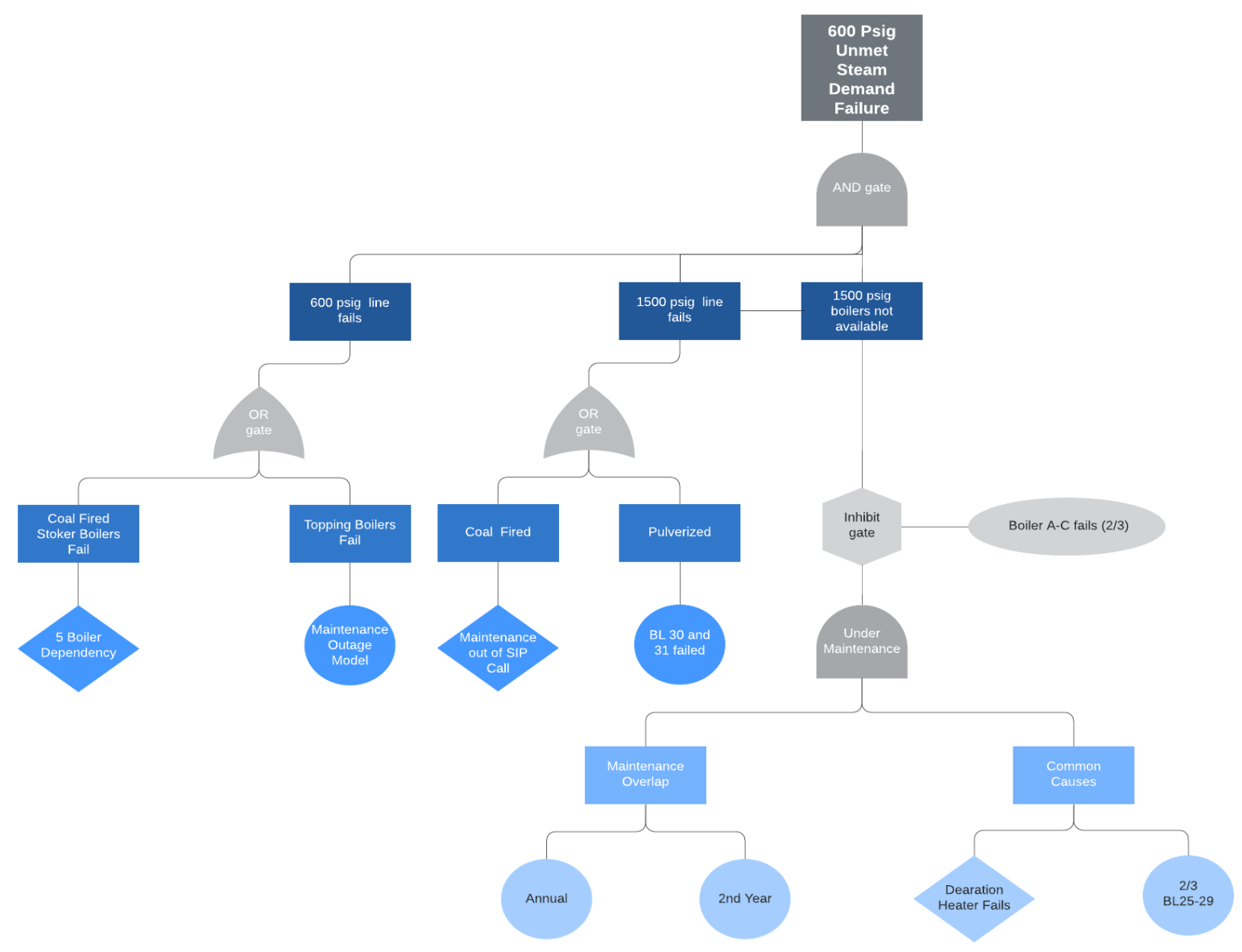

Figure 16. Simplified fault tree of the steam supply failure.

Because of the redundancy and diversity of boilers and their availability being affected by maintenance activities, the additional rules listed below are implemented in the fault tree to ensure maintaining the power system reliability:

- No more than one 1,500 psig boiler is scheduled for an outage at a time, as represented by an $\mathbf{O R}$ gate on the steam supply fault tree model.

- Only two of Boilers 25 through 29 will have 14-day outages during a given year, as indicated by 2 out of 5 gates on the fault tree.

- No more than one of the A-C boilers ${ }^{14}$ is scheduled to be down at the same time, as indicated by 2 out of 3 in the fault tree. Given the criticality of these boilers, the second-year outage will never be scheduled to occur concurrently with a scheduled outage for a 1,500 psig unit.

- Annual maintenance of Boilers 18-22 will not overlap with maintenance of any 1,500 psig boiler.

Boilers 18-22 will have annual maintenance each year, which will be limited to only 7-14 days, as needed. As indicated in the last bullet, it is typically not desired to overlap outages of these units with 1,500 psig

14 The outage dates for these three boilers are only provided for 2015. 
boiler topping units. However, due to required special repair projects on the topping units, such as replacement of economizer or superheater tubes, the topping unit outage windows are sometimes extended to allow for these replacement activities. This sometimes causes work on Boilers 18-22 to overlap with topping unit outages. This is not captured in the fault tree model.

These rules are represented on the simplified fault tree shown in Figure 16 to capture the overall steam supply outage for the 600 psig line, which is based on unplanned component outages in Building 83, coal fired stoker boilers 18-22. To capture dependency, all boilers are included in fault tree.

The events such as maintenance of Boiler 25 on November 14, 2013, tripped on the high-water level when the load was increased to make up for the loss of Boiler 28, as indicated by the steam supply reliability's failure. Further investigation of this event is needed but it is included as a rare event in the model.

Turbogenerators: There are 19 turbogenerators in the plant that are categorized as topping units, back pressure units, and condensing units. Two types of maintenance activities implemented on these turbogenerators:

- An annual E-1 entails preventative maintenance. If the turbogenerator is a topping unit, then the outage duration required will be same as that associated with boiler outage as listed in Table 7. For non-topping turbogenerator sets, the planned outage duration is 7-10 days.

- An E-3 maintenance activity consists of removing the upper turbogenerator casing and completely disassembling the turbine to allow inspection of the steam path. This activity takes 6 weeks for topping and non-topping turbogenerators, and it takes 8 weeks for condensing turbogenerators.

\subsubsection{Steam Supply Reliability Analysis}

The simplified version of the steam supply fault model shown in Figure 16 shows the steam supply's unplanned outages based on the outages of 17 boilers and 19 turbogenerators. The model includes unplanned outage dates for each year. This was compared with the steam generation curve for the period of 2013-2019 for 600 psig to examine which lower peaks are caused by reliability-related failures. This provided data on the expected steam demand that was not supplied as a reliability metric to be compared with an AR's configuration.

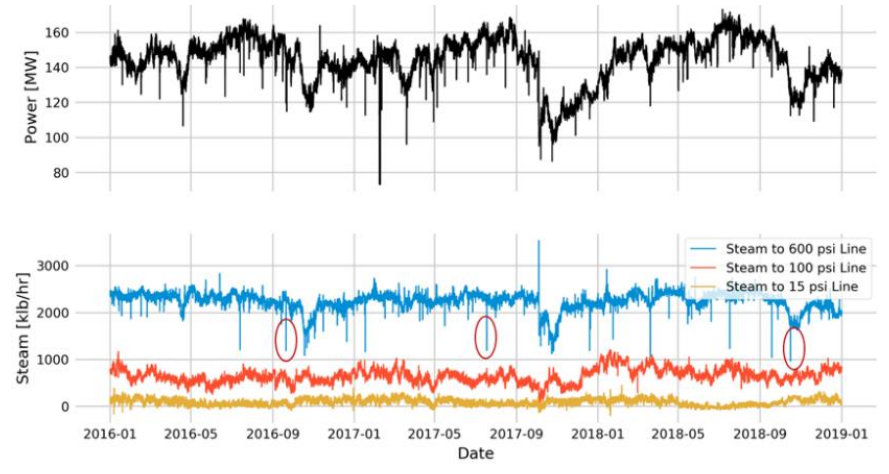

\begin{tabular}{|c|c|c|}
\hline $\begin{array}{c}\text { Outage } \\
\text { Dates }\end{array}$ & $\begin{array}{c}1500 \text { psig } \\
\text { Boiler }\end{array}$ & Overlap type* \\
\hline $12-130 c t$ & BL24 & $P$ \\
\hline 15-16 Jan & BL29 & $P$ \\
\hline 10-16 Aug & BL24 & $M$ \\
\hline 12-14 Nov & BL25 & $\mathbf{P}$ \\
\hline \multicolumn{3}{|c|}{$\begin{array}{l}{ }^{*} \mathrm{M}-\text { Maintenance overlap } \\
* \mathrm{P}-\text { Boilers overlap }\end{array}$} \\
\hline
\end{tabular}

Figure 17. Reliability Outages on Steam Demand

There appears to be strong seasonal behavior near the fall of each year, and a less significant seasonal behavior occurs in the spring. Most reliability-induced system outages are observed during the fall as can be seen by bolded red outages dates in the table and red circles on lower-peaks in the plot. 


\subsubsection{The Influence of Nuclear Reactor on the Reliability of Steam Supply}

This reliability analysis considered the assumptions under which ARs would be a valid choice for replacement of the coal boilers in the chosen market beyond the year 2030. Note, it might still be too early to answer the main question of this section definitively: under which assumptions would ARs - specifically the NuScale reactor as an SMR demonstration — be appealing for CHP operational reliability?

Capacity factors and marginal operating factors are the two metrics used in literature to compare gas, coal, and nuclear power plants.

Consideration of capacity factors [9]: Nuclear power plants (NPPs) are producing maximum baseload power and lead the power industry in capacity factors at more than $92 \%$ of the time during the year vs. coal and gas power plants, which are at around 50\% capacity. Operations of integrated energy system configurations can be more flexible with load following capacity of NPPs and this may affect listed industry averaged capacity factor but the advent of advanced SMR designs is expected to enhance the capacity factor, although the actual NuScale plant capacity cannot be determined until the first plant is in operation.

Consideration of marginal operating costs [9]: NPPs can operate continuously for periods exceeding one year - or typically up to 1.5 or 2 years for SMRs - without the need to refuel. Nuclear power has always played an important role in providing reliable electricity to the grid.

This project defines potential deployment scenarios for NuScale multi-unit reactors.

\subsubsection{NuScale Operational Reliability Demonstration Case}

Although advanced high-temperature reactors appear to be capable of reaching the required temperatures directly, an LWR-based nuclear system can be available in the near-term and can provide a high level of confidence in deployment and operational reliability. Therefore, the NuScale reactor, at $160 \mathrm{MWt}, 50 \mathrm{MWe}$ integral pressurized water reactor (IPWR) design consists of a redundant array of independent reactors (up to 12 modules), was selected as a representative SMR.

The NuScale design has two benefits regarding the reliability. First, it permits staggered refueling so the total plant continues to produce $550 \mathrm{MWe}$ (50 MWe per module) gross, even during refueling. The second benefit is a very high availability of 50-100 MWe power levels per module. This is the range of power typically needed for facilities that require ultra-high reliability for mission-critical processes.

Doyle's paper on mission-critical applications [10] demonstrates that, because of its configuration as an independent unit and its island mode capability, a 12-module NuScale plant can provide $100 \mathrm{MWe}$ to a dedicated micro-grid at $99.95 \%$ reliability for the 60 -year life of the plant.

Operational reliability in a nuclear reactor depends on reactor scrams, which can cause shutdown. The $\mathrm{NuScale}$ reactor is designed to reduce the frequency of inadvertent reactor scrams compared to the currently operating reactor fleet.

Energy resilience is the ability to prepare for and recover from energy disruptions. Resilient power systems minimize the effect of such costly failures. Reyes and Ingersoll [11] assessed the energy resilience of a $\mathrm{NuScale}$ plant relative to existing commercial nuclear fleet reactor scrams and note that NuScale eliminated $>70 \%$ of existing 2015 commercial nuclear fleet scrams by design. Three key factors can be attributed to the NuScale's improved performance: (1) fewer and simpler systems, resulting in fewer potential failures, (2) island mode power, and (3) a 100\% steam-turbine bypass [11]. 
To determine how many modules are needed to meet the non-electrical energy demands requires a better understanding of the detailed process flow characteristics of the Eastman plant. A standard plant would consist of 12 modules submerged in a common below-grade reactor pool with each module having its own dedicated turbine generator. For the suitability, reliability and cost-effectiveness of NuScale units for CHP evaluated based on the thermal-hydraulic scenario model, see Figure 15(d).

As extrapolated from Eastman steam production data for Net600 psig, the plant considered here for steam production features an average of $5 \mathrm{NuScale}$ modules and $6 \mathrm{NuScale}$ modules on demand peaks either as a heat-only boiler or as a CHP plant. In additional to the reliability of 6 independent modules, 120-140 MW of the fossil heat required to heat the NuScale steam to maintain $750^{\circ} \mathrm{F}$ of 600 psig should be considered a support system in the fault tree model.

The results are not intended to be final due to the high amount of uncertainty surrounding most of the data for ARs. However, the results provide a preliminary overview of an AR's potential and its possible role for Eastman.

\subsubsection{Plant Availability}

The NuScale capacity factor (91\% breaker-to-breaker) extends for at least 18 months between refueling outages, and the refueling outage period is 30 days [12]. The design $87 \%$ capacity factor is based on an estimated 6\% downtime for scheduled maintenance and refueling and an estimated 7\% downtime for unscheduled maintenance. Therefore, the $87 \%$ capacity factor corresponds to a $92-93 \%$ breaker-to-breaker capacity factor. With an overall capacity factor of $90 \%$ and with the same allowance for scheduled maintenance and refueling, the breaker-to-breaker capacity factor would increase to about 95\% [12].

\subsubsection{Safety Performance under Accident Conditions}

The demonstration case choice of NuScale over other ARs is also motivated by the availability of public data and a more mature probabilistic risk assessment model, which is required for AR licensing safety assessments. A comprehensive assessment of the NuScale plant's reactor safety was performed, and supporting information was submitted to the NRC in January of 2017 as part of its design certification application. The application was docketed in March 2017, and details are publicly available on the NRC ADAMS website (docket number 52-048).

The NuScale plant is designed so that a single module can supply all house loads for the entire plant to maintain power to a mission-critical facility without external grid connection. The island mode feature coupled to $100 \%$ steam turbine bypass ensures that the reactors do not need to scram on loss of grid connection.

Challenges for the viability of using a NuScale plant to provide steam at a chemical plant are primarily regulatory - both for the nuclear plant and the chemical plant. The potential impact of an accident at either plant must be carefully analyzed. The low risk factor and high level of robustness in the NuScale design expected to help reducing the regulatory and social-political hurdles to be cleared to place a nuclear facility near a chemical plant.

\subsubsection{Reliability-Informed Forecasting}

Plant failures are often caused by inadequate maintenance and an inability to predict problems that may occur during plant operation. Measuring plant and equipment reliability by quantifying the annual cost of unreliability incurred by the facility puts reliability into a business context. This is an area not covered in this work but is a potential area of future research. 


\subsubsection{Conclusion}

This study captured reliability based on Eastman unplanned outage data as a function of CHP component reliability characteristics. Therefore, the steam supply reliability for the different combinations of supply connections in the CHP were determined. Reliability enhancements and higher capacity factors lower the expected unplanned outage estimates for the proposed AR portfolio with $6 \mathrm{NuScale}$ modules vs. unplanned outage estimates for the current Eastman portfolio.

Further analysis should consider the relations and dependencies between the thermal network and the electrical or chemical networks for CHP gas-fired power stations [13].

\subsection{ECONOMICS}

Cost is a primary factor when selecting a power option. Overall, costs for a nuclear plant and various alternatives were analyzed. Considerations included the cost to build the plant, as well as factors such as the time to build the nuclear plant and alternatives in service. Benefits were also considered, including the availability of clean, carbon-free energy; and the avoidance of fossil fuel price swings.

Due to lack of experience with SMRs and lack of licensed SMR systems, this effort only included a generic economic analysis. Compared to more traditional power reactors, SMRs have a smaller capital cost in absolute terms, but they may be higher on a per MW basis due to possible decreases in economy of scale. Large power reactors cost upwards of $\$ 10 \mathrm{~B}$. SMR proponents argue that decreased economy of scale is compensated for by a more standardized production process, and each new plant is not the first of a kind (FOAK) in some sense. Mignacca and Locatelli [14] present construction cost projections for SMRs against those of more traditional units. On a per $\mathrm{kW}$ capacity basis, the SMR is roughly $10 \%$ more cost intensive than a traditional LWR during construction. Little data exist for operational cost, but overall, SMR costs could be $20 \%$ larger than LWR costs on a per MW basis. The decommissioning sector is presently experiencing substantial build out. Decommissioning would involve cessation of operations and defueling of the plant, along with some time to allow activation products to decay away, and finally, demolition. Presently there is a backlog of spent nuclear fuel stored at reactor sites. Given the 30+ years to safely emplace spent nuclear fuel in a geologic repository - due in large part to sustained political opposition-it is conceivable that this perception problem may endure for decades to come. Therefore, onsite storage of spent nuclear fuel would be necessary, but the volume would be minimal. Maintenance costs for the parcel of land where the fuel would be stored is a small fraction of plant economics, but it should be stated up front. The NRC requires maintenance of a decommissioning trust fund.

The goal in this analysis is to simply provide top-down, rough order of magnitude cost estimates to show how a generic SMR system may perform in the Eastman context. A more design-specific analysis is not possible at present because design work is still ongoing. Cost estimates are obtained by reviewing SMR costs and the costs of competitive technologies. Both capital expenditures and annual operating, maintenance, and fuel costs are examined. Some discussion regarding the types of risk that may be encountered in an SMR project follows to demonstrate the uncertainty in the estimates. Finally, some hypothetical economic scenarios were developed based on the capital and annual costs, and they are compared herein under differing financial conditions.

\subsubsection{Analogous Plant Size}

Obtaining a plant size analogous to the 167 MWe plant also supplying 2.6 million lbm per hour of 600 psig steam is accomplished by assuming the plant conversion efficiency found in the Federal Energy Regulatory Commission (FERC) Form 1 survey. 167 MWe is assumed in this section to add conservatism to the approximate figures $(\sim 150 \mathrm{MWe})$ discussed elsewhere. More efficient plants produce less heat per MWe, 
so a more efficient plant will be sized larger because the heat production capacity is desired. A $30 \%$ efficient equivalent plant (nuclear and combustion turbine [CT]) could produce $600 \mathrm{MWe}$, whereas a $45 \%$ equivalent efficient plant (combined cycle [CC]) could produce $810 \mathrm{MWe}$. These efficiencies reflect those found for plants in the FERC Form 1 data surveyed elsewhere in this section.

The Eastman plant requires steam in addition to electricity, whereas electricity generation is implicitly included in the source cost data. These cost differences are assumed to be similar for both the nuclear and natural gas options. Customization work is needed to convert a standard SMR to a custom-pressure steam supply system. This may or may not balance out the cost reduction due to decreased electrical generation capacity. Regardless, this cost is not considered for rough order of magnitude cost estimation purposes, because it is likely design-specific. This, and all rough order of magnitude costs should be re-evaluated for any specific plant design prior to commencement of construction.

\subsubsection{SMR Capital Expenditures}

To accomplish SMR buildout, licensing, site prep work, construction, and startup testing are required. At this juncture, no SMR designs are fully licensed, although some licensing action is likely forthcoming [15]. While the design license is a major step, formal site evaluation and licensing are also necessary. Licensing can take several years and is discussed in Section 6.1. Therefore, estimates rely upon EIA estimates and estimates from traditional nuclear facilities with adjustments, as noted. Note that in this work, "capital cost" is not restricted to material procurements, but includes all costs associated with plant procurement, with the exclusion of construction financing, and replacement power, which are not addressed in this study.

Cost estimates are presented in Table 8 Nuclear initial capital cost estimates. The first two costs listed are from Sargent and Lundy's study commissioned by the EIA [16]. The NuScale estimate is taken from trade publications.

Table 8 Nuclear initial capital cost estimates

\begin{tabular}{lcc}
\hline Cost (\$/kW) & Details & $\begin{array}{c}\text { Equivalent cost } \\
(\mathbf{\$} /[\mathbf{l b m} / \mathbf{h o u r}])^{*}\end{array}$ \\
\hline $\mathbf{6 , 0 4 1}$ & $2,156 \mathrm{MW}$ & 719 \\
$\mathbf{6 , 1 9 1}$ & $600 \mathrm{MW}$ SMR & 737 \\
$\mathbf{4 , 2 0 0 - 5 , 0 0 0}$ & NuScale Estimate & $500-595$ \\
\hline *This cost restates entire plant scale in terms of $615 \mathrm{psia}, 750^{\circ} \mathrm{F}$ \\
steam, assuming converting a 30\% electric conversion \\
efficiency. To do this, the cost per kW value is divided by 8.39 \\
lbm/hr-kW.
\end{tabular}

To provide perspective for the cost estimates shown above, traditional nuclear costs were taken from FERC Form 1 for Duke, Georgia Power, and Virginia Electric [19-24]. The costs were inflated to 2019 dollars using the annual averaged producer price index, and they are plotted in Figure 18. Note that the SMR cost factors recorded in other studies [14] could be applied to the FERC Form 1 data points to approximate the analogous SMR. The FERC Form 1 data are principally shown to demonstrate the variability of nuclear costs. As learning occurs, the SMR costs should begin to reflect the lower values of the nuclear construction costs.

Capital costs for existing nuclear plants tended to vary between $\$ 3,000-10,000$ per $\mathrm{kW}$ capacity. This large variation is evident in the plant costs not following a clear linear trend in Figure 18. Noting values from a literature review that place SMR capital costs at about 1.1 times those of conventional nuclear on a percapacity basis, recent estimates from NuScale are in this wide range. Noting that they are preliminary 
estimates from the developer, one should exercise due caution given that buildout has not occurred yet, and large projects have a history of underestimating costs on the front end [25, 26].

In Figure 18, the capital cost data from FERC Form 1 for nuclear plants in the southeast was inflated to 2018 dollars using the producer price index. It should be noted that the costs reported include both costs incurred during construction in mixed-year dollars, as well as follow-on capital expenditures. Thus, inflating from the date that the last plant at a site became operational is a rather large approximation given that the costs were accrued across a decade or more of construction and follow-on years of operation. In any case, it was seen that the costs increase significantly for plants finished in the 1980s after the Three Mile Island incident. The cost increase is generally attributable to delays caused by retrofits and redesigns and delays caused by interveners, both of which led to accrued construction loan interest. Noting the costs shown in Figure 18, the EIA and NuScale numbers appear comparable for the rough order of magnitude estimates made here. Furthermore, they roughly align with magnitudes reported by Lovering et al. [27].

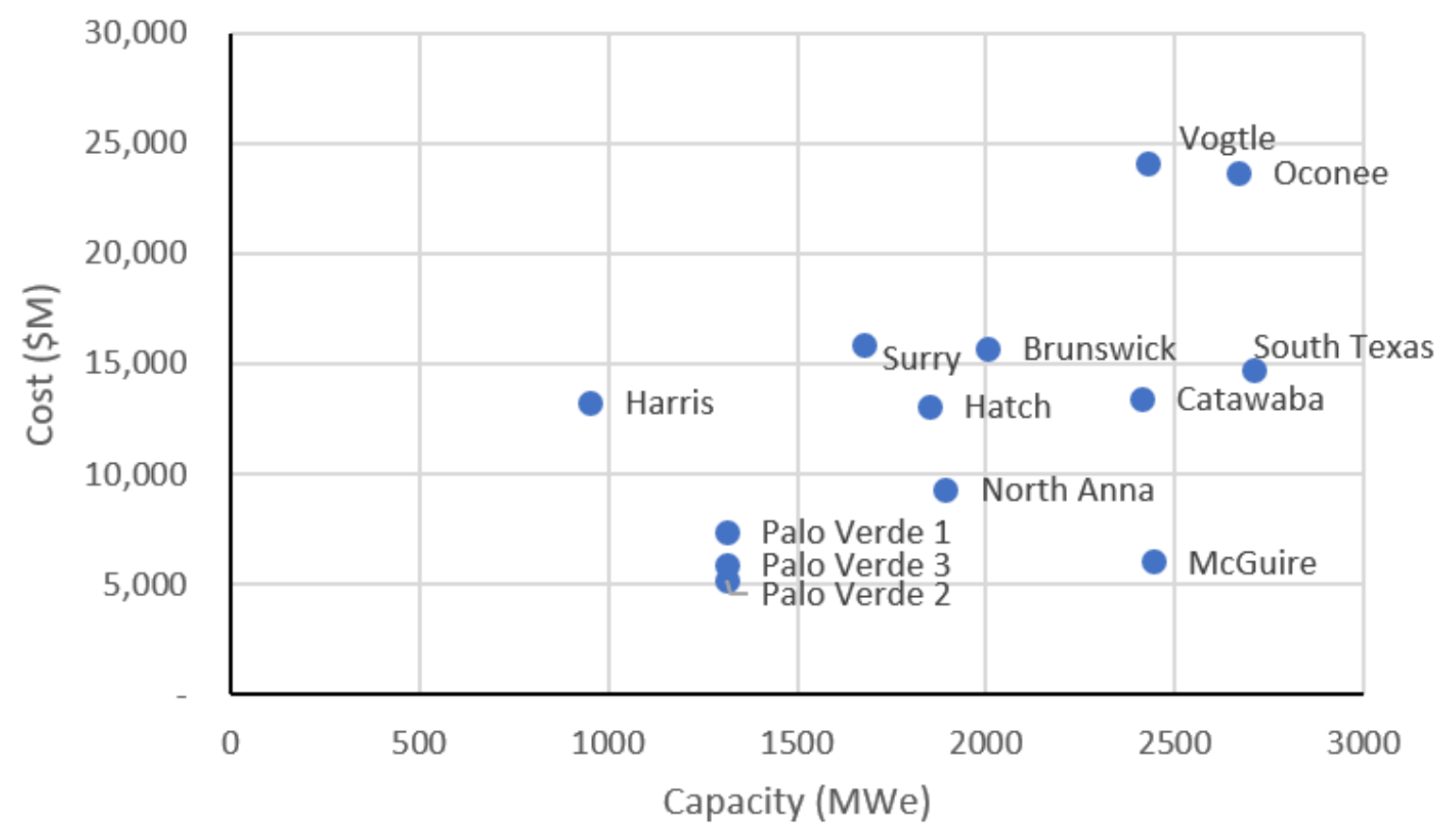

Figure 18. Cost of nuclear plants plotted against plant capacity.

\subsubsection{Capital Expenditures for Combustion Turbine and Combined Cycle}

Capital expenditures for CT and CC plats were developed from Form 1 data. Capital costs were plotted against plant capacity for CT plants as shown in Figure 19 and CC plants as shown in Figure 20. Very clear linear trends are apparent. This did not occur for nuclear projects, which were highly variable. The CT cost is $\$ 417 / \mathrm{kWe}$, and the CC cost is $\$ 640 / \mathrm{kWe}$. Form 1 values were treated as single payments in the year the last unit came online. Then dollar values were inflated to 2018 dollars using the producer price index. 


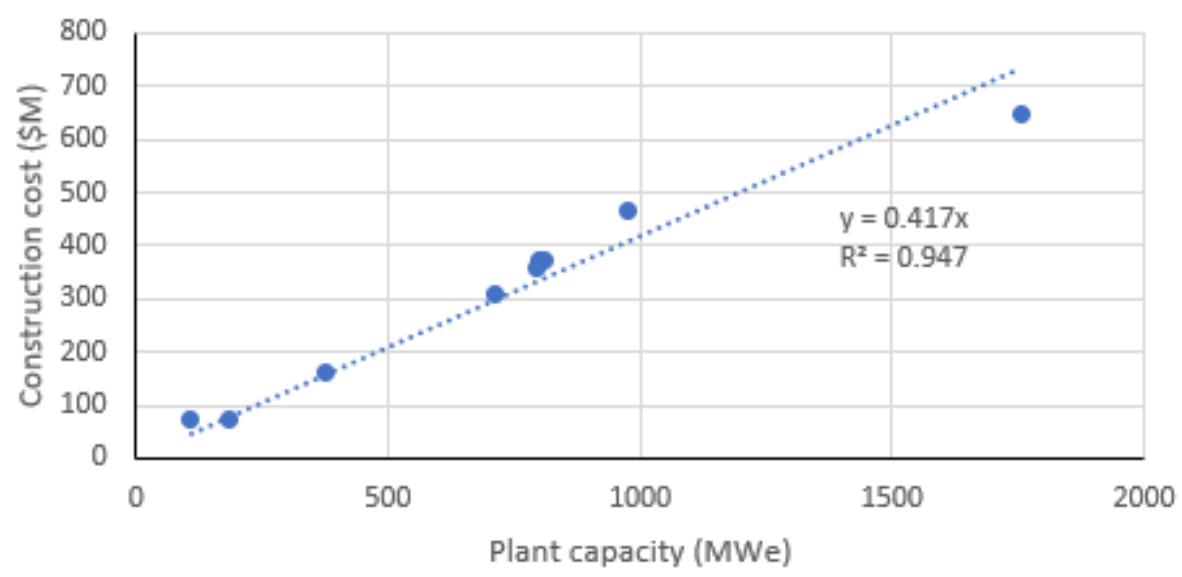

- Total Cost (\$M 2018)

Linear (Total Cost (\$M 2018))

Figure 19. Capital costs for CT plants surveyed in Form 1.

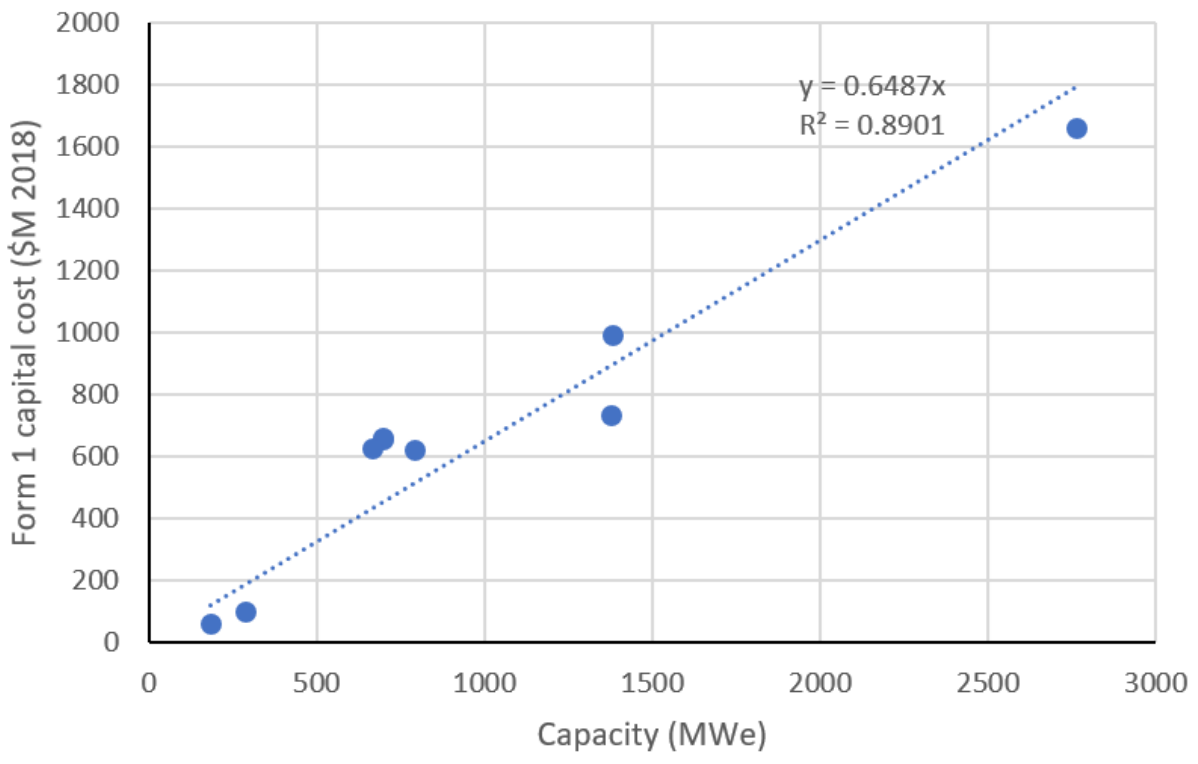

Figure 20. Capital costs for CC plants surveyed in Form 1.

\subsubsection{SMR Annual costs}

There are few operating cost estimates for SMRs, and the estimates that do exist do not benefit from operating experience. Inevitably, there would be operator staff, as well as maintenance support and 24/7 security. Pending design approval, operators could control multiple units simultaneously, so the smaller unit size should not increase staff size excessively [18]. Outage staff will be needed onsite because one of the many units will almost always be down for maintenance or refueling. Presently there are few staffing estimates in existence for SMRs. A NuScale publication lists 365 staff for a 600MWe plant, with a breakdown by education level [15]. Assuming $\$ 220 \mathrm{~K}$ of operation and maintenance (O\&M) costs per staff (as seen in O\&M costs for nuclear plants from Form 1) yields an O\&M cost of roughly $\$ 80 \mathrm{M} /$ year in operating costs. Nuclear O\&M costs averaged $\$ 110 / \mathrm{kW}$ of capacity from the Form 1 data, so a $600 \mathrm{MWe}$ plant would require $\$ 66 \mathrm{M} /$ year in operating costs (not including fuel). The differences in these numbers reflects the typical uncertainty inherent in rough order of magnitude estimates. There is a substantial tail in 
the upward direction, with Harris recording $\$ 160 \mathrm{M} / \mathrm{kW}$ annual operating costs. This is likely because the site has more staff per MW than others, as seen in Table 9. A third estimate can be made based on another report from May 2018, which states that NuScale is targeting a level of 0.7 staff/MW [28], which would place O\&M costs for a $600 \mathrm{MWe}$ plant near $\$ 92 \mathrm{M}$ per year, assuming the $\$ 220 \mathrm{~K} /$ staff-year of O\&M costs. Of note: electricity-related expenses were approximately $7 \%$ of the O\&M cost for the nuclear sites examined in Form 1.

Table 9. Staff size per megawatt of capacity

\begin{tabular}{lc}
\hline Plant & Staff \\
\hline NuScale 600 MW SMR & $0.61-0.7$ \\
\hline Vogtle & 0.38 \\
\hline Catawba & 0.39 \\
\hline Oconee & 0.43 \\
\hline McGuire & 0.45 \\
\hline Brunswick & 0.45 \\
\hline North Anna & 0.49 \\
\hline Hatch & 0.52 \\
\hline Surry & 0.56 \\
\hline Harris & 0.79 \\
\hline
\end{tabular}

Nuclear plants operate 24/7, so determining a variable O\&M component was impossible using only the Form 1 data. Therefore, the plants are listed as having O\&M costs proportional to plant size. Fuel costs are taken directly from Form 1. Plants partially owned by a utility had their costs scaled by the ownership share. These are compared to EIA-commissioned estimates presented in the first two rows of Table 10. Because nuclear plants in the United States operate at high capacity factors, it is difficult to determine O\&M costs as a function of operating time. Natural gas plant operating cost is later seen to depend little on the fraction of time operating. Considering that nuclear O\&M includes substantial staffing costs, it is also unlikely to change much with capacity factor for the purposes of rough order of magnitude cost estimation.

Table 10. Nuclear annual O\&M and fuel cost estimates

\begin{tabular}{|c|c|c|c|}
\hline Cost & Plant concept & $\begin{array}{l}\text { Plant cost } \\
\text { (\$M/year) }\end{array}$ & $\begin{array}{l}\text { Scaled to } 600 \text { MWe with } 80 \% \\
\text { capacity factor }(\$ M / y e a r)\end{array}$ \\
\hline $\begin{array}{l}121.64 \$ / \mathrm{kW} \\
+2.37 \$ / \mathrm{MWh} \\
+5.70 \$ / \mathrm{MWh} \text { fuel* }\end{array}$ & $\begin{array}{c}\text { Advanced nuclear } 2156 \mathrm{MW} \\
\text { AP1000 [EIA1] }\end{array}$ & N/A & 106.9 \\
\hline $\begin{array}{l}95.00 \$ / \mathrm{kW} \\
+3.00 \$ / \mathrm{MWh} \\
+5.70 \$ / \mathrm{MWh} \text { fuel* }\end{array}$ & 600 MW SMR [EIA1] & N/A & 93.6 \\
\hline $\begin{array}{l}120 \$ / \mathrm{kW} \\
+7.60 \$ / \mathrm{MWh} \text { fuel }\end{array}$ & Hatch & 344.8 & 103.9 \\
\hline $\begin{array}{l}89 \$ / \mathrm{kW} \\
+7.48 \$ / \mathrm{MWh} \text { fuel }\end{array}$ & Vogtle I and II & 375.2 & 84.8 \\
\hline $\begin{array}{l}92 \$ / \mathrm{kW} \\
+5.75 \$ / \mathrm{MWh} \text { fuel }\end{array}$ & McGuire & 348.3 & 79.6 \\
\hline $\begin{array}{l}96 \$ / \mathrm{kW} \\
+5.74 \$ / \mathrm{MWh} \text { fuel }\end{array}$ & Catawba & 351.6 & 81.7 \\
\hline $\begin{array}{l}107 \$ / \mathrm{kW} \\
+5.57 \$ / \mathrm{MWh} \text { fuel }\end{array}$ & Oconee & 416.4 & 87.9 \\
\hline
\end{tabular}

*Fuel term assumed cost is based on other plants. 
Table 10 assumes that O\&M costs shown in Form 1 are principally a function of plant capacity rather than hours of operation.

Fuel costs were not included in the EIA estimate. The FERC Uniform System of Accounts lists the Form 1 fuel costs as cost for assemblies, which was roughly \$5.7/MWh.

\subsubsection{Gas Annual Costs}

Gas O\&M costs were assumed to vary as a function of capacity and equivalent hours operated, as shown in the equation below:

$$
[O \& M]=[\text { Base cost }]+a[\text { Capacity }(k W)]+b[\text { Production }(M W h)]
$$

Ten plants from Form 1 had maintenance costs fitted to the model above. These were compared to the EIA model. No operating costs included fuel in the comparison. Overall, the b coefficient had a small impact on the fit, so it was set to 0 . This agrees with Maloney's findings that production and operating time had a relatively small impact on operating cost [29].

Fuel costs dominate annual costs at natural gas sites. Natural gas plants often use fuel oil as an alternative fuel when gas price spikes during periods of high demand. In addition to its greater expense, fuel oil introduces more contaminants and dirt into the CT, so it is not a preferred fuel.

Fuel prices for plants result from efficiency and proportion of gas burnt. Overall, efficiency averaged at $30 \%$, and $19 \%$ of energy came from fuel oil. Buck, the most recently built plant, reported an efficiency of $48 \%$ and 0 oil usage. It is the outlier of the capital cost curve, requiring substantially more startup expense. Oil costs averaged 210 \$/MWh, and gas costs averaged 51 \$/MWh.

For CC plants surveyed, efficiency averaged $46 \%$, with $10 \%$ of fuel coming from fuel oil. Gas fuel costs come in at 30.4\$/MWh, and fuel oil costs are $115 \$ / \mathrm{MWh}$ due to increased plant efficiency. CT estimates are also shown in Table 11.

Table 11. Summary of annual O\&M and fuel costs for natural gas plants

\begin{tabular}{|c|c|c|c|c|c|c|c|}
\hline & $\begin{array}{l}\text { Base cost } \\
\quad(\$ M)\end{array}$ & $\begin{array}{c}a \\
(\$ / k W)\end{array}$ & $\begin{array}{c}\text { B } \\
\text { (\$/MWh) }\end{array}$ & $\begin{array}{c}\text { Size } \\
(\mathbf{M W e})\end{array}$ & $\begin{array}{c}\text { Annual } \\
\text { O\&M cost } \\
\text { (minus fuel) }\end{array}$ & $\begin{array}{l}\text { Fuel } \\
(\$ M)\end{array}$ & $\begin{array}{l}\text { Total } \\
\text { O\&M } \\
(\$ M)\end{array}$ \\
\hline EIA CT A & 0 & 16.3 & 4.7 & 600 & 28.8 & 328.7 & 357.5 \\
\hline EIA CT & 0 & 7 & 4.5 & 600 & 22.4 & 328.7 & 351.1 \\
\hline Form 1 CTs & 0.4 & 4.1 & 0 & 600 & 2.5 & 328.7 & 331.1 \\
\hline EIA CC $2 \times 2 \times 1$ GE 7 HA.02 & 0 & 12.2 & 1.87 & 850 & 20.1 & 212.3 & 232.4 \\
\hline EIA CC B 1×1×1 H class & 0 & 14.1 & 2.55 & 810 & 25.4 & 212.3 & 237.7 \\
\hline $\begin{array}{l}\text { EIA CC B } 1 \times 1 \times 1 \text { H class } \\
\text { with } 90 \% \text { carbon capture }\end{array}$ & 0 & 27.6 & 5.84 & 810 & 54.3 & 212.3 & 266.6 \\
\hline Form 1 CCs & 0 & 15.7 & 0 & 810 & 12.7 & 212.3 & 225.0 \\
\hline
\end{tabular}

\subsubsection{Cost Overruns in Nuclear Projects}

To a greater extent than other construction projects, nuclear construction requires clear satisfactory completion of every step. Because the project requires a high level of integration and quality assurance, a single delay can have knock-on effects throughout a large portion of the project. Thus, project phasing should be robust against unexpected, high-consequence events. The standardized nature of SMRs mitigates this risk to an extent through the use of multiple modules of smaller scales. However, the first few plants built will not benefit from much learning. For traditional plants, construction can take almost a decade. The 
SMR should reduce this time by using centralized, standardized fabrication of modules. This section reviews the history of nuclear costs to provide perspective on what the SMR concept is designed to address.

Historically, nuclear projects have almost always involved substantial cost escalation. Reasons for this include the high level of project integration, large scale, exacting quality standards, lack of standardization, and the requirement to win competitive bids. These factors can lead to optimism bias. Overruns occur for almost all megaprojects, albeit some experience this to a lesser extent for a variety of reasons [26].

The FOAK Vogtle 3 and 4 projects are expected to come online in the early 2020s. Sister newbuilds at the Summer site experienced cost overruns similar to those experienced with the Vogtle units and was canceled. Arguably, the experience at Vogtle and Summer are not representative, as these were FOAK projects for the contractors involved (specifically Shaw) and for a generation of American construction workers. The project was complicated by several events. The first was the use of inadequate fill dirt in site preparation, and a second instance involved revisions to the shielding building design. Whether the problems were due to the vendor, contractor, or regulator is unclear. The project was further complicated by the vendor declaring bankruptcy midway through construction [30]. When the project was approaching 80 percent complete, it was estimated to cost roughly $\$ 27$ billion, or $\$ 11,000 / \mathrm{kW}$ in August 2018 [31-33]. The initial cost estimate was $\$ 14.3$ billion [31]. The Vogtle expansion represents a proportionally smaller, $70 \%$ budget increase than what has occurred in past nuclear projects, where at the $75 \%$ phase, costs on average increased by $87 \%$ to $181 \%$, as shown in Table 11 [34].

Historical cost and schedule overruns are shown in Table 12 and Table 13. These are rather substantial. Many of the cost overruns are believed to have been produced by Three Mile Island-related retrofits and public opposition.

Table 12. Cost overrun tabulated by year of construction start (Data from DOE EIA-0485)

\begin{tabular}{cccccccc}
\hline $\begin{array}{c}\text { Year of } \\
\text { construction start }\end{array}$ & $\begin{array}{c}\text { Number of } \\
\text { plants }\end{array}$ & $\mathbf{0 \%}$ & $\mathbf{2 5 \%}$ & $\mathbf{5 0 \%}$ & $\mathbf{7 5 \%}$ & $\mathbf{9 0 \%}$ & $\begin{array}{c}\text { Realized } \\
\text { costs \% }\end{array}$ \\
\hline $\mathbf{1 9 6 6}-\mathbf{1 9 6 7}$ & 11 & 0 & 27 & 39 & 87 & 96 & 109 \\
$\mathbf{1 9 6 8 - 1 9 6 9}$ & 26 & 0 & 34 & 53 & 116 & 143 & 194 \\
$\mathbf{1 9 7 0}-\mathbf{1 9 7 1}$ & 12 & 0 & 37 & 69 & 143 & 174 & 159 \\
$\mathbf{1 9 7 2}_{\mathbf{1 9 7 3}}^{\mathbf{1 9 7 3}}$ & 7 & 0 & 6 & 39 & 152 & 198 & 218 \\
$\mathbf{1 9 7 4 - 1 9 7 5}^{\mathbf{a}}$ & 14 & 0 & 56 & 84 & 181 & 251 & 281 \\
$\mathbf{1 9 7 6}_{\mathbf{1 9 7 7}}^{\mathbf{a}}$ & 5 & 0 & 15 & 34 & 120 & 144 & 169 \\
\hline
\end{tabular}

a "A sample of plants scheduled to become operational by the end of 1986 was used. These groups include 8 units that are only about 90 percent complete. For those 8 units the estimated cost was assumed to equal the realized cost." 
Table 13. Schedule overrun tabulated by year of construction start (Data from DOE EIA-0485)

\begin{tabular}{ccccccc}
\hline $\begin{array}{c}\text { Year of } \\
\text { construction start }\end{array}$ & $\mathbf{0 \%}$ & $\mathbf{2 5 \%}$ & $\mathbf{5 0 \%}$ & $\mathbf{7 5 \%}$ & $\mathbf{9 0 \%}$ & Actual lead time \\
\hline $\mathbf{1 9 6 6 - 1 9 6 7}$ & 0 & 8 & 25 & 46 & 58 & 75 \\
$\mathbf{1 9 6 8 - 1 9 6 9}$ & 0 & 15 & 31 & 51 & 65 & 95 \\
$\mathbf{1 9 7 0 - 1 9 7 1}$ & 0 & 31 & 56 & 64 & 86 & 124 \\
$\mathbf{1 9 7 2 - 1 9 7 3}$ & 0 & 34 & 48 & 65 & 77 & 102 \\
$\mathbf{1 9 7 4 - 1 9 7 5}^{\mathbf{a}}$ & 0 & 37 & 54 & 72 & 81 & 94 \\
$\mathbf{1 9 7 6}_{\mathbf{1 9 7 7}}^{\mathbf{a}}$ & 0 & 24 & 28 & 31 & 35 & 51 \\
\hline
\end{tabular}

a "A sample of plants scheduled to become operational by the end of 1986 was used. These groups include 8 units that are only about 90 percent complete. For those 8 units the estimated lead-time was assumed to equal the realized lead-time."

The dismal cost performance of nuclear projects should not be representative of SMR concepts because of their different design, which relies much more on passive safety and standardized components, which should enable better performance monitoring.

Most of the aforementioned financial problems involved in a nuclear plant is not related to the nuclear systems themselves, but rather to the complex plant construction process [35] with exacting quality requirements. This environment amplifies project risks and the likelihood that some unplanned development could derail project schedule. Use of SMR systems on a standardized footprint should allow contractors to build up experience in how to satisfy NRC requirements, methods for coordinating a highly complex project effectively, and ultimately how to deliver on schedule. Also, performance management can be improved with multiple units on each site producing more standardized quality and efficiency benchmarks. With standardization, past performance monitoring can be improved, reducing optimism bias in cost estimates. Construction firms regularly underbid projects due to optimism bias and a desire to win the bid [26].

The modular nature of SMRs enables construction contractors to improve efficiency through learning at an individual site. This can be crucial, as local contractors are often involved in plant construction. These companies may not have learned how to efficiently operate under a nuclear quality assurance program. In a traditional build, a contractor's error would delay the entire project. However, if a contractor has a delay completing the first modules, the next set of contractors could be tasked with additional work on other modules until the issue in question has been addressed. In this manner, construction would be more like building a road than building a space shuttle.

The first SMRs are expected to be constructed by NuScale with the Utah Associated Municipal Power System (UAMPS) at Idaho National Laboratory with DOE funding support[28]. This arrangement could be an indicator as to whether the SMR approach breaks with the nuclear track record, thus making the technology economically competitive.

\subsubsection{Comparison of Scenarios}

Six natural gas scenarios and three SMR scenarios were evaluated to provide a rough idea of how various developments could impact the economics driving plant selection decisions. The scenarios are outlined in Table 14. Scenarios based upon three SMR project capital costs are considered, two within the range of expected capital costs, and one representing a substantial cost overrun. The natural gas scenarios are a CT plant and a CC plant. Because the CC plant performed better overall in cost terms, four variants of the combined cycle scenario were created: two of which capture the impacts of fuel price spikes, and two of which capture the impact of a carbon tax. Construction loans, impacts of project delays, and the cost of 
replacement power are not accounted for in this analysis. Ramp rates and capacity factors are assumed to be similar for all scenarios. Plant modifications to change from electricity to heating are assumed to cost the same in both cases.

Values were selected from ranges in the previous subsections. Capital costs for the CT and CC options are from Section 5.2.3. SMR capital costs are based on the NuScale and EIA estimates in Section 5.2.2. The cost overrun case assumes a $\$ 10,000 / \mathrm{kW}$ capital cost because it is a round number near the upper end of capital costs in historical nuclear projects.

$\mathrm{CT}$ and CC operating costs were taken from the respective Form 1 estimates given in Table 11. These were the lowest of each technology's operating costs, thus making natural gas options tilt slightly to the competitive side. A carbon tax of $\$ 50$ per metric ton was added to the CC operating cost to create a variant. Another variant scenario was created by roughly doubling fuel costs, resulting in $\$ 428 \mathrm{M} /$ year in operating costs for a 10-year period shortly after the plant starts operation. Both variants were also evaluated with a 20-year delay. SMR operating costs were taken from the SMR estimate provided in Table 10. The cost overrun case added $20 \%$ to the SMR operating cost number.

Table 14. Summaries of natural gas and SMR scenarios evaluated

\begin{tabular}{|c|c|c|c|c|c|}
\hline Name & Description & $\begin{array}{l}\text { Capital } \\
\text { cost } \\
(\$ / \mathbf{k W})\end{array}$ & $\begin{array}{l}\text { Equivalent } \\
\text { capacity } \\
\text { (MWe) }\end{array}$ & $\begin{array}{c}\text { Operating } \\
\text { cost } \\
\text { (\$M/year) }\end{array}$ & $\begin{array}{c}\text { High } \\
\text { operating } \\
\text { (\$M/year) }\end{array}$ \\
\hline CT & CT nominal case & 417 & 600 & 331 & -- \\
\hline $\mathrm{CC}$ & CC nominal case & 679 & 810 & 225 & -- \\
\hline $\begin{array}{l}\text { CC+10-year fuel } \\
\text { price spike }\end{array}$ & $\begin{array}{l}\text { CC with } 10 \text {-year gas price } \\
\text { roughly doubling }\end{array}$ & 679 & 810 & 225 & 428 \\
\hline CC+carbon tax & $\begin{array}{l}\text { CC with carbon tax of } \\
\$ 50 \text { per metric ton }\end{array}$ & 679 & 810 & 332 & -- \\
\hline $\begin{array}{l}\text { CC+delayed price } \\
\text { spike }\end{array}$ & $\begin{array}{l}\text { CC with gas price roughly } \\
\text { doubling } 20 \text { years into } \\
\text { operation for } 10 \text { years }\end{array}$ & 679 & 810 & 225 & 428 \\
\hline $\begin{array}{l}\text { CC+delayed } \\
\text { carbon tax }\end{array}$ & $\begin{array}{l}\text { CC with carbon tax of } \\
\$ 50 \text { per metric ton } \\
\text { implemented } 20 \text { years } \\
\text { into operation }\end{array}$ & 679 & 810 & 225 & 332 \\
\hline SMR $\$ 4.2 / \mathrm{kW}$ & $\begin{array}{l}\text { SMR NuScale low } \\
\text { estimate }\end{array}$ & 4,200 & 600 & 93 & -- \\
\hline SMR $\$ 6.1 \mathrm{k} / \mathrm{kW}$ & SMR EIA estimate & 6,100 & 600 & 93 & -- \\
\hline $\begin{array}{l}\text { SMR }+\$ 10 / \mathrm{kW}+ \\
20 \% \text { operating cost }\end{array}$ & $\begin{array}{l}\text { SMR cost overrun case } \\
\text { with } 20 \% \text { increased } \\
\text { operating costs }\end{array}$ & 10,000 & 600 & 111 & -- \\
\hline
\end{tabular}

Figure 21 shows the cumulative expenditure in millions for the various scenarios. The natural gas options become more expensive than the nuclear options anywhere from 10 to 50 years after plant commissioning. This date can be of substantial importance once time value of money is considered, and there is no clear best choice of plant. 


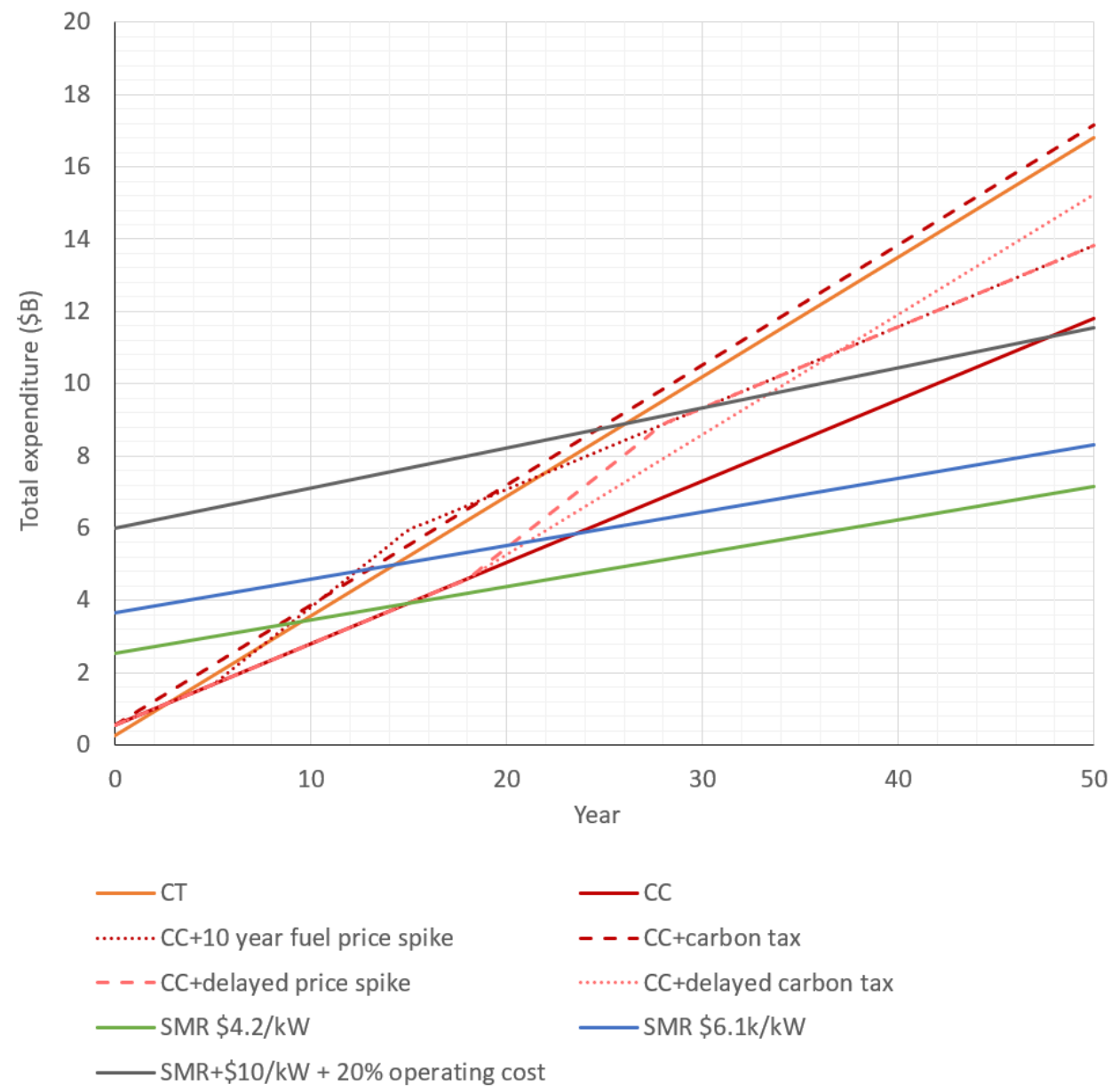

Figure 21. Cost performance with constant dollars.

To evaluate how the scenarios evaluated compared when the value of money varies with time, three different interest rates were applied to the cash flows to show future values of expenditures. Then the values were plotted against the future value of the $\mathrm{CC}$ option. To make the ratio, the cumulative expenditures made by each year $\left(V_{n}\right)$, denominated in dollars of the future year $n$, using a constant interest rate $(r)$ were computed using the equation below:

$$
V_{n}=\sum_{i}^{n} E_{i}(1+r)^{\mathrm{n}}
$$

The expenditure in each year $i$ is denoted as $E_{i}$. The vertical axes in Figure 22 through Figure 24 correspond to the future cumulative value in the given year for an option divided by the future cumulative value of the $\mathrm{CC}$ option in that same year. Thus, for years in which curves fall above the value of 1 , performance is worse in terms of cost over the time up until that year. If a curve falls below the value of 1, then performance is better than the $\mathrm{CC}$ option over the entire period prior up until that year. Similar comparisons can be made between any pair of curves.

In the $2 \%$ case (Figure 22), the two nominal SMR scenarios become the preferred options if operations span more than 35 years. This can be seen in the figure, as the SMR scenario curves cross below the curves for all other scenarios, indicating the lowest future value of expenditures. They become competitive, falling within the range of the natural gas scenarios, in roughly 15 years. The SMR overrun scenario becomes competitive only with at least 40 years of operation. 


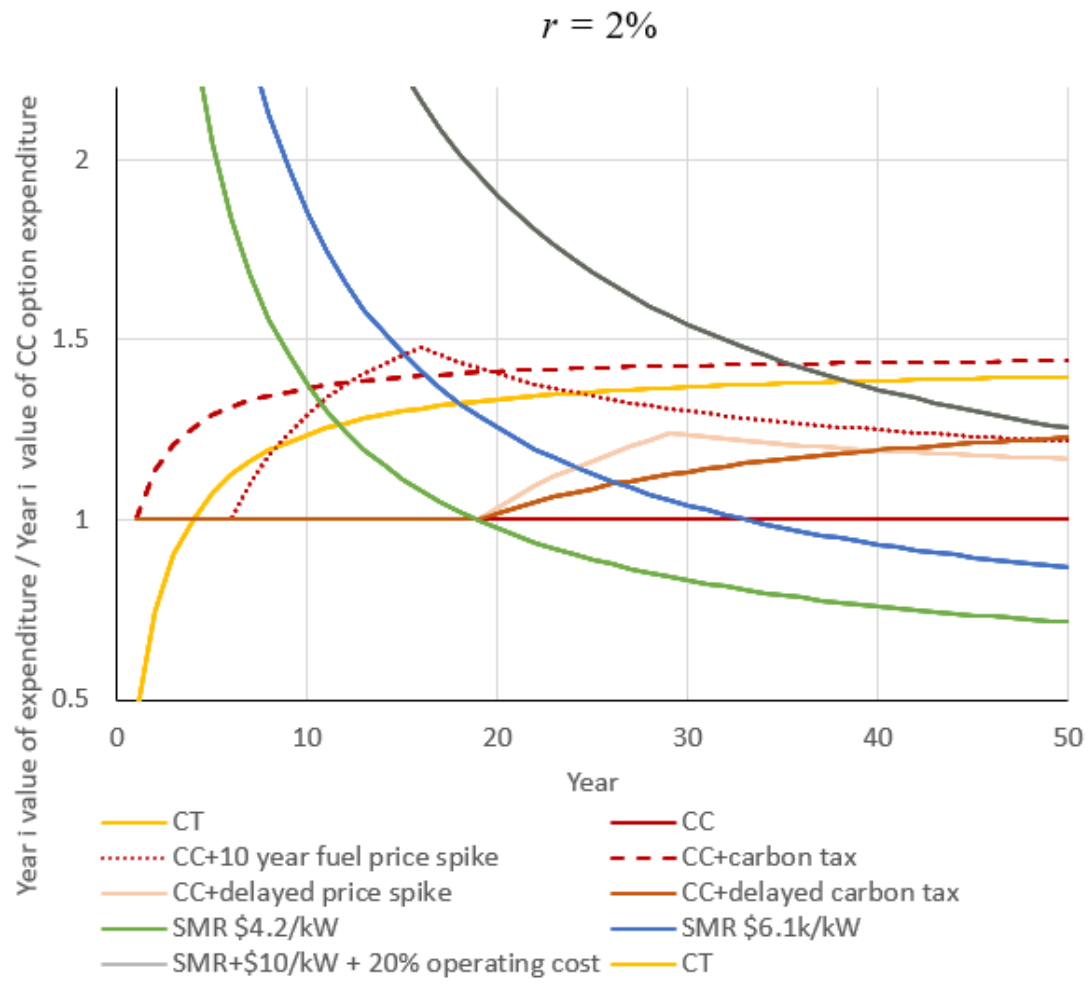

Figure 22. Cost performance in a $2 \%$ rate environment.

With an interest rate of 5\% (Figure 23) the less expensive of the nominal SMR scenarios becomes a competitive option after roughly 15 years of operation, and it becomes the preferred option if operations span more than 30 years. However, the higher estimate becomes competitive only after about 25 years, and it never becomes the preferred option. The overrun scenario never becomes competitive. 


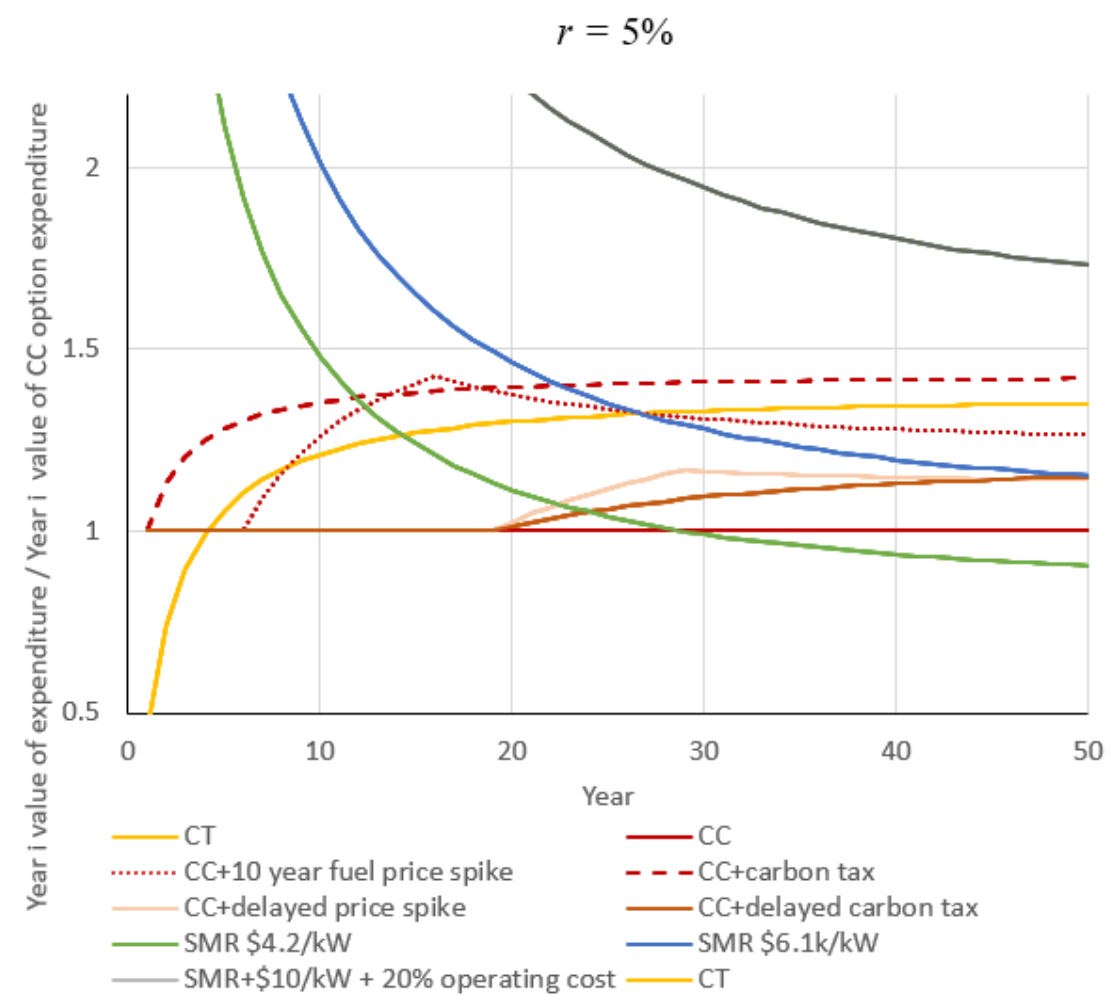

Figure 23. Cost performance in a $5 \%$ rate environment.

With an interest rate of 7\% (Figure 24), the least expensive of the nominal SMR scenarios becomes a competitive option after roughly 15 years of operation, and it never becomes the preferred option. The overrun estimate is never competitive. The higher nominal SMR scenario becomes competitive only if a $\$ 50$ per metric ton $\mathrm{CO}_{2}$ tax is implemented when operations commence. 


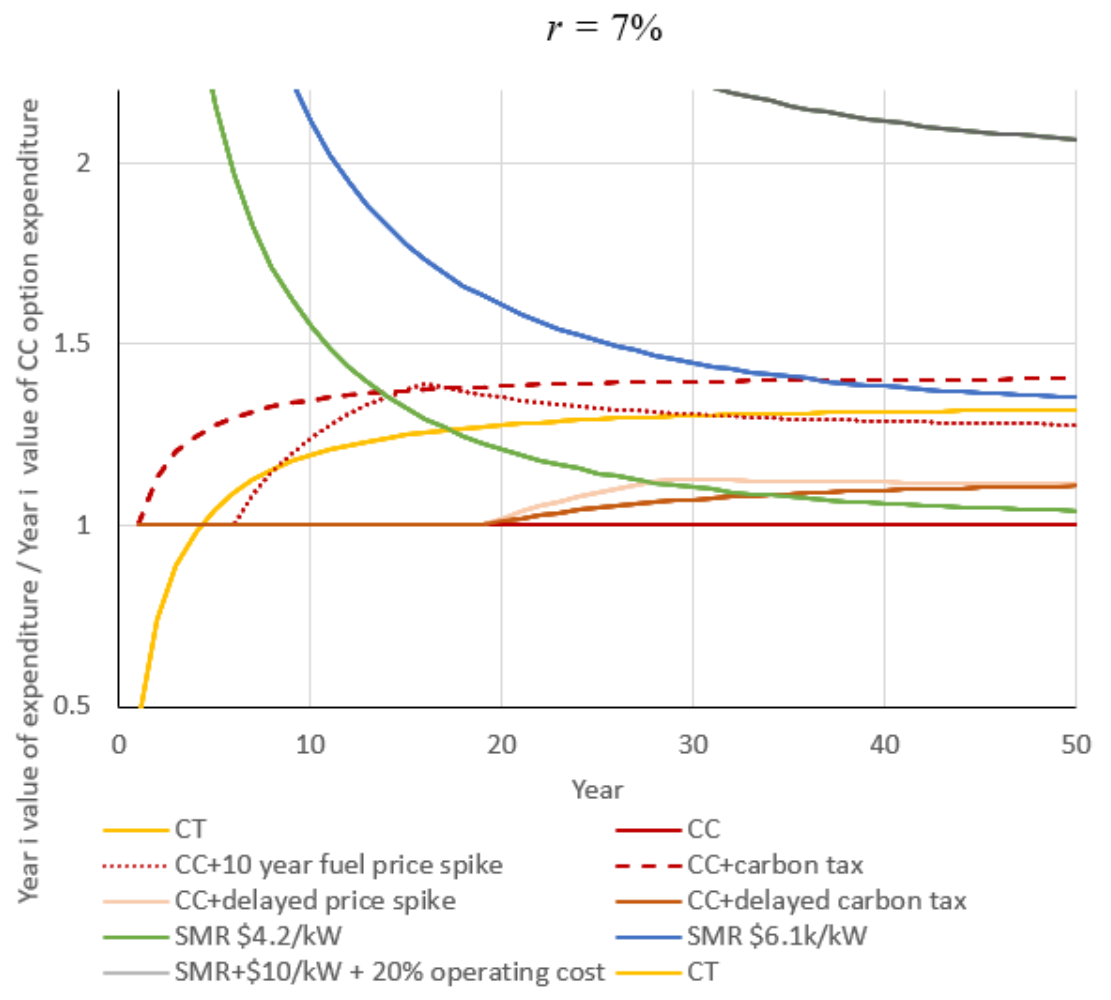

Figure 24. Cost performance in a $7 \%$ rate environment.

\subsubsection{Summary of Economic Considerations}

This economics study evaluated generic units capable of energy production sufficient to supply 600 psig steam at 2.6 million $\mathrm{lbm} / \mathrm{hour}$ while supplying electricity demanded by the Eastman application. This topdown analysis only evaluated plants at the technology level, with each plant scaled to supply the thermal energy required to meet the application need. For this work, based on EIA data, historic cost overrun data, and operating costs obtained from FERC Form 1 and other data, the SMR option is preferred for longer time horizons and lower interest rate environments, assuming no cost overruns. This is due to its high initial cost and low operating cost. The initial plant cost, which is based on EIA data, was calculated to be between \$2.5B and \$3.6B in 2020 dollars without considering cost overruns risk, delays risk, or construction loans. The system would nominally operate at a cost of $\$ 90 \mathrm{M}$ per year. Due to the lack of experience in construction or operations with SMR plants, any SMR cost projection lacks precision.

The high-level projections presented in this section are simplified models of what could happen. As previously stated, they do not account for delayed construction, the cost of replacement power/steam, construction loan interest, or other considerations. Due to a lack of cost data for hybrid plants, the plants in this economic assessment were assumed to be analogously sized electricity generation plants capable of producing the required steam supply. The interest rate analyses only compared expenses of the various options, and if the options produced differing benefits for some reason, then the comparisons were reevaluated with those in mind. Cost and schedule overruns have been common in the nuclear industry. However, the SMR approach attempts to address these overruns through standardization, modularization, and use of passive safety in the SMR designs. If the NuScale plant in Idaho is built to demonstrate the SMR concept, then it should provide better insight into the level of project risk that may be encountered. 


\section{REGULATORY, LICENSING, AND SITING CONSIDERATIONS}

Besides the design, operation, and economic aspects of IESs, it is extremely important to be aware of licensing and siting at the very beginning of any exploratory work. Given the nature of nuclear energy, these aspects are of particular importance in nuclear applications to ensure the health and safety of the workers, the public, and the environment. However, it is likely that many entities with an interest in creating IESs do not have experience with the nuclear regulatory process. Therefore, this section provides readers with non-nuclear backgrounds an introduction into that process. As needed, the reader should seek additional information and guidance on regulatory, licensing, and siting by further investigating the referenced resources and engaging in early and frequent discussions with US regulating bodies such as the NRC.

\subsection{NUCLEAR PLANT REGULATORY AND LICENSING CONSIDERATIONS}

The NRC's mission includes licensing and regulation of commercial nuclear power plants to protect the health and safety of the public, workers, and the environment. The NRC reviews the applicant's capability to build and safely operate a nuclear power plant, performs an environmental review for the potential operating site, and evaluates the proposed plant's safety analysis report associated with its construction and operation. The NRC reviews the potential environmental impacts and benefits of the proposed plant. This includes impacts on air, water, animal life, vegetation, natural resources, and property of historic, archaeological, or architectural significance. Other items evaluated include economic, social, and cultural impacts on the surrounding communities. The findings of the NRC's environmental review are documented in an environmental impact statement (EIS). Finally, the NRC reviews the applicant's safety analysis report describing the plant's final design, safety evaluation, operational limits, anticipated response to postulated accidents, and plans for coping with emergencies. The regulations and requirements that govern the plant are evaluated to determine whether the applicant's plans are adequate to provide reasonable assurance of adequate protection of the health and safety of the workers, the public, and the environment.

\subsubsection{Reactor license}

Nuclear power plants can be licensed under Title 10 of the Code of Federal Regulations (CFR) Part 50, Domestic Licensing of Production and Utilization Facilities, or Part 52Licenses, Certifications, and Approvals for Nuclear Power Plants. Nuclear power plants licensed under Part 50 undergo a two-step licensing process that first grants a construction permit $(\mathrm{CP})$ and after further review an operating license (OL). In 1989, the NRC established an alternative licensing process under Part 52 that combines a CP and an OL, with certain conditions, into a single license, which is known as a combined license, or COL. Part 52 also includes provision for a reactor manufactured under an NRC manufacturing license to be transported to and installed at an approved site for which a CP or COL has been issued. Presumably, Eastman's most favorable options would be factory-built reactor modules transported to the site and installed there.

NRC requires that an application, including the applicant's safety analysis and environmental report, be submitted for verification of its adequacy prior to its formal review. Only when the NRC staff is satisfied as to its quality and completeness is the application placed on the docket, and the agency publishes a notice of receipt in the Federal Register.

After the initial license is granted, the license may be amended, renewed, transferred, or otherwise modified, depending on activities that affect the reactor during its operating life.

There are advantages for choosing either the Part 50 or Part 52 licensing paths, depending on whether the plant design has already been certified by the NRC. The Part 50 option may be advantageous for an applicant with a relatively mature plant design that is not yet certified by the NRC with an objective to take 
the shortest path to building and operating the plant. The Part 50 option would permit construction of the plant based on NRC approval of the preliminary safety analysis, allowing time to finalize the design as construction continues. A subsequent review and approval of the final safety analysis of the as-built design would be necessary before the NRC would issue the operating license. The Part 52 option would generally provide more certainty to the applicant from regulatory and project management perspectives. In this case, the plant designer gains NRC certification for the design prior to its being built. Subsequently, an applicant would build the plant based on its referenced, certified design. That design certification takes place before construction starts, so that the applicant has greater certainty of the project's cost and schedule.

Descriptions of the Part 50 and Part 52 licensing process are provided in Sections 6.1.2 and 6.1.3. The NRC's licensing processes generally assume that a nuclear power plant will be built where it will be operated. Section 6.1.5 discusses how a reactor manufactured under an NRC manufacturing license can be transported to and installed at an approved site.

\subsubsection{Construction Permit and Operating License (10 CFR 50)}

Obtaining an OL under 10 CFR 50 is a two-step process that requires the applicant to apply for the CP first and then to apply for the OL as construction is completed. After the NRC reviews and is satisfied with the safety of the preliminary plant design and the suitability of the prospective site, the agency issues a CP that allows an applicant (e.g., utility) to begin building a plant. At some point during construction, the utility applies for an OL, which the NRC issues only if all safety and environmental requirements are met.

\subsubsection{Construction Permit (CP)}

An application for a $\mathrm{CP}$ must contain three types of information:

1. financial and antitrust statements (10 CFR 50.33),

2. an environmental report (10 CFR 51.50), and

3. preliminary safety analysis report (10 CFR 50.34[a]).

The NRC's environmental review evaluates the potential environmental impacts and benefits of the proposed plant. Findings from the NRC's environmental review are documented in an EIS. The NRC then reviews the application and documents its findings on site safety characteristics and emergency planning (EP) in a safety evaluation report (SER).

Upon determination that an application for a license meets the standards and requirements of the act and regulations, and that notifications, if any, to other agencies or bodies have been duly made, the NRC issues a $\mathrm{CP}$, in such form and containing such conditions and limitations, including technical specifications, as it deems appropriate and necessary (10 CFR 50.50). A CP constitutes an authorization to the applicant to proceed with construction, but it does not constitute NRC's approval of the safety of any design features or specifications unless the applicant specifically requests such approval and such approval is incorporated into the permit (10 CFR 50.35). The CP process is summarized in Figure 25. 


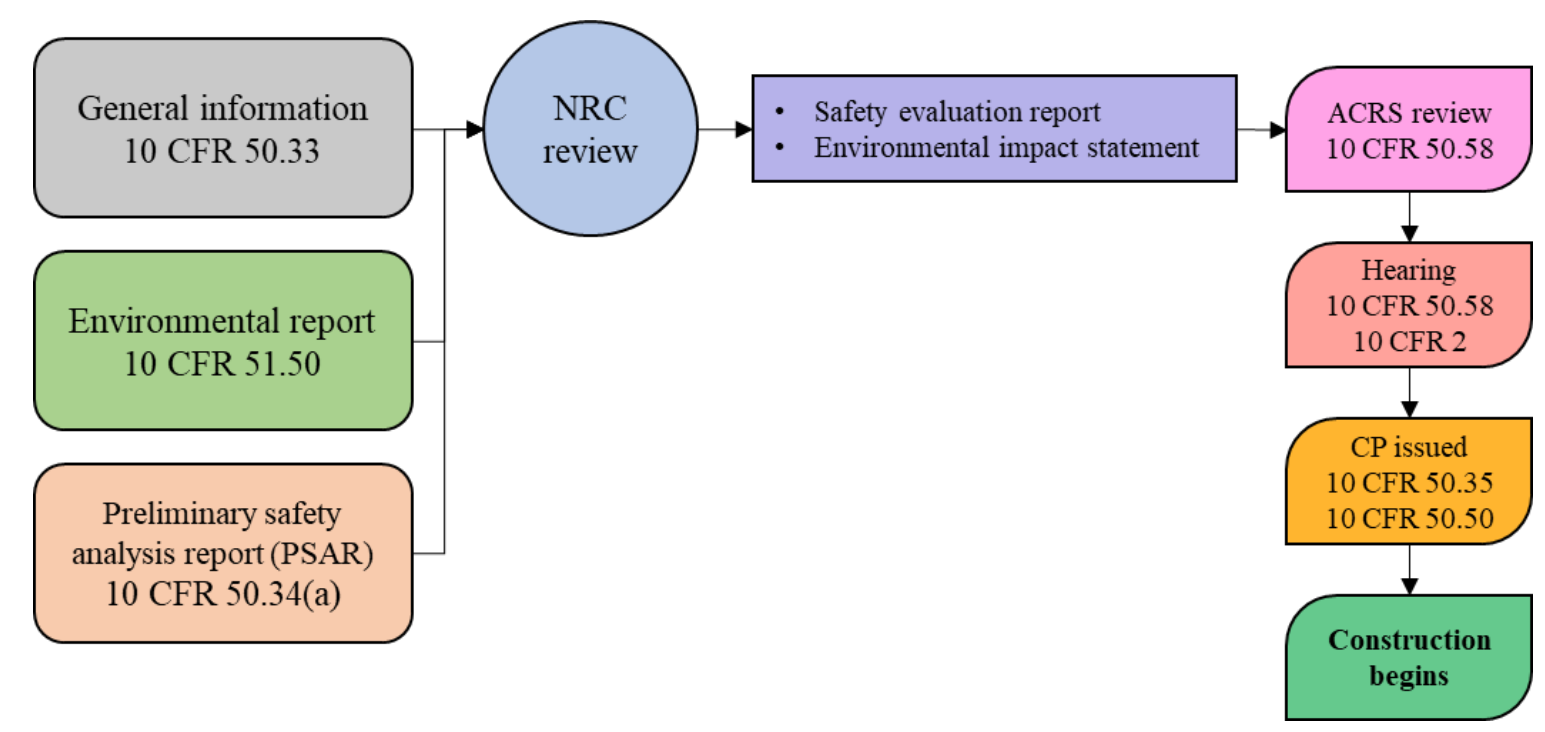

Figure 25. 10 CFR 50 construction permit process [36].

\subsubsection{Operating License (OL)}

The application for an OL contains

1. a final safety analysis report (10 CFR 50.34[b]), and

2. an updated environmental report (10 CFR 51.53).

The final safety analysis report describes the plant's final design, safety evaluation, operational limits, anticipated response of the plant to postulated accidents, and plans for coping with emergencies. The NRC reviews the applicant's emergency plans (10 CFR 50.33) in consultation with the Federal Emergency Management Agency (FEMA) to determine whether the plans are adequate and whether there is reasonable assurance that they can be implemented.

Upon determination that an application for a license meets the standards and requirements of the Atomic Energy Act (AEA) and NRC regulations, and that notifications, if any, to other agencies or bodies have been duly made, the NRC will issue a license (10 CFR 50.50). The issuance of an OL (10 CFR 50.57) indicates that the construction of the facility has been substantially completed, the facility will operate in conformity with the application as amended, and there is reasonable assurance that the activities authorized by the OL can be conducted without endangering the health and safety of the public. The OL process is summarized in Figure 26. 


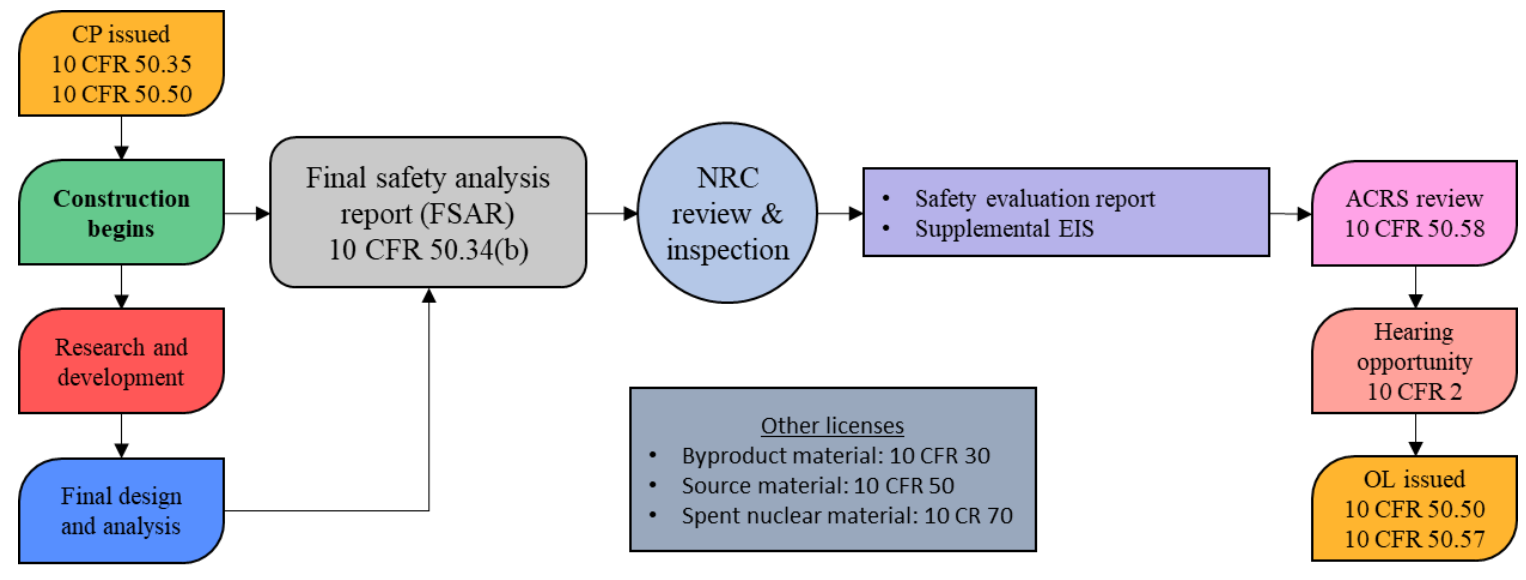

Figure 26. 10 CFR 50 operating license process [36].

\subsubsection{Combined License (10 CFR 52)}

In 1989, the NRC established new alternatives for nuclear plant licensing under 10 CFR 52, which describes

- $\quad$ an early site permit (ESP) (10 CFR 52.17),

- a standard plant design certification (10 CFR 52.47), and

- a COL (10 CFR 52.79).

A COL authorizes construction and conditional operation of a nuclear power plant. The application for a COL must contain essentially the same information that is required in an application for an OL issued under 10 CFR 50. The application must also describe the inspections, tests, analyses, and acceptance criteria (ITAAC) that are necessary to ensure that the plant has been properly constructed and will operate safely. The COL process is summarized in Figure 27.

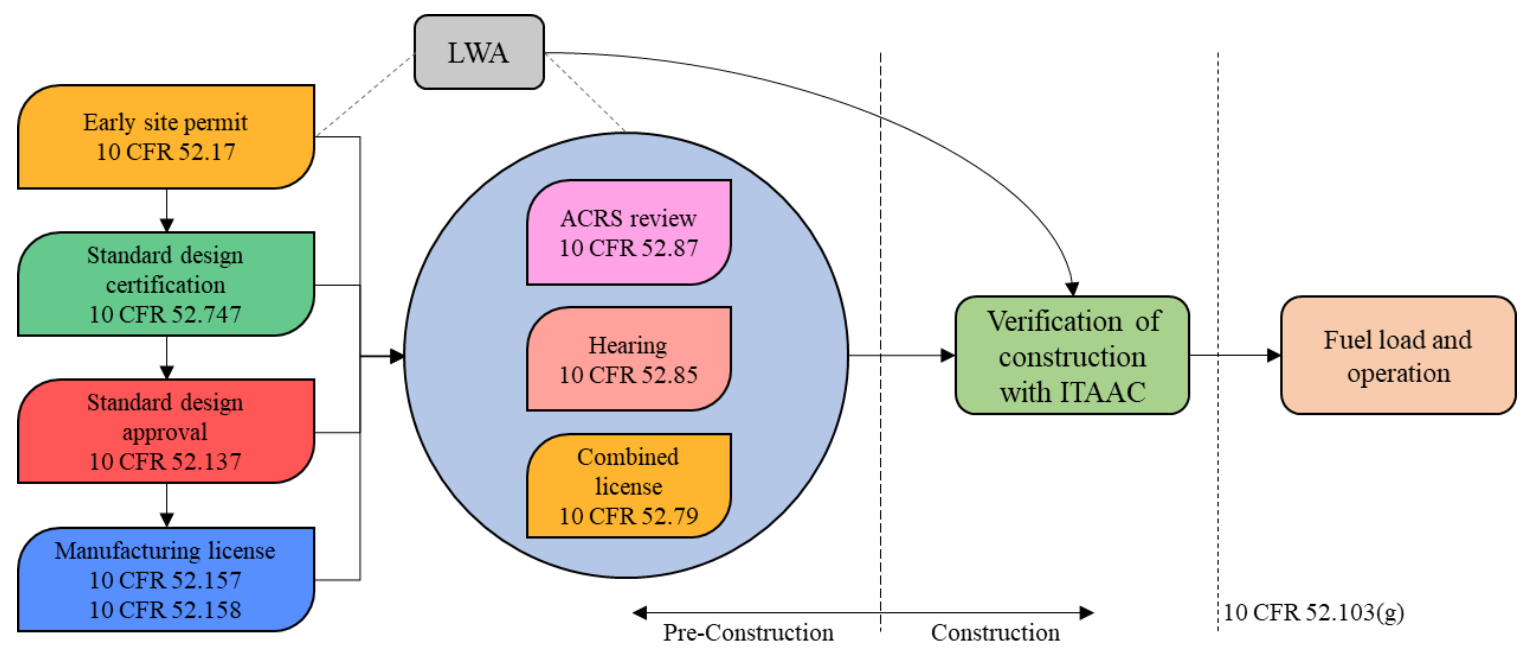

Figure 27. 10 CFR 52 licensing process [36]. 


\subsubsection{Early Site Permit (ESP)}

Under the NRC's regulations in 10 CFR 52, the agency can issue an early site permit (ESP) for approval of one or more sites separate from an application for a CP or COL. Such permits address site safety issues, environmental protection issues, and plans for coping with emergencies independent of the review of a specific nuclear plant design.

An application for an ESP must contain the following information (10 CFR 52.17):

- definition of the site's boundaries, including a discussion of the exclusion area (EA) for which the applicant has the authority to remove or exclude persons or property;

- characteristics of the site, including seismic, meteorological, hydrologic, and geologic data;

- the location and description of any nearby industrial, military, or transportation facilities and routes;

- the existing and projected future population of the area surrounding the site, including a discussion of the expected low-population zone around the site and the locations of the nearest population centers;

- an evaluation of alternative sites to determine whether there is any obviously superior alternative to the proposed site;

- the proposed general location of each plant on the site;

- the number, type, and power level of the plants, or a range of possible plants planned for the site;

- the maximum radiological and thermal effluents expected;

- the type of cooling system expected to be used;

- radiological dose consequences of hypothetical accidents; and

- plans for coping with emergencies.

For emergency plans, 10 CFR 52.17 requires the applicants to identify the physical characteristics of the site that could significantly hinder the development of a complete emergency plan. As in the 10 CFR 50 $\mathrm{CP}$ process, the NRC reviews the EP information in consultation with FEMA.

The NRC documents its findings regarding site safety characteristics and EP in a SER, and environmental protection issues are documented in draft and final EISs (FEISs). The ESP also has provisions for limited work authorization (LWA) to perform non-safety-related site preparation activities before a COL is issued.

\subsubsection{Standard Design Certification and Standard Design Approval}

The follow terms are helpful for understanding the COL process (10 CFR 52.1):

- Standard design: a design which is sufficiently detailed and complete to support certification or approval in accordance with subpart B or E of 10 CFR 52 and which is usable for a multiple number of units or at a multiple number of sites without reopening or repeating the review.

- Approved standard design: a nuclear power reactor design that has been approved and issued by NRC staff for either the final design for the entire reactor facility or the final design of major portions thereof.

- Certified standard design: a design certification issued by the NRC that constitutes approval of a nuclear power plant design, independent of an application to construct or operate a plant. A design certification is valid for 15 years from the date of issuance but can be renewed for an additional 10 to 15 years.

An application for a COL may reference a standard design certification (10 CFR 52.47), an ESP (10 CFR 52.17), both, or neither [37]. This approach allows early resolution of safety and environmental issues to 
prevent potential costly delays in obtaining an OL under 10 CFR 50 while matters that arose during plant construction are addressed. The issues resolved by the design certification rulemaking process and during the ESP hearing process are not reconsidered during the COL review.

10 CFR 52.47 describes the information to be included at an appropriate level in final safety analysis reports supporting applications for standard design certifications, and 10 CFR 52.137 describes the information to be included at an appropriate level in final safety analysis reports supporting standard design approvals.

If the application references a standard design certification (10 CFR 52.47), then the applicant must perform the ITAAC for the certified design and the site-specific design features. If the application does not reference a standard design certification, then the applicant must provide complete design information, including the information that would otherwise have been submitted for a standard design certification.

If the application references an ESP (10 CFR 52.17), then the applicant must demonstrate that the design of the plant is compatible with the ESP.

If the application does not reference an ESP, then the applicant must provide the site information that would be included in an ESP and must also include a complete emergency plan.

\subsubsection{Combined License (COL)}

The application for a COL must provide a standard design or reference a certified standard design. The application must contain the proposed inspections, tests, and analyses that the licensee shall perform, including those applicable to EP. The licensee shall also submit an environmental report, either in accordance with 10 CFR 51.50(c) if an LWA under 10 CFR 50.10 is not requested in conjunction with the COL application, or in accordance with 10 CFR 51.49 and 10 CFR 51.50(c) if an LWA is requested in conjunction with the COL application.

A licensee shall not operate the facility until the NRC makes a finding that the acceptance criteria in the COL are met, except for those acceptance criteria that the NRC found were met under 10 CFR 52.97(a)(2) (i.e., the ITAAC).

\subsubsection{Manufacturing License (10 CFR 52)}

The NRC's licensing processes generally assume that a nuclear power plant will be built in the location where it will be operated. A manufacturing license can be obtained under 10 CFR 52.167 if "there is reasonable assurance that the reactor(s) will be manufactured, and can be transported, incorporated into a nuclear power plant, and operated in conformity with the manufacturing license, the provision of the [Atomic Energy] Act, and the Commission's regulations."

Reactor options at the Eastman site would likely have a sizeable portion of factory-built reactor and supporting modular assemblies. Thus, an applicant may apply under 10 CFR 52 Subpart F for a license to manufacture a nuclear power plant that will be fabricated at one location but sited and operated elsewhere.

The manufacturing license requires that each application for a manufacturing license specify:

- technical specifications for operation of the manufactured reactor;

- site parameters and design characteristics for the manufactured reactor; and

- the interface requirements to be met by the site-specific elements of the facility - such as the service water intake structure and the ultimate heat sink - that are not within the scope of the manufactured reactor. 
Under the manufacturing license, a reactor can only be delivered to a fixed site where a licensee holds a CP or a COL. 10 CFR 52.167(c)(1) states that "A holder of a manufacturing license may not transport or allow to be removed from the place of manufacture the manufactured reactor except to the site of a licensee. The licensee construction permit or combined license must authorize the construction of a nuclear power facility using the manufactured reactor(s)."

The manufacturing license provision in $10 \mathrm{CFR}$ 52, Subpart F, allows for a license to be issued that authorizes the manufacture of reactors, including their associated nuclear steam supply system (NSSS) and balance of plant (BOP). A CP will not be issued for a particular site until the relevant manufacturing license has been issued. However, the manufacturing license does not authorize installation of reactors at the sites where the reactors are to be operated. A CP under 10 CFR 50, or a COL under 10 CFR 52, would be required for those activities.

The site parameter issues that fall under the AEA and National Environmental Policy Act (NEPA) will not involve consideration of the particular sites where any of the reactors to be manufactured will be located and operated [38]. These issues will be the subject of the CP associated with the particular sites.

The contents of the application for the licensee that will be operating the reactor must provide reasonable assurance that the reactor has been manufactured in conformity with the manufacturing license and that the manufactured reactor will be operated in conformity with the approved design and any license authorizing operation of the manufactured reactor (10 CFR 52.158).

If the application references a standard design certification, then the ITAAC contained in the certified design must apply to those portions of the facility design covered by the design certification. If the application references a standard design certification, then the application may include a notification that a required inspection, test, or analysis in the design certification ITAAC has been successfully completed and that the corresponding acceptance criterion has been met. If the manufacturing license application references a standard design certification, then the environmental report is not required to contain a discussion of severe accident mitigation design alternatives for the reactor.

\subsubsection{Hazards from Onsite and Nearby Facility}

In 10 CFR 50.34(a)(1), the NRC requires that an application for a CP include a description and safety assessment of the site on which the facility is to be located, with appropriate attention to features affecting facility design.

10 CFR 100.20(b) requires that the nature and proximity of hazards related to human activity (e.g., airports, dams, transportation routes, and military and chemical facilities) must be evaluated to establish site parameters for use in determining whether a plant design can accommodate commonly occurring hazards and if the risk of other hazards is very low.

An application for an ESP must contain the location and description of any nearby industrial, military, or transportation facilities and routes. The application for a COL must describe the general location of the site and any nearby industrial, military, or transportation facilities and routes.

Descriptions of the nature and extent of activities conducted at the site and in its vicinity - including the products and materials likely to be processed, stored, used, or transported and sufficient statistical data with respect to hazardous materials - should be provided to establish a basis for evaluating the potential hazards to the plant or plants considered at the site [39]. The orientation of plant structures with respect to nearby roads, railroads, and waterways should illustrate that there is no obvious way that transportation routes traversing the EA can interfere with normal plant operations. 
Onsite or nearby facilities that could pose a risk to safe reactor operation include (1) onsite compressed or liquid hydrogen and propane and (2) industrial, transportation, or military facilities that could involve the use of hazardous materials (e.g., oil or toxic chemicals) or pose other risks (e.g., a barge collision with an intake structure or an airplane crash at the site). If unfavorable physical characteristics exist, then the proposed site may be found acceptable if the facility design includes appropriate and adequate engineering safeguards to compensate for the observed deficiencies [39].

NRC also evaluates hazards on transportation routes near nuclear plants, such as:

1. hazards associated with nearby industrial activities such as manufacturing, processing, or storage facilities;

2. hazards associated with nearby military activities, such as military bases, training areas, or aircraft flights; and

3. hazards associated with nearby transportation routes (aircraft routes, highways, railways, navigable waters, and pipelines).

The following principal types of hazards will be considered with respect to each of the above areas of review:

4. toxic vapors or gases and their potential for incapacitating nuclear plant control room operators;

5. overpressure resulting from explosions or detonations involving materials such as munitions, industrial explosives, or explosive vapor clouds resulting from the atmospheric release of gases (such as propane and natural gas or any other gas) with a potential for ignition and explosion;

6. missile effects attributable to mechanical impacts, such as aircraft impacts, explosion debris, and impacts from waterborne items such as barges; and

7. thermal effects attributable to fires.

Any hazards associated with a co-located industrial facility require evaluation. The closer the industrial facility to the reactor, which will depend on the source term and EAB, the greater the potential hazards and risk to the reactor. However, the closer the co-located facility the greater the efficiency of the process.

Co-generation concerns for an industrial facility that uses process heat from a nuclear power plant are sitespecific issues. Once a license application is received, the NRC staff will review how the nuclear facility is connected to the industrial facility, consider the interrelationship between the staffs of both facilities, consider white papers or topical reports concerning this issue that it receives from potential SMR applicants, discuss design-specific proposals to address this matter, and review similar activities with nuclear and nonnuclear facilities [40].

For all IES systems, and not just Eastman alone, the close coupling of the nuclear and process facilities raises concerns involving interface requirements and regulatory jurisdiction issues. Effects of the reactor on the commercial product of the industrial facility during normal operation must also be considered.

\subsection{EASTMAN FACILITY SITING CONSIDERATIONS}

Siting criteria for power reactors is found in regulations and in various guidance documents. The ability to visualize the various criteria is of tremendous value in evaluating potential sites. Protecting the public from excessive dose (health and safety of the public) and safeguarding the environment are at the core of siting requirements. 


\subsubsection{Reactor Siting Regulations}

The requirements for siting a power reactor are found in 10 CFR 100, Reactor Site Criteria [41]. Definitions of siting terminology are provided in 10 CFR 100.3. The requirements in 10 CFR 100 Subpart B apply to new reactor applications. The factors to be considered for siting are listed in 10 CFR 100.20 and are summarized below:

- population density and use characteristics of the site environs, including the EA and the population distribution; per 10 CFR 100.3:

- exclusion area (EA) is the area surrounding the reactor, in which the reactor licensee has the authority to determine all activities including exclusion or removal of personnel and property from the area;

O low population zone (LPZ) is the area immediately surrounding the EA which contains residents, the total number and density of which are such that there is a reasonable probability that appropriate protective measures could be taken in their behalf in the event of a serious accident;

- $\quad$ societal risk associated with potential plant accidents;

- unique physical characteristics of the proposed site that could pose a significant impediment to the development of emergency plans;

- the nature and proximity of human-related hazards (e.g., airports, dams, transportation routes, military and chemical facilities); and

- physical characteristics of the site, including seismology, meteorology, geology, and hydrology.

These criteria are further explained in 10 CFR 100.21, Non-Seismic Siting Criteria, and 10 CFR 100.23, Geologic and Seismic Siting Criteria. Applications for site approval for commercial power reactors shall demonstrate that the proposed site meets the criteria summarized below:

- Every site must have an EA and an LPZ.

- The population center distance must be at least one and one-third times the distance from the reactor to the outer boundary of the low population zone (Per 10 CFR 100.3, population center distance is the distance from the reactor to the nearest boundary of a densely populated center containing more than about 25,000 residents).

- Site atmospheric dispersion characteristics must be evaluated such that:

- radiological effluent release limits associated with normal operation from the type of facility proposed to be located at the site can be met for any individual located offsite, and

- radiological dose consequences of postulated accidents shall meet the criteria set forth in 10 CFR 50.34(a)(1), as follows:

- an individual located at any point on the EAB for any 2-hour period following the onset of the postulated fission product release would not receive a radiation dose in excess of 25 rem total effective dose equivalent (TEDE), and

- an individual located at any point on the outer boundary of the LPZ who is exposed to the radioactive cloud resulting from the postulated fission product release (during the entire period of its passage) would not receive a radiation dose in excess of 25 rem TEDE.

- The physical characteristics of the site must be evaluated and site characteristics must be established such that potential threats from such physical characteristics will pose no undue risk to the proposed facility.

- Potential hazards associated with nearby transportation routes, or with industrial and/or military facilities must be evaluated, and site characteristics must be established such that potential hazards from such routes and facilities will pose no undue risk to the proposed facility.

- Site characteristics must be such that adequate security plans and measures can be developed. 
- Physical characteristics unique to the proposed site that could pose a significant impediment to the development of emergency plans must be identified.

- Reactor sites should be located away from very densely populated centers. Areas of low population density are generally preferred. However, in determining the acceptability of a particular site located away from a very densely populated center but not in an area of low density, consideration will be given to safety, environmental, economic, or other factors, which may result in the site being found acceptable.

- The geologic and seismic siting factors considered for design must include a determination of the safe shutdown earthquake ground motion, which is the vibratory ground motion for which certain structures, systems, and components must be designed.

\subsubsection{Oak Ridge Siting Analysis for Power Generation Expansion (OR-SAGE)}

ORNL has developed a siting process tool that considers many of the siting requirements noted above. The tool, Oak Ridge Siting Analysis for power Generation Expansion (OR-SAGE), is based on guidance provided in Regulatory Guide (RG) 4.7, General Site Suitability Criteria for Nuclear Power Stations [42], and the 2002 Electric Power Research Institute (EPRI) Siting Guide, Siting Guide: Site Selection and Evaluation Criteria for an Early Site Permit Application [43]. These guidance documents provide insights on the regulatory criteria listed above.

The OR-SAGE tool has been used to support numerous power plant siting evaluations [44]. The objective in developing OR-SAGE was to use industry-accepted approaches and/or develop appropriate criteria for screening sites for a power generation technology application. The basic premise requires the development of exclusionary, avoidance, and suitability criteria to evaluate sites for a given siting application such that of as siting SMRs. For specific applications of the tool, it is necessary to develop site selection and evaluation criteria (SSEC) that encompass several key benchmarks that essentially form the site environmental characterization for that application. In consideration of the regulatory and guidance materials, ORNL staff developed a subset of SSECs for nuclear plant siting that were considered to have the most impact on the viability of any given site and that were directly amenable to the application of spatial techniques associated with geographic information systems (GIS). These SSEC might include applications of GIS data for population density, ground slope, seismic activity, proximity to cooling water sources, proximity to hazardous facilities, avoidance of protected lands and floodplains, susceptibility to landslide hazards, and others. Applying SMR-centric screening criteria in OR-SAGE provides the ability to characterize potential SMR sites. The siting analysis for the Eastman Chemical Plant site documented in this report is conducted using an array of GIS data sources available at ORNL.

In essence, OR-SAGE is a visual, relational database. The SSECs are the fields of the database, and the GIS data for a given variable represent the values against which searches are performed. Each graphic result is a static response to an input query and not an ultimate depiction of the power plant siting opportunity for the area of interest. However, well-crafted SSECs do give a reasonable picture of the siting opportunities. The database partitions the contiguous United States, a total of 7.2E8 hectares ( 1.8 billion acres), into 100 $\times 100 \mathrm{~m}$ ( 1 hectare or $\sim 2.5$ acre) squares (cells). Therefore, the database is tracking just under 700 million individual land cells for the contiguous US terrain (48 adjacent states). For a site evaluation like that for the Eastman Plant site in Kingsport, Tennessee, only the $100 \times 100 \mathrm{~m}$ cells in the immediate site vicinity are displayed and evaluated.

For a complete reference on the OR-SAGE process, a national look at siting LWR-based SMRs completed in 2012 for DOE-NE provides significant background material on the application of the OR-SAGE tool to SMRs [45]. The 2012 report outlines the approach ORNL developed for screening the various power supply sites of interest to DOE-NE, the methodology employed, including spatial modeling, and initial results for the contiguous United States. 


\subsubsection{Evaluation of the Eastman Site}

Datasets with attributes matching the desired SSECs are selected. The specific SSECs identified for each power source are detailed as part of the results discussion for each power source. Greater than national coverage is preferred to prevent map "edge-effects." Appropriate scaling and resolution of each dataset must be considered before a dataset is used in the study. There are more than 30 datasets supporting the SMR evaluations. The dataset sources include:

- US Geological Survey (USGS),

- US National Park Service,

- US Forest Service,

- US Fish and Wildlife Service,

- US Department of Transportation,

- Federal Emergency Management Agency,

- Federal Aviation Administration (FAA),

- US Census Bureau,

- ORNL LandScan ${ }^{\mathrm{TM}}$ data (a high-resolution population distribution database developed by ORNL),

- ORNL 7-day, 10-year low flow calculated data, and

- other commercial sources.

Some data layers involve generating an appropriate selection query and applying a buffer zone. The application of the buffer zone can be a complex process. For example, one of the SMR power plant SSECs is a population density of less than 500 people per square mile (ppsm). RG 4.7 indicates that "a reactor should preferably be located such that, at the time of initial site approval and within about 5 years thereafter, the population density, including weighted transient population, averaged over any radial distance out to 20 miles (cumulative population at a distance divided by the circular area at that distance), does not exceed 500 persons per square mile." To meet the guidance, each cell in the database is queried for ambient population, which considers the weighted transient population. If a cell population is greater than $500 \mathrm{ppsm}$, it is immediately excluded. If a cell population is less than $500 \mathrm{ppsm}$, the surrounding area is evaluated by calculating the population density in an expanding set of rings out to a maximum of 20 miles (in simple terms, a buffer zone). If any ring is calculated to have a population density above $500 \mathrm{ppsm}$, then the center cell is excluded. If no ring around the central cell exceeds a population density of $500 \mathrm{ppsm}$, then the cell remains viable regarding population.

\subsubsection{Nominal SMR Site Selection and Evaluation Criteria}

The Eastman plant analysis characterizes suitable areas for near-term SMRs as part of a hybrid energy system and longer term SMRs. Near-term SMRs are based on LWR technology with compact design features that are expected to offer a host of safety, siting, construction, and economic benefits. Longer term SMRs are based on non-LWR technology which may operate at lower pressures and use air-cooled decay heat removal. These smaller plants are ideally suited for direct energy applications, small electric grids, and locations that cannot support large reactors. The smaller plants provide licensees with the flexibility to scale power production as demand changes by deploying additional power modules or reactors in phases.

The selected SMR SSEC for the nominal SMR power plants operating at $600 \mathrm{MW}$ (e) or less (nominally bounded by a 12-module NuScale plant) are based on providing a high level of discrimination and readily available data. A summary of the SSECs selected for SMR siting is provided here, and a more detailed discussion of each individual SSEC follows below. 
1. population proximity,

2. wetlands and open water,

3. protected lands,

4. land with a moderate or high landslide hazard susceptibility,

5. land within a 100-year floodplain,

6. land with slope concerns,

7. areas greater than 20 miles from cooling water makeup sources with at least $65,000 \mathrm{gpm}$,

8. land within a standoff distance to identified fault lines (length of fault line determines standoff distance),

9. proximity to hazardous facilities (airports and oil refineries), and

10. safe shutdown earthquake peak ground acceleration ( 2 percent chance in a 50-year return period) greater than $0.5 \mathrm{~g}$.

Based on preliminary design information and expert judgment, it is assumed that the SMR base design package (single unit or multi-module) from each vendor can easily be accommodated on a bounding 50acre footprint. For example, NuScale touts a footprint of 35 acres for its 600 MWe 12-module plant [46]. Holtec projects a 5-acre footprint for its $160 \mathrm{MWe}$ SMR. ${ }^{15}$ The high-temperature Westinghouse microreactor is projected to fit on 0.1 acres [47].

\subsubsection{Geologic Factors}

RG 4.7 notes that, in general, "the most restrictive safety-related site characteristics considered in determining the suitability of a site are surface faulting, potential ground motion and foundation conditions (including liquefaction, subsidence, and landslide potential), and seismically induced floods." Guidance to the NRC staff reviewing an applicant's SAR includes specific mention of data on vibratory ground motion, tectonic and non-tectonic surface deformation, earthquake recurrence rates, fault geometry and slip rates, site foundation material, and seismically induced floods and water waves. Appendix S to 10 CFR 50 succinctly notes that:

Each applicant is required by 10 CFR 50.34(a)(12), 50.34(b)(10), or 10 CFR 52.79(a)(20), and General Design Criterion 2 of Appendix A to this part, to design nuclear power plant SSC [structures, systems, and components] important to safety to withstand the effects of natural phenomena, such as earthquakes, without loss of capability to perform their safety functions.

Therefore, all nuclear plants must consider proximity to fault lines, seismic restrictions, and landslides as public safety issues. The smaller structures associated with SMR designs should allow greater flexibility in designing to higher seismic conditions, including seismic isolators. The peak acceleration value is variable within the OR-SAGE database and can be adjusted. The baseline cutoff value in the database has been set higher (less limiting) for SMRs than for large LWRs. The standoff distance to fault lines is limited within OR-SAGE by an algorithm that implements Table 1 of 10 CFR 100, Appendix A. This is not variable within the database. Landslide hazard is based on a USGS risk assessment, and broad areas with medium risk and higher are excluded. Although the OR-SAGE setting is not variable, the landslide hazard information is intended to be informational but not exclusionary.

Steeper slopes are avoided by the database based on the economic cost of preparing a site for construction. Initial OR-SAGE studies for large reactor sites limited the slope to $12 \%$ based on the 2002 EPRI guidance. Since SMR designs have a significantly smaller footprint, this value was relaxed to $18 \%$, recognizing that

\footnotetext{
${ }^{15}$ https://smrllc.com/technology/smr-160-overview/ accessed 2/11/2020
} 
more extensive site work to prepare a relatively small site may be justifiable. This value is variable within the database.

Many SMR vendors expect to place their reactors fully or partially underground, potentially providing better flexibility and resilience to the geologic factors listed above. The geologic factors are shown in Figure 28, Figure 29, and Figure 30.

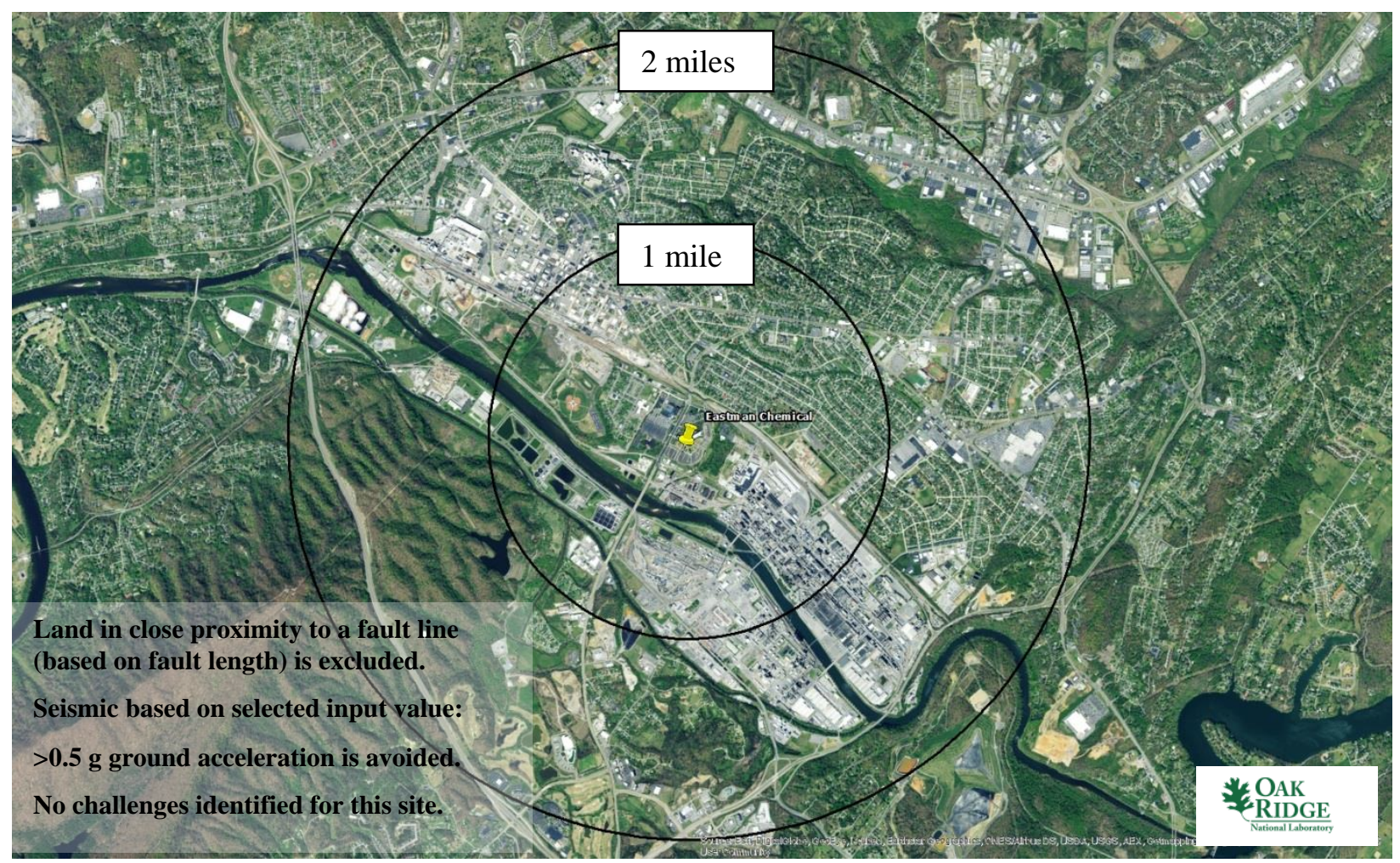

Figure 28. Eastman site SMR fault line proximity and safe shutdown earthquake SSEC layers. 


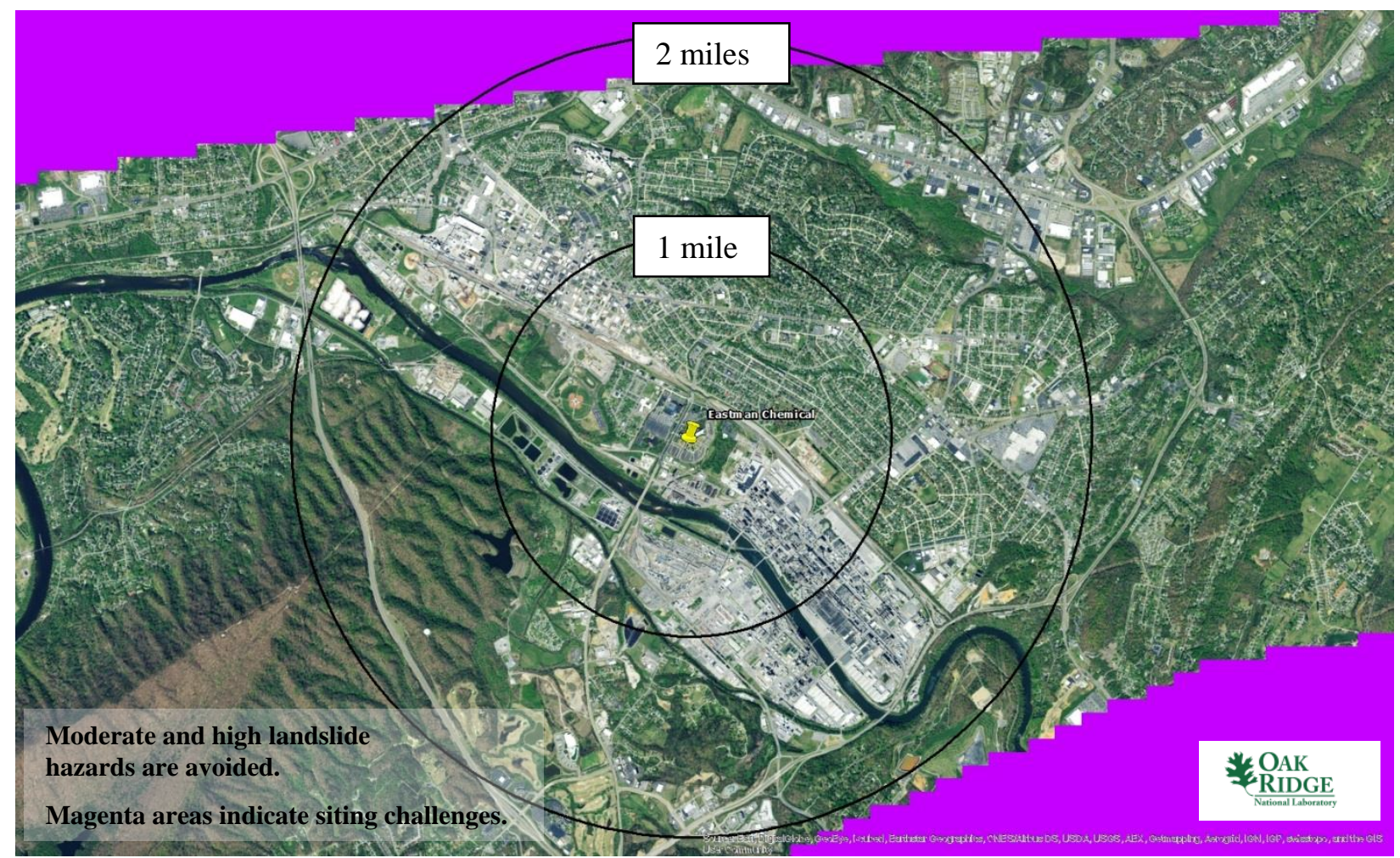

Figure 29, Eastman site SMR landslide hazards SSEC layer.

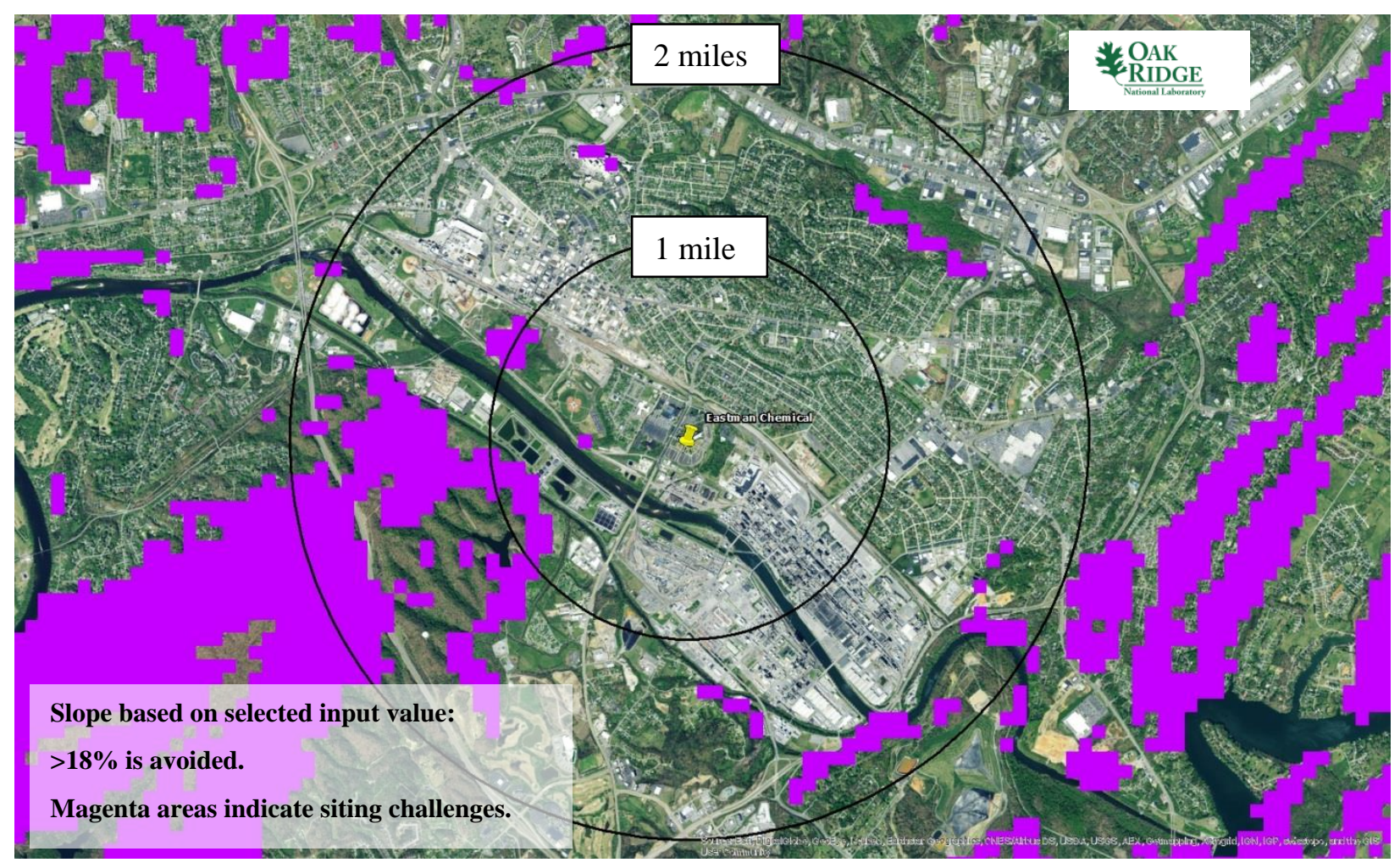

Figure 30. Eastman site SMR high slope SSEC layer. 


\subsubsection{Protected Lands and Hazardous Facilities}

Protected lands would include public property considered to have high value to the community such as historic landmarks, national parks, national monuments, national forests, wilderness areas, wildlife refuges, wild and scenic rivers, state parks, county parks, American Indian lands, and public facilities including schools, libraries, places of worship, and hospitals. These lands, shown in Figure 31 for the Eastman site, are excluded based on their public nature.

Hazardous facilities include military facilities, chemical plants, and commercial airports. These areas are noted for their potential to interact with a nuclear power plant. A variable buffer is placed around these locations to indicate that any possible risk from these facilities on the SMR site should be evaluated further. For example, a potential SMR site may be close to a nearby commercial airport or a runway associated with a military base and appear to be excluded. For example, the Tri-Cities Regional Airport is approximately 8 miles southeast of the Eastman property. However, the main runway is parallel to the plant, so there is little added risk to the Eastman property from airport operations. The airport exclusion is shown in Figure 32.

In this case, the site itself is a chemical facility which includes a hydrogen production facility (exclusions are not shown); there are railways running through the site; and there is a military ammunition production facility nearby (out of the frame). The major considerations required to take these factors into account would include ensuring that adequate boundaries are established to withstand common and abnormal casualties of these different hazardous facilities.

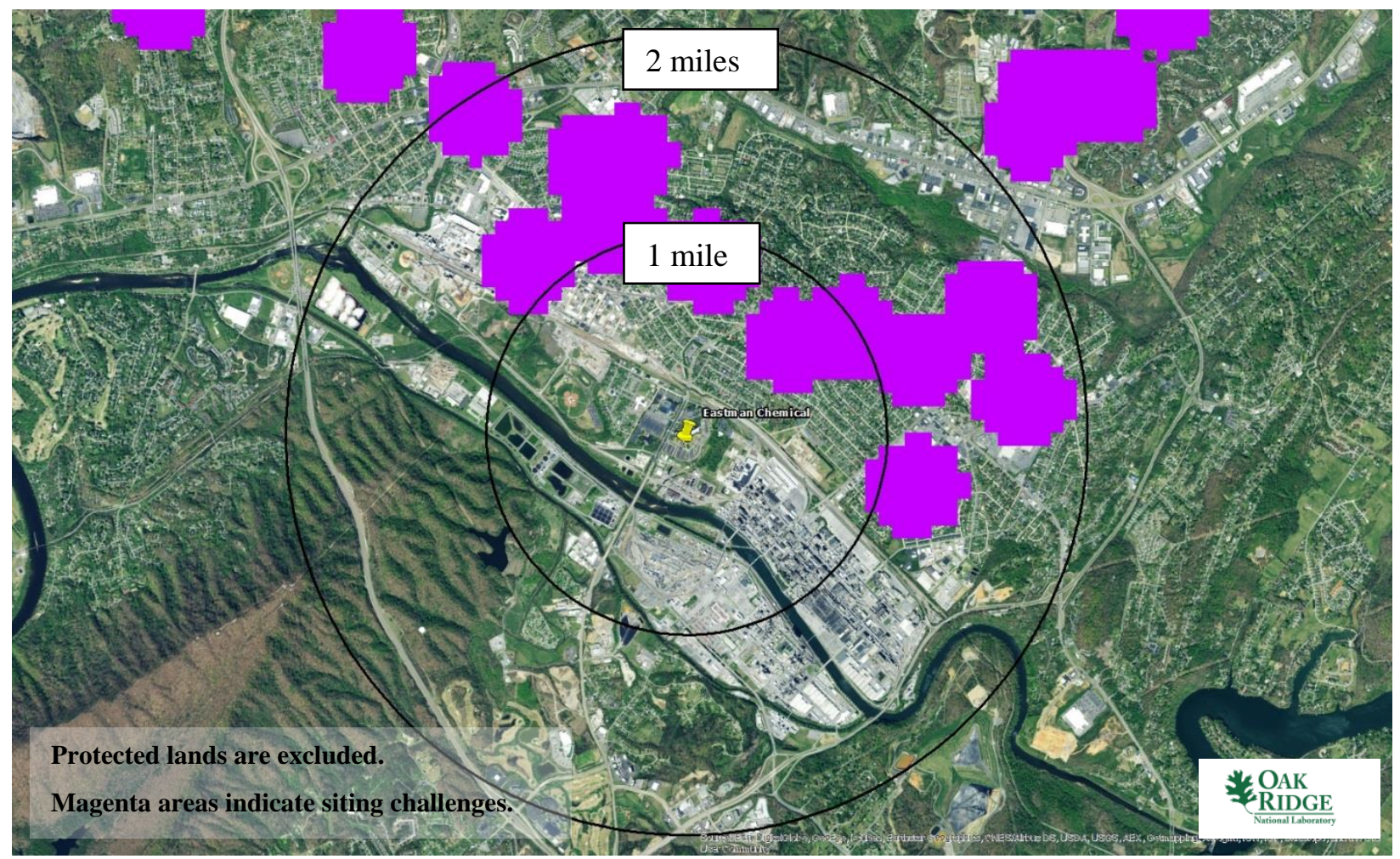

Figure 31. Eastman site SMR protected lands SSEC layer. 


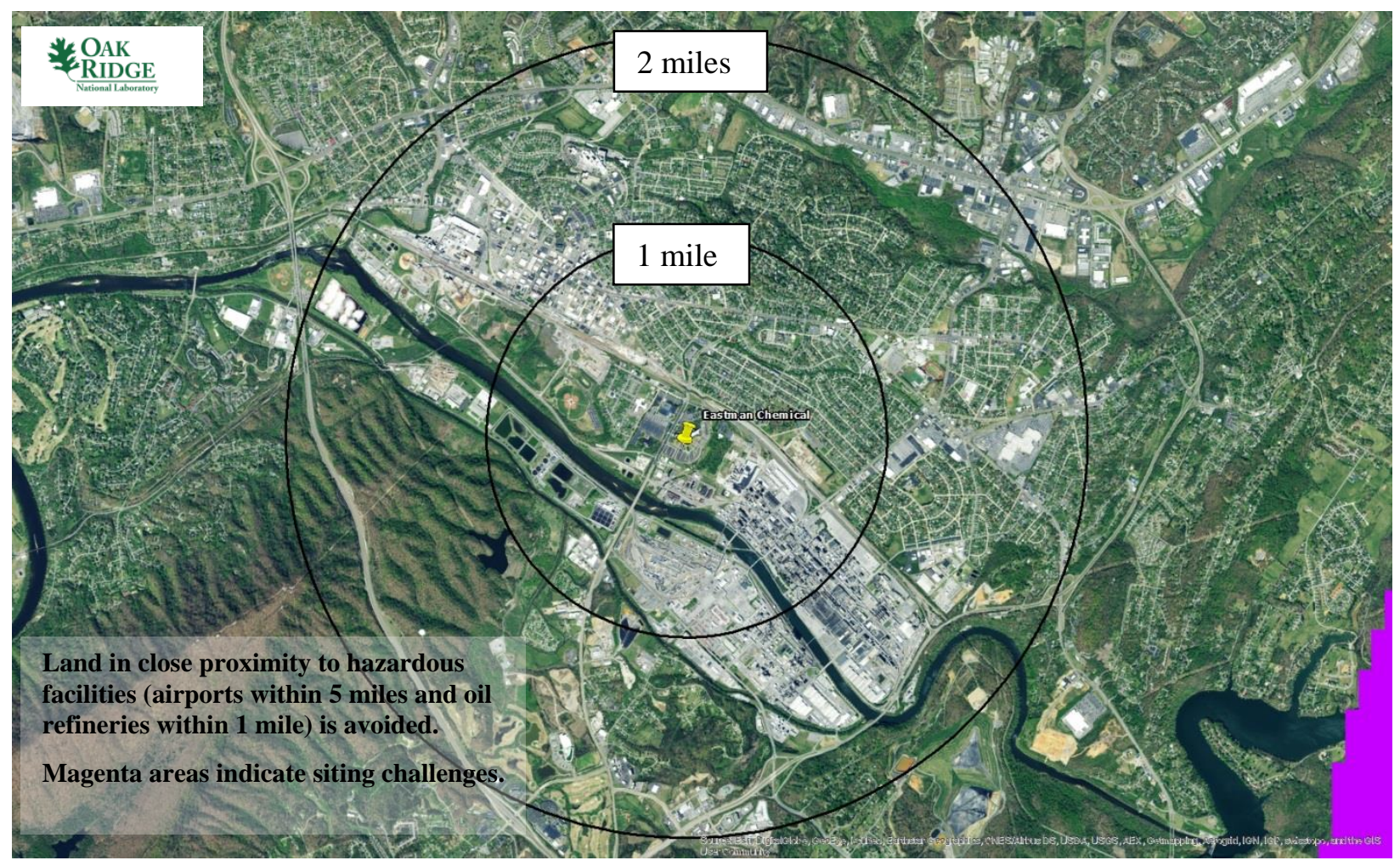

Figure 32. Eastman site proximity to hazards SSEC layer.

\subsubsection{Water}

Cooling water makeup requirements are based on rules of thumb for cooling water makeup as required per megawatt of generation (NETL 2009). These rules of thumb are consistent with environmental analyses supporting site evaluations that have been submitted to the NRC. The OR-SAGE SMR value of 65,000 gpm was selected to bound the largest MWe rating of the nominal vendor configuration of the US SMR designs under consideration - the bounding SMR and the assumption that cooling water makeup should be limited to taking no more than $10 \%$ of the available stream flow. OR-SAGE looks for acceptable makeup water values within 20 miles of a perspective site. Based on engineering judgement and expected cost, 20 miles is within reasonable proximity to a cooling water source, allowing for piping and pumps. Any of the SMR designs with a lower installed capacity would require less stream flow and thus would increase the candidate areas available for siting. As shown in Figure 33, the Eastman plant is not impacted by this parameter due to the immediate proximity to the South Fork of the Holston River.

Advanced reactor designs that remove decay heat and waste heat using ambient air or a medium other than water do not need to consider the cooling water makeup layer imbedded in the OR-SAGE database. Likewise, water-cooled plants that have sufficient water onsite for long-term decay heat removal do not need to consider cooling water makeup.

Additional water-related concerns include proximity to wetlands, open water, and floodplains. These parameters, shown in Figure 34 and Figure 35, are considered siting exclusions and are not variable within the database. An SMR would not be sited within one of these defined areas. 


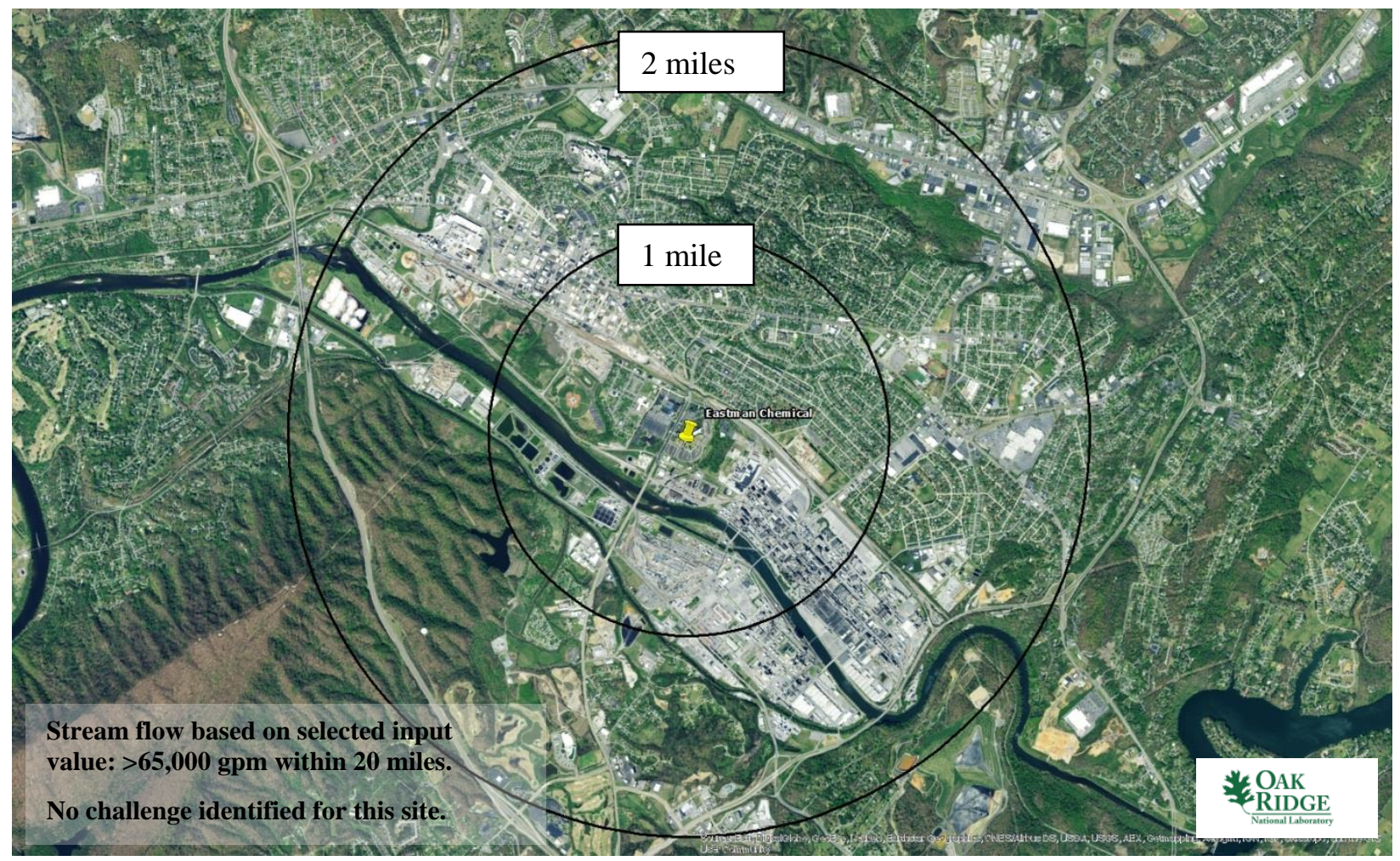

Figure 33. Eastman site SMR minimum low stream flow SSEC layer. Stream flow is conservatively calculated using USGS low stream flow data and existing lakes and reservoirs with average flows above 65,000 gpm.

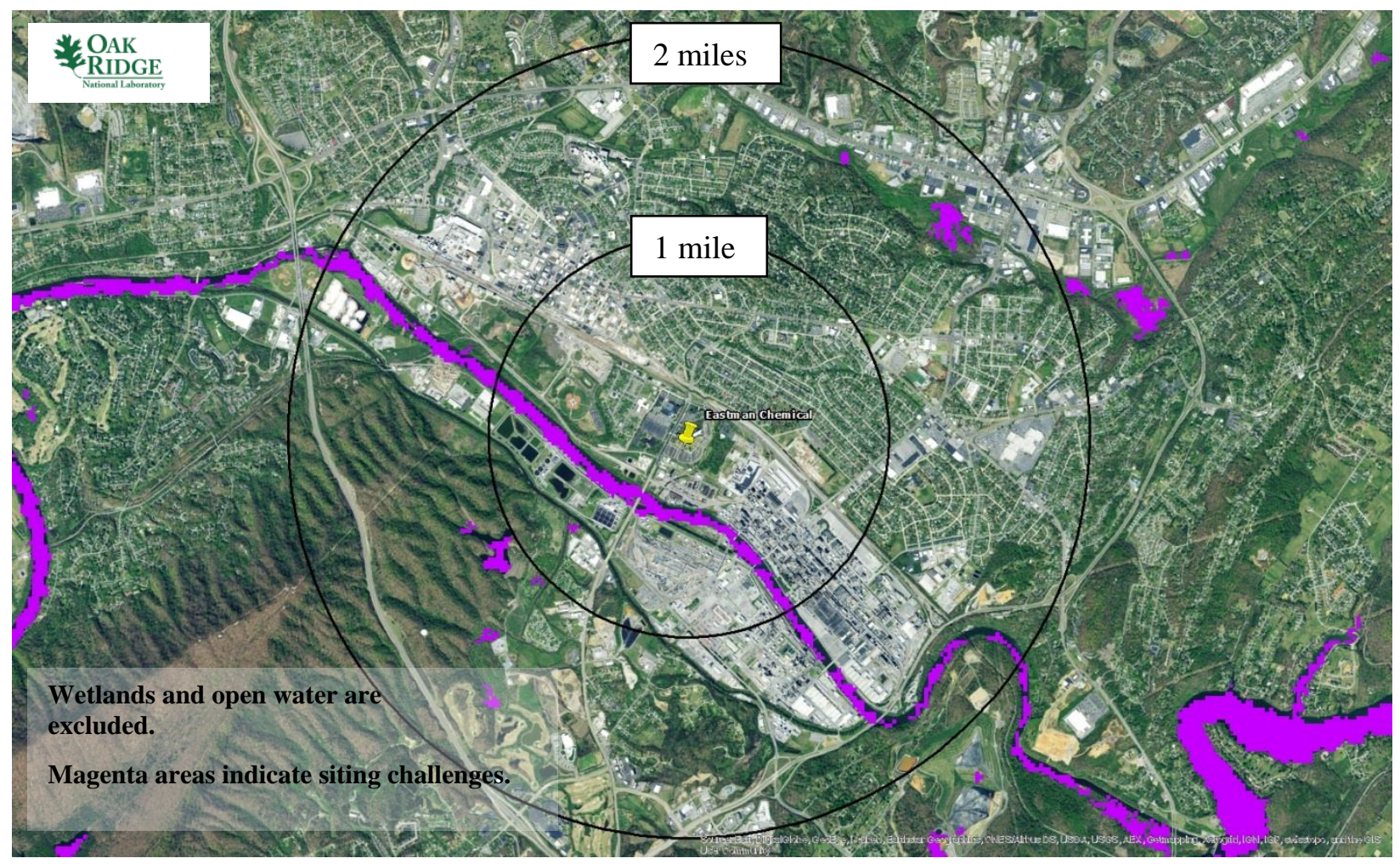

Figure 34. Eastman site SMR wetlands and open water SSEC layer. 


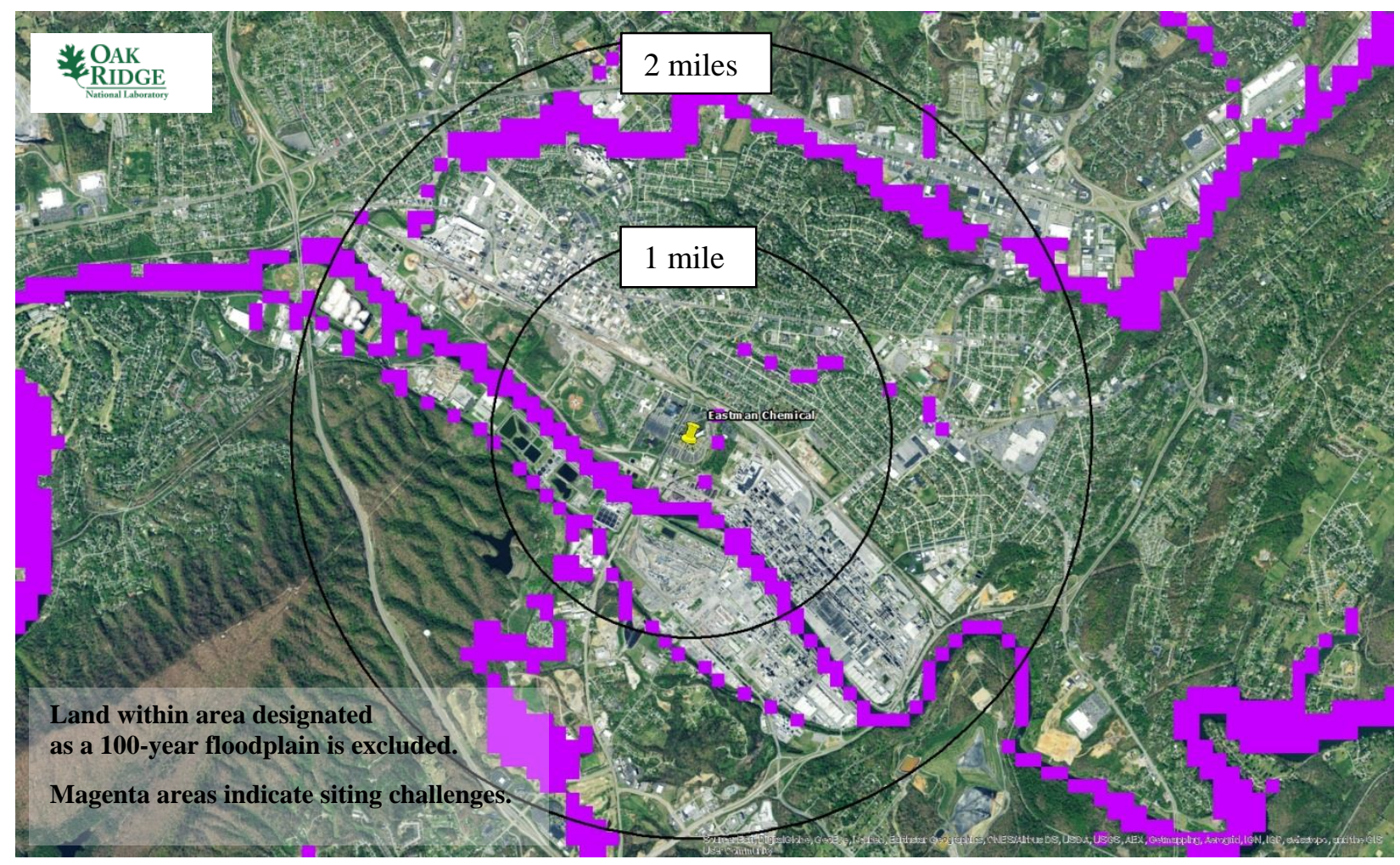

Figure 35. Eastman site SMR 100-year floodplain SSEC layer.

\subsubsection{Population Considerations}

Population densities of greater than 500 ppsm begin to transition into an urban setting. Current siting guidance provided in NRC RG 4.7 suggests that licensees should avoid siting nuclear plants within 20 miles of population densities that exceed 500 ppsm or areas that are projected to exceed such a density over the next 5 years. This is intended to ensure that reactor siting meets the requirements of 10 CFR 100 with respect to population centers of 25,000 residents or more. Such guidance would exclude any site on or in the vicinity of the Eastman property in Kingsport, Tennessee. In addition, EP requirements found in 10 CFR 50.47 require consideration be given to a 10-mile radius for an accident plume exposure pathway and a 50-mile radius for an accident ingestion pathway. This could lead to a prohibitive EP expense associated with the operation of a nuclear facility on the Eastman site.

However, the siting guidance has a somewhat arbitrary history, and changes are under consideration by the NRC. Specifically, the staff has submitted SECY-18-0103, Proposed Rule: Emergency Preparedness for Small Modular Reactors and Other New Technologies (RIN 3150-AJ68; NRC-2015-0225) [48], to the NRC for their consideration. SECY-18-0103 proposes amended SMR EP regulations and guidance based on the expected reduction in the source term for SMRs and other advanced reactors. For reactors in the size category that will likely meet Eastman's needs, Draft Guide 1350, Performance-Based Emergency Preparedness for Small Modular Reactors, Non-Light-Water Reactors, and Non-Power Production or Utilization Facilities [49], suggests that EP for the plume exposure pathway be determined by the area where the public dose is projected to exceed 1 rem TEDE over 96 hours following the release of radioactive materials from the spectrum of accidents that are credible for a given facility. For SMRs and micro-reactors, this would be expected to be much smaller than the current 10-mile plume exposure pathway that must be considered for large LWRs. 
Building on proposed revisions to the EP regulations for SMRs, NRC staff have proposed changes in the siting guidance with respect to SMRs. In a draft SECY paper for the commission, Population-Related Siting Considerations for Advanced Reactors [50], the staff recommends accessing the population density "out to a distance equal to twice the distance at which a hypothetical individual could receive a calculated [TEDE] of 1 rem over a period of 1 month from the release of radionuclides resulting from the subject event categories." The staff selected these values because they would build on the 1 rem TEDE EP calculations for the 96-hour period discussed previously. The siting requirements of 10 CFR 100 would continue to apply; however, SMR siting would be much more flexible with respect to population density.

As noted in Section 6.2.1, the EAB is based on an evaluation of radiation dose to an individual from a postulated fission-product release, for a 2-hour exposure period. Likewise, the LPZ outer boundary is determined based on an evaluation of radiation dose to an individual during the entire period of passage of a radioactive cloud resulting from a postulated fission-product release. By regulation, the outer edge of any population center with more than 25,000 residents must be 1.33 times the distance to the outer edge of the LPZ. The relationships of these areas are shown in Figure 36 (taken from an NRC staff presentation to the Advisory Committee on Reactor Safeguards on August 23, 2019).

Consider the following cases taken from the draft NRC siting SECY and the related NRC staff presentation to the Advisory Committee on Reactor Safeguards from August 23, 2019. The cases consider siting guidance for offsite doses above and below the 25-rem regulatory limit and above and below the $1 \mathrm{rem}$ guidance limit over the 30-day period proposed above.

In Case 1, shown in Figure 37, the LPZ outer boundary is at a distance beyond the EAB. In this set of postulated events, the allowable distance from the reactor to a densely populated center of approximately 25,000 residents would be no closer than 1.33 times the radius of the LPZ per 10 CFR Part 100. In addition to these requirements, the revised guidance would also assess the total population near the plant site by calling for the population density to be less than $500 \mathrm{ppsm}$ out to a distance equal to twice the distance at which an individual would be estimated to receive 1 rem over the month following any design-basis or beyond-design-basis event. The population density will be evaluated within an area that encompasses the LPZ and extends it.

In Case 2, shown in Figure 38, the LPZ outer boundary is at the EAB based on dose calculations. In this set of postulated events, the population density would be assessed against a criterion in the guidance that the population density is expected to be less than 500 ppsm out to twice the distance at which the 1 rem dose was calculated. The requirements of 10 CFR Part 100 provide an additional limitation that precludes a reactor from being within a population center of greater than approximately 25,000 residents.

In Case 3, the LPZ outer boundary is at the EAB. In this set of postulated events, there are no calculated offsite consequences in excess of 1 rem over the month following a reactor event. In Figure 39, two population centers are shown: one with more than 25,000 residents, and one with fewer than 25,000 residents. Regulations in 10 CFR 100 prevent a reactor from being sited within the boundaries of the population center, but a reactor can be sited just outside the population boundary under the circumstances provided by Case 3 . On the other hand, a reactor can be sited within a population center with less than 25,000 residents if there are no calculated offsite dose consequences in excess of 1 rem in the month following a reactor event. 


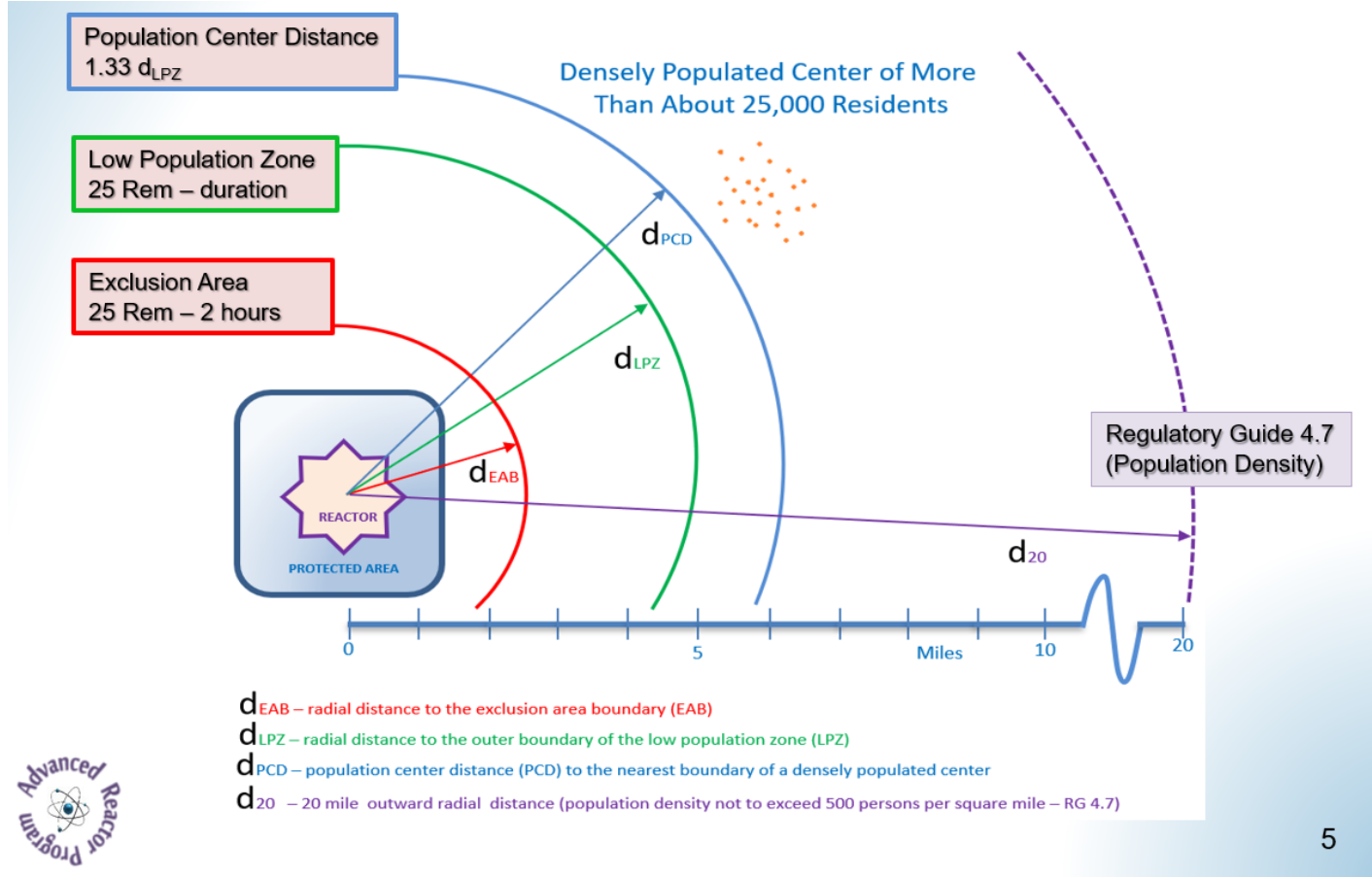

Figure 36. Limitations on populations near nuclear power plants.

Case 1:

Event Sequences with Offsite Doses $>25$ rem over course of event

Event Sequences with Offsite Doses $>1$ rem over the month following event

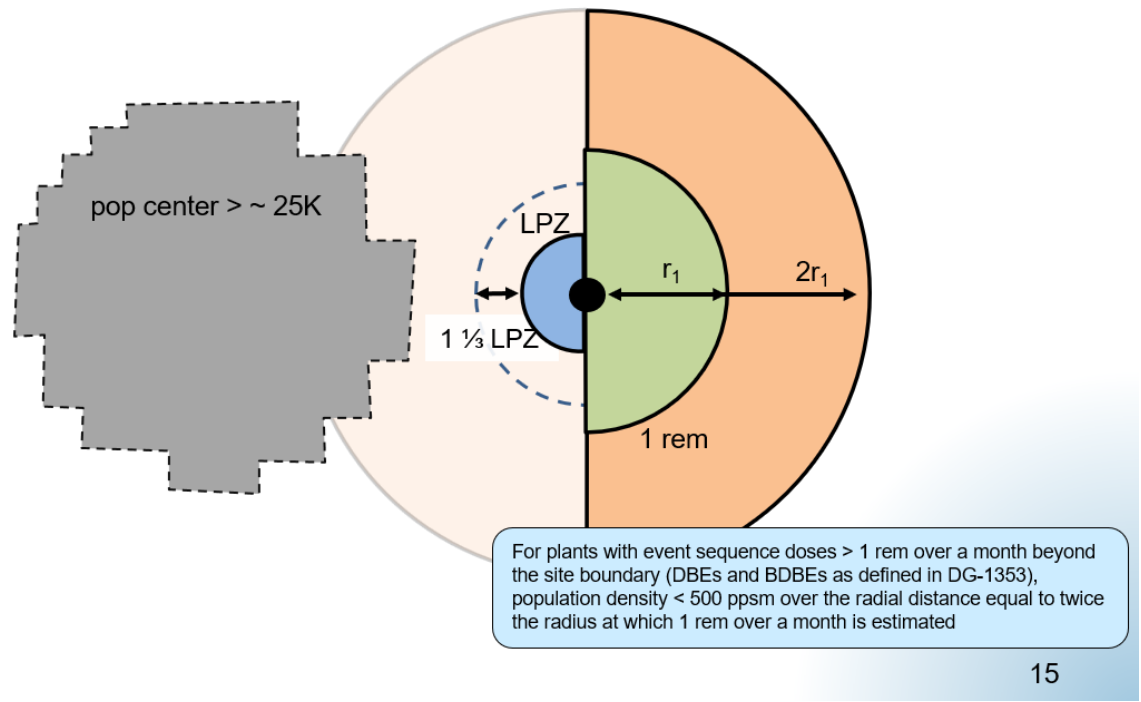

Figure 37. Proposed NRC advanced reactor siting guidance - Case 1. DBE - design basis event, BDBE - beyond design basis event. 


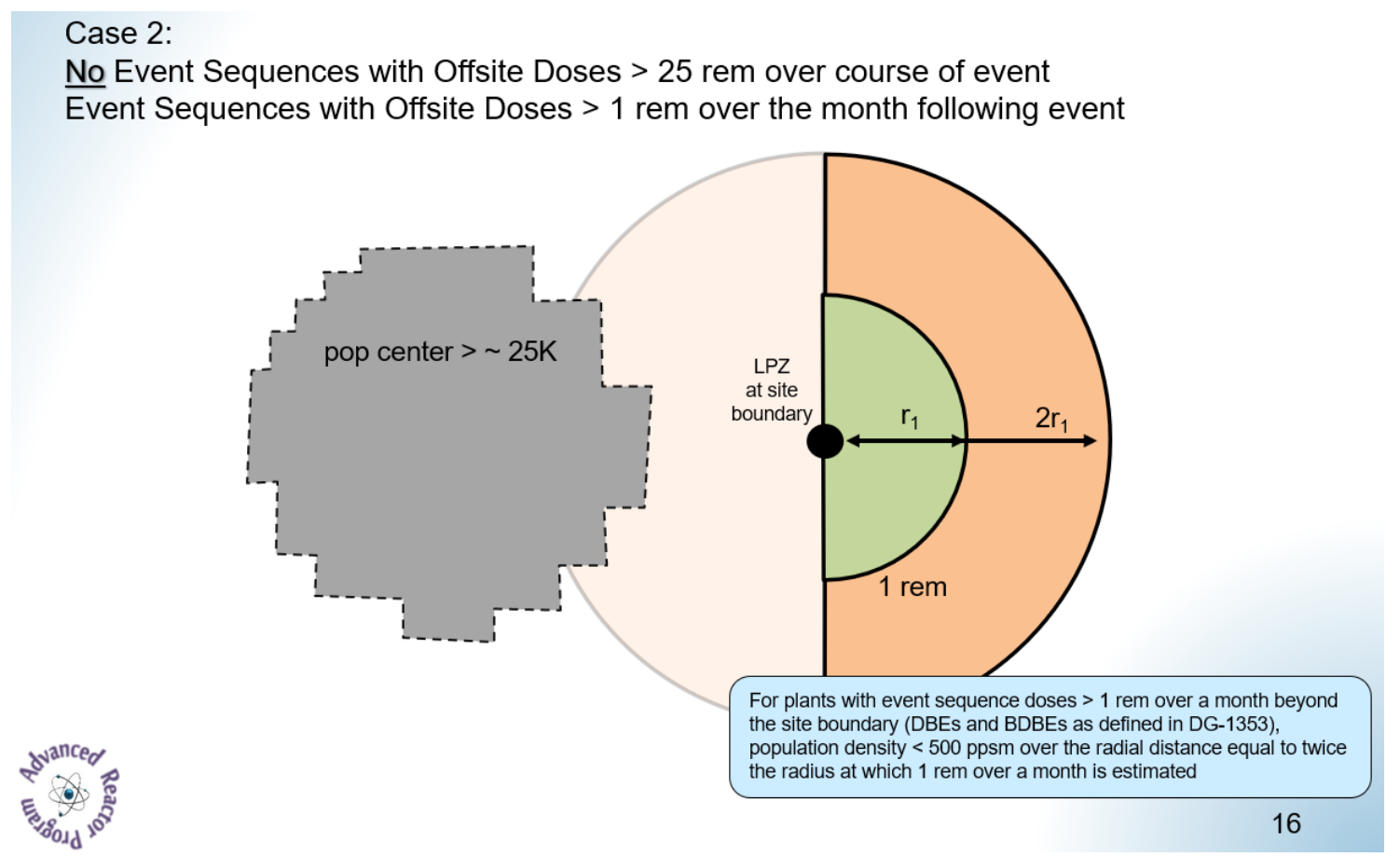

Figure 38. Proposed NRC advanced reactor siting guidance - Case 2.

\section{Case 3:}

No Event Sequences with Offsite Doses $>25$ rem over course of event (LPZ at site boundary) No Event Sequences with Offsite Doses > 1 rem over the month following event

$\underline{A}$

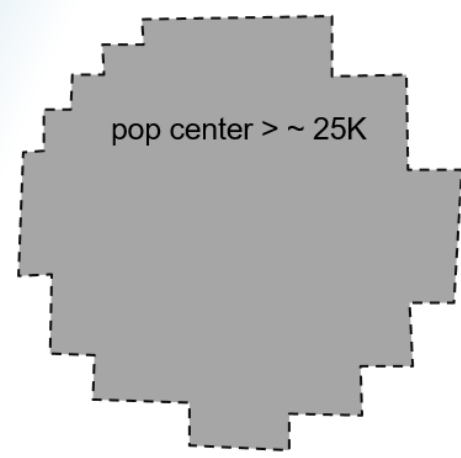

$\underline{B}$

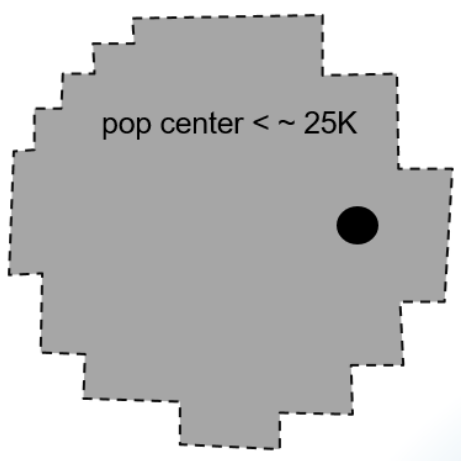

Population center distance means the distance from the reactor to the nearest boundary of a densely populated center containing more than about 25,000 residents

Figure 39. Proposed NRC advanced reactor siting guidance - Case 3.

Using current siting guidance, there is no space on or immediately adjacent to the Eastman site that supports reactor siting. However, based on the discussion above, the siting guidance related to population density for advanced reactors is under review and will change soon. In Figure 40, a translucent blue area is overlaid on a portion of the Eastman site that is furthest away from downtown Kingsport. This is intended to be an 
area of interest for siting and is not intended to be a siting recommendation. Additional sites near Eastman may be appropriate, depending on the particular reactor technology under consideration. An advanced reactor in this area is the most likely to meet revised siting requirements, depending on its footprint and source term. It is expected that advanced reactors will limit the emergency planning zone to the reactor boundary or footprint. Industrial operations would be allowed within the reactor boundary. However, any emergency response within that boundary would be dictated by the needs of the reactor. The area is southeast of South Eastman Road down to $13^{\text {th }}$ Street. This area is approximately 160 acres in size. A 600 MWe 12-module NuScale plant would require about $22 \%$ of this land space. A single 160 MWe Holtec reactor would require about $3 \%$ of this space. Multiple micro-reactors ( $25 \mathrm{MWe}$ each) could be placed on a single acre, or approximately $1 \%$ of the space. Obviously, there are tradeoffs between power level, steam generation, and space.

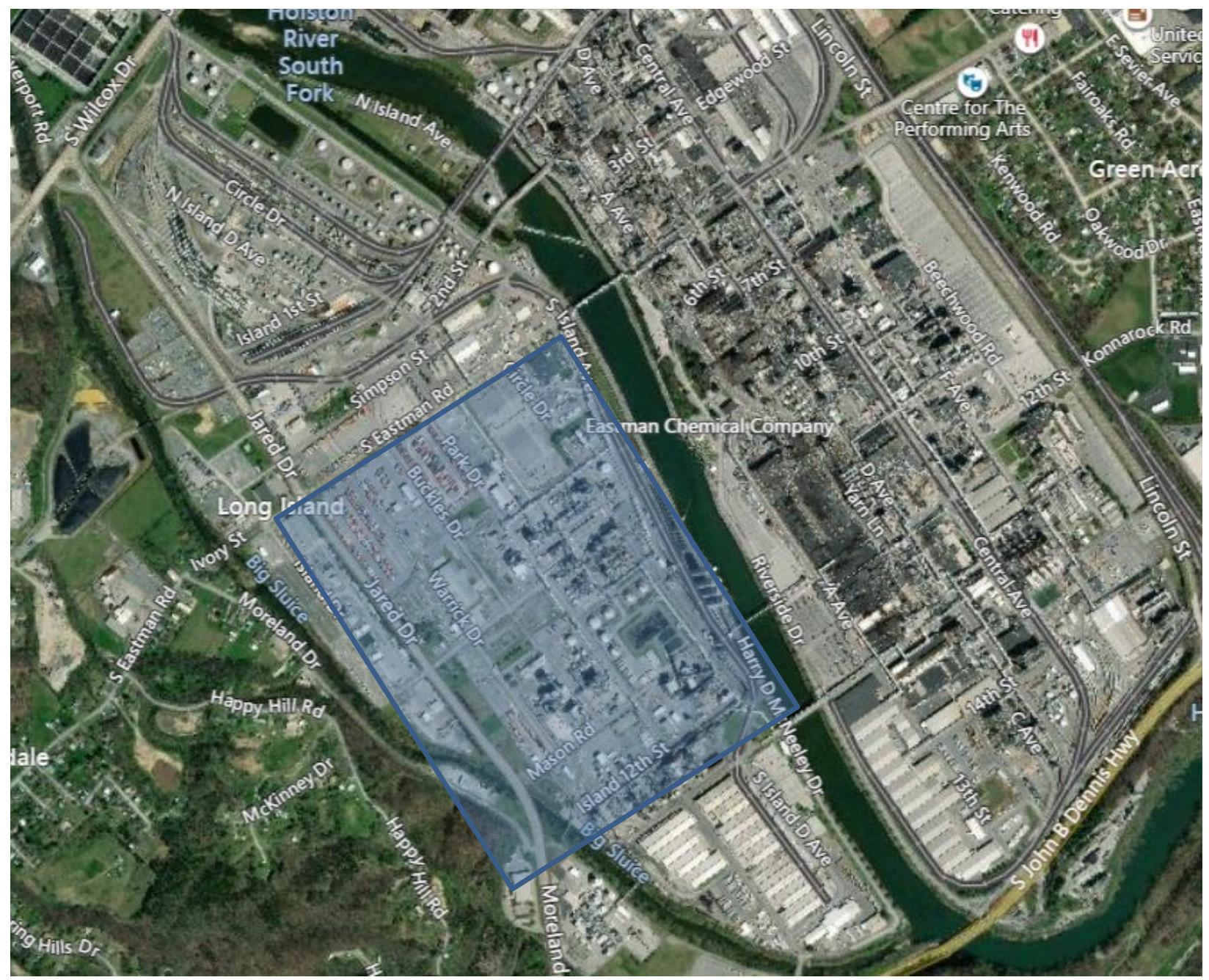

Figure 40. Eastman site with potential reactor siting area.

\subsubsection{Population Proximity and Density}

The OR-SAGE tool evaluates population proximity and density using high-resolution global population distribution data from the LandScan ${ }^{\mathrm{TM}}$ Population database. The LandScan ${ }^{\mathrm{TM}}$ algorithm uses spatial data and imagery analysis technologies and a multi-variable dasymetric modeling approach to disaggregate census counts within an administrative boundary. The database provides the ambient population (average 
over 24 hours). Seasonal averages can also be evaluated, which provides a seasonally adjusted ambient population. OR-SAGE uses this information to analyze individual cell locations for population density within a buffer distance as large as 20 miles. However, data can be taken directly from LandScan ${ }^{\mathrm{TM}}$ to depict the daytime and nighttime population density differences for a given area. This depiction of the population is more useful to an evaluation of the Eastman site than the typical OR-SAGE output, which would show most of the area as unacceptable for reactor siting using current LWR standards.

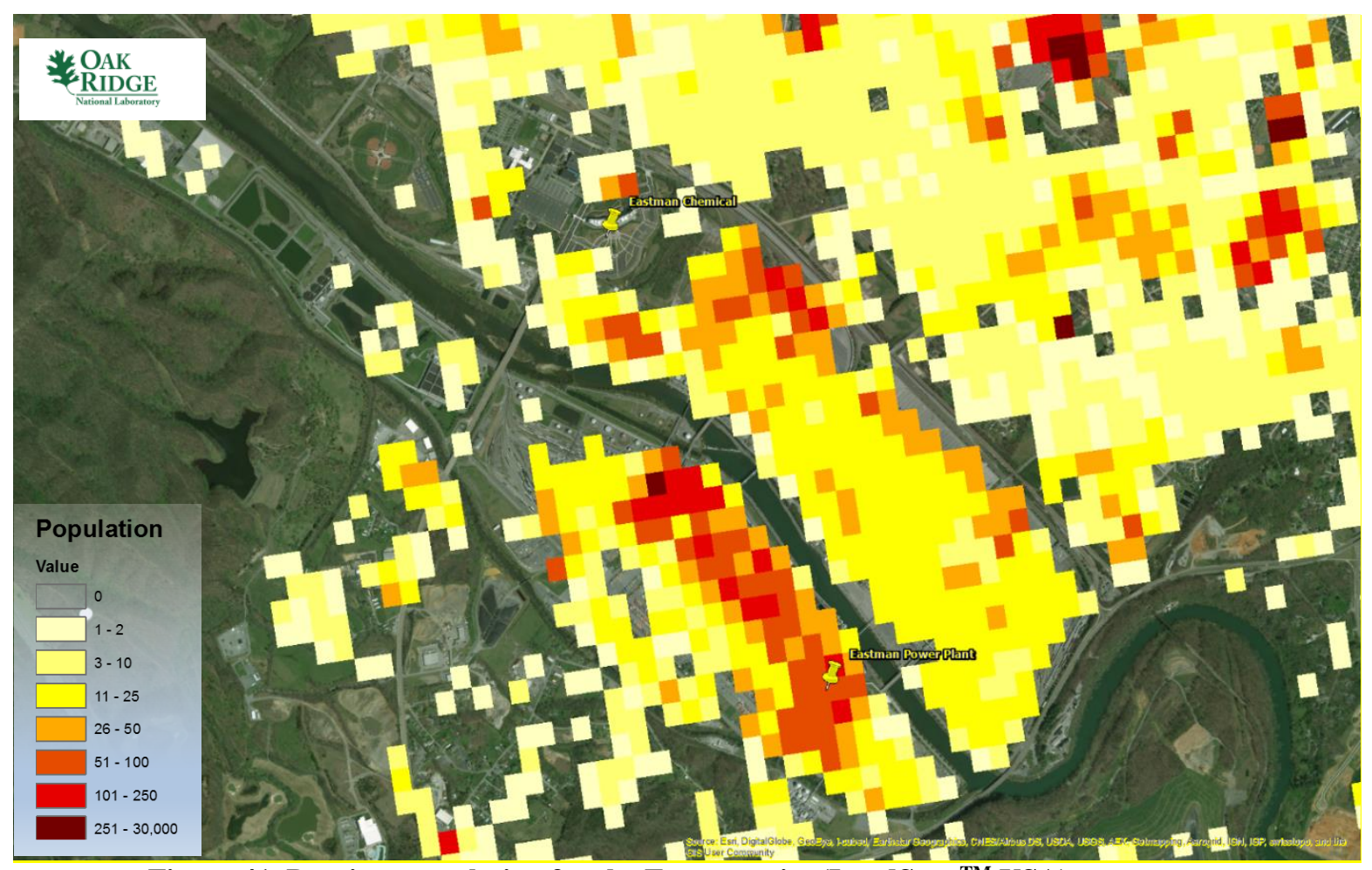

Figure 41. Daytime population for the Eastman site (LandScan ${ }^{\mathrm{TM}}$ USA).

Figure 41 shows the daytime population on and around the Eastman site. Onsite population is significant during the day due to the presence of the Eastman and contractor workforce. Eastman is a 24/7 operation and thus has employees onsite continuously, but the nighttime population on and around the site would be lighter during this time period.

With current regulations and supporting siting guidance, much of the Eastman site is considered a siting challenge due to population density within Kingsport. An OR-SAGE-generated exclusion layer based on current siting guidance would depict population exclusions for most of the area. These regulations are applicable for large LWRs, which require a much larger boundary for public protection than is expected to be required for SMRs or other advanced reactors. Therefore, with proper boundary design and implementation of revised guidelines, the challenges associated with population density near the Eastman site may be mitigated. 


\subsubsection{Additional Siting Considerations}

\subsubsection{Transportation}

Transportation resources are plentiful in and around the Eastman site. There are 37 miles of Eastman rail track and 28 miles of paved roads within the Eastman property. ${ }^{16}$ Rail Link provides railcar movements using five diesel locomotives, switching, and track maintenance for the company. Interstate-26 is within 2 miles of the plant, and Interstate-81 is within 4 miles of the plant.

\subsubsection{Construction}

Investment in siting and building a new reactor plant also requires infrastructure for construction. This includes temporary facilities to support construction. Limitations on locations for construction include proximity of discharge to water, identifying a location for excavated dirt, and limits to excavation depth and site preparation.

Temporary facilities would include a concrete plant, parking for construction support personnel and vehicles, an operation site, and a laydown area. The construction required for this facility would not only have the potential to boost the local economy for locally sourced construction material but would also provide new jobs to Kingsport and the surrounding areas.

\subsubsection{Hazards Analysis}

A hazards analysis is required to assess the threat to the public and surrounding area if the integrity of the primary and/or secondary reactor boundaries is insufficient. A hazards analysis would analyze the likelihood of an event occurring, the proximity allowable to the reactor plant, and the expected damage allowed to the reactor to limit potential exposure to the public and the environment. Specific guidance for this analysis can be found in NGNP-LIC-ETR-RPT-0001, Procedure for Site Hazards Evaluation and Impact Assessment [51]. The proximity of hazardous facilities is a key element of this analysis.

\subsubsection{Onsite Resources}

Eastman has the capability to process 30 million gallons of wastewater daily. This would be an asset to a water-based SMR technology. The chemical plant provides onsite medical services, which should be able to support required fitness-for-duty testing for select nuclear plant personnel. The chemical plant also provides onsite firefighting services. The Kingsport community offers a substantial population base and public services to attract the necessary SMR plant personnel.

\subsubsection{Regional Resources}

Nuclear power assets are sited in the East Tennessee region, providing the basis for a generally favorable attitude toward nuclear power. The University of Tennessee in Knoxville, Tennessee, offers degrees in nuclear engineering and other engineering disciplines. Numerous community colleges are available and could support aspects of nuclear power training with proper support and perceived demand. ORNL operates a research reactor for DOE. In addition, Tennessee hosts two commercial nuclear power plants, Sequoyah and Watts Bar, operated by the Tennessee Valley Authority (TVA). Watts Bar Unit 2 is the most recently completed nuclear power plant in the nation. Moreover, TVA has been granted an early site permit to hold a potential SMR site on the Clinch River near Oak Ridge, Tennessee. The NRC has interacted with the

\footnotetext{
${ }^{16}$ https://www.eastman.com/Literature_Center/Misc/Kingsport_Facts_Figures.pdf
} 
public many times in the recent past regarding the construction of Watts Bar Unit 2 and the Clinch River early site permit application. Because of the significant nuclear industry presence in East Tennessee, numerous private entities are available to support nuclear operations and the associated supply chain. 


\section{SUMMARY OF NUCLEAR REACTOR OPTIONS FOR THE EASTMAN KINGSPORT, TENNESSEE, SITE}

This report examines the use of a nuclear reactor to provide steam and electricity to the Eastman facility in Kingsport, Tennessee, replacing the existing natural gas and coal boilers while assuming that the principal steam distribution system remains intact. This report analyzes the ability of various advanced reactors to meet the demands of the facility, as well as the reliability, economic, regulatory, licensing, and siting considerations. The principal conclusions of the report from the considered topics are provided below. For more discussion on any particular topic, the reader is directed to the associated section in the report.

- $\quad$ Facility Demand $\mid$ Results from simulating six years of Eastman steam demand show that the electrical and steam demand can be met or exceeded using high-temperature reactor technologies. Current light-water technologies, including nearer term LWR-SMRs, will require natural gas to meet the desired steam conditions.

- $\quad$ Reliability $\mid$ Steam supply reliability of the current portfolio modeled using fault tree model and it has been compared with ARs portfolio-specifically the NuScale reactor (up to 6 modules) as an SMR demonstration — can be appealing for CHP operational reliability.

- Economic|The initial plant cost to meet the steam and electricity demand of Eastman based on EIA data, was calculated to be between \$2.5B and \$3.6B in 2020 dollars without considering risks in cost, delays, or construction loans. The system would nominally operate at a cost of $\$ 90 \mathrm{M}$ per year. It is important to note that there is a significant amount of uncertainty in these numbers since no advanced reactor has yet been built as of the studies conducted for this report. However, regardless of the specific technology, the objective of the SMR approach is to remove uncertainty and risk via standardization, modularization, and the use of passive safety within the SMR designs.

- Regulatory \& Licensing | The summary provided on the regulatory and licensing framework requires Eastman to engage with the regulator and reactor designer. In-process amendments to the regulatory process have also been mentioned which, if enacted, are expected to improve the ability to license, build, and operate reactors economically.

- $\quad$ Siting $\mid$ A review of the Eastman site was conducted based on siting requirements for nuclear reactors. This analysis concludes that, at this stage in the analysis, the geography and demographics of Kingsport, Tennessee, and the site would support a nuclear plant coupled with the Eastman facility.

This report does not address reactor-specific analyses such as determination of the specific reactor location, the method of physically piping connections to the 600 psig steam network, or other site modifications or contractual/business arrangements for operation, construction, or related activities necessary to realize the integration of a nuclear plant with the Eastman facility. However, this report provides important basic information about nuclear reactor technology as it pertains to Eastman. This information will assist Eastmain in moving forward with specific thrusts into areas of inquiry such as discussions with specific reactor vendors, utilities, and internal management. 


\section{PROJECT CONCLUSION}

\subsection{BENEFIT TO THE DOE-NE MISSION}

The ability for nuclear reactor technologies to support non-traditional customers, such as industrial energy demands, in an IES approach can be a critical part of delivering a clean and economic energy future. This report covers several topics critical to the success of a nuclear project in relation to an industrial partner and provides an entry document to IES related investigations. In these ways, this report is assisting the advancement of nuclear energy and the fulfillment of the DOE-NE office's mission.

\subsection{SUBJECT INVENTIONS}

Not applicable.

\subsection{COMMERCIALIZATION POSSIBILITIES}

The analysis presented in this report assists in laying groundwork necessary to evaluate the economic, technical, and social benefit of pursuing a nuclear power energy solution to meet Eastman's thermal and electrical demands. Before commercialization is achieved, many more studies - economic, technical, and social—will need to be performed to determine more specific items such as economic outlook, reactor vendor and technology, siting, public acceptance, and ownership and operation agreements.

\subsection{FUTURE WORK}

There are many topics covered in the report that must be addressed in greater detail to provide actionable information regarding the construction of an IES for Eastman's Kingsport, TN facility. Possible topics of future work include, but are not limited to:

- selection of specific reactor vendors and in-depth technical evaluations of the appropriateness of their specific technology to Eastman's needs, including reasonable schedule estimates and other economic predictions,

- investigation of modifications or upgrades required of the steam distribution network to couple with the identified nuclear technology,

- analysis of various owner/operator financial arrangements which would be appropriate for Eastman and potential partners,

- expansion of the reliability analysis to accurately gauge the ability of the specific nuclear technology and overall IES arrangement to meet the needs of Eastman, and

- further exploration of the ability to couple plant data with forecasting methods at various time scales in order to optimize plant operation by such actions as minimizing unplanned outages and improving utilization of resources. 


\section{REFERENCES}

1. Bragg-Sitton, S.M., Rabiti, C., Boardman, R.D., O’Brien, J., Morton, T.J., Yoon, S.J., Yoo, J.S., Frick, K., Sabharwall, P., Harrison, T.J., Greenwood, M.S., Vilim, R.B.: Integrated Energy Systems: 2020 Roadmap. Idaho National Laboratory (2020)

2. Annual Energy Outlook 2020. U.S. Energy Information Administration, Washington DC, USA (2020)

3. Varma, V.K., Holcomb, D.E., Peretz, F.J., Bradley, E.C., Ilas, D., Qualls, A.L., Zaharia, N.M.: AHTR Mechanical, Structural, and Neutronic Preconceptual Design. Oak Ridge National Lab. (ORNL), Oak Ridge, TN (United States) (2012)

4. Shenoy, A., Saurwein, J., Labar, M., Choi, H., Cosmopoulos, J.: Steam Cycle Modular Helium Reactor. Nucl. Technol. 178, 170-185 (2012). https://doi.org/10.13182/NT12-A13558

5. Triplett, B.S., Loewen, E.P., Dooies, B.J.: PRISM: A Competitive Small Modular Sodium-Cooled Reactor. Nucl. Technol. 178, 186-200 (2012). https://doi.org/10.13182/NT178-186

6. Chapter 5 Reactor Coolant System and Connecting Systems, Revision 4. Nuclear Regulatory Commission, Washington DC, USA (2020)

7. Greenwood, M.S., Cetiner, M., Fugate, D., Hale, R., Harrison, T., Qualls, A.: TRANSFORM TRANsient Simulation Framework of Reconfigurable Models. Oak Ridge National Laboratory (ORNL), Oak Ridge, TN (United States) (2017)

8. Warburton, D., Strutt, J.E., Allsopp, K.: Reliability prediction procedures for mechanical components at the design stage. Proc. Inst. Mech. Eng. Part E J. Process Mech. Eng. 212, 213-224 (1998). https://doi.org/10.1243/0954408981529420

9. Altenburg, R.: The Cost of Replacing Nuclear Power with Natural Gas, https://www.pennfuture.org/Blog-Item-The-Cost-of-Replacing-Nuclear-Power-with-Natural-Gas

10. Doyle, J., Haley, B., Fachiol, C., Galyean, B., Ingersoll, D.T.: Highly Reliable Nuclear Power for Mission Critical Applications. In: Proceedings of ICAPP 2016. American Nuclear Society, San Francisco, CA (2016)

11. Reyes, J., Ingersoll, D.: NuScale Power Plant Resilience Studies. In: Transactions of the American Nuclear Society. American Nuclear Society, Philadelphia, PA (2018)

12. Barringer, H.P.: Practical Reliability Tools For Refineries And Chemical Plants, (1999)

13. Billinton, R., Allan, R.N.: Reliability evaluation of power systems. Plenum Press, New York (1996)

14. Mignacca, B., Locatelli, G.: Economics and finance of Small Modular Reactors: A systematic review and research agenda. Renew. Sustain. Energy Rev. 118, 109519 (2020). https://doi.org/10.1016/j.rser.2019.109519

15. Marcinkiewicz, C.: NuScale Small Modular Reactors: Advanced, Scalable, Flexible, Economic. PNWER Energy Working Group. (2017)

16. Capital Cost and Performance Characteristic Estimates for Utility Scale Electric Power Generating Technologies. U.S. Energy Information Administration, Sargent and Lundy (2020)

17. Patel, S.: NuScale Boosts SMR Capacity, Making it Cost Competitive with Other Technologies, https://www.powermag.com/nuscale-boosts-smr-capacity-making-it-cost-competitive-with-othertechnologies/, (2018)

18. Adrian, C.: Smaller, safer, cheaper: One company aims to reinvent the nuclear reactor and save a warming planet, https://www.sciencemag.org/news/2019/02/smaller-safer-cheaper-one-companyaims-reinvent-nuclear-reactor-and-save-warming-planet, (2019)

19. FERC Financial Report FERC form No. 1: Annual Report of Major Electric Utilities, Licensees and Others and Supplemental Form 3-Q: Quarterly Financial Report, (2019)

20. FERC Financial Report FERC form No. 1: Annual Report of Major Electric Utilities, Licensees and Others and Supplemental Form 3-Q: Quarterly Financial Report, (2019)

21. FERC Financial Report FERC form No. 1: Annual Report of Major Electric Utilities, Licensees and Others and Supplemental Form 3-Q: Quarterly Financial Report, (2019) 
22. FERC Financial Report FERC form No. 1: Annual Report of Major Electric Utilities, Licensees and Others and Supplemental Form 3-Q: Quarterly Financial Report, (2019)

23. FERC Financial Report FERC form No. 1: Annual Report of Major Electric Utilities, Licensees and Others and Supplemental Form 3-Q: Quarterly Financial Report, (2019)

24. FERC Financial Report FERC form No. 1: Annual Report of Major Electric Utilities, Licensees and Others and Supplemental Form 3-Q: Quarterly Financial Report, (2019)

25. Budzier, A., Flyvbjerg, B., Garavaglia, A., Leed, A.: Quantitative Cost and Schedule Risk Analysis of Nuclear Waste Storage. Social Science Research Network, Rochester, NY (2018)

26. Flyvbjerg, B.: What you Should Know about Megaprojects and Why: An Overview: Proj. Manag. J. (2014). https://doi.org/10.1002/pmj.21409

27. Lovering, J.R., Yip, A., Nordhaus, T.: Historical construction costs of global nuclear power reactors. Energy Policy. 91, 371-382 (2016). https://doi.org/10.1016/j.enpol.2016.01.011

28. NuScale targets SMR staff costs below nuclear industry average | Nuclear Energy Insider, https://analysis.nuclearenergyinsider.com/nuscale-targets-smr-staff-costs-below-nuclear-industryaverage, (2018)

29. Maloney, M.T.: Economies and Diseconomies: Estimating Electricity Cost Functions. Rev. Ind. Organ. 19, 165-180 (2001). https://doi.org/10.1023/A:1011140400951

30. Hals, T., Flitter, E.: How two cutting edge U.S. nuclear projects bankrupted Westinghouse, https://www.reuters.com/article/us-toshiba-accounting-westinghouse-nucle-idUSKBN17Y0CQ, (2017)

31. Patel, S.: How the Vogtle Nuclear Expansion's Costs Escalated, https://www.powermag.com/how-thevogtle-nuclear-expansions-costs-escalated/, (2018)

32. Kovaleski, D.: New Vogtle nuclear reactors in Georgia are on target for 2021, 2022 opening, https://dailyenergyinsider.com/news/21469-new-vogtle-nuclear-reactors-in-georgia-are-on-target-for2021-2022-opening/, (2019)

33. Rapoport, I.: First Nuclear Reactors Built in 30 Years Take Shape at Georgia Power Plant, https://www.constructionequipmentguide.com/first-nuclear-reactors-built-in-30-years-take-shape-atgeorgia-power-plant/46939, (2019)

34. Walton, R.: Vogtle Cost Upgrade Causes Rethinking of $\$ 25 \mathrm{~B}$ Nuclear Plant's Future, https://www.power-eng.com/2018/08/09/vogtle-cost-upgrade-causes-rethinking-of-nuclear-plant-sfuture/, (2018)

35. The Future of Nuclear Energy in a Carbon-Constrained World. MIT Energy Initiative (2018)

36. Williams, J.: Existing NRC Regulations, Policies, and Guidance for Licensing. , Washington DC, USA (2015)

37. NRC: Nuclear Power Plant Licensing Process. Nuclear Regulatory Commission, Washington DC, USA

38. Licenses, Certifications, and Approvals for Nuclear Power Plants. Nuclear Regulatory Commission, Washington DC, USA (2007)

39. Identification of Potential Hazards in Site Vicinity. Nuclear Regulatory Commission, Washington DC, USA

40. Potential Policy, Licensing, and Key Technical Issues for Small Modular Nuclear Reactor Designs. Nuclear Regulatory Commission, Washington DC, USA (2010)

41. NRC: 10 CFR Part 100-Reactor Site Criteria, https://www.nrc.gov/reading-rm/doccollections/cfr/part100/

42. General Site Suitability for Nuclear Power Stations. Nuclear Regulatory Commission, Washington DC, USA (2014)

43. Rodwell: Siting Guide: Site Selection and Evaluation Criteria for An Early Site Permit Application. Electric Power Research Institute, Palo Alto, CA (United States) (2002)

44. Mays, G.T., Belles, R., Blevins, B.R., Hadley, S.W., Harrison, T.J., Jochem, W.C., Neish, B.S., Omitaomu, O.A., Rose, A.N.: Application of Spatial Data Modeling and Geographical Information 
Systems (GIS) for Identification of Potential Siting Options for Various Electrical Generation Sources. Oak Ridge National Lab. (ORNL), Oak Ridge, TN (United States) (2012)

45. Belles, R. (ORCID:0000000195319150), Mays, G.T. (ORCID:0000000229155415), Omitaomu, O.A. (ORCID:0000000230787196), Poore III, W.P. (ORCID:000000030223003X): Updated Application of Spatial Data Modeling and Geographical Information Systems (GIS) for Identification of Potential Siting Options for Small Modular Reactors. Oak Ridge National Lab. (ORNL), Oak Ridge, TN (United States) (2012)

46. Atkinson, D.: NuScale Update for NASEO. (2019)

47. Arafat, Y., Van Wyk, J.: eVinci Micro Reactor, (2019)

48. Proposed Rule: Emergency Preparedness for Small Modular Reactors and Other New Technologies (RIN 3150-AJ68; NRC-2015-0225). Nuclear Regulatory Commission, Washington DC, USA (2018)

49. Performance-Based Emergency Preparedness for Small Modular Reactors, Non-Light-Water Reactors, and Non-Power Production or Utilization Facilities. Nuclear Regulatory Commission, Washington DC, USA (2018)

50. Population-Related Siting Considerations for Advanced Reactors. Nuclear Regulatory Commission, Washington DC, USA (2019)

51. Procedure for Site Hazards Evaluation and Impact Assessment. Entergy Nuclear Inc. (2009) 


\section{APPENDIX A. EASTMAN OPERATIONAL DATA CHARACTERIZATION}

Unless otherwise noted, the analysis of the data was performed using Python 3 and associated open-source python packages such as pandas and numpy. The source code for the generated plots may be made available upon request.

\section{A.1 Simple Moving Average}

\section{A.1.1 Multi-Year View}

Figure 42 presents the raw minute data from 2016-2018, along with different simple moving average calculations with varied window lengths. This plot is used to determine the rate at which spurious signals disappear, in which signal noise decreases significantly over short periods of time. This may be attributed either to measurement system issues or short, less impactful glitches in facility operation. Any prolonged signals could be due to unplanned maintenance issues. In either case, useful information that may be found in this high-frequency information, but for the primary purposes of this study, longer term facility requirements are the primary interest. Therefore, a daily smoothing average was chosen as a compromise in retaining signal integrity while smoothing out signal noise (Figure 43).

Additional features of Figure 42 of note include the seasonal drops in production which occur in the springtime, April, and in the fall, October, each year for electricity generation and 600 psig steam flow. These seasonal occurrences are associated with planned maintenance activities at the Eastman site. The event in October 2017 is larger than the events shown in the other two years due to some additional irregularities at the facility. The observations in data were connected with maintenance issues as verified by the Eastman subject matter expert. The 100 psig line does not have any readily apparent seasonal behaviors, and there does not seem to be a strong correlation with the other lines except during the recovery from the fall 2017 maintenance. The 15 psig line is similar to the 100 psig line in that it does not have a strong correlation with the other lines that is readily apparent in this view. However, there is a clear seasonal behavior likely associated with changes in HVAC needs when transitioning between winter and summer weather.
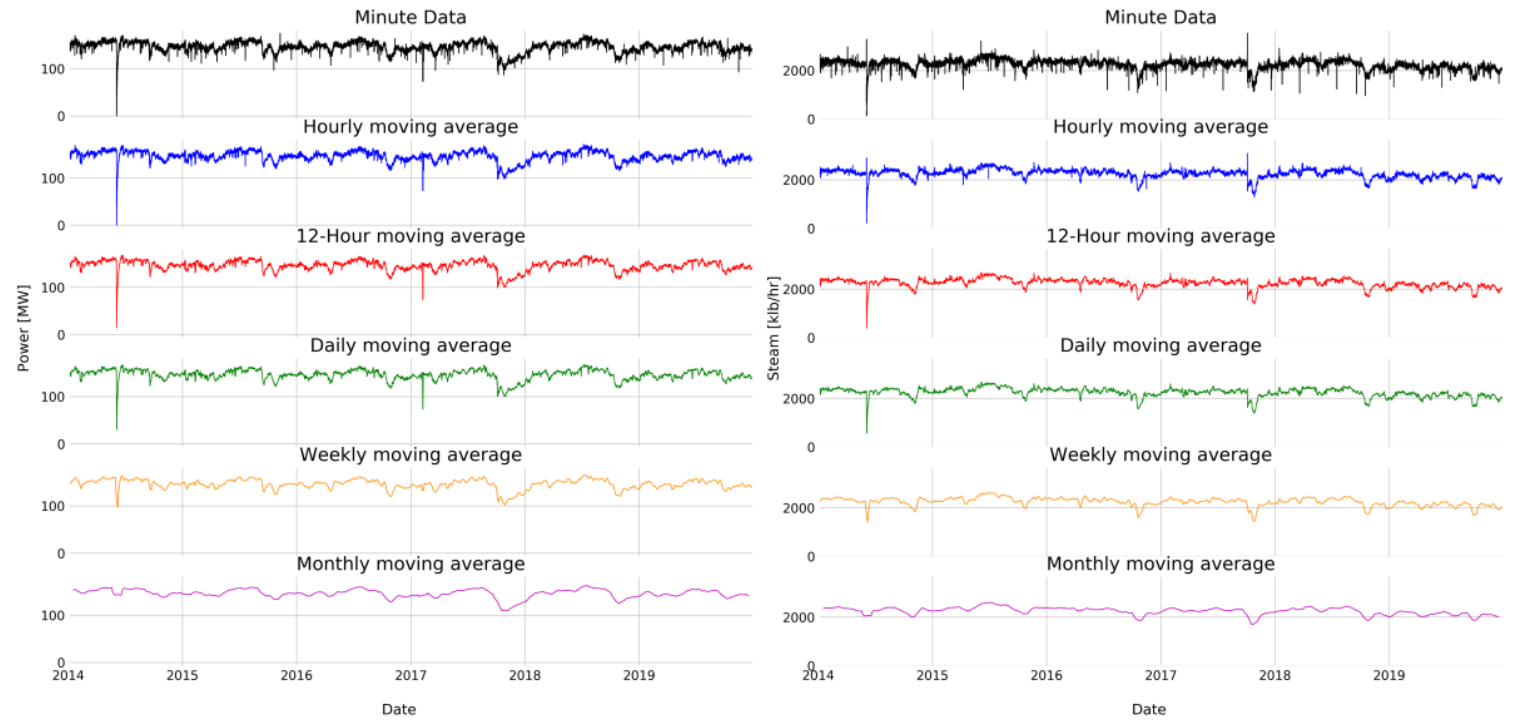

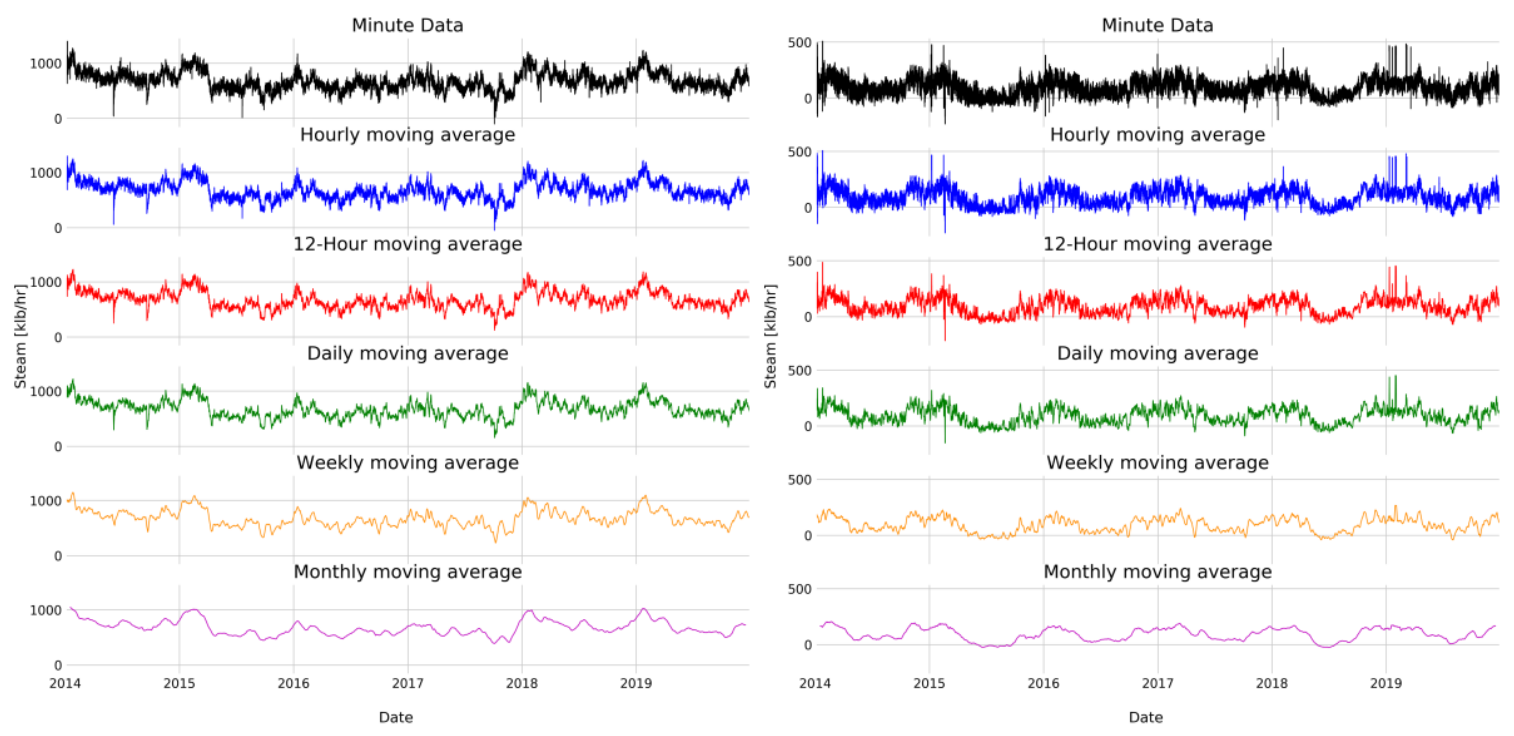

Figure 42. Electricity generation and steam line data displayed using various simple moving averages.
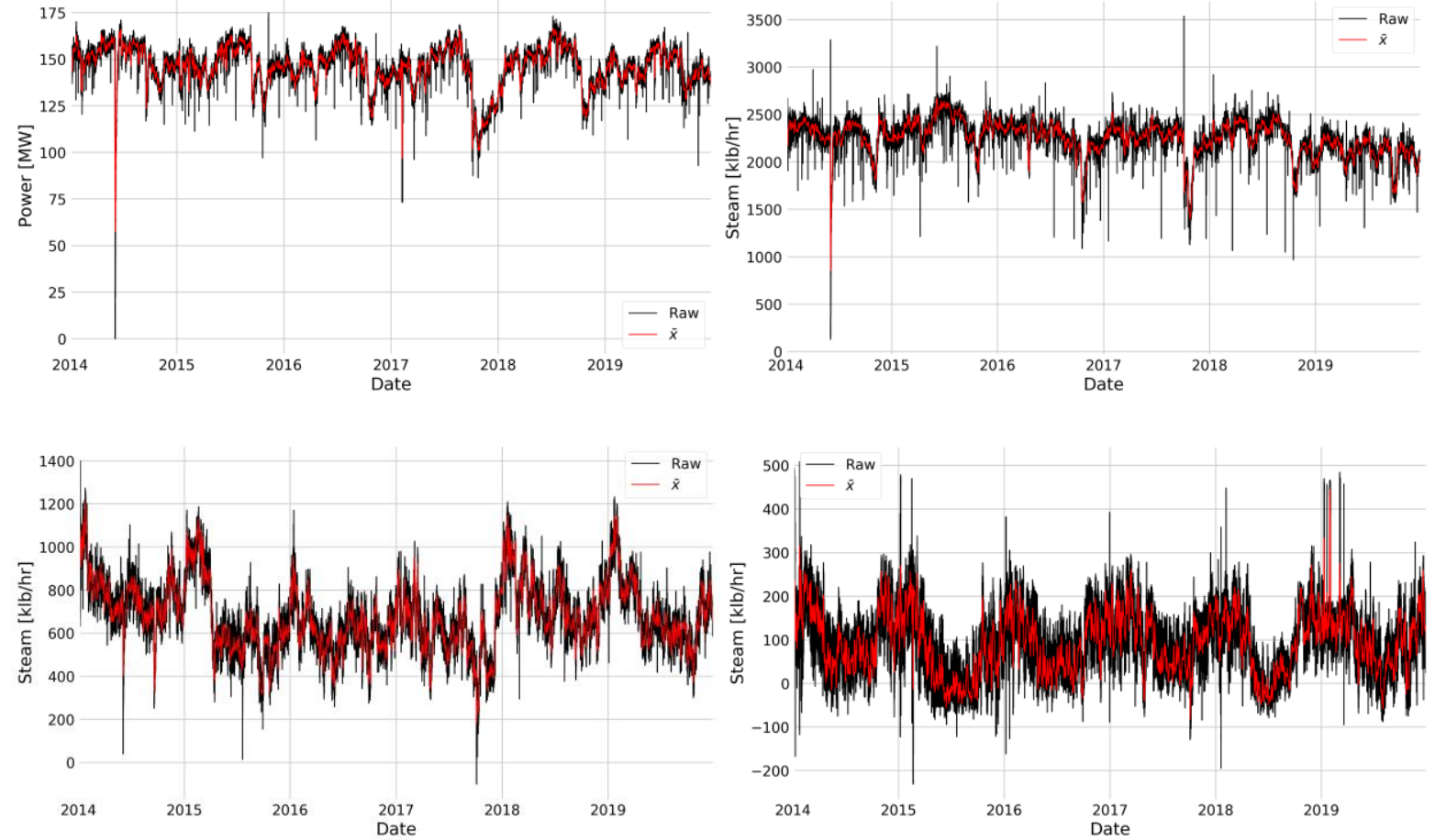

Figure 43. Electricity generation and steam line raw vs. daily moving average data.

\section{A.1.1.1 Rate of Change}

One of the key elements of the behavior found in this analysis is the rate of the system's change with respect to time. This rate of change, or ramp rate, is important for a nuclear facility with strict guidelines on how quickly things may change. This is necessary to ensure that the facility remains within an acceptable operation regime. The following plots provide the first derivative with respect to time for each of the signals presented in Figure 42. Table 15 summarizes the global statistics for each of the plotted signals. 

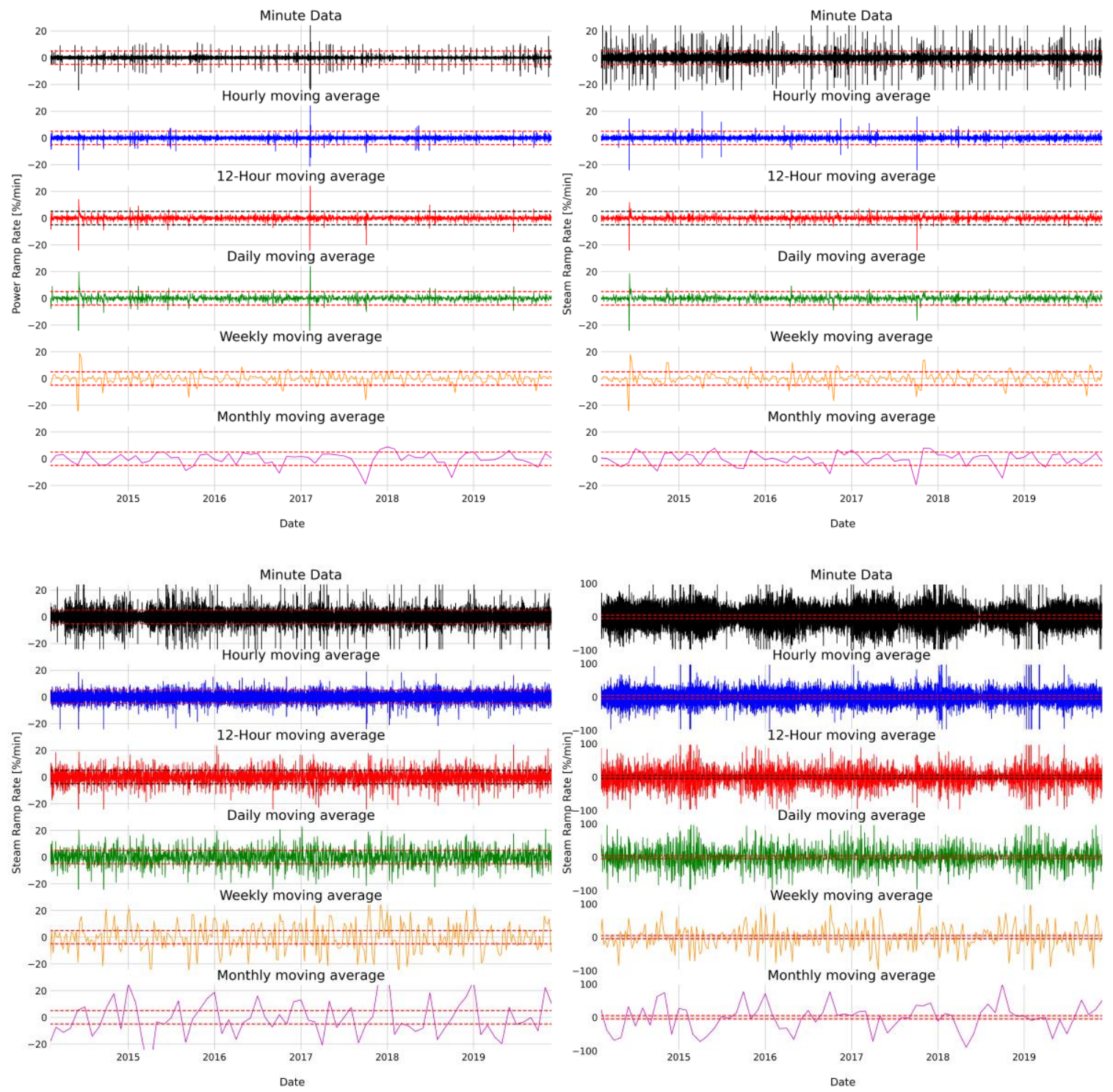

Figure 44. First derivative with respect to time for electricity generation and steam line data for raw and moving averages.

The dotted line indicates a $5 \% / \mathrm{min}$ ramp rate. 
Table 15. Summary statistics of the first derivative with respect to time for the signals shown in Figure 44. Units are the measurement unit of the original signal per time unit of the column

\begin{tabular}{lcrrrrrr}
\hline & & Raw & Hourly & 12-hour & Daily & Weekly & Monthly \\
\hline \multirow{2}{*}{ Electricity } & $\min (x)$ & -73.50 & -100.66 & -85.22 & -80.48 & -46.66 & -27.48 \\
generation & $\max (x)$ & 69.59 & 49.94 & 43.68 & 50.17 & 27.49 & 13.10 \\
& $\bar{x}$ & 0.00 & 0.00 & 0.00 & 0.00 & -0.03 & -0.14 \\
& $\sigma$ & \multicolumn{1}{c}{0.30} & 0.97 & 2.76 & 3.48 & 5.76 & 7.06 \\
\hline \multirow{5}{*}{ 600 psig Line } & $\min (x)$ & -1207.13 & -1287.05 & -1314.44 & - & -608.59 & -436.47 \\
& $\max (x)$ & 958.40 & 443.83 & 264.94 & 416.14 & 405.47 & 179.36 \\
& $\bar{x}$ & 0.00 & 0.00 & -0.02 & -0.05 & -0.73 & -4.63 \\
& $\sigma$ & 11.23 & 16.08 & 38.19 & 46.63 & 94.87 & 115.35 \\
\hline \multirow{3}{*}{ 100 psig Line } & $\min (x)$ & -659.40 & -432.85 & -251.59 & -303.40 & -238.37 & -285.15 \\
& $\max (x)$ & 559.18 & 301.24 & 227.15 & 153.06 & 209.38 & 259.80 \\
& $\bar{x}$ & 0.00 & 0.00 & -0.04 & -0.09 & -0.95 & -3.87 \\
& $\sigma$ & 5.36 & 14.91 & 35.40 & 42.12 & 70.24 & 95.22 \\
\hline \multirow{3}{*}{ 15 psig Line } & $\min (x)$ & -292.50 & -297.85 & -218.90 & -217.40 & -118.04 & -82.53 \\
& $\max (x)$ & 299.91 & 209.90 & 305.79 & 241.39 & 112.98 & 90.80 \\
& $\bar{x}$ & 0.00 & 0.00 & -0.01 & -0.01 & -0.15 & -0.13 \\
& $\sigma$ & 6.68 & 12.64 & 27.25 & 29.29 & 33.57 & 37.32 \\
\hline
\end{tabular}

\section{A.1.2. Multi-Day View}

Due to the quantity of data and length of time under inspection, short-term data must also be viewed in smaller windows to gain a perspective on how the system operates. This windowed view of the data may help clarify alternative analyses or shed light on why various analysis methods do not perform well. Similar to the multi-year plots, Figure 45 through Figure 48 plot the measured raw data and additional moving average plots to help visualize short-term (i.e., minute to daily) trends, seasonality, and other operational modes. These plots demonstrate that there do appear to be seasonal behaviors that are likely associated with daily weather and night/day patterns, as well as short-term trends. In other advanced analyses, some behaviors may be captured, but there is significant variation that appears to be stochastic, without further information. Therefore, using smoothed data which suppresses shorter timeframe fluctuations for forecasting and overall analysis of the system behavior is likely appropriate.

Window views are helpful in gaining a better understanding of the underlying data, but by themselves, they do not provide sufficient information for analysis of short-term behaviors in large data sets. This is largely because there is too much data to be broken into multi-day windows and viewed in this format. An alternative approach such as the use of frequency analysis may be more helpful. In any case, these views help the analyst understand the complexity of the signals being investigated, and they can help justify decisions such as smoothing approaches to capture longer term behaviors. 

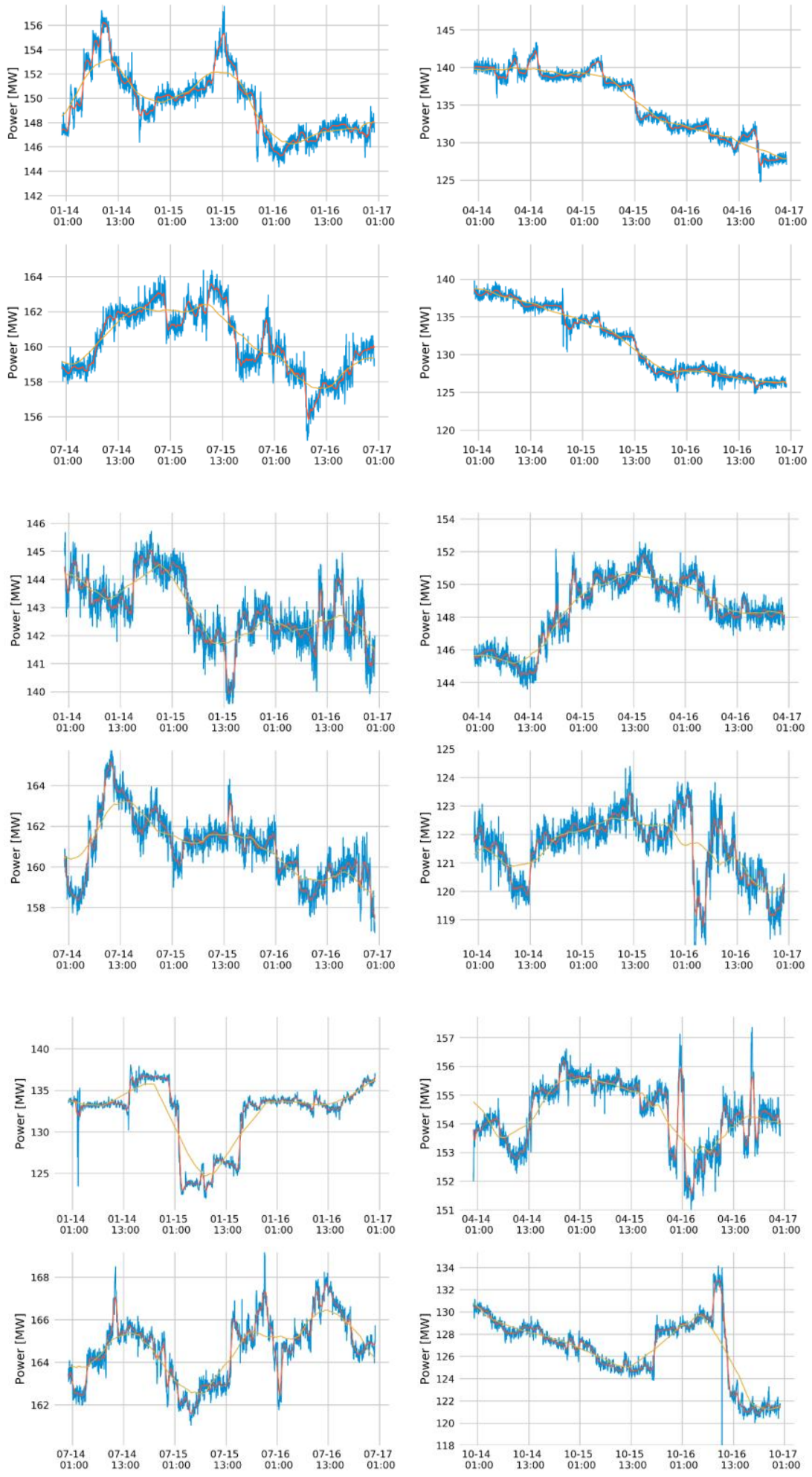

Figure 45. Electricity generation raw (blue) and moving averaged data (red indicates the hourly average, and orange indicates the 12-hour average) for 3-day periods in January, April, July, and October for 2016-2018. 

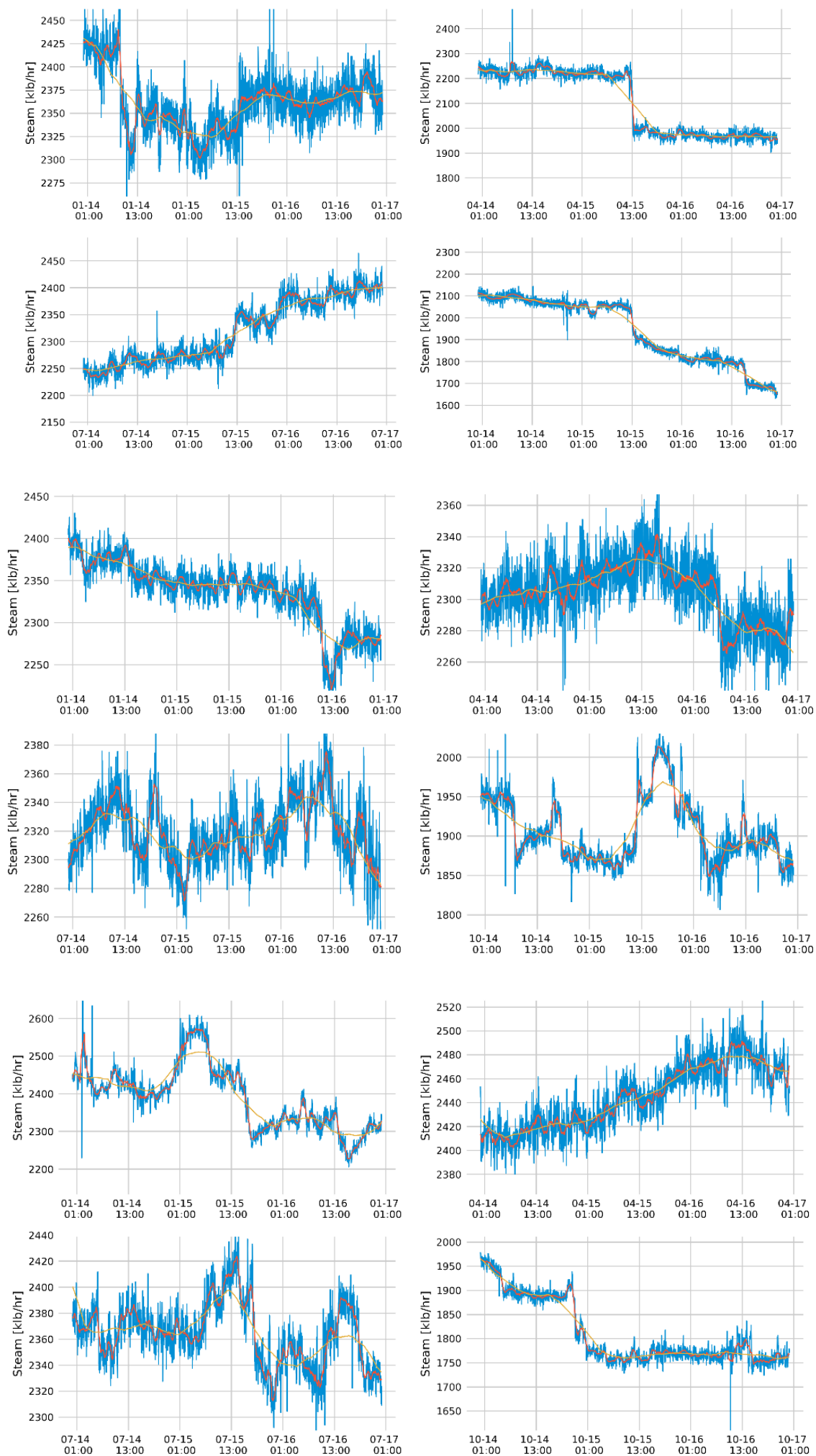

Figure 46. 600 psig line raw (blue) and moving averaged data (red indicates hourly average; orange indicates 12-hour average) for 3-day periods in January, April, July, and October for 2016-2018. 

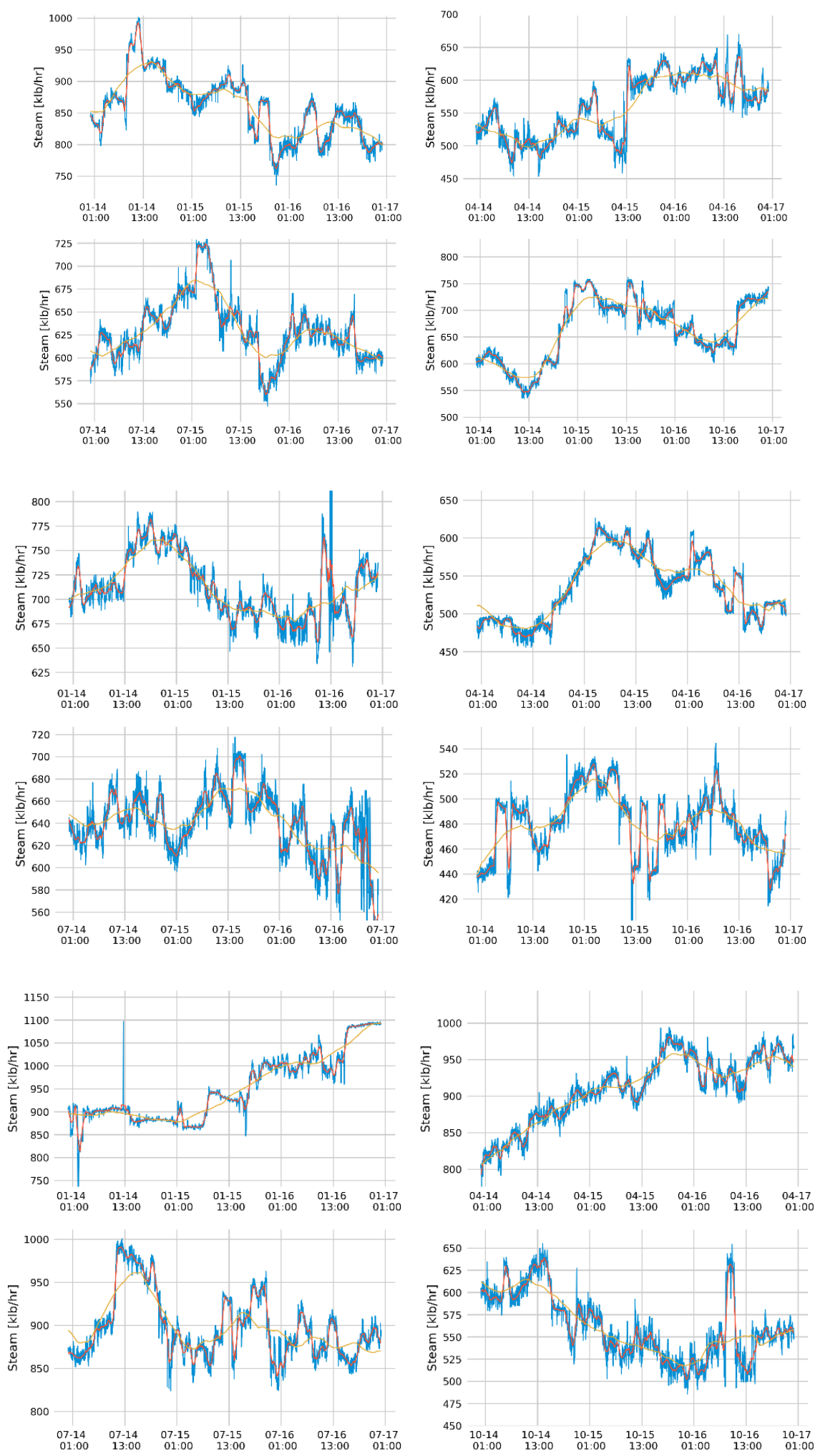

Figure 47. 100 psig line raw (blue) and moving averaged data (red indicates hourly average; orange indicates 12-hour average) for 3-day periods in January, April, July, and October for 2016-2018. 

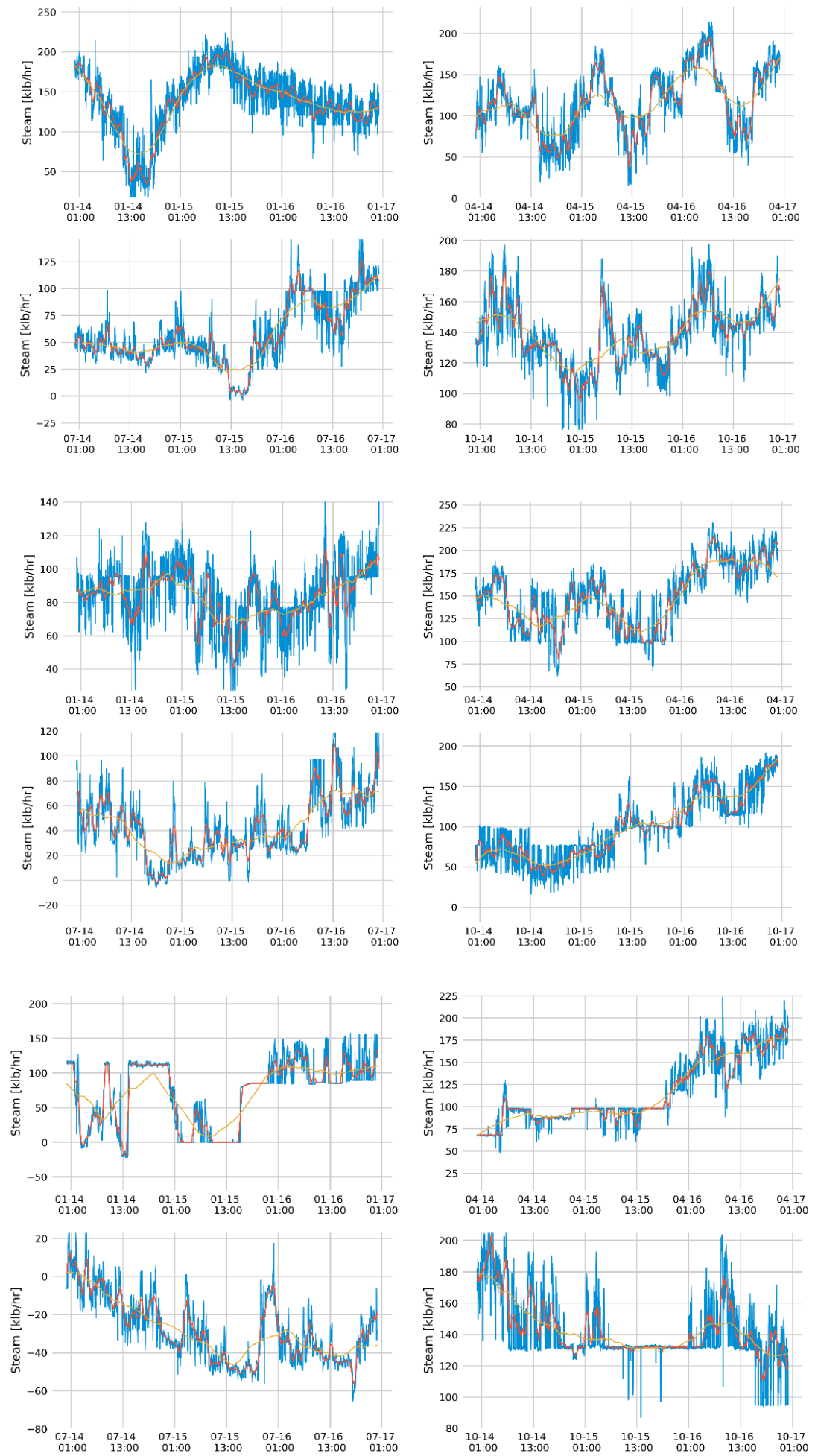

Figure 48. 15 psig line raw (blue) and moving averaged data (red indicates hourly average; orange indicates 12-hour average) for 3-day periods in January, April, July, and October for 2016-2018. 


\section{A.2 Histogram}

Figure 49 shows histograms of smoothed data over the total timeframe and for each year. For the electrical generation and 600 psig steam line, each year has a bimodal distribution with peaks at approximately 120 and $145 \mathrm{MW}$. The $120 \mathrm{MW}$ peak is far more prominent in 2017 than in other years. These peaks coincide with the fall maintenance period and the facility's normal operation average. The $100 \mathrm{psig}$ line has gaussian distribution, indicating that it is less impacted by weather variations. The 15 psig line has a clear bimodal distribution, likely due to winter-summer HVAC demands.

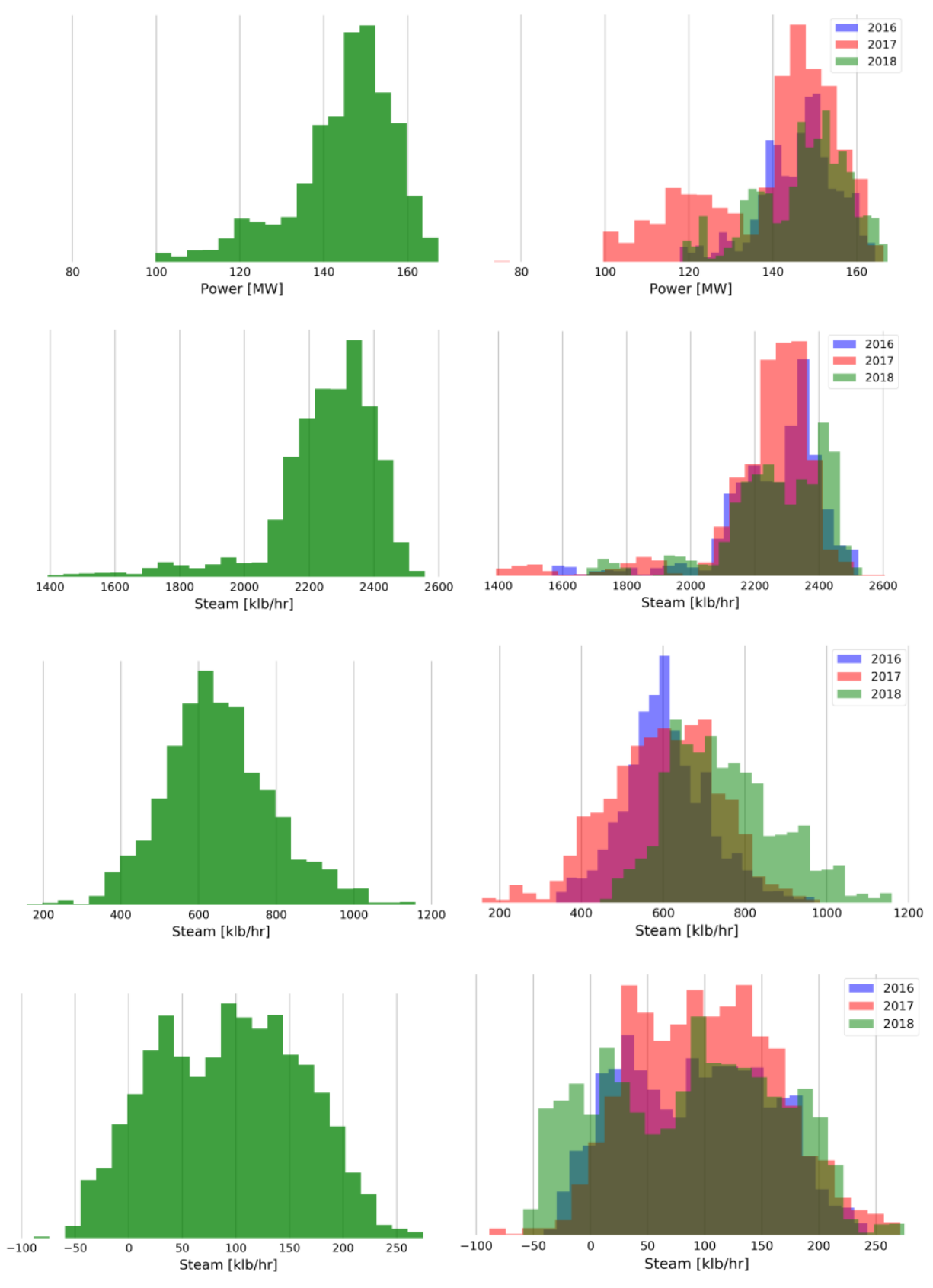

Figure 49. Electricity generation and steam line histograms for 2016-2018 over total timeframe (left) and per year (right). 


\section{A.3 Boxplots}

To gain further understanding of the facility's behavior, various box plots were generated (Figure 52). Each of the plots bins the smoothed data based on a specific time frame. Those presented here are for each hour of the day, each day of the week, and each month of the year. If there were a clear operational mode of the facility — such as weekends or shift changes - then these plots would help elucidate it.

The top figure provides binned data for each month of the year. The large outlier in February may be attributed to failures in the measurement system in 2017, unless maintenance or other operation records deem otherwise. The plot shows the general increase in demand into the summer, which is likely due to HVAC systems, and an abrupt drop-off in the fall for maintenance. The uncertainty bars are also slightly larger in the March-April timeframe, supporting minor spring maintenance activities as expected.

The middle figure bins all the days of the year which fall on the same day of the week, and the bottom figure bins the hours of the day. These bins were selected to determine if there appeared to be any impact from day-to-day operational changes (i.e., weekends or shift changes). The stable mean and median of the data demonstrate that there are no readily apparent patterns, and that for any given day or time of the day, the Eastman facility operates in a steady-state fashion. It is unclear why the hour-wise outliers appear to have a symmetric pattern. Change in facility demands only seem to appear over longer periods of time (i.e., months). The number of outliers in the middle and bottom plots are expected and are associated with the distinct variations which occur due to seasonal variations or large spikes in the data (i.e., February 2017). These variations were not smoothed out completely in the daily moving average calculation.

The Figure 51 and Figure 52 box plots are not meant to show short-term (e.g., sub-weekly) behavior. The data set tends to average out any short, non-repeated patterns that may be present. These plots simply indicate that there is no repeated pattern, such as shutdowns on weekends, shifts, etc., occurring at the same interval.
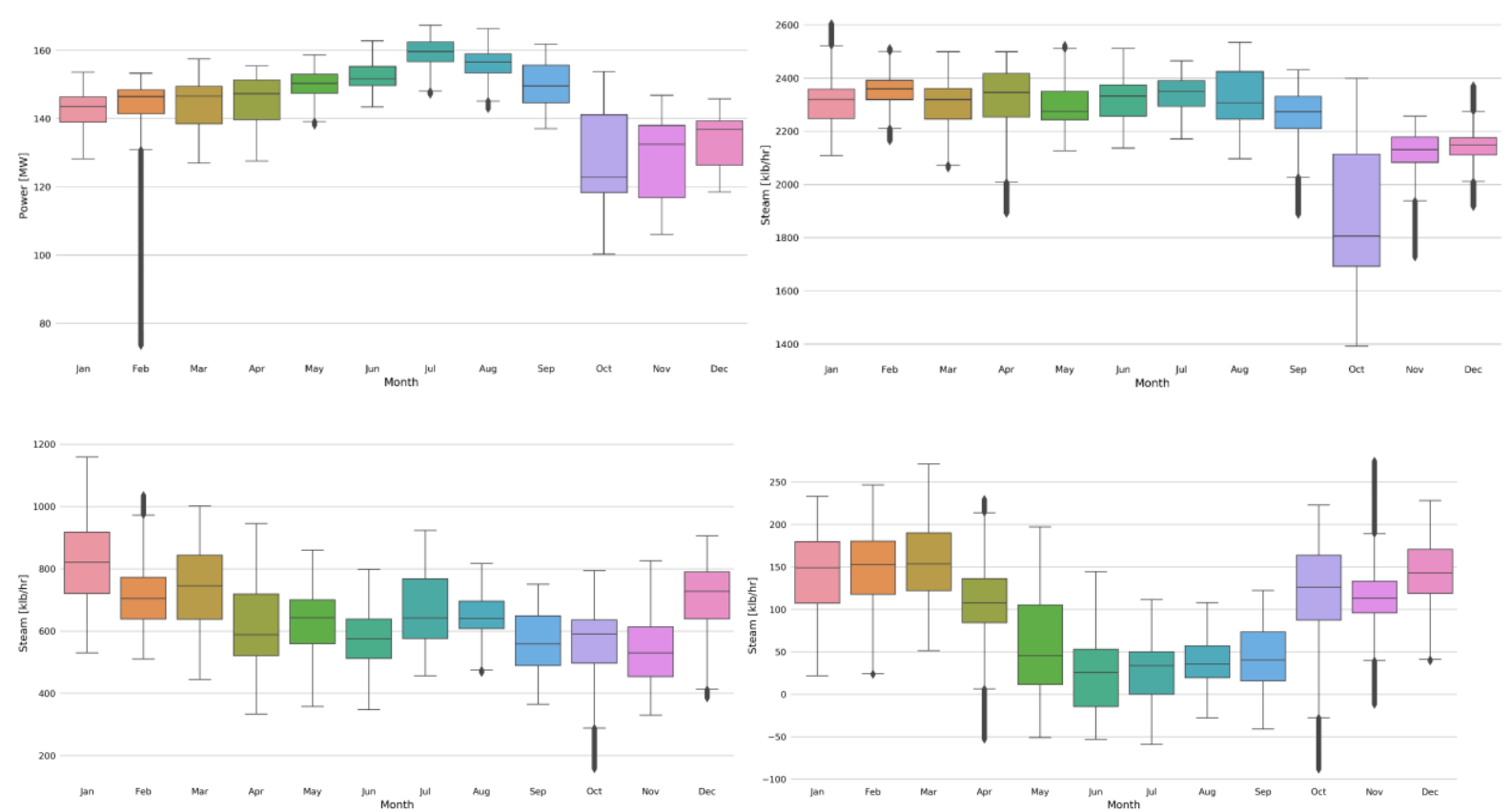

Figure 50. Electricity generation and steam line boxplots of the smoothed data using months for the entire timeframe 2016-2018. 

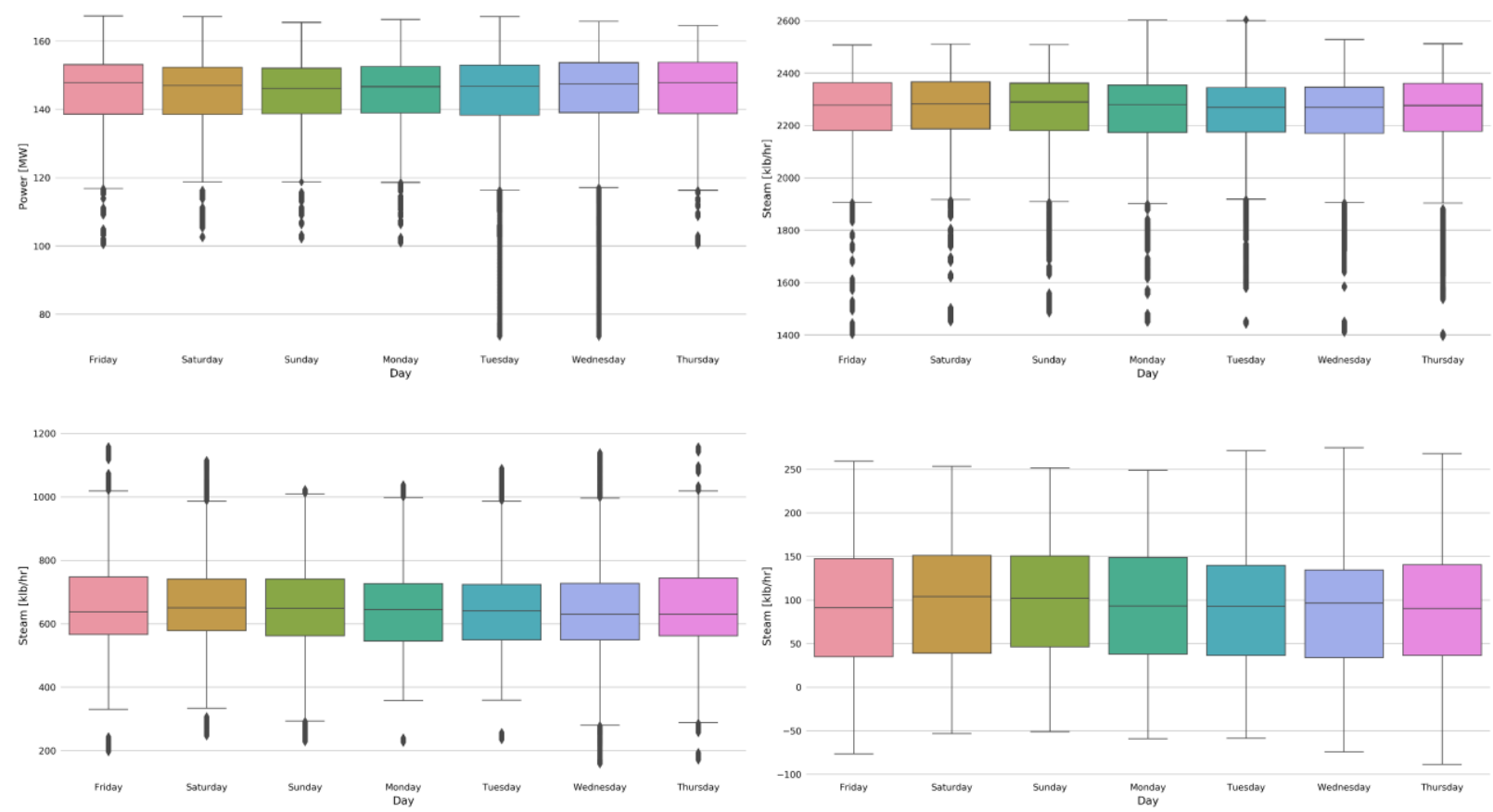

Figure 51. Electricity generation and steam line boxplots of the smoothed data using days of the week for the entire timeframe 2016-2018.
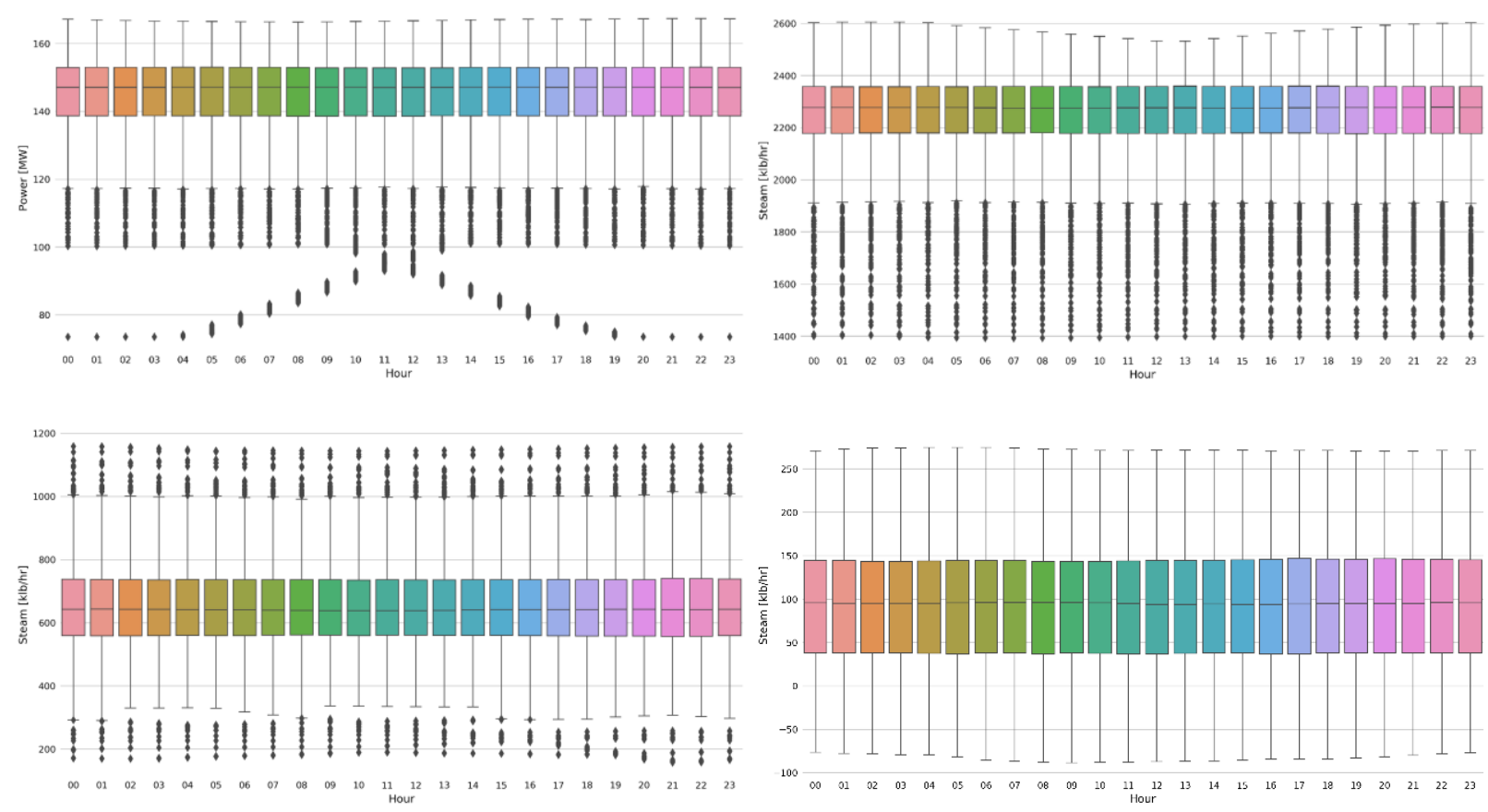

Figure 52. Electricity generation and steam line boxplots of the smoothed data using hours of the day for the entire timeframe 2016-2018. 


\section{A.4 Frequency Analysis}

The graphs presented above provide several adequate methods to evaluate longer term signal behavior. There was concern that important information may be overlooked for short time scales due to either the quantity of data being evaluated, as in significant noise in the results which could mask high-frequency data, and the methods of smoothing or binning. To investigate high-frequency behaviors, frequency analysis was performed using periodograms to capture the power of a signal at various frequencies.

Two approaches were used. The first analysis used data that were resampled at different rates (Figure 53). A variety of sampling frequencies were selected to determine whether what type of information may have been be lost when data were down sampled,. The plots show no significant difference in the frequency analysis based on the sampling frequencies investigated. Furthermore, the frequency analysis supports the observed seasonal behavior at semi-year to year-long seasonality. However, at higher frequencies, the number of observations and the nature of the data add much noise to the signal, so any important signals are not distinguishable.

The second analysis used grouped periods of time and the frequency analysis was performed on each period. The results of each resulting periodogram were averaged (Figure 54). This objective of this analysis was to isolate any high-frequency data which may be within the raw data by decreasing the impact of noise in the signal, thus informing the analyst of any interesting aspects of the plant's behavior. The plots demonstrate that there may indeed be some repeated signals at daily periods and perhaps at other frequencies which exhibit small local peaking (e.g., hourly). However, the clearly dominating behaviors are low frequency and are likely associated with seasons of the year. As shown previously in the multi-day view of data, there appear to be significant variations in the plant's behavior over short time scales. Without further linking information, this indicates that the process is essentially stochastic. In the frequency analysis, this shows up as noisy results from which no strong conclusion can be made.

The analysis of this data, although not very useful for this report, leads to several possibilities on how the data could be used for forecasting. Although the signals appear stochastic over shorter time frames, it is highly likely that many of the operations in the facility are planned, so the response of the system is likely more deterministic than it appears. For example, there are numerous production facilities within the Eastman facility, each of which has various operational modes and tests. Many of these activities are likely scheduled. The facility data could be mined, linked with scheduled operations, weather predictions, etc., and then analyzed to quantify the effects of each facility and the planned operations. These data could then be stored and used to create what could be a highly accurate prediction scheme, except for unplanned maintenance and other anomalies. The scheme's ability to predict would be limited by the ability to properly plan and organize O\&M schedules. This type of deep data analysis is far beyond the scope of this work, but that type of study could offer a significant opportunity to improve system efficiency and cash-flow by reducing system stresses and providing more accurate information when pursuing related activities such as fuel contracts. Furthermore, it may be highly beneficial for an integrated nuclear-industrial system to have a more predictable demand for regulatory and financial purposes. 

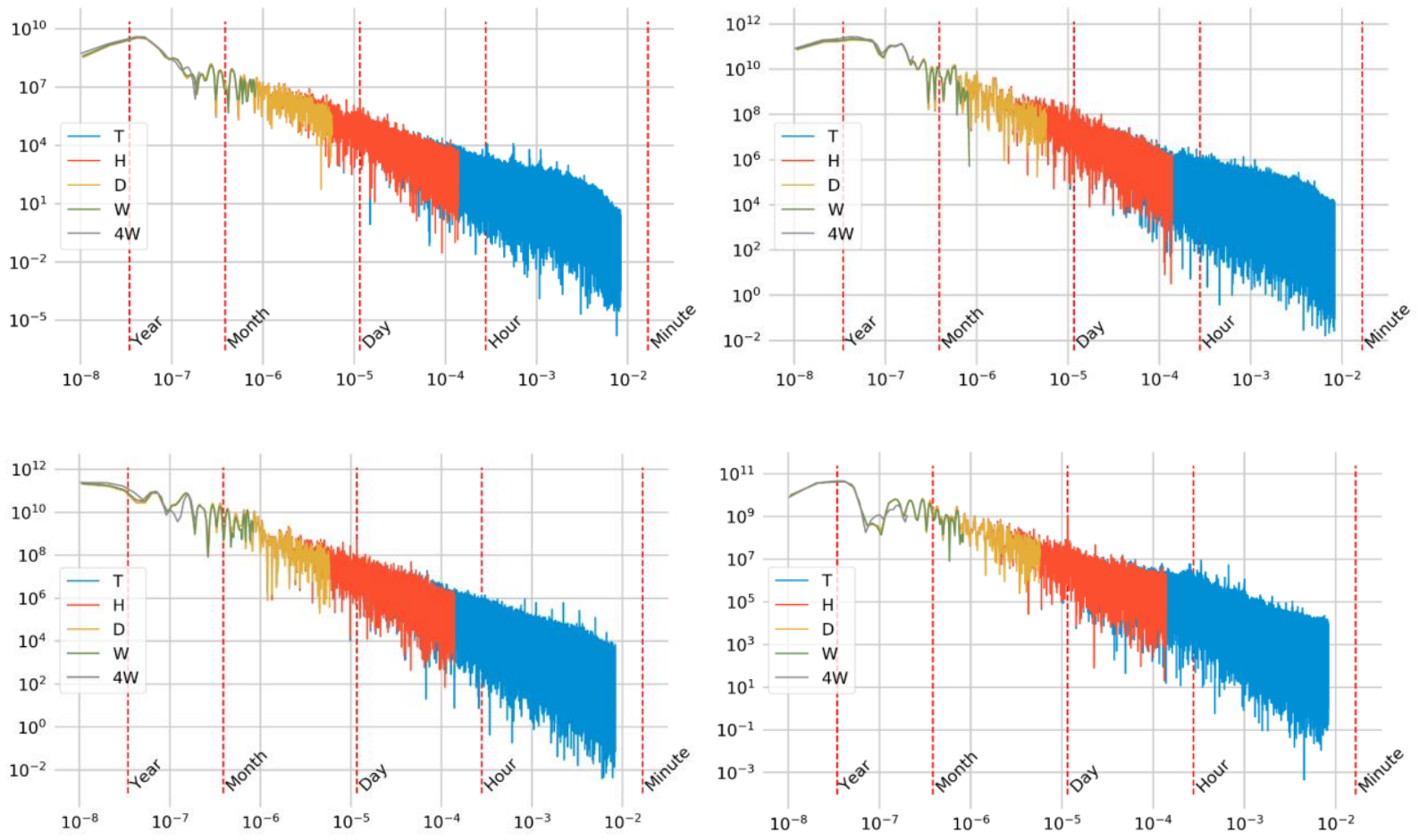

Figure 53. Electricity generation and steamline periodogram plots using data resampled at various rates for the entire timeframe 2016-2018 (Resampling definitions: $T=$ Minute, $H=$ Hour, $D=$ Day, $W=$ Week). 

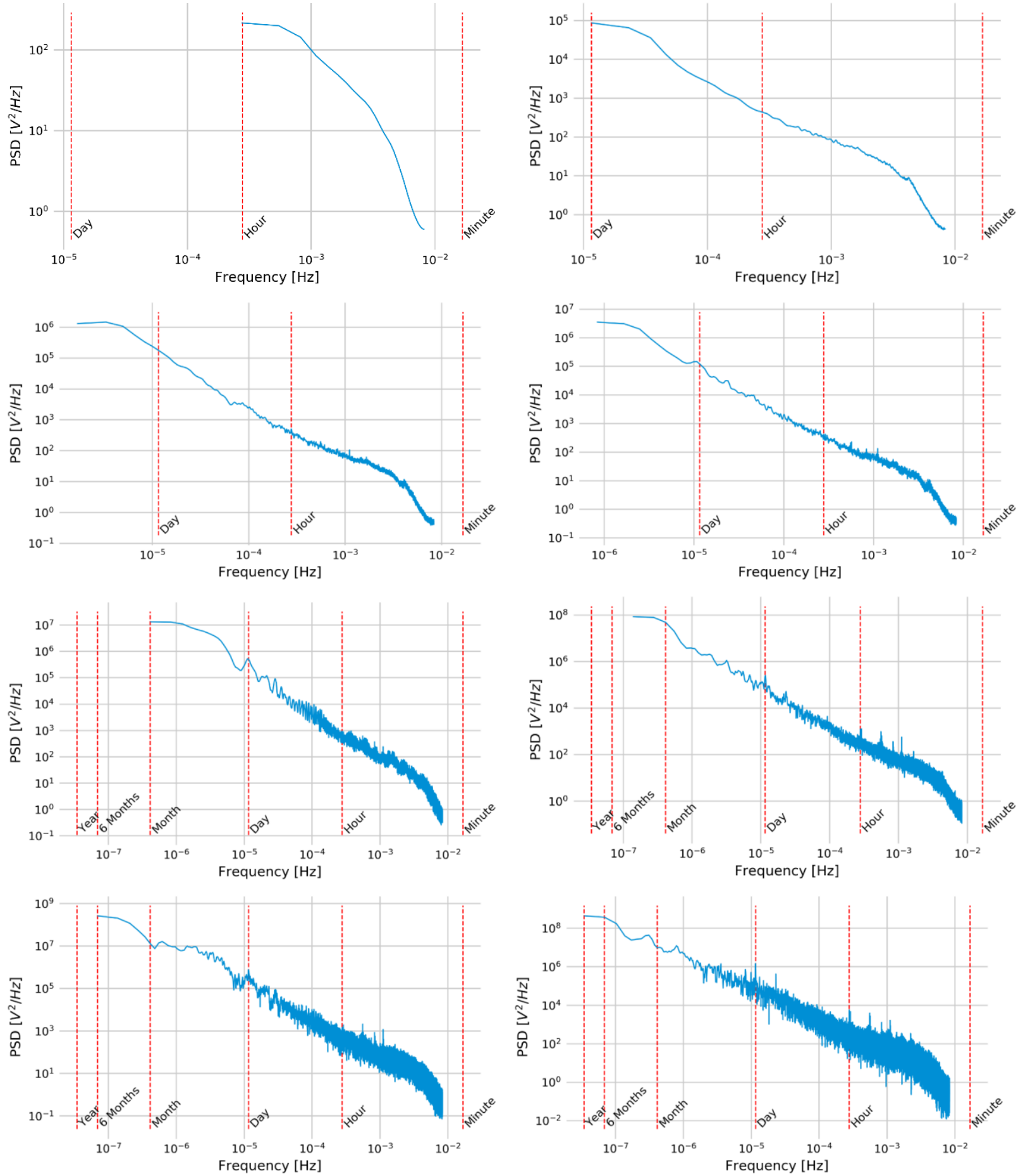

Figure 54. Electrical generation frequency data grouped by periods of time, analyzed, and averaged to produce the show frequency plots. The longest time in each plot represents the period grouped. 


\section{APPENDIX B. ELECTRICITY AND STEAM FORECASTING}

\section{B.1 Introduction and Motivation}

Time series forecasting has been applied to a multitude of industries, ranging from the stock market to ridesharing. Accurate forecasts can help with power generation in two ways. First, knowing how much electricity will be needed for a given time period enables planning for operational expenses such as fuel. Second, depending on the model, a forecast of changes in expected downtime can be created and its effect on electricity production can be observed. Forecasting can also be used to detect anomalies. For example, if the measured electricity produced is significantly different from the forecast, then this could signify that some type of malfunction has occurred.

The recent increase in deep learning has also affected the forecasting community. The literature is now replete with studies using deep learning methods to produce accurate forecasts. However, the M4 forecasting competition was won using a hybrid statistical and deep learning approach, and pure machine learning methods could not outperform the baseline algorithm. Runners-up mainly consisted of an ensemble of statistical methods such as seasonal autoregressive integrated moving average (SARIMA) and exponential smoothing. [1] A few studies using machine learning for time series forecasting related to the power generation industry are reviewed here.

There have been numerous efforts in forecasting for wind energy because of its inherent intermittent nature. More accurate forecasts allow for better planning with power grids that have multiple energy sources. One attempt at forecasting wind energy used a combination of a long short-term memory (LSTM) neural network and a support vector regression machine (SVRM). Forecasting was performed for two scenarios: a 10-minute horizon and an hourly prediction horizon. However, both scenarios only predicted a single time-step ahead, because the time-step was changed to match the horizon. The authors compared their method against other models such as ARIMA, and they demonstrated that their method had the lowest error [2]. Nevertheless, the fact that a forecast of only a single step ahead was performed indicates that the model likely has poor performance at longer prediction horizons. For example, it is common for machine learning methods to simply learn the degenerate case in which the next measurement is nearly equal to the current measurement.

Another study attempts to forecast temperatures in a coal-fired power plant with an encoder-decoder neural network with gated recurrent units (GRUs). This method can handle multivariate inputs and outputs, and the authors used this to incorporate multiple signals from various parts of the plant into their forecasting model. The authors also performed a proper dataset split with a hold-out validation set, where model development was performed. Then they took their best models and evaluated them on a separate test set to obtain a better estimate of model performance and capability to generalize to unseen data. However, only a short-term forecast of 5 minutes was performed, with measurements every minute, corresponding to a prediction of 5 steps ahead. The authors stated that their model has an acceptable level of accuracy, but they make no comparisons against any other baseline methods. In addition, there are no plots of the actual forecasted temperatures, so it is not certain when the model performs well or poorly. For example, the overall error may be low because the temperature remains relatively constant [3].

Finally, an investigation on demand forecasting for part of Australia's power grid used deep belief networks (DBNs) and preprocessing with empirical mode decomposition (EMD). The authors used 4 months of data, one month from each season, and sampled at 30-minute intervals. Their proposed method had the lowest error when compared against various other models for 30 minutes and a day-ahead prediction. However, it is unclear if the day-ahead prediction was a multi-step forecast or just a single value at 24 hours in the future. The authors do note that their most naïve method, which assumes that the prediction is equal to a previously recorded value, performs very well [4]. 
In light of the M4 competition results, it is not clear whether many of the published machine learning methodologies would perform any better than an ensemble of traditional methods. In addition, increasing prediction horizons may elucidate the deficiencies in models that only succeeded for short time horizons. Many of the studies also do not provide source-code or data, so their results cannot be easily verified. One major disadvantage with deep learning is that a large amount of data is typically required, which is not always available, especially for yearly recordings.

As the literature has shown, deep learning has been mainly applied for short-term forecasts. Therefore, forecasting is investigated using relatively simple methods that do not rely on an abundance of data, to predict a full year into the future. The hope is to provide a perspective on forecasting for medium- to longterm horizons. Furthermore, these methods are open source, so they allow for reproducible results and are relatively easy to use.

\section{B.1.1 Baseline Model}

Visualization for steam mass flows at various pressures and electricity generation have been performed as described in Appendix A, so background descriptions of the time series will not be repeated. No preprocessing of the time series is performed for any of the forecasting methods, such as removal of data due to suspected sensor failure or any type of smoothing. This choice allows for observations on the robustness of a model's performance.

Beginning with a naïve model, the forecast is taken to be equal to the unweighted average of the previous two years. Only the mean absolute error (MAE) will be reported due to its intuitive nature. As described in the below, MAE is simply the average of the absolute values between the forecast and actual measurements, as shown below:

$$
M A E=\frac{1}{n} \sum_{i=1}^{n}\left|y_{\text {actual }, i}-y_{\text {forecast }, i}\right|
$$

Figure 55 shows the ground truth in red and the forecast from the averaging method in blue. Note that there are no forecasts for 2014-2016, because two years were needed to make the first forecast. As the previous visualizations have shown, there is an obvious correlation between the electricity generation and the net steam mass flows at $600 \mathrm{psig}$. However, the lower pressures are markedly different. In all of the time series, there are distinct seasonal trends that seem to repeat every year. The MAE for every year and variable, along with the average over all forecasted years, is reported in Table 16. Overall, good forecasting performance is observed, even using this naïve approach. This is likely because the processes are maintained at steady outputs, so the future outputs are very similar to those from the past. 
a)

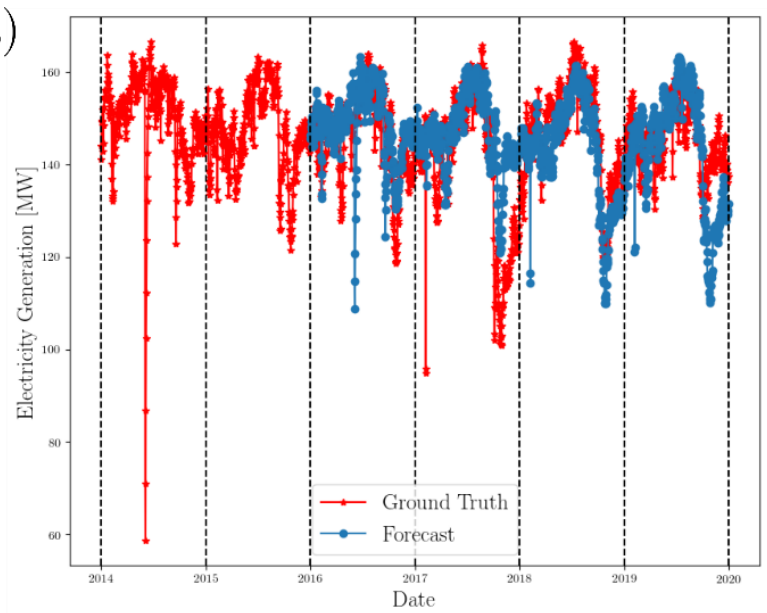

c)

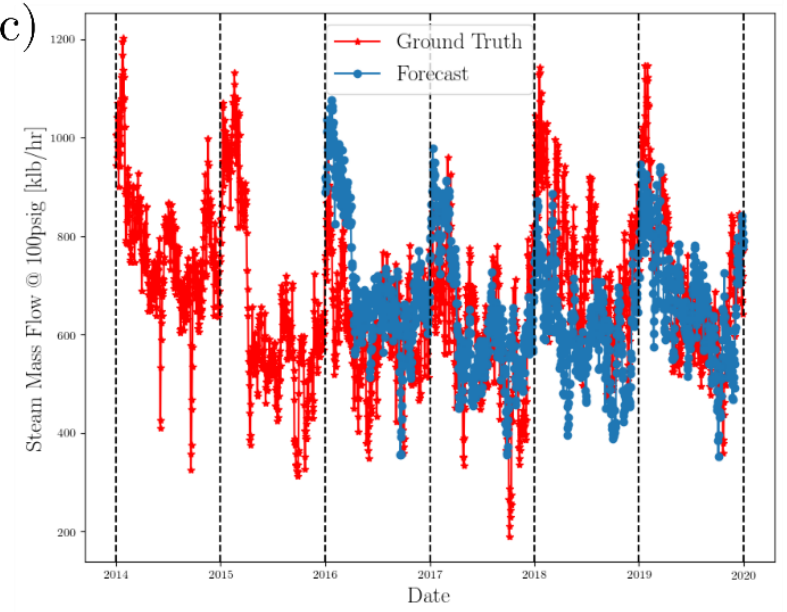

b)

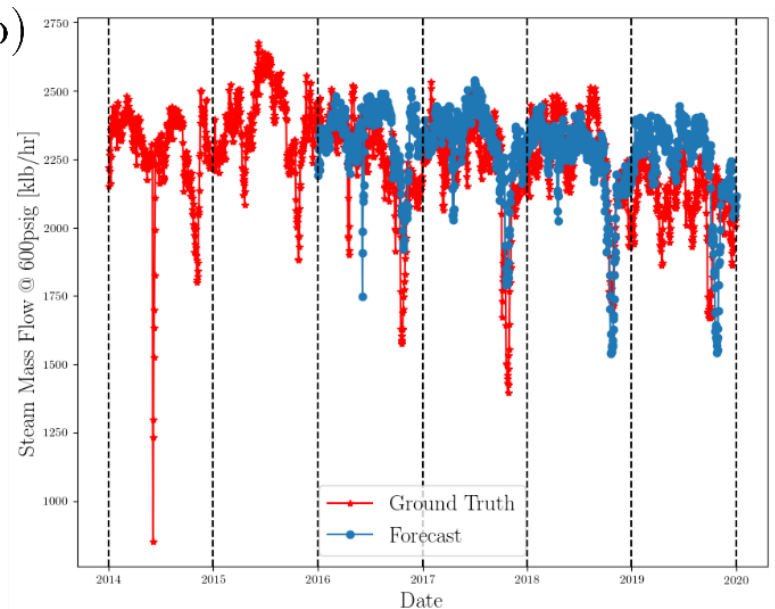

d)

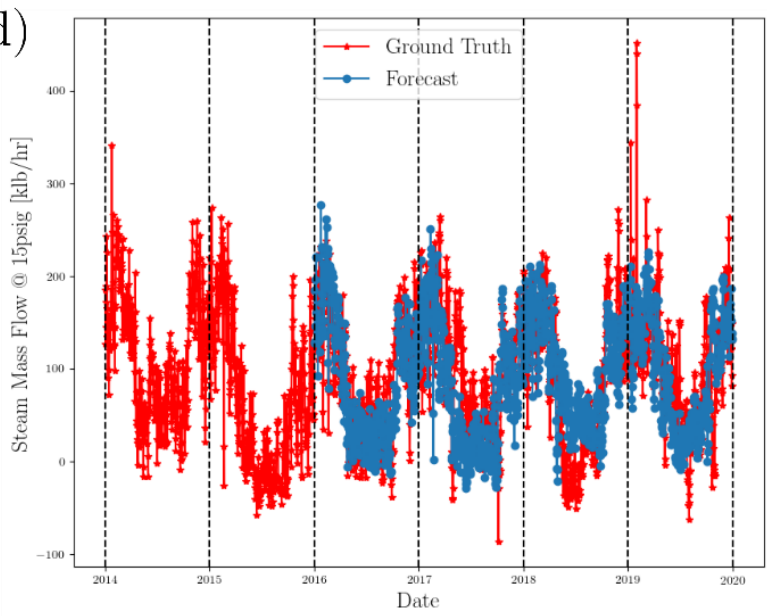

Figure 55. Averaging forecasts for electricity generation (a) and steam mass flows at various pressures (b-d).

Table 16. Averaging method MAE results

\begin{tabular}{lccccc}
\hline & 2016-2017 & 2017-2018 & 2018-2019 & 2019-2020 & Average \\
\hline Electricity & 6.4 & 9.7 & 6.0 & 8.9 & 7.8 \\
Steam @ 600 psig & 133.2 & 125.1 & 94.2 & 194.5 & 136.8 \\
Steam @ 100 psig & 130.8 & 107.1 & 153.9 & 98.8 & 122.7 \\
Steam @ 15 psig & 37.8 & 50.2 & 47.5 & 48.6 & 46.0 \\
\hline
\end{tabular}

\section{B.1.2 SARIMA}

Models similar to SARIMA are quite common in the time series forecasting literature. Therefore, the performance of a SARIMA model was evaluated using the statsmodels package in Python3. SARIMA models come with various hyperparameters that must be set by the forecaster based on prior experience or other analysis. Therefore, automatic ARIMA methods to bypass manual hyperparameter tuning were attempted to improve on the few manually specified parameters trialed [5]. However, this effort could not produce forecasts better than the averaging method. The SARIMA parameters were $(2,1,1)$ for the autoregressive, integrated, and moving average components, respectively. The seasonal parameters are 
$(1,1,1,30)$ indicating that monthly seasonality is modeled. Only one seasonal component could be added, and it was manually specified to be 30 days based on visually identified monthly trends.

As in the averaging method, the SARIMA model was fit or trained on two years of data and tasked with producing a daily forecast for the following year. For example, the model takes data from January 1, 2014 through December 31, 2015 and produces a forecast for each day in 2016. This was repeated for a total of 4 years. An identical approach was taken for all methods presented in this investigation. Figure 56 shows the SARIMA forecast of electricity generation and steam mass flows for 2016-2017, which is the year with the lowest MAE. Table 17 contains the MAE for all variables and years, resulting in a more quantitative comparison. Other years are not plotted due to brevity and also because they display the same deficiency in SARIMA models for this application. SARIMA models also provide uncertainty bounds or confidence intervals, but they are also not shown to reduce clutter in the graphs. A constant trend is observed in the forecast for all variables due to the nature of the SARIMA forecast. The biggest issue with the forecast is that the monthly oscillations do not fit well with the actual future measurements. For example, there is a significant historical drop in electricity generation during the fall season, which is completely unresolved in the forecast. The amplitude of the various oscillations throughout the year are also underpredicted. Therefore, SARIMA is ill-suited for the case of year-out forecasts with daily resolution.

a)

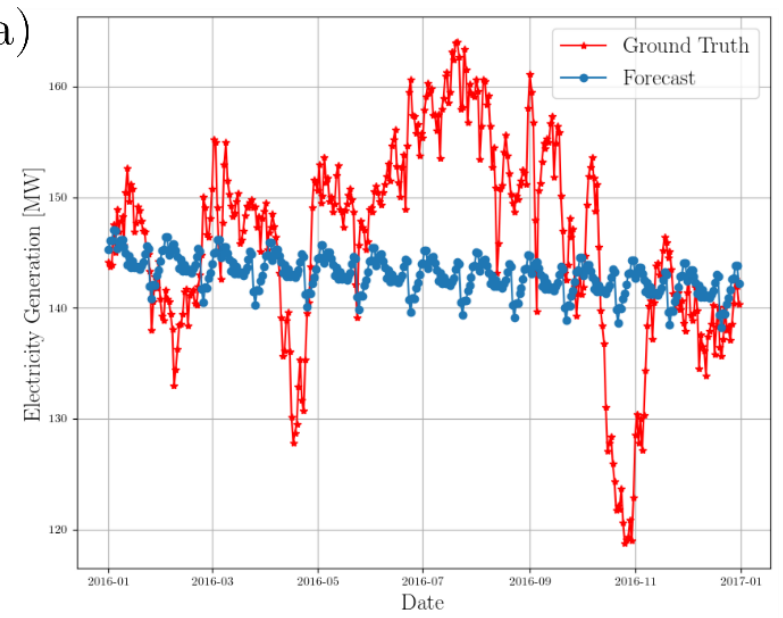

c)

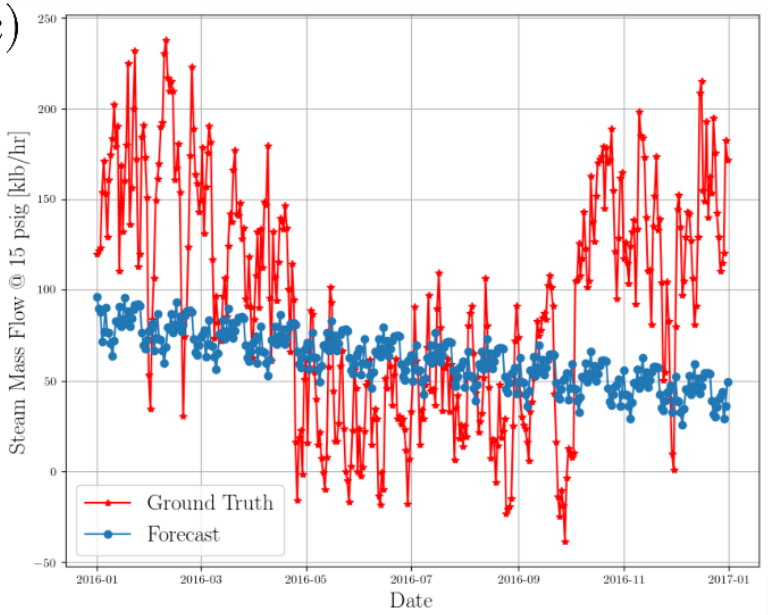

b)

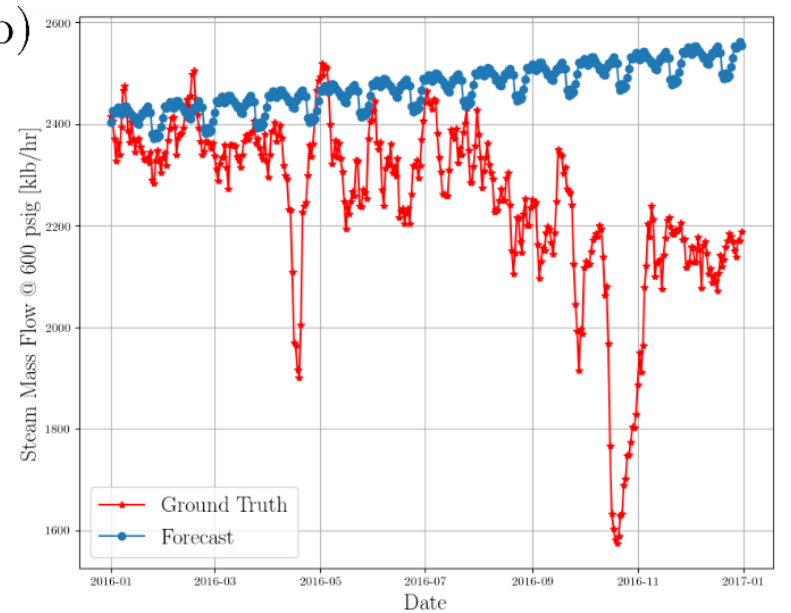

d)

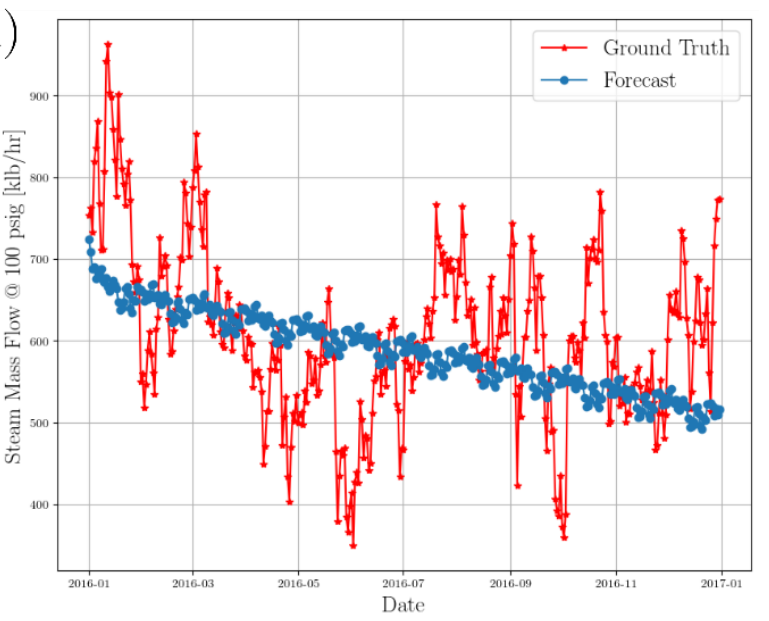

Figure 56. SARIMA forecasts for electricity generation (a) and steam mass flows at various pressures (b-d). 
Table 17. SARIMA $(2,1,1) \times(1,1,1,30)$ MAE results

\begin{tabular}{lccccc}
\hline & 2016-2017 & 2017-2018 & 2018-2019 & 2019-2020 & Average \\
\hline Electricity & 7.3 & 13.7 & 26.0 & 15.2 & 15.6 \\
Steam @ 600 psig & 227.9 & 154.6 & 151.7 & 200.0 & 183.5 \\
Steam @ 100 psig & 84.2 & 133.5 & 119.7 & 160.9 & 124.6 \\
Steam @ 15 psig & 57.4 & 94.2 & 84.7 & 54.1 & 72.6 \\
\hline
\end{tabular}

\section{B.1.3 Prophet}

Facebook open-sourced their time series forecasting tool named Prophet in 2017 for both R and Python programming languages [6]. It is a type of generalized additive model with only time as the dependent variable or regressor. However, the open-source implement does have options for additional regressors and multiplicative affects. Equation (B.2) is adapted from the original paper showing how the trend (g), seasonal (s), holiday (h), and noise (e) terms are summed together to produce the forecast. In this investigation of the data, standard US holidays had little-to-no impact, so that component is unused in these findings. However, that portion of the model could be replaced by planned maintenance if that information is regularly available:

$$
\hat{y}(t)=g(t)+s(t)+h(t)+e_{t}
$$

One major difference between Prophet and SARIMA is that Prophet models seasonality as a Fourier series. This allows the seasonal component of the forecast to consist of a summation of multiple frequencies in contrast to SARIMA, which only has one frequency. This provides the capability to easily model weekly, monthly, and yearly trends. One similarity between SARIMA and Prophet is that the forecast will also have a constant trend component. However, in this work the growth or decay was set to be bounded to values based on previous extremes. This is another feature that is easily configurable in Prophet.

All of the Prophet forecasts shown in Figure 57 were generated using the same manually specified hyperparameters. Including multiple seasonalities using Prophet markedly improved the shape of the forecast compared to the SARIMA results. The downward trend in Electricity Generation and Steam @ 600 psig during the fall season is well reflected by the Prophet forecast. Table 18 shows the MAE results for the Prophet model. Lower errors are observed for Electricity Generation and Steam @ 15psig, while the other two variables have slightly higher MAEs than those obtained using the SARIMA forecast. However, Prophet cannot outperform the two-year averaging method. 
a)

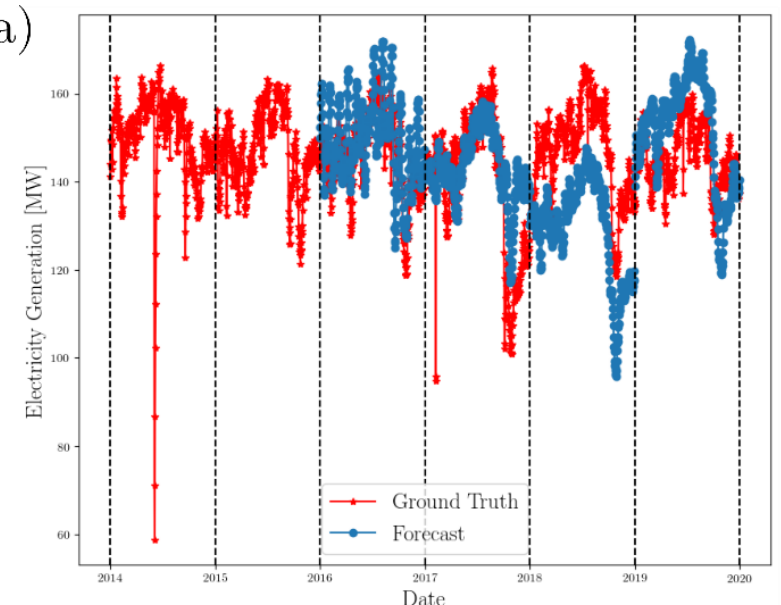

$$
\text { c) }
$$

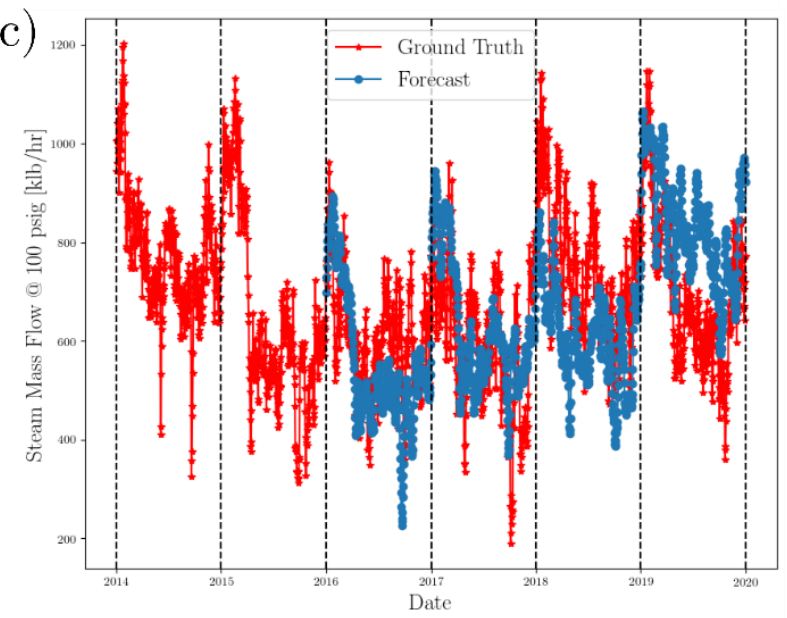

b)

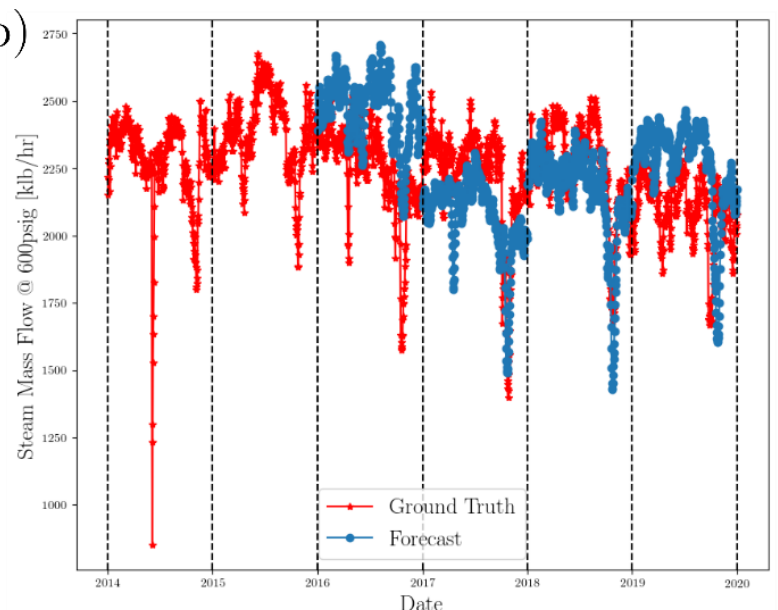

d)

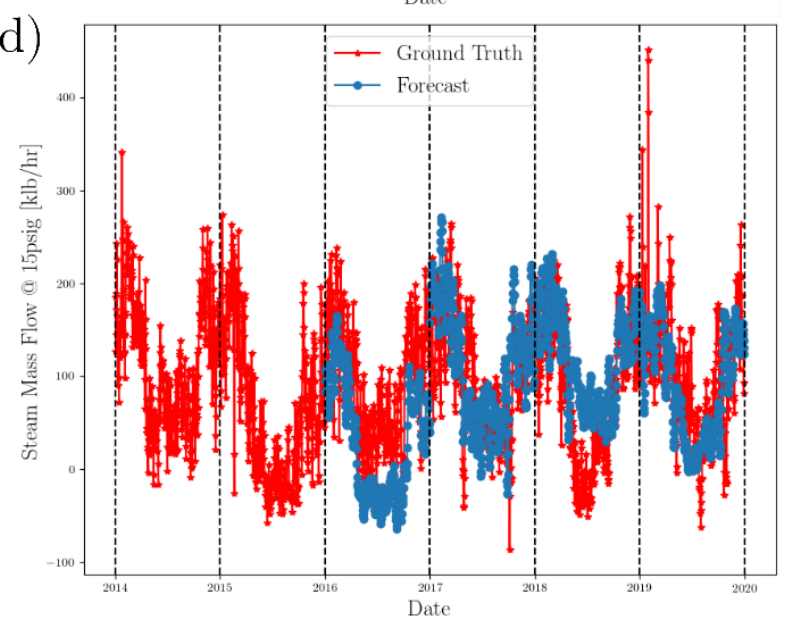

Figure 57. Forecasts with Prophet for electricity generation (a) and steam mass flows at various pressures $(b-d)$

Table 18. Prophet MAE results

\begin{tabular}{lccccc}
\hline & $\mathbf{2 0 1 6}-\mathbf{2 0 1 7}$ & $\mathbf{2 0 1 7 - 2 0 1 8}$ & $\mathbf{2 0 1 8}-\mathbf{2 0 1 9}$ & $\mathbf{2 0 1 9 - 2 0 2 0}$ & Average \\
\hline Electricity & 7.9 & 8.8 & 17.9 & 10.4 & 11.2 \\
Steam @ 600 psig & 225.9 & 167.0 & 130.2 & 212.9 & 184.0 \\
Steam @ 100 psig & 106.0 & 104.6 & 150.2 & 151.6 & 128.1 \\
Steam @ 15 psig & 67.9 & 47.1 & 52.8 & 47.9 & 53.9 \\
\hline
\end{tabular}

The impact of the forecast using weather information uses an idealized scenario in which a perfect forecast of the temperature is available. Data from the weather station located very close to the Eastman site, shown in Figure 58 by the red marker, is taken National Oceanic and Atmospheric Administration (NOAA) data. ${ }^{17}$

${ }^{17}$ (https://www.ncdc.noaa.gov/cdo-web/datasets/GHCND/stations/GHCND:USC00404858/detail). 
The associated temperature range is displayed in Figure 59. Eighteen days out of the six years had missing recordings, so they were filled in with linearly interpolated values.

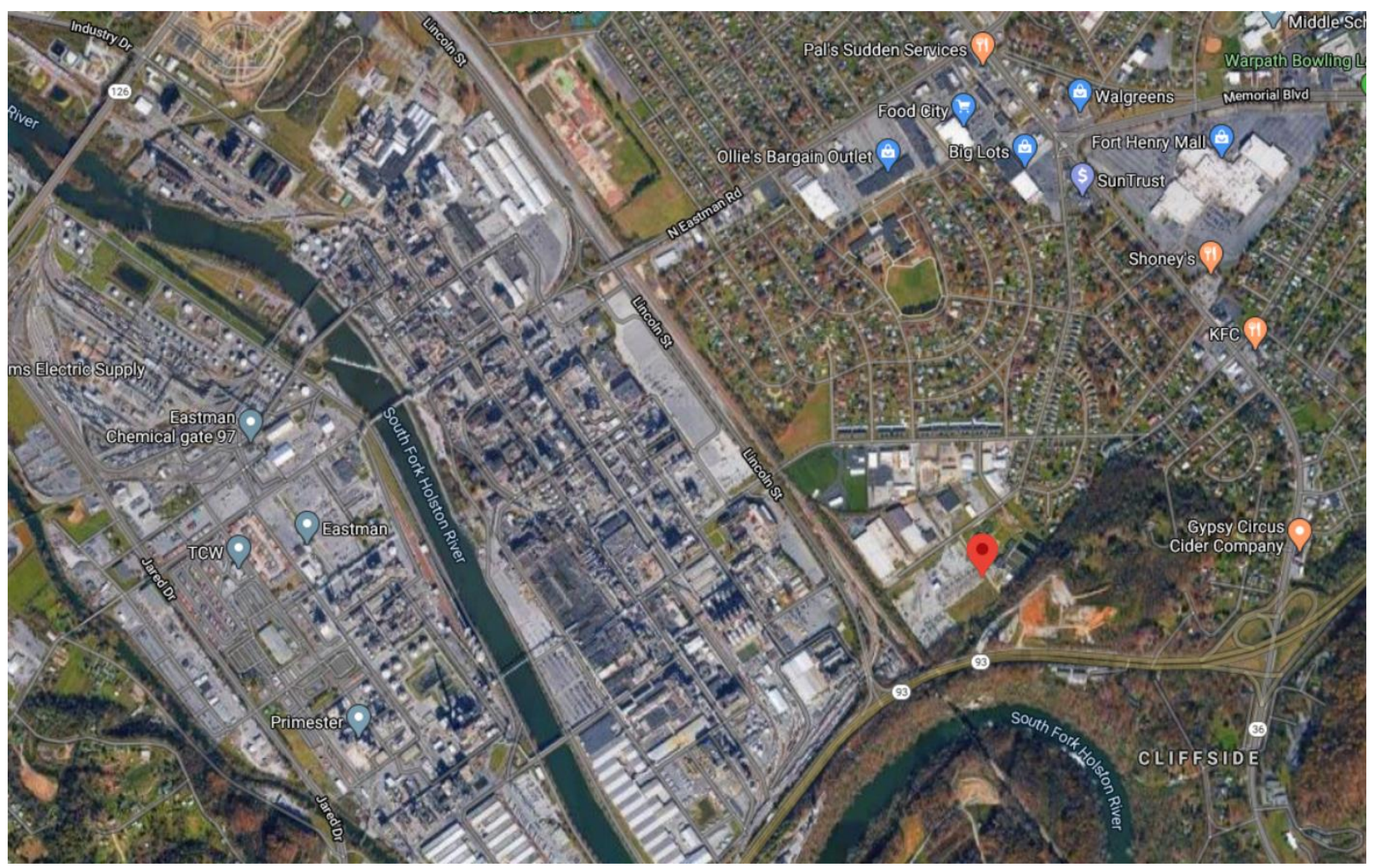

Figure 58. Location of the weather station in Kingsport, Tennessee, indicated by the red pin. 


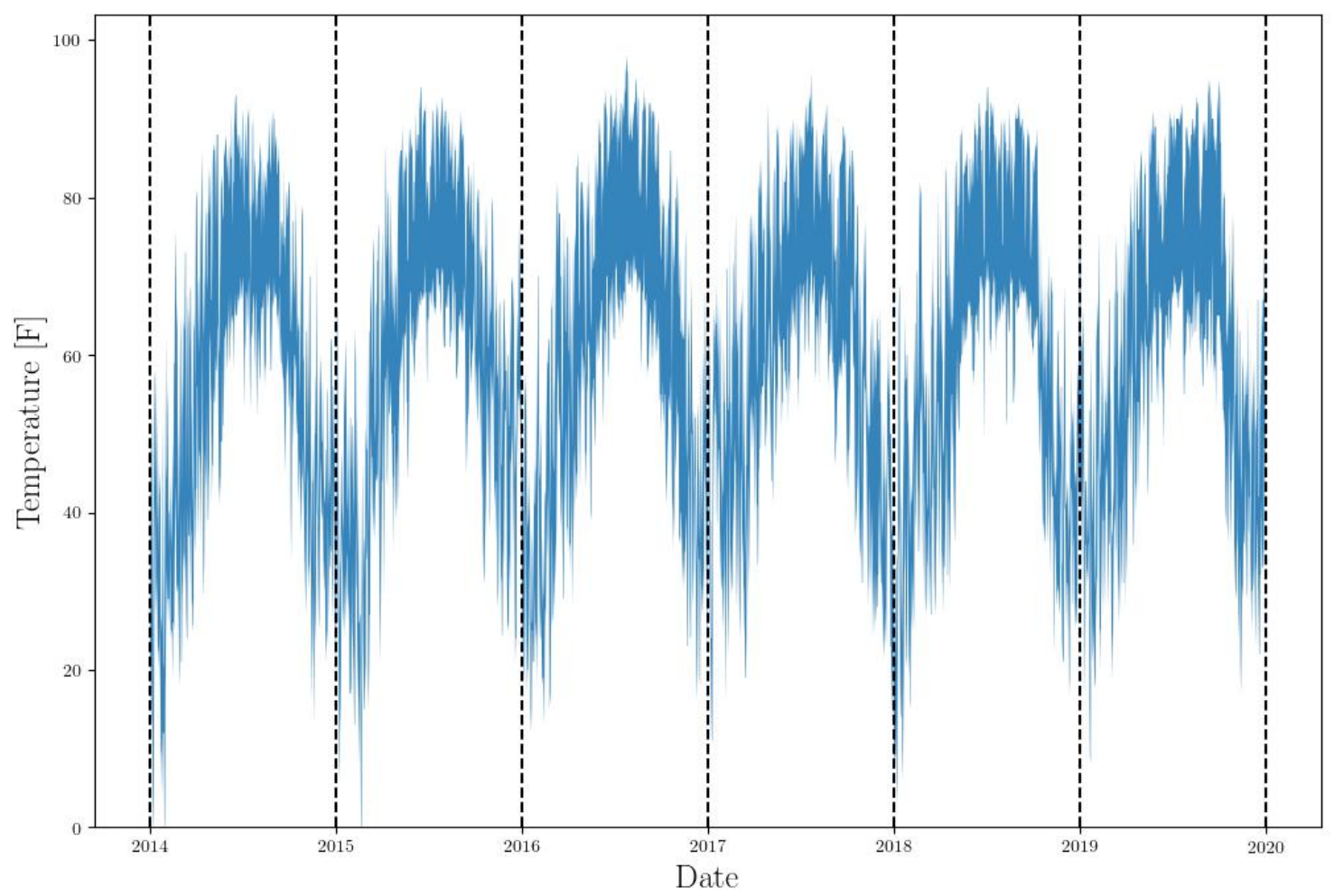

Figure 59. Temperature range from the weather station near Eastman's site.

The daily minimum and maximum temperatures were incorporated into Prophet as additional summation terms for the forecast. The resulting MAEs of the forecasts are shown in Table 19. The additional temperature information did not appreciably change the forecasts. Graphs of the actual forecasts are not shown for brevity, but they are very similar in shape to those without temperature. This result suggests that temperature is redundant when a model already includes the date. This is reasonable given the steady oscillation in the temperature range shown in Figure 59.

Table 19. Prophet with temperature MAE results

\begin{tabular}{lccccc}
\hline & $\mathbf{2 0 1 6 - 2 0 1 7}$ & $\mathbf{2 0 1 7 - 2 0 1 8}$ & $\mathbf{2 0 1 8 - 2 0 1 9}$ & $\mathbf{2 0 1 9 - 2 0 2 0}$ & Average \\
\hline Electricity & 8.1 & 8.8 & 17.8 & 10.4 & 11.3 \\
Steam @ 600 psig & 227.7 & 167.3 & 127.8 & 215.3 & 184.5 \\
Steam @ 100 psig & 102.2 & 95.5 & 148.6 & 154.5 & 125.2 \\
Steam @ 15 psig & 70.6 & 40.9 & 49.6 & 48.1 & 52.3 \\
\hline
\end{tabular}

Overfitting to a single year was done by manually changing hyperparameters of the Prophet forecasting model. Figure 60 demonstrates this effect for Electricity Generation, but the approach same applies to the steam mass flows. The forecasts for 2018-2019 match very well with the actual observations having a MAE $=6.0$, which is less than half that of the first Prophet model shown. However, performance in the other years is dramatically reduced. The average MAE across all years has dramatically increased to 21.6. This illustrates that caution must be used when fitting a model to a single year and then applying that model to forecast other years. 


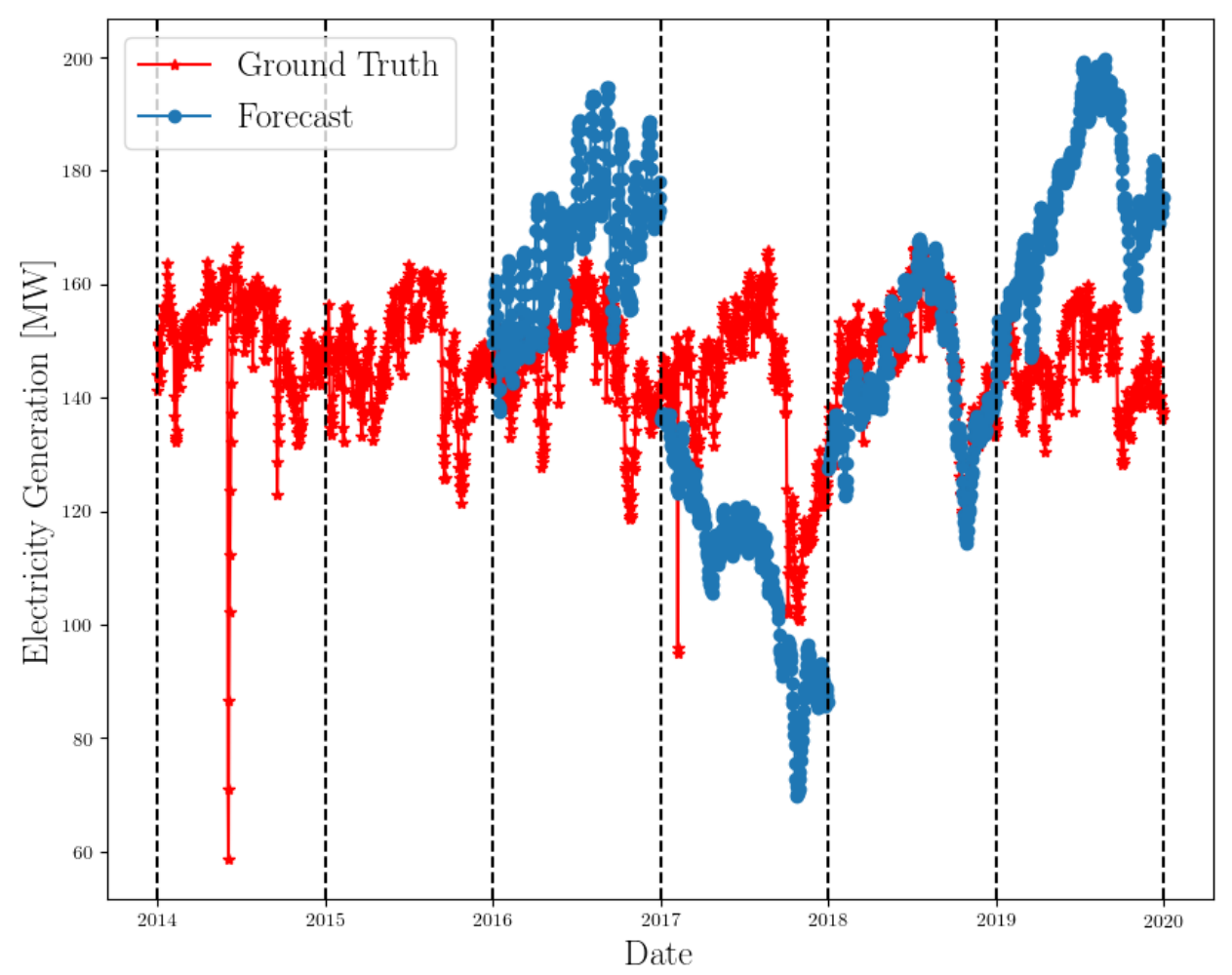

Figure 60. Prophet forecasts for electricity generation demonstrating overfitting to 2018-2019.

\section{B.1.4 Gaussian Processes}

Finally, the Gaussian process (GP), which is another popular method for forecasting or regression, is evaluated on this dataset. Numerous references can be found addressing the theoretical background for this method, so only specific details are repeated here [7]. This work uses the implementation found in the opensource scikit-learn package for Python3. As in the Prophet model, GP allows for modeling of multiple seasonalities through the summation of multiple covariance kernels. A simple set of kernels is chosen to reflect the patterns observed when parsing through the time series. Three periodic kernels in the form of Eq. (B3) corresponding to weekly, monthly, and yearly trends are summed with a kernel for Gaussian noise, as shown in Eq. (B4). No trending components are used, because previous observations have shown that the time series are relatively steady with no growth or decay. Length scales were set to 1 , and the variance for the Gaussian noise was equal to 0.036 . The time series for each forecast was rescaled between 0 and 1 before fitting with a GP was performed.

$$
\begin{gathered}
k\left(x_{a}, x_{b}\right)=\sigma^{2} \exp \left(-\frac{2}{l^{2}} \sin ^{2}\left(\frac{\pi\left|x_{a}-x_{b}\right|}{p}\right)\right) ; l=\text { lengthscale } ; p=\text { period } \\
k\left(x_{a}, x_{b}\right)=\sigma^{2} I_{n} ; \sigma^{2}=\text { variance of the noise }
\end{gathered}
$$


Table 20 shows the MAE of the GP forecast with lower errors than the averaging method for a few years and variables. Most noticeably, the electricity generation MAE for 2019-2020 is 40\% lower than the averaging method. However, the average MAE across the 4 years for all forecasted variables is still higher. One issue with GPs is that they can exhibit instability in terms of getting stuck at local minimums during model fitting. For example, Figure 61 shows the forecasts for steam mass flows at 100 psig.

During the 2016-2017 timeframe, the forecast oscillates once and then reverts to a straight line. All of the variance in the forecast is then explained by the extremely wide uncertainty bounds shown by the light blue bands. This actually has lower MAE than the averaging method, because the straight-line forecast is close to the mean for that year. However, the forecast gives no information about the monthly or seasonal trends, which are more useful for the purposes of planning and anomaly detection. Confidence intervals are also available from the Prophet and SARIMA forecasts, but they were omitted for clarity of the figures. Nevertheless, a $2 \sigma$ or $95 \%$ confidence interval could not capture the range of the actual measurements throughout the forecasted year for any of the methods.

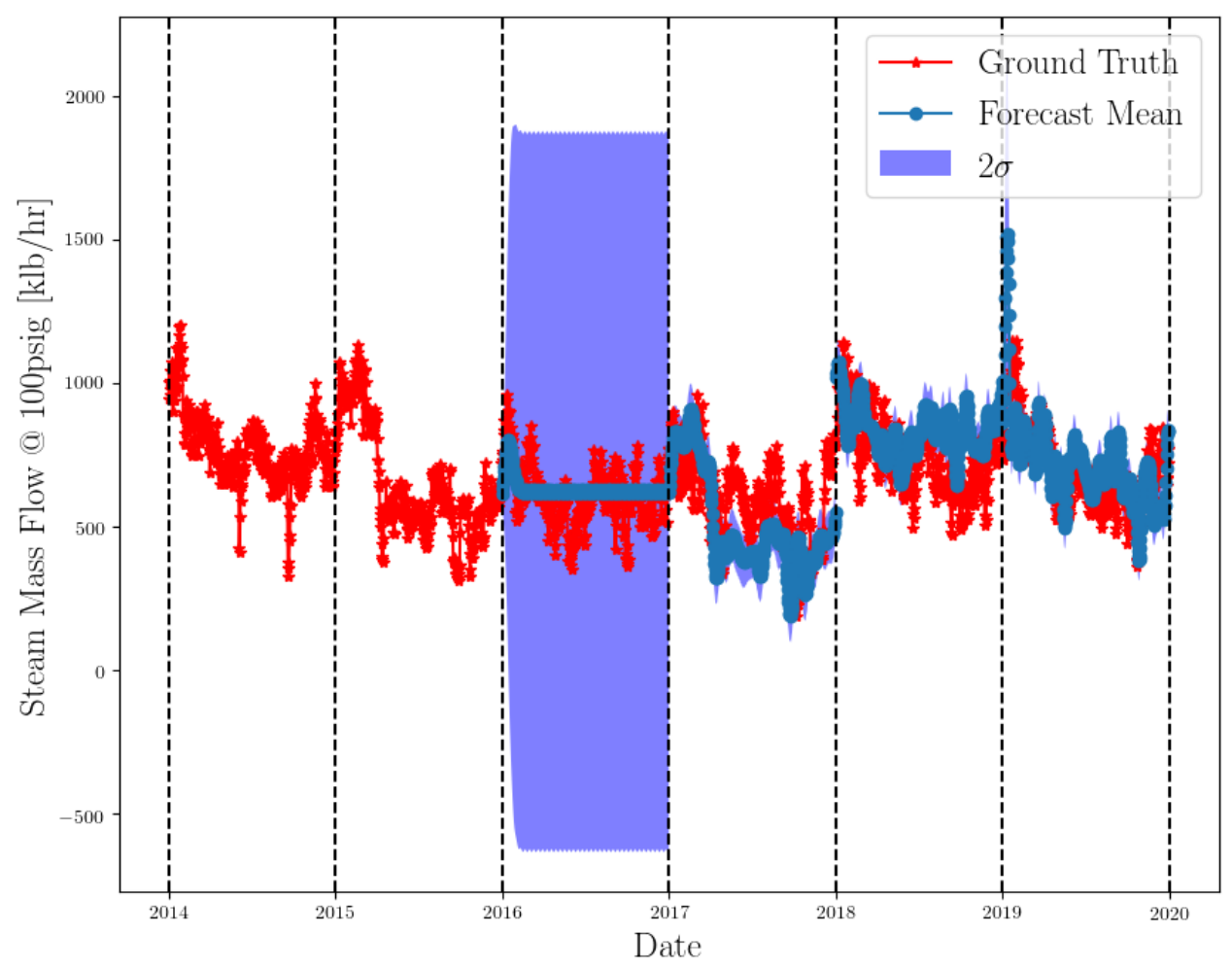

Figure 61. GP forecast for 100 psig steam mass flow rates. 
Table 20. GP forecast MAE results

\begin{tabular}{lccccc}
\hline & 2016-2017 & 2017-2018 & 2018-2019 & 2019-2020 & Average \\
\hline Electricity & 11.8 & 9.9 & 7.3 & 5.1 & 8.5 \\
Steam @ 600 psig & 127.5 & 220.5 & 119.4 & 95.7 & 140.8 \\
Steam @ 100 psig & 75.4 & 158.8 & 130.5 & 115.6 & 120.0 \\
Steam @ 15 psig & 112.0 & 79.8 & 77.5 & 129.8 & 99.8 \\
\hline
\end{tabular}

\section{B.1.5 Conclusion}

Four methods of forecasting were investigated, ranging from (1) averaging the last two years of data to (2) implementing a GP: an infinite dimensional set of random variables. Every algorithm was run on modest computer hardware, and a graphics processing unit (GPU) was not needed. Run-times to generate forecasts were at most a few minutes, with GPs being the slowest due to the need for multiple restarts to avoid local minima.

Increased complexity has not resulted in more accurate forecasts for the case of making daily predictions for a full year in the future. Simply taking the average of the last two years outperformed all methods over the 4 years investigated. This high performance is attributed to the steadiness of the time series forecasted here. However, this naïve approach would fail for the case of a trending variable, and no confidence intervals are produced. In addition, there are no parameters that can be changed to change to reflect any domain knowledge such as planned maintenance.

Deep learning methods were investigated, but they were ultimately abandoned because of their data requirements. This is especially severe for a time horizon of 365 days. Less aggressive forecasting horizons (shorter time spans) could see the more complicated models outperform a simple averaging method. This would also ease the data requirements for other machine learning algorithms, because smaller slices of the data can be used to create training samples.

N-BEATS is a promising deep learning model which purportedly outperforms the winner of the M4 competition [8]. One avenue for future work would be to aggregate Eastman's dataset with additional longrunning time series with a daily resolution. The stock market would be one example of a very extensive dataset. However, training a model in which the vast majority of the data is dissimilar from the microgrid time series can cause problems. For example, the forecasting model may predict more erratic oscillations than the steady outputs from the Eastman microgrid because the stock market is more chaotic.

\section{REFERENCES}

[1] Makridakis, S., Spiliotis, E., and Assimakopoulos, V. (2020). (The M4 Competition: 100,000 Time Series and 61 Forecasting Methods.” International Journal of Forecasting, 36(1), 54-74. https://doi.org/10.1016/j.ijforecast.2019.04.014

[2] Chen, J., Zeng, G.-Q., Zhou, W., Du, W., and Lu, K.-D. (2018). "Wind Speed Forecasting Using Nonlinear-Learning Ensemble of Deep Learning Time Series Prediction and Extremal Optimization." Energy Conversion and Management, 165, 681-695. https://doi.org/10.1016/j.enconman.2018.03.098 
[3] Laubscher, R. (2019). “Time-Series Forecasting of Coal-Fired Power Plant Reheater Metal Temperatures Using Encoder-Decoder Recurrent Neural Networks.” Energy, 189, 116187. https://doi.org/10.1016/j.energy.2019.116187

[4] Qiu, X., Ren, Y., Suganthan, P. N., and Amaratunga, G. A. J. (2017). "Empirical Mode Decomposition Based Ensemble Deep Learning for Load Demand Time Series Forecasting." Applied Soft Computing, 54, 246-255. https://doi.org/10.1016/j.asoc.2017.01.015

[5] Hyndman, R., and Khandakar, Y. (2008). "Automatic Time Series Forecasting: The Forecast Package,” R. Journal of Statistical Software, 27(3), 1-22. doi:http://dx.doi.org/10.18637/jss.v027.i03

[6] Taylor, S. J., and Letham, B. (2017). Forecasting at Scale [Preprint]. PeerJ Preprints. https://doi.org/10.7287/peerj.preprints.3190v2

[7] Rasmussen, C.E. and Williams, C.K.I. (2006). Gaussian Processes for Machine Learning. MIT Press.

[8] Oreshkin, B. N., Carpov, D., Chapados, N., and Bengio, Y. (2020). "N-BEATS: Neural Basis Expansion Analysis for Interpretable Time Series Forecasting." ArXiv:1905.10437 [Cs, Stat]. http://arxiv.org/abs/1905.10437 